\section{SANDIA REPORT}

SAND97-1922 * UC-900

Unlimited Release

Printed August 1997

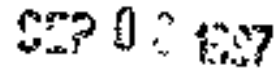

Q $S T$

\title{
Final Project Report: The Role of Technology in Reducing Health Care Costs
}

Anthony E. Sill, Steve Warren, John D. Dillınger, Bryon K Cloer, ,

Praparad by

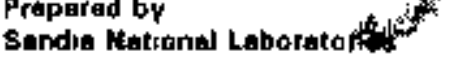

Albuquerque, Naw Moxico a7185 and Lwermora, Califorms 94850

Sendwa is a moltupeogrem laboratory aparted by Sandie

Corporation, a Lookhesd Martun Compathing the United Statos

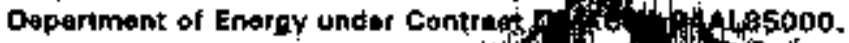

Approved or pubde

Approwed for pubfec relepese, dretribuion

(17) Sandia National Gorates
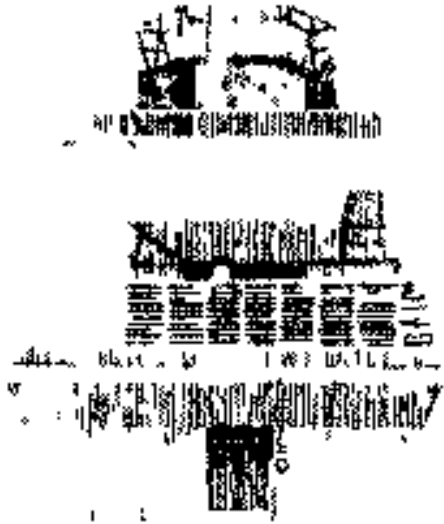

SF29000(8 81)
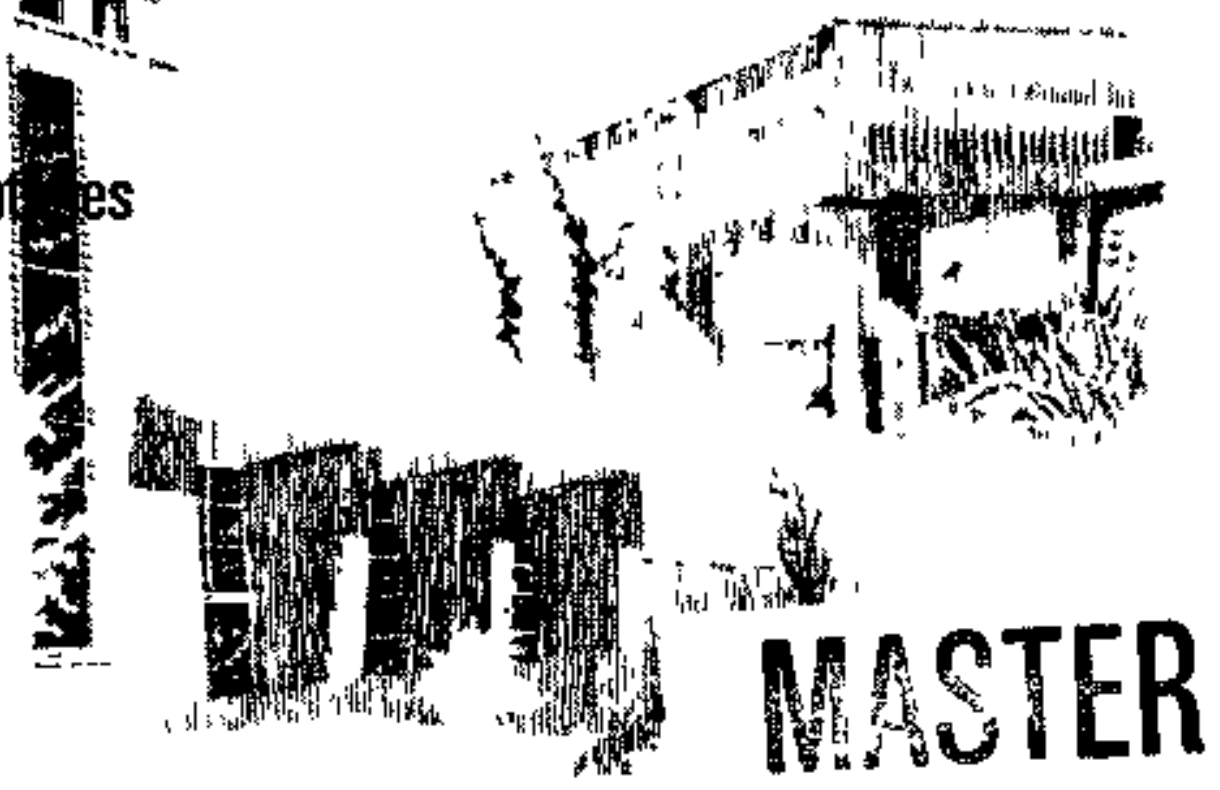
Isaued by Sandia National Laboratories, operated for the United States Department of Energy by Sandia Corporatjon.

NOTICE: This report $w$ as prepared as an account of work spansored by an agency of the United States Government. Neitber the United States Govern. ment nor any agency thereof, nor any of their emplogees, nor any of their contractors, subeontractors, or their employoes, makses any warranty, express or implied, or assumes any legal tiability or responojibility for the aceuracy, coppleteness, or usefulness of any information, apparatus, produet, or process disclosed, or represents that its use would not infringe privately owned rights. Reference herein to any specife commercial product, process, or service by trade name, trademark, manufacturer, or otherwise, does not necessarily constitute or imply its endorsement, recommendation, ar favoring by the United States Government, any agency thereot, or any of their contractors of subeontractors. The views and opinions expressed herein do not necessarily state or reflect those of the United States Government, any agency thereof, or any of their contractors.

Printed in the United States of America. This mport has been reproduced directly from the best available copy.

Available to DOE and DOE contractors from

Oftice of Sciantific and Tachnical lnformation

P.O. Box 62

Oak Ridge, TN 3783$\}$

Pricen available from (6]5) 576-840], FTS 626-8401

Available to the public from

National Teohnical Infornation Service

U.S. Department of Copinerce

5285 Port Royel Rd

Spring(jield, VA 2216)

NTIS price codes

Printed copy: Al]

Microfiche copy: A01 


\title{
FINAL PROJECT REPORT: The Role OF TECHNOLOGY IN REDUCING HEALTH CARE COSTS
}

\author{
Anthony E. Sill, Ph.D., MGR-MTS \\ Communications Systems Engineering Department \\ Steve Warren, Ph.D., SMTS \\ Communications Systems Engineering Department \\ John D. Dillinger, MTS \\ Communications Systems Engineering Department \\ Bryon K. Cloer, SMTS \\ Infrastructure Surety Department \\ Sandia National Laboratories \\ P.O. Box 5800 \\ Albuquerque, NM 87185-0785
}

\begin{abstract}
Sandja National Laboratories applied a systems approach to identifying innovative biomedical technologies with the potential to reduce U.S. health care delivery costs while maintaining care quality. This study was conducted by insplementing both top-down and bottom-up strategies. The top-down approach used prosperity gaming methodology to identify future health care delivery needs. This effort provided roadmaps for the development and integration of technology to meet perceived care delivery requirements. The bottom-up approach identified and ranked interventional therapies employed in existing care delivery systems for a host of health-related conditions. Economic analysis formed the basis for development of care pathway interaction models for two of the most pervasive, chronic disease/disability conditions: coronary artery disease (CAD) and benign prostatic hypertrophy (BPH). Societal cost-benefit relationships based on these analyses were used to evaluate the effect of emerging technology in these treatment areas.
\end{abstract}




\section{Acknowledgments}

This work is an aggregation of material written by many members of the project team. Most of the information originated from two sources: a series of reports witten by Bryon Cloer of Sandia National Laboratories, and a comprehensive final report from an Alton Ochsner Medical Foundation contract with Sandia National Laboratories. That dociment was written by several people under the direction of Br. Richard Re, M.D., the Alton Ochsner principal investigator for this effort. The report is entitled The Role of Technology in Reducing Health Care Costs. This work was supported by the U.S. Amny Medical Research and Materiel Command, Fort Detrick, Frederick, MD.

\section{Note}

No animal or human experiments were conducted during the course of this development. 


\section{DISCANMTR}

Portions of this docament may be illepible in electrosic image prodnets. Impes are produced from the best avalioble origton document. 


\section{Table of Contents}

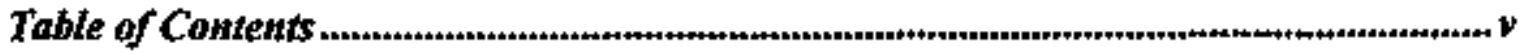

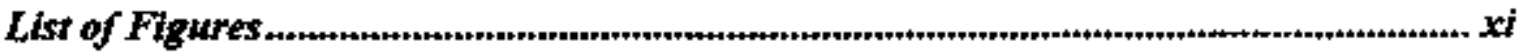

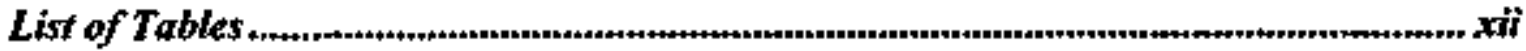

Chapter 1 - Introduction ….............................................................................................I

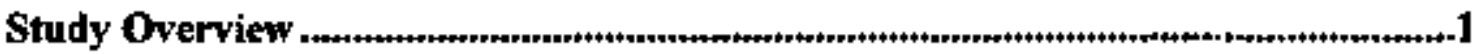

Sandia National Laboratories Project Team ............................................................4

Chapter 2 - Economic Analysis of Selected Disease/Disability States ..............................7

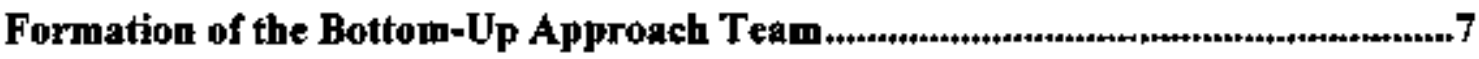

Medical Research Institutions Invited to Participate .............................................. 7

Medical Partnering Team Membership.................................................................8

Summary of Bottom-Up Approach Tasks and Gogls................................................10

Review of Medical Databases Task .............................................................................10

Global Rank Ordering of Cost-Effective Technologies..........................................1]

Interventional Foctrs Areas ...................................................................................17

Disease/Disability Condituns Assessed ...............................................................17

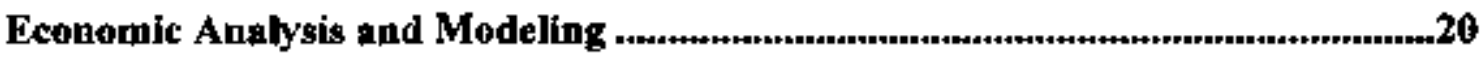

Definitions...............................................................................................................

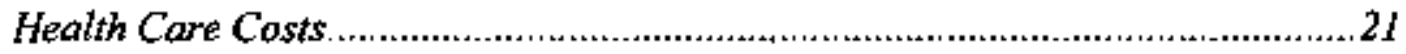

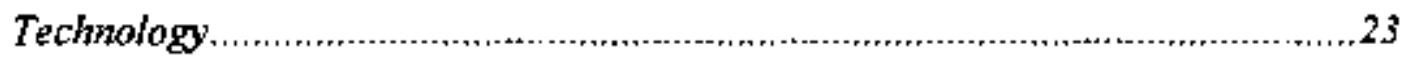

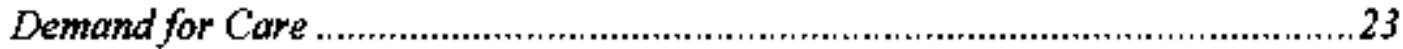

Quality-Adjusted Life Years.............................................................................23

The Value of a QALY..............................................................................24

Cost-Benefit Analysis Applied to CAD and BPH ............................................25

Appropriate Measure of Social Costs and Beneffts .......................................26

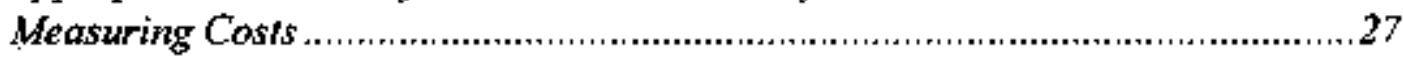

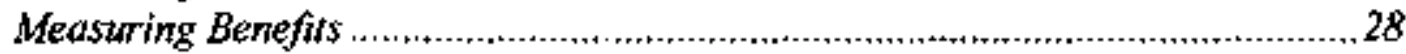

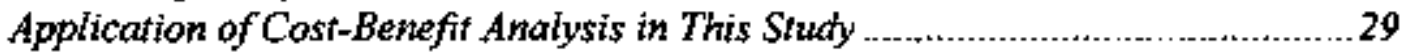

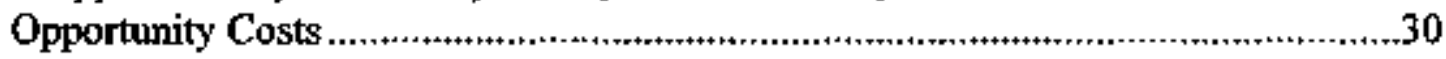

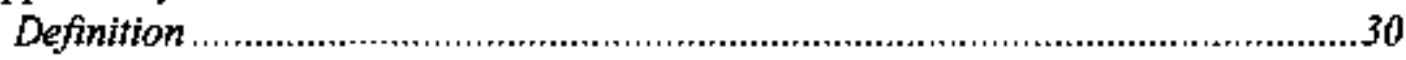

Methodologies for Evaluating the Opportunity Cost of Time................................3I

The "Revealed Value" Approach .............................................................32

Stochastic Frontier Methodology Applied to CAD (PTCA vs CABG).....................33

Further Information in the Appendices......................................................34

Estimating Costs in the Hospital Via a Physicians' Workshop Model ................34

Stochastic Frontier Model Formulation .......................................................34

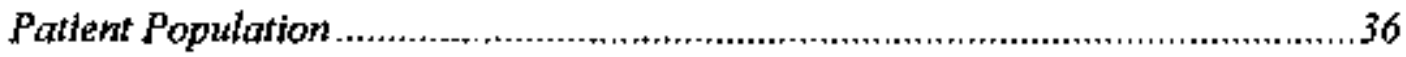

Input Prices, Behavioral Factors, and Health Factors …...................................37 


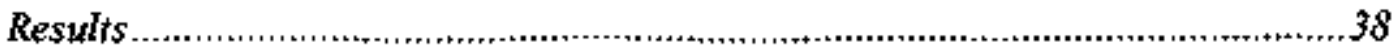

Charge Results .........................................................................................38

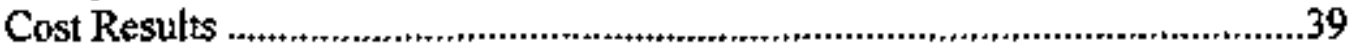

Simulation of Changing Technology or Practice ........................................ 40

Care-Pathway Interaction Models........................................................................41

Diseases and Treatments Addressed by the Models ......................................42

Coronary Artery Disease (CAD) ...............................................................42

Treatment Alternatives ........................................................................42

Definition of the Treatment Process ......................................................4j

Benign Prostatic Hypertrophy (BPH) ....................................................4 46

Types of Simulation Models.........................................................................4 46

Modeling of CAD Treatment Using Analytica..............................................46

Index To Important Input Variables In The Coronary Artery Distase Model...48

Interrelationship Diagram................................................................48

Stent-Related Variables .....................................................................49

PTCA Costs ......................................................................... 49

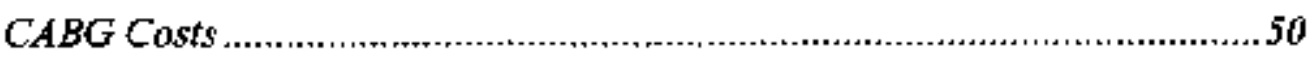

Demand Override Functions...............................................................50

Proceduralist Demand Multipliers .........................................................5]

Repeat Patient Populations..................................................................

Population Functions ...................................................................

Diagnosis J Library ....................................................................52

Prevention Function........................................................................52

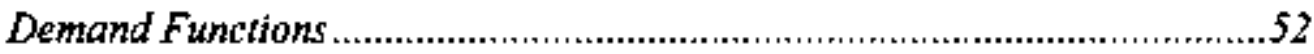

Results Module ....................................................................................

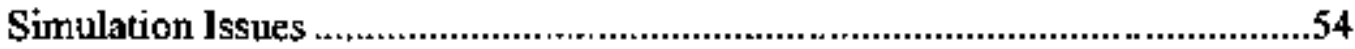

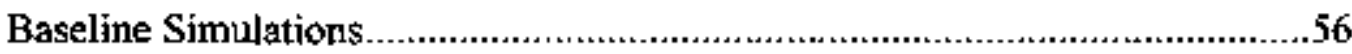

Unit Costs ......................................................................................................56

Coronary Artery Disease Model: Comparison of Economic Assumptions and

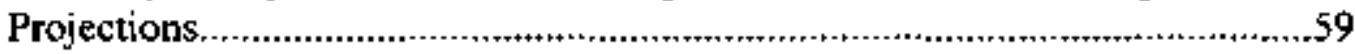

Sensitivity Analysis ..............................................................................60

Cost-Effectiveness Analysis ....................................................................64

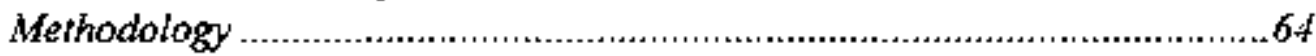

Cost Effectiveness Ratio.....................................................................64 64

Cost-Effectiveness Analysis: Stent Technology ...........................................65

Coronary Artery Disease Laparascopic CABG Simulation...............................67

Modeling of BPH Treatment Using Analytica ............................................ 70

Summary of the Benign Prostatic Hypertrophy Analytica Model......................70

Index To Important Input Variables In The Benign Prostatic Hypertrophy

Model ...............................................................................................72

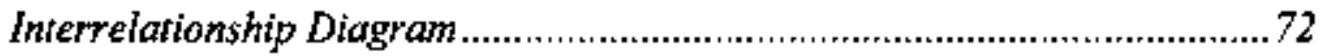

Poputation Related Variables..............................................................73

Variables Related to Repeat Procedures and Patients Crossing Over From

One Procedure fo Another .................................................................73

Relief Of Symptoms ............................................................................ 73 
Transurethral Prostatectomy for Indications Other Than Benign Prostatic Hypertrophy ............................................................................................74

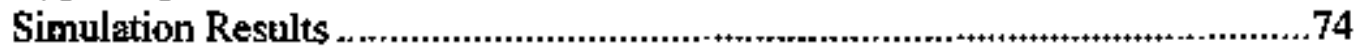

Sensitivity Analysis of TURP Repeat Rate ....................................................76

A Representative Simulation of the Introduction of Microwave Therapy.........78

Simulation of the Introduction of Transurethral Needle Ablation (TUNA) as

Therapy for Benign Prostatic Hypertrophy ................................................79

Modeling of CAD Treatment Using ARENA................................................81

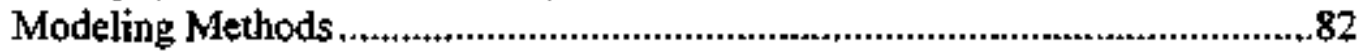

Population Demographics ..............................................................82

Demand for Current Treatment Methodologies .......................................83

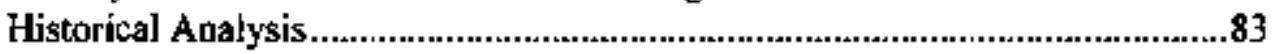

Modeling

Treatment Decision Module ...................................................................87

Static and Dynamic Treatment Decision Factors.............................................88

Abstract Trearnent Decision Factor Routines....................................................89

Level of Invasiveness of Treatment.........................................................89

Knowledge of Long-Term Treatment Outcomes.........................................89

Potential Changing Practices in the Treatment Alternatives........................89

Treatment Outcomes Module ..................................................................90

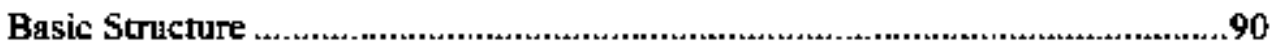

Effects of Technology on Treatment Effectiveness.......................................92

Calculation of Treatment Cost ...................................................................92

Analysis of CAD Model Output ................................................................92

Generating Output with the ARENA Model

Baseline Results and Confidence Intervals..............................................93

Sensitivity Analysis...............................................................................94

Potential Effects of Coronary Stent............................................................94

Potential Effects of Laparoseopic CABG ..................................................96

Modeling of BPH Treatment Using ARENA …….......................................96

Modeling Methods ..................................................................................96

Population Demographics .............................................................96

Demand for Current Treatment Methadologies .........................................97

Treatment Decision Module.................................................................98

Treatment Outcomes Module ..............................................................99

Analysis of BPH Model Output ................................................................99

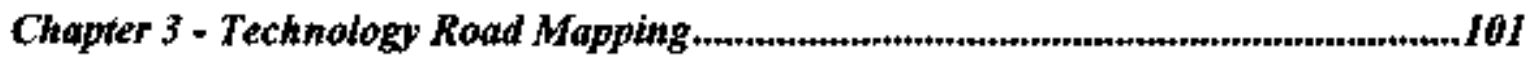

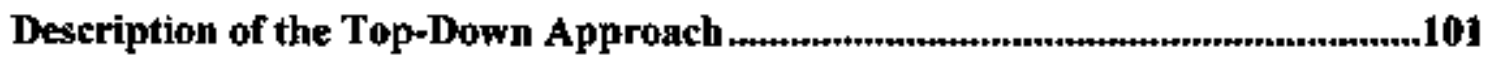

Introduction to the Biomedical Prosperity Game Concept......................................102

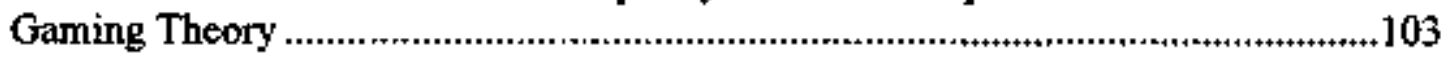

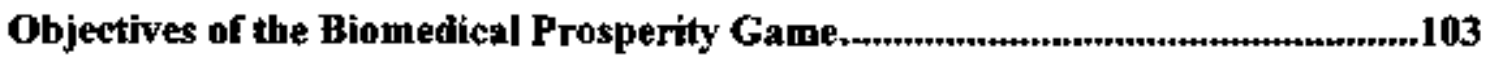

Biomedical Prosperity Game Description .........................................................105

Bionedical Prosperity Game Teaming Groups ................................................... 105 
Technology Areas Addressed by the Biomedical Prosperity Game ........................106

Policy Areas Addressed by the Biomedical Prosperity Game ..................................106

Biomedical Prosperity Game Execution ..............................................................106

Technology Development Process............................................................................109

Measure of Game's Care Quality .........................................................................110

Measure of Game's Care Cost .....................................................................111

Disease/Disability Card Description.....................................................................111

Techrology and Policy Toolkit Options .............................................................114

Gaming Dollars....................................................................................116

Biomedical Technology Issues and Potential Solutions ......................................117

Biomedical Technology and Policy Roadmapping............................................... 118

Roadmnap Development Definitions.....................................................................118

Biomedical Technology Roadmap Description .................................................120

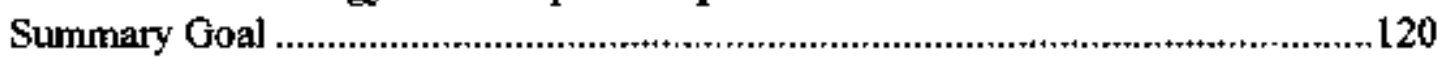

Rationale for Technology Roadmap Development.........................................120

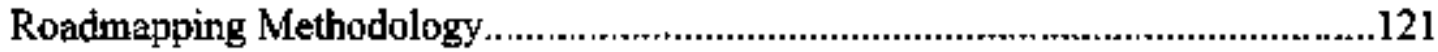

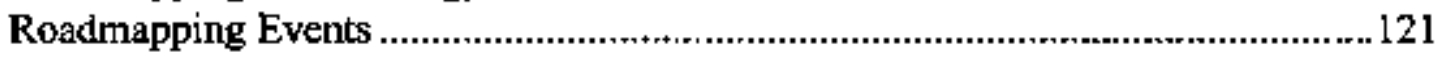

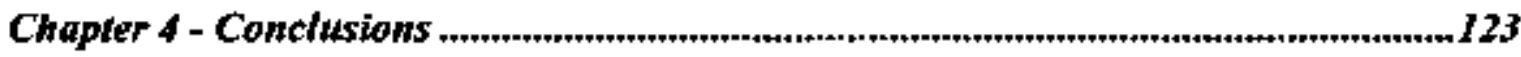

Bottom-Up Approach: Cost-Effectiveness Analysis for Selected Disease/Disability

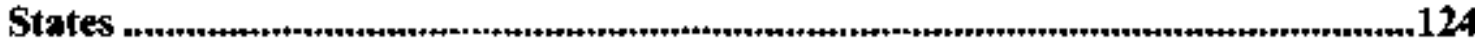

Econometric Analyses .............................................................................124

Care Pathway Integration Modeling ……...........................................................125

Methods By Whick Technology Can Reduce Societal Health Care Costs.............127

Top-Down Approach: Technology Roadmapping Efforts.................................127

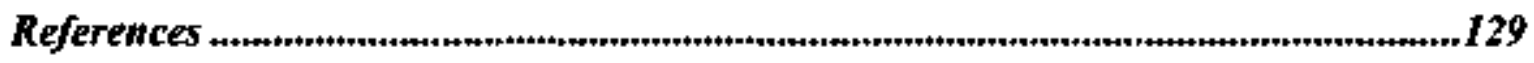

Appendix A - Derivation of Rank Order Data .....................................................137

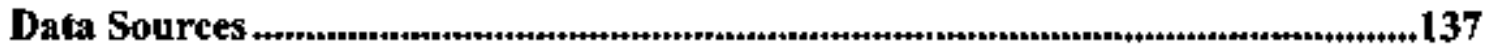

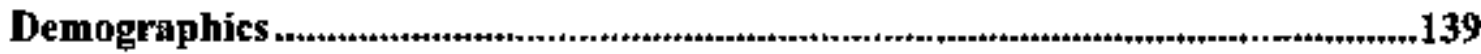

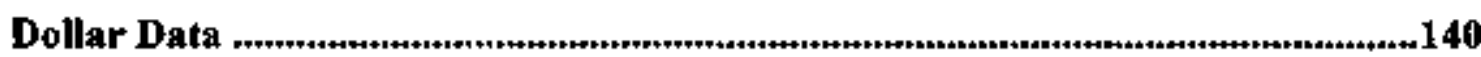

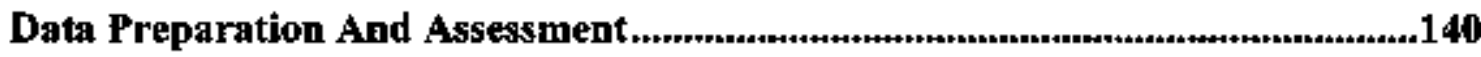

Rank Order By Volume (ROV) ......................................................................141

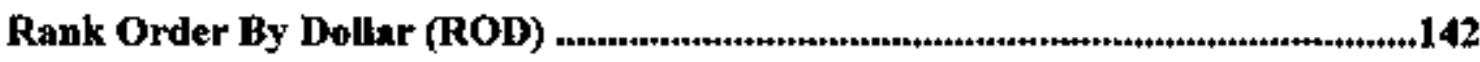

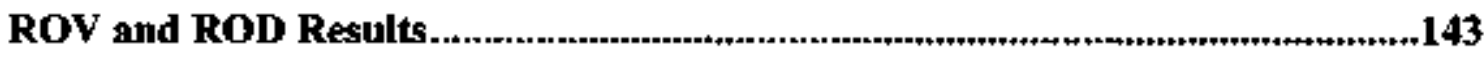

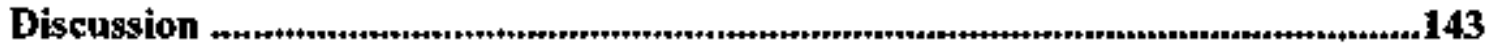

Rank Ordering Of Combined Inpatient And Outpatient Procedures .......................143

Rank Ordering Of Inpatient Procedures........................................................144

Appendix B - Econometric Analysis of Savings Available from PTCA Innovation: The

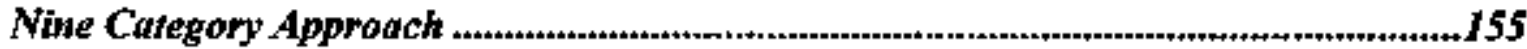




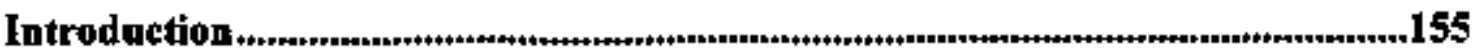

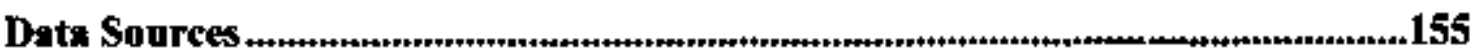

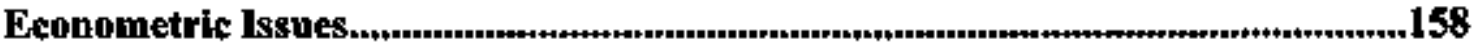

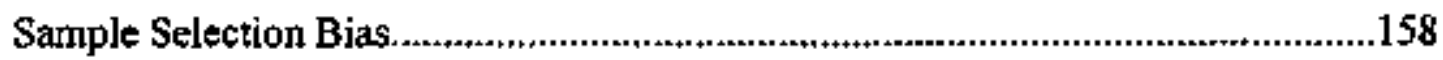

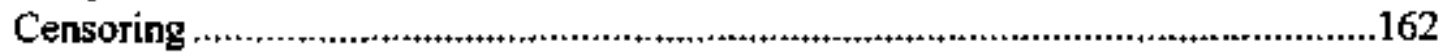

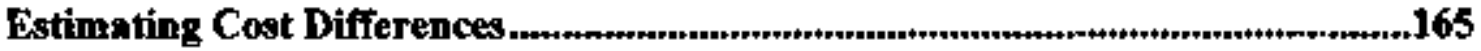

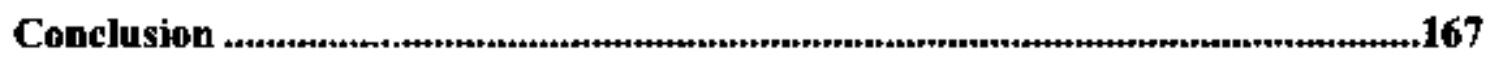

Sabappendix B1: Calculating Unexpected Adverse Events ................................168

Subappendix B2: The Choice of PTCA Vs. CABG ........................................171

Appendix C -Stochastic Frontier Estimation of Cast Modets Within the Hospital: The

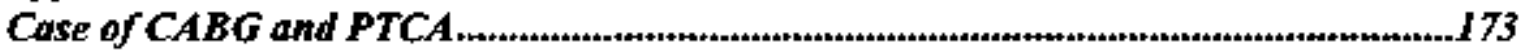

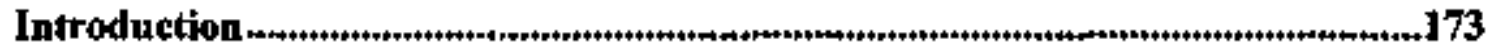

Estimating Costs in the Hospital: A Return to the Physicians' Workshop Model173 The Appropriate Level of Aggregation.........................................................173 Introducing Non-Cost Minimizing Behavior......................................................175 Modifying the Basic Stochastic Cost Frontier:..................................................1 176

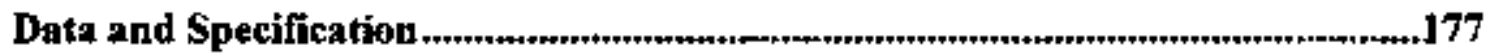

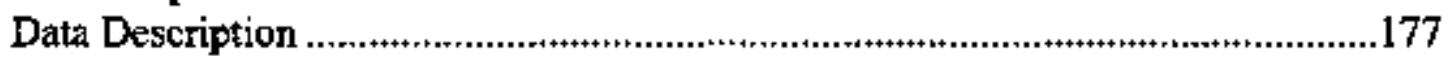

Dependent Variable

Explanatory Variables: Input Prices ..............................................................178

Explanatory Variables: Behavioral and Heatth Factors ...........................................178

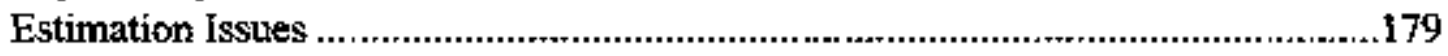

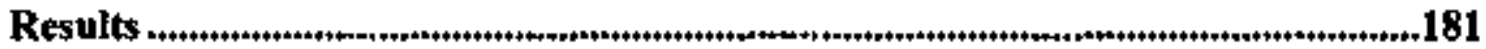

Simulating Changing Technology or Practice.....................................................184

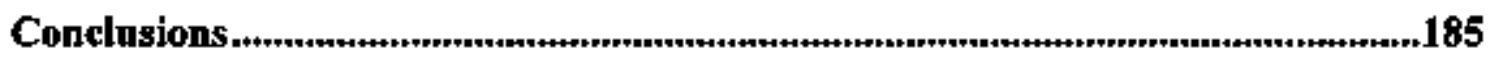

Appendix D - PTCA vs. CABG Across Sereral Hospitals......................................

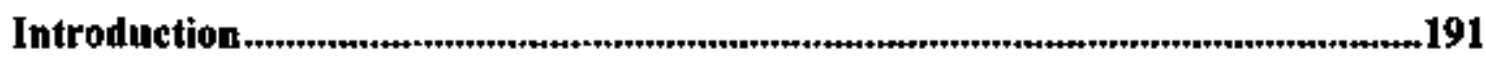

Data and Estimation Technique ...........................................................................191

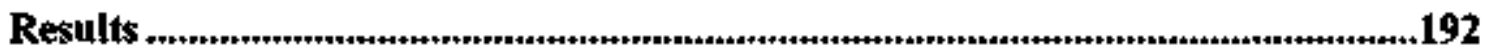

Regressions Across the Six Hospitals...........................................................192

Testing For Different Coefficients Across Hospitals..........................................197

Meta-Analysis .................................................................................................198

Appendax E - A Two-Part Model of the Costs of Treating Benign Prostatic Hyperplasia

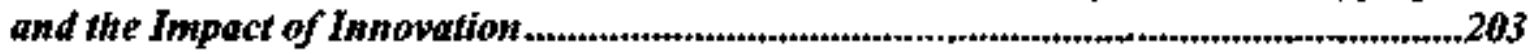

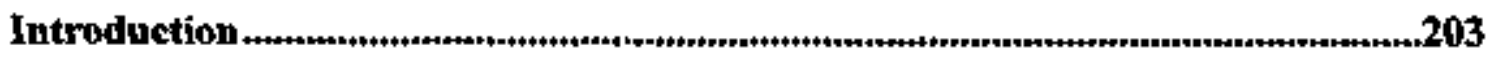




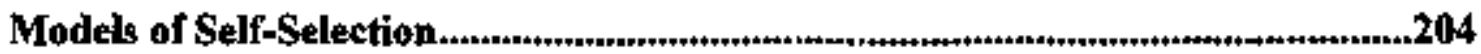

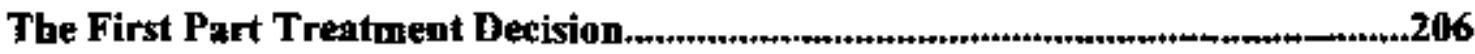

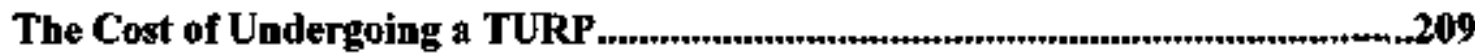

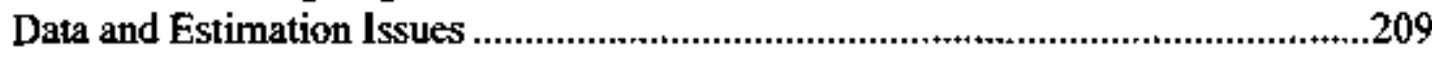

Estimation Results ........................................................................................2] I

Testing for Fixed Effects and For An Aggregate Model .....................................213

Testing For Differential Effects Across States .....................................................214

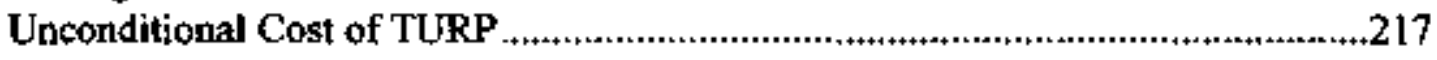

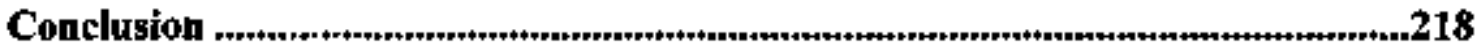

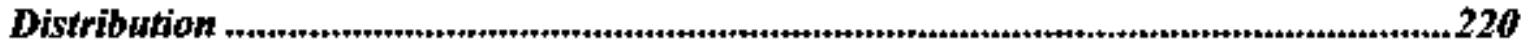




\section{List of Figures}

Figure 1. Fundamental supply/demand relationship in economics. (MC = Marginal Cost, $\mathrm{S}=$ Supply, $\mathrm{MB}=$ Marginal Benefit, D = Demand)..........................................27

Figure 2. CAD treatment process flow diagram. .....................................................45

Figure 3. Depiction of the intertelationships used in the Analytica CAD model ............48

Figure 4. Depiction of the interrelationships used in the Analytica BPH model.............72

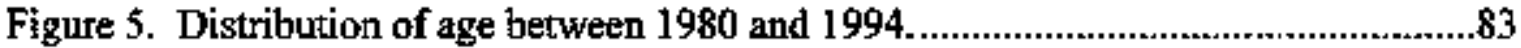

Figure 6. Historical demand for revascularization ....................................................84

Figtre 7. Growth of the PTCA market share.......................................................84

Figure 8. Growth of the CABG market share.....................................................85

Figure 9. Event-free survival after tregtment.................................................................9]

Figure 10. Demand for revascularization...............................................................93

Figure 11. Hospital costs as a function of time.....................................................94

Figure 12. Impact of stent effectiveness on demand for revascularization.......................95

Figure 13. Procedure distribution for the treatment of BPH.....................................98

Figure 14. Validation of BPH model data. ..............................................................99

Figure 15. Schematic of some possible team interactions. .............................................109

Figure 16. Patient Disease/Disability Card ...............................................................114

Figure 17. Probabilistic Determination of Toolkit Investments Ontcomes ...................115 


\section{List of Tables}

Table 1. Rank Order Dolkar - High Dollar Procedures Comprising the Top 20 Procedure Categories (Ranked by Total Estimated Allowed Charges") for the Combined

Inpatient and Outpatient Report ......................................................................13

Table 2. Rank Order Volume - High Volume Procedures Comprising the Top 20 Ranked

Procedure Categories for the Combined Inpatient and Outpatient Report ..................15

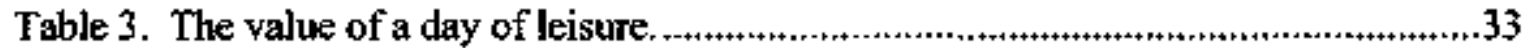

Table 4. Predicted Savings from Switching CABG Patients to PTCA .............................41

Table 5. Year 2004 results for the Analytica CAD stent simulations.............................58

Table 6. Sensitivity analysis: net economic benefit as a function of QALY ................63

Tabie 7. Sensitivity analysis: net economic benefit as a function of CABG cost............63

Table 8. Benign prostatic hypertrophy baseline simulation year 2000 results. ................ 76

Table 9. Sensitivity analysis of transurethral prostatectomy repeat rate: year 2005 results. 77

Table 10. BPH simulation resulss from the introduction of microwave therapy.............79

Table 11. Simulation results from the introduction of transurethral needle ablation

(TUNA) as a therapy for benign prostatic hypertrophy...........................................79

Table 12. Static and dynamic treatment decision factors.,...........................................88

Table 13. Standard Process for Technology Development............................................110

Table 14. D/D Cards, insurance Type, and Patient Descriptions .................................112

Table 15. Conversion Descriptors for Game Dollars .................................................116

Table 16. Team and Player External Income Per Session ...........................................117

Tabte 17. General Technology Area .....................................................................119

Table 18. Rank Order Volume - High Volume Procedures Comprising the Top 20

Ranked Procedure Categories for the Combined Inpatient and Outpatient Report..146

Table 19. Rank Order Dolkar - High Dollar Procedures Comprising the Top 20 Procedure

Categories (Ranked by Total Estinated Allowed Charges') for the Combined

Inpatient and Outpatient Report ....................................................................148

Table 20. Rank order volume: weighted ranks for the top 20 DRG's ranked by number of discharges for inpatient data ${ }^{*}$ only ...............................................................150

Table 21. Rank order dollar: weighted ranks for the top 20 DRG's ranked by total covered charges' for inpatient data' only.

Tabie 22. Rank Order Volume: top 20 DRGs ranked by the wejghted national estimates of the total number of discharges for I 994 National Inpatient Sample Data

Table 23. Rank Order Doliar: top 20 DRG's tanked by the total covered chargest For the

I994 National Impatient Sample (NIS) Data.......................................................153

Table 24. Varable Means (Standard Deviations in Parentheses) .................................157

Table 25. Test of Different Coefficients for CABG and PTCA. 95\% Cutoff Threshold: 22.3620 .

Table 26. Test of Tobit vs. OLS. 95\% Cutoff Threshold: $3.84146 \ldots \ldots \ldots \ldots \ldots \ldots \ldots \ldots . . . \ldots 163$

Table 27. Summary of Econometric Tests............................................................164

Table 28. Charge Savings Available From PTCA Technotogy Category By Category. 165

Table 29. Cost Savings Available From PTCA Technology. 
Table 30. Poisson Regression Estimates (Significant Coefficients in bold)

Table 31. Probit Results (Significant coefficients in bold).

Tabie 32. Means of Variables for PTCA and CABG Patients.

Table 33. Stochastic Frontier Estimations of TOTAL CHARGE for PTCA and CABG

Patients (Linear). T-Statistics in Parentheses

Table 34. Stochastic Frontier Estimations of TOTAL COST for PTCA and CABG

Patients (Linear). T-Statistics in Parentheses ...................................................189

Table 35. Predicted Savings from Switching CABG Patients to PTCA........................190

Table 36. Hospitals 002, 003, 004, and 005 (T-statistics in Parentheses, significant coefficients in bold)

Table 37. Hospitals 007, 012, and Six Hospitals Aggregated (T-statistics in Parentheses, significant coefficients in bold)

Table 38. Dummy Variable Values in Aggregate Equation (Hospital 002 Null Hospital,

Significant Values in bold) 195

Table 39. Coefficient Significance Across Six Hospitals ..........................................196

Tabje 40. Predicted CABG at Each Hospital (5301 Total Observations)......................197

Table 41. Meta-Analysis 198

Table 42. Marginal Effects in Meta-Model (CABG Probability of "Standard" Patient: $71.2 \%)$

Table 43. Regression Results for First-Stage Logit on Probability of TURP (T-statistics

in parentheses, significant coefficients in bold) ...........................................208

Table 14. Data Summery by State

Tabie 45. Estimation Results - All Payer Data (T-statistics in Parenthesis, significant

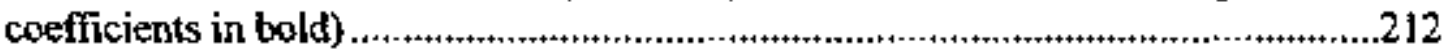

Table 46. Test For Fixed Effects....................................................................2214

Table 47. Different Effects Across States .................................................+...............216

Table 48. Average Predicted Unconditionat Cost of TURP by State ..........................217 
Intentionally Left Blank 


\section{Chapter 1 - Introduction}

\section{Study Overview}

Sandia National Laboratories applied a systems approach to address the identification of innovative biomedical technologies with the potential to reduce U.S. health care delivery costs while maintaining (or improving) care quality. This study (MIPR No.

MM4592KC6, SNL Proposal No. 94940719/1) was conducted by implementing topdown and bottom-up strategies.

The top-down approach addressed the identification of furure health care delivery needs. Biomedical technology roadmaps, developed as part of this approach, can guide the introduction and development of technologies to meet these care delivery requirements.

The complete results of the top-down approach were published by Sandia National Laboratories in October 1996 in a separate document entitled The Role of Technology in Reducing Health Care Cost. This document identifies eight technologies and tectnology-retated policies that have the potential to reduce health care costs while maintaining or improving quality. For each of these areas, strategic roadmaps were developed to provide guidance for future development and the introduction of costeffective technologies and technology-related policies for the U.S. health care delivery system.

The roadmaps, or strategic plans, identify a common vision for timely solutions of fundamental system problems that are "needs-driven" rather than "solutions-driven." Roadmaps provide consensus in the development and introduction of innovative technologies by reducing duplication of essential research, development and application activities among stakeholders. In addition, roadmaps (1) address technology challenges that may be too expensive or too risky for a single organization to solve and (2) provide a comprehensive view for addressing solutions to broad system problems.

Because of the complexity of the issues facing the U.S. health care delivery system, a gaming approach was selected as the mechanism to build consensus and to develop roadmaps establishing technology's role in meeting care delivery needs. These prosperity games are interactive role simulations that explore complex issues in a variety of economic, political and social arenas: they are not computer simulations. The simulations are high-level exercises relying on participants' discretion, judgment, planning and negotiating skills. 
The prosperity games provided participants with an understanding of some of the obstacles and opportunities associated with current and proposed technologies and technology-related policy. For example, participants explored problems and opportunities faced by doctors and other health care providers, patients, technology developers, the military, regulators, legislators, insurance agencies, lawyers, and other stakeholders in the biomedical engineering field.

The biomedical prosperity game produced a ptioritized list of technology and technologyrelated policy areas for roadmapping, including

- advanced telemedicine,

- bealth and healthcare informatics,

- information and network surety,

- integrated predicative diagnostics,

- minimally invasive therapy, inaging, and energy delivery systems,

- performance measurement and outcomes research,

- preventive medicine and incentive prograns, and

- rehabilitative science and assistive technologies.

Overall, the players expressed a strong interest in emphasizing general health care information areas for future technology and technology-related policy development. The players' general consensus was that the future health care information infrastructure must support systems capablc of handling complex care scenarios while maintaining flexibility, responsiveness and quality. Several participants pointed out the current imbalance in health-related information: doctors are increasingly burdened with a deluge of information while patients have access to rejatively little information. In particular, future health information systems were postulated that would allow individuals to proactively participate with care professionals in the improvement of their personal health status.

The list of co-sponsors for the overall roadmapping effort included the following:

- U.S. Army Medical Research \& Materiel Command,

- The Koop Foundation, Inc. (KFI),

- Defense Advanced Research Projects Agency (DARPA),

- Massachusetts General Hospital,

- Pennsylvania State University Applied Research Laboratory,

- Presbyterian Hospital of Dallas, and

- Sandia National Laboratories.

It should be noted that more than 75 organizations and 150 individuals participated in the roadnap development process. Commitment from this broad spectrum of participants validates the objectives and details for each roadmap. 
The complete roadmap doctument is available electronicaliy on the DoD Telemedicine world wide web site at

http:/www.matmo.org/news/sections/civprog/sandia.html.

The bottom-up approach identified key technologies and outcome measures in existing care delivery systems. In addition, Care Pathway Interaction Models were constructed for two chronic disease/disability conditions to simulate the impact of new technology on overall costs and outcomes for these conditions.

The goals of the bottom-up approach wete

- to identify current technology usage on a national level so that likely targets for technological improvement could be identified, and

- to model the cost-effectiveness of the technology utilized in the treatment of the representative medical conditions so as to permit the identification of figures of merit for technology improvements which could lower health care costs while maintaining health care quality.

In the bottom-up approach, Sandia National Laboratories (SNL) and Alton Ochsner Medical Foundation (AOMF) sought to determine if technology could in fact lower health care costs irrespective of the ambient social climate, payment mechanism, or introduction of implicit/explicit rationing of care. To address this issue, it became important to first define the cost of technology in addition to identifying those factors which favorably or unfavorably influence that cost. Because the aim of SNL and AOMF was to identify means by which technology could reduce cost without lowering the quality of delivered care, rationing was explicitly removed from consideration as a means of reducing health care costs.

Initially, medical data bases were reviewed to determine the most frequently performed and most costly medical procedures. Two technology-intensive disease/disability states were selected for modeling to determine the effect of applying new and altemative technologies to the treatment of these disease/disability states. Aggregate and patientspecific models were then developed for each disease/disability state. As part of the model development, significant research was conducted on the economic factors related to the application of new and alternative technologies.

Development of the care pathway interaction models has provided a new methodology that can be applied to help make decisions on the introduction of technology for the treatment of other disease/disability states. These models can be used as prototypes for future models and should serve as educational tools for the investigation of the impact of a wide variety of variables on health care costs and quality. 
This effort is a new paradigm for technology assessment: one which can direct similar efforts aimed at other disorders. Curtent approaches to technology assessment center around (1) the evaluation of tectmology currently employed in clinical settings or (2) pilot trials of new technology. The present effort addresses the problem in a fundamentally different manner. It attempts to predict the economic and medical impact of new technologies before they are developed. This permits the analyst to vary the figures of merit for proposed new technologies in order to identify parameters associated with reduced cost and constant or enhanced patient outcome.

The majority of the infomation from the bottom-up approach is available in Volume 1 of a May 1997 report by the Alton Ochsner Medical Foundation entitled The Role of Technology in Reducing Health Care Costs.

\section{Sandia National Laboratories Project Team}

The major members of the Sandia National Laboratory Project team follow:

Samuel Varnado, Ph.D. Program Manager, Co-Investigator

Sandia National Laboratories, Director of Information Systems Engineering Center, Manager of Biomedical Informatics Program

Bryon Cloer $\quad$ Former Projec. Leader, Co-Investigator

Sandia Nattonal Laboratories, Information Systems Engineering Center

Marsball Berman, Ph.D. Prosperity Game Directot

Sandia National Laboratories, Manager of Innovative Industrial Alliances Department

Kevin Boyack, Ph.D. Prospertity Game Co-Director

Sandia National Laboratories, Innovative Industrial Alliances Department

Joe Boyce, M.D. Medical and Technology Consultant

Sandia National Laboratories, Medical Clinic, Information Systems \& Emergency

Services

John Dillinger Project Investigator

Sandia National Laboratories, Information Systems Engineering Center

Marie Garcia Technology Roadmap Consultant

Sandia National Laboratories, Strategic Planning Program Office

A. Wayne Johnson, Ph.D. Project lnvestigator

Formerly with Sandia National Laboratories, Information Systems Engineering Center 
Lawrence Larsen, M.D., Ph.D. Medical and Technology Consultant

Sandia National Laboratories, Manager of Nuclear Medicine Laboratory, Sr. Scientist, IEEE Fellow

Cheryl Mitchell Prosperity Game Support

Sandia National Laboratories, Innovative Industrial Alliances Department

Tony Sill, Ph.D. Current Project Manager

Sandia National Laboratories, Information Systems Engineering Center

Steve Warren, Ph.D. Project Investigator

Sandia National Laboratories, Information Systems Engineering Center

Don Wesenberg, $\mathrm{Ph} . \mathrm{D} . \quad$ Project Investigator

Formerly with Sandia National Laboratories, Informotion Systems Engineering Censer

Timely consultation and technology roadmap development support was also provided by these Sandia National Laboratories biomedical program thust area leaders:

Thurman Allard, Ph.D.

Medical microelectronics

Keith Miller, Ph.D.

Assistive Technologies

Don Sctroeder, Ph.D.

Minimally Invasive Therapy

Mike Sjulin

Medical Information Systems 
Intentionally Left Blank 


\section{Chapter 2 - Economic Analysis of Selected Disease/Disability States}

\section{Formation of the Bottom-Up Approach Team}

The bottom-up approach to the study was supported through a competitive contract awarded to Alton-Ocbsner Medical Foundation.

\section{Medical Research Institutions Invited to Participate}

During the period from October 1994 through December 1994, Sandia developed and distributed a statement of work (SOW) to 18 medical research institutions. These institutions included

- Alton Ochsner Medical Foundation,

- Johns Hopkins University, School of Medicine,

- Stanford University Hospitad,

- The Lovelace Instittute (TLI),

- Massachusetts General Hospital ,

- The University of Texas, M.D. Anderson Cancer Center,

- Mayo Clinic, Department of Community Internal Medicine,

- University of California, UCSD Medical Center,

- University of Califomia, San Francisco, Radjologic Inaging Laboratory,

- Washington University, Technology Group (St. Louis, MO),

- UCLA Medical Center, Department of Radiological Sciences,

- New York University Medical Center, Department of Neurosurgery,

- Duke University Medical Center,

- Medical College of Georgia,

- Presbyterian Hospital of Dallas,

- University of Washington (Seattle, WA),

- University of Michigan, School of Public Health, and

- University of New Mexico, School of Medicitre.

This SOW identified the areas of tasking for the bottorn-up approach to the study. In addition, evaluation criteria for potential partnering medical institutions were also identified.

During the period from January 1995 through March 1995, Sandia held a pre-proposal conference for the potential bidders to the request for quotation. In the conference, Sandia responded to both technical and contractual questions. A summary of the responses to these questions as well as questions formally submitted to Sandia before the conference was transcribed and sent to each of the potential medical institution bidders. 
The formal RFQ was sent to the list of potential partners from 18 medical research institutions in February 1995. The RFQ established the guidelines for submitting proposals by interested instinutions. It also delineated the terms, conditions, and responsibilities for participation in the study. In addition, Sandia further clarified technical and contractual questions subminted by potential bidders.

Acceptable responses were received from three leading medical research institutions:

- Alton Ochsner Medical Foundation, New Orleans, LA (with partners at the Stanford University School of Medicine and the Johns Hopkins University Division of Internat Medicine),

- The Lovelace Institute (TLI), Albuquerque, NM and

- University of Texas Southwestern Medical Center at Dallas, TX.

Evaluation of the submitted proposals was perforned by a team of Sandians with broad systems experience. The evaluation was based upon the technical capabilities of each submitting organization in addition to the soundness of their proposed approach for conducting the bottom-up investigation for this study.

The proposed approach by the team headed by the Alton Ochsner Medical Foundation was very comprehensive. It identified effective methods for the collection and anatysis of health care cost data which would lead to the identification, prioritization and specification of technologies with the potential to reduce health care costs. Although the quotations proposed by the other two institutions identified some strong capabilities, their proposals did not meet essential elements for conducting the study and were not considered broad enough to address all of the stated goals.

\section{Medical Partnering Team Membership}

Sandia National Laboratories' partnering team for addressing the bottom-up tasks included the following individuals:

Richard N. Re, M.D. Principal Investigator

Alton Ochsner Medical Foundation, Director of Research

Marie Krousel-Wood, M.D., MSPH Co-investigator

Alton Ochsner Medical Foundation, Heallh Outcomes Research

Ahmed A. Abdoh, Ph.D. Consultant

Winnipeg Canada

David Bradford, Ph.D. Economist

University of New Hampshire, Department of Economics

Randall Campbell, Research Assistant

Louisiana State University, Department of Economics 
Richard Chambers, MSPH

Biostatistician

Alton Ochsner Medical Foundation

Jorge Cheirif, M.D.

Ochsner Clinic, Deportment of Cardiology

A. Mark Fendrick, M.D. Consultant

University of Michigan Medical Center

John M. Francis, M.D.

Cardiologist

Ochsner Clinic, Department of Cardiology

Natalie Ggomez, R.N.

Research Assistant

Alon Ochsner Medical Foundation

Clifford Goodman, Ph.D.

Consultant

Goadman \& Associates, Health Care Technology Assessments

Andrew Kleit, Ph.D.

Economist

Louisiana State University, Department of Economics

Robert Maness, Ph.D.

Economist

Federal Trade Commission, Bureau of Economics

P. Michael McFadden, M.D.

Cardiothoracic Surgeon

Ochsner Clinic

Blackford Middleton, M.D., MPH Consultant

M.Sc., FACP

Medical Logic, Vice President

Robert Nease, Ph.D.

Consultant

Washington University School of Medicine, Laboratory for Medical Decision Sciences

Etienne Pracht

Research Assistant

Louisiana State University, Department of Economics

Lester Prats, M.D.

Urologist

Ochsner Clinic, Department of Urology

Haya Rubin, M.D., Ph.D. Consultant

John's Hopkins University, Director of Quality Care Research

John Runnels, B.S.

Avalyst

Alton Ochsner Medical Foundation 
Patricia Scheaffer, R.N.

Research Technician

Alton Ochsner Medical Fotmdotion

Richard M. Scheffler, Ph.D. Consultant

University of California at Berkeley, School of Public Health

Raju Thomas, M.D.

Urologist

Tulane Medical Center, Chairman of Urology Department

Erid Walden

Research Assistant

Lousiana State University, Depariment of Economics

\section{Summary of Bottom-Up Approach Tasks and Goals}

In order to determine where technology might be best applied to reduce costs, a broad collection of health care databases was reviewed to determine a rank ordering of disease states by cost/charge and volume/frequency indices.

Outcomes measures were also collected to quantify the application of technologies for specific disease/disability states. These cost/charge, volume/frequency, and outcomes measures were used to construct Care Pathway lnteraction Models (CPIM's) for two chronic disease/disability (D/D) states: coronary artery disease (CAD) of sufficient severity to warrant revascularization, and benign prostatic hypertrophy (BPH).

The CPIM's simulate the overall cost impact of technology on the D/D states. The models for $\mathrm{BPH}$ and $\mathrm{CAD}$ were developed such that specific costs and outcome measures for the application of a care delivery technology can be determined at an individual node or for a complete pathway within the model. Further, the CPIM's may be modified to determine care delivery characteristics as a function of future technology-based treatments.

\section{Review of Medical Databases Task}

Several national, regional, and local medical databases were teviewed to support two essential tasks of the bottom-up approach for the study:

- cost/charge and volume/frequency measures data were collected for care delivery technologies in order to compile a global rank ordering technologies, and

- cost/charge, volume/frequency, and outcome measures data were collected to develop the economic and outcomes baseline for the CPIM care delivery interaction nodes and pathways. 
Because no central repository exists for administrative or outcome-related medical data in the United States, determining a rank order of technology usage required that a variety of information sources be interrogated, with the results extrapolated to the national population. These information sources included Medicare administrative records, the records of regional health maintenance organizations, and the Healthcare Cost and Utilization Project (HCUP), National inpatient Sample.

The characteristics considered when selecting a medical data base included the following:

1. Patient-specific, visit-specific, and population-based measures should be identified.

2. A source should address inpatient, outpatient, Medicare, and managed care delivery.

3. A database's scope should address national, regional, and/or local data.

4. Demographic information should include age, gender, ethnic origin, payer class, income level, and level of education.

5. International Classification of Diseases, 9th revision, (hereafter denoted as JCD-9) Health Care Financing Administration's Common Procedure Coding System (hereafter denoted as HCPCS) or the Current Procedural Terminology, 4th revision (hereafter denoted as CPT-4) coding structures for conditions and/or procedures should be designated.

6. Information sources (e.g. survey versus claims) should be identified.

7. The timeframe of a database"s collection should be indicated (e.g. current versus past years).

8. The source data should be available within the study's time constraints, and data access cost should be minimized.

\section{Global Rank Ordering of Cost-Effective Technologies}

After an extensive review of existing databases, the following data sources were selected for the project:

1. Health Care Finance Administration,

2. Healthcare Cost Utilization Project (HCUP-3), National Inpatient Sample,

3. a southern managed care organization, and

4. a large western managed care organization.

The databases were reviewed to identify the highest aggregate "charge" and volume for given patient populations using HCPCS, ICD-9 and CPT-4 codes. Since charge data is not a direct reflection of cost, units of services (e.g. laboratory and x-ray utilization, pharmaceutical data, ICU length of stay, overall length of stay) were also obtained in order to better compare conditions associated with higher charges across providers of care. These sources not only provided information on direct, indirect, and (to some extent) opportunity cost, but they also provided information on pertinent outcomes, whether they be ultimate or surrogate measures.

A summary of the characteristics of the selected databases is as follows: 
- A rank ordering of the top 200 technologies sorted by allowable charges and by frequency/volume for 1994 was obtained from the Health Care Finance Administration (HCFA) data using CPT-4 and HCPCS procedure codes. HCFA is the primary payer for the Medicare population characterized by high utilization of medical services. The data contained in the Medicare Part $B$ files have inputs from physicians, hospitals, and outpatient facilities and include a broad listing of technologies and other services.

- A southern managed care organization provided data on approximately 63,000 enrollees in calendar year 1994. These data were used to develop a composite list of the top 200 procedures by dollar and volume.

- A large western managed care organization provided data on approximately 2.4 million enrollees in calendar year 1994. These data were used to develop a composite list of the top 200 procedures by dollar and volume.

- Data were also obtained from the National Inpatient Sample (available through the National Technology Information Service (NTIS) and the Agency for Health Care Policy and Research (AHCPR)) to address the generalization of a composite rank ordering to the U. S. population. The NIS data represent a 5\% sample of all hospital discharges for the years 1988-1992.

The integration of information from these data sources was used to determine a global rank ordering of technologies in the United States. A rank ordering of combined inpatient and outpatient procedwes was carried out and a listing of the top twenty procedures by dollar rank is show in Table 1. The top five medical technology charge groups in order are

1. patient visit/mpatient and outpatient,

2. chest $\mathrm{X}$-ray,

3. mammography,

4. ophthalmologic services, and

5. ECG.

A rank ordering by volume was also performed, and the top twenty procedures are shown in Table 2 . In this case, the top five groups were

1. patjent visit,

2. chest x-ray,

3. ophthalmologic services,

4. ECG, and

5. manunography.

Note that the top five procedures by dollar order and volume order differ only in arrangement of absolute ranking of the items. Details of how the rank order data were derived are discussed in Appendix $\mathrm{A}$. 
Table 1. Rank Order Dollar - High Doltar Procedures Compriging the Top 20 Procedure Categories (Ranked by Total Estimated Allowed Charges") for the Combined Inpatient and Outpatient Report

\begin{tabular}{|c|c|c|c|c|c|}
\hline Nwnber & $\begin{array}{l}\text { Category } \\
\text { Wenghr } \\
\text { Rank }\end{array}$ & $\begin{array}{l}3 \text { Digit } \\
\text { Procedure } \\
\text { Caresory } \\
\text { (CPT and } \\
\text { HCPCs } \\
\text { codes"in) }\end{array}$ & $\begin{array}{l}\text { Abbrevialed } \\
\text { Trele }\end{array}$ & $\begin{array}{l}\text { Dnver Procedures * } \\
\text { for Caregory }\end{array}$ & 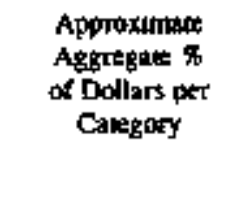 \\
\hline 1 & $\mathbf{1}$ & 992 & Panem Visul & 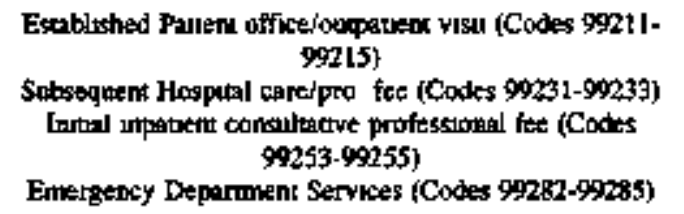 & $\begin{array}{c}416 \% \\
243 \% \\
73 \% \\
70 \% \\
\text { Subtotil }=802 \%\end{array}$ \\
\hline 2 & 2 & 710 & Chese X-Ray & 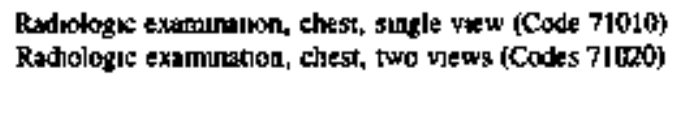 & $\begin{array}{c}384 \% \\
616 \% \\
\text { Subtwal }=1000 \%\end{array}$ \\
\hline 3 & 3 & 760 & Mammegram & $\begin{array}{l}\text { Matumography, bilateral (code 76091) } \\
\text { Scretning Mammograpty, blateral (Code } 76092 \text { ) }\end{array}$ & $\begin{array}{c}635 x \\
361 \% \\
\text { Subtotal }=994 \%\end{array}$ \\
\hline 4 & 4 & 920 & $\begin{array}{l}\text { Ophrtalmologic } \\
\text { Services }\end{array}$ & 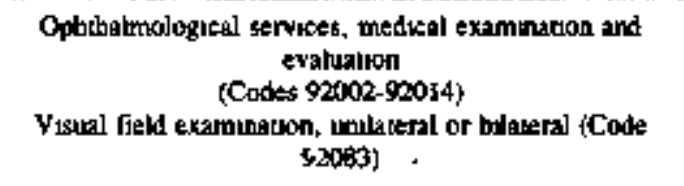 & $\begin{array}{c}885 \% \\
111 \% \\
\text { Subsotal }=996 \%\end{array}$ \\
\hline 5 & 3 & 930 & ECG & $\begin{array}{l}\text { Electrocardiogram (ECG), rourde ECG wh at leass } 12 \\
\text { leads } \\
\text { (Codes } 93000-93010)\end{array}$ & $\begin{array}{c}97 \% \\
\text { Subtotal }=97 \%\end{array}$ \\
\hline 6 & 6 & 908 & Psychotherspy & $\begin{array}{l}\text { Individual medical psychotherapy by a physcean } \\
\text { (Codes 90843-90844) } \\
\text { Group moducal psychotherapy (Code 90859) }\end{array}$ & $\begin{array}{c}769 \% \\
75 \% \\
\text { Subtotal }=844 \%\end{array}$ \\
\hline 7 & 7 & 933 & $\begin{array}{l}\text { Echoeardiograph } \\
y\end{array}$ & 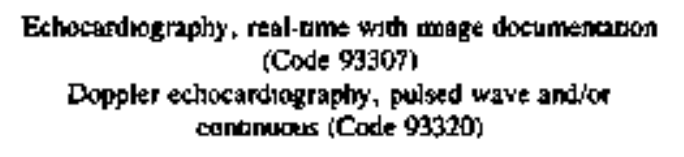 & $\begin{array}{c}574 \% \\
231 \% \\
\text { Sahtomal }=805 \%\end{array}$ \\
\hline 8 & 8 & 971 & $\begin{array}{l}\text { Physucal } \\
\text { Meducine } \\
\text { Treapmenx }\end{array}$ & 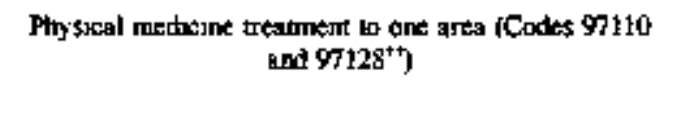 & $\begin{array}{c}9748 \\
\text { Stubtotal }=874 \%\end{array}$ \\
\hline 9 & 9 & 993 & $\begin{array}{l}\text { Nurșige Futily } \\
\text { Care }\end{array}$ & $\begin{array}{l}\text { \$ubsecpuent mursmo facility care/po-fee (Codes } 9931 \text { !- } \\
\text { 99313) }\end{array}$ & $\begin{array}{c}99 \% \\
\text { Subotil }=999 \%\end{array}$ \\
\hline 10 & 10 & 768 & Echograpty & $\begin{array}{l}\text { Echography, pregnant uıerus, lımired (Code 76815) } \\
\text { Echography, transwagma1 (Code 76830) } \\
\text { Echography, pelyk, not os (Code 76856) }\end{array}$ & $\begin{array}{c}393 \% \\
165 \% \\
353 x \\
\text { Subotalal }=91 \quad 1 \%\end{array}$ \\
\hline II & $10^{\circ}$ & $\mathrm{BOH}$ & $\begin{array}{l}\text { Laboratory } \\
\text { Elood Tests }\end{array}$ & 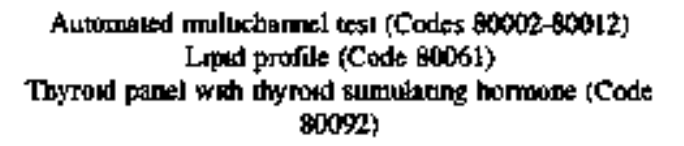 & $\begin{array}{c}632 \% \\
143 \% \\
178 \% \\
\text { Subcolal }=9535\end{array}$ \\
\hline
\end{tabular}




\begin{tabular}{|c|c|c|c|c|c|}
\hline 12 & 12 & 994 & $\begin{array}{l}\text { Evaheuon and } \\
\text { Management } \\
\text { Sorvice }\end{array}$ & $\begin{array}{l}\text { Unhered evaluanon and mangrament sorvke (Code } \\
99499 \text { ) }\end{array}$ & $\begin{array}{c}100 \& \\
\text { Subnot }=108 x\end{array}$ \\
\hline 13 & 13 & 453 & $\begin{array}{l}\text { Sigmandlosecopyt } \\
\text { Colonosecopy }\end{array}$ & 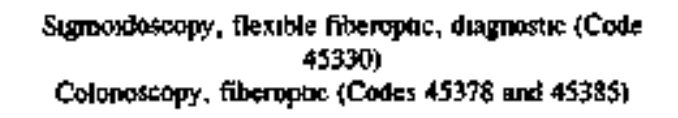 & $\begin{array}{c}601 \% \\
39.9 \% \\
\text { Subtrol }=100 \%\end{array}$ \\
\hline 14 & 14 & 735 & Hup, Knes Xr & 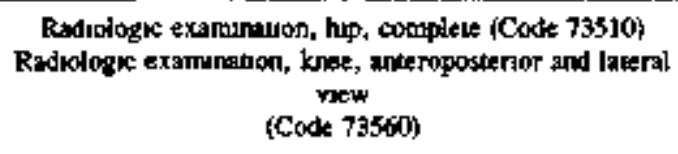 & $\begin{array}{c}60.0 \% \\
379 \% \\
\text { Subtotpl }=979 \%\end{array}$ \\
\hline 15 & $14^{+}$ & 850 & Blood Count & 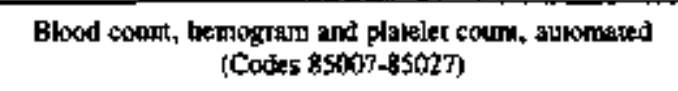 & $\begin{array}{c}95.5 \% \\
\text { Subtokat }=95.9 \%\end{array}$ \\
\hline 16 & 16 & 883 & $\begin{array}{l}\text { Surgical } \\
\text { Paholagy }\end{array}$ & 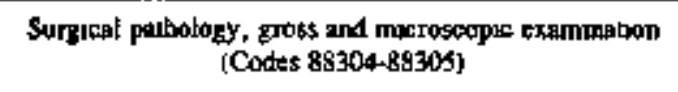 & $\begin{array}{c}100 \% \\
\text { Subtotzl }=100 \%\end{array}$ \\
\hline IT & $16^{+}$ & $A D Q^{* * n}$ & Amibulance & $\begin{array}{l}\text { Ambulance service and supplies (Codes A0215, A0220. } \\
\qquad A 0222)\end{array}$ & $\begin{array}{c}100 \% \\
\text { Subjobl }=160 \%\end{array}$ \\
\hline 18 & 18 & 704 & $\begin{array}{l}\text { CAT Stan - } \\
\text { Head }\end{array}$ & 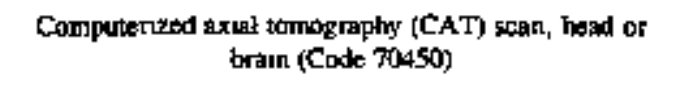 & $\begin{array}{c}\text { 98.6\% } \\
\text { Subtoplal }=9 \% 6 \%\end{array}$ \\
\hline 19 & $\mathrm{IS}^{1}$ & 774 & Ratiotherppy & $\begin{array}{l}\text { Weekdy radkotherapy mamgenent, complex (Code } \\
\qquad 7430)\end{array}$ & $\begin{array}{c}99.9 \% \\
\text { Subcotal }=999 \%\end{array}$ \\
\hline 20 & 20 & 767 & $\begin{array}{l}\text { Abdominal } \\
\text { Echography }\end{array}$ & $\begin{array}{l}\text { Echography, sbdotrumal B scan andfor teal brte (Code } \\
\qquad 6700 \text { ) }\end{array}$ & $\begin{array}{c}99.0 \% \\
\text { Subwol } 99.0 \%\end{array}$ \\
\hline
\end{tabular}

t Some categorkes have simplar weight ranks

* HCFA natonal averace "dlowed" chacge for each rekvan code was applied across each data set (Medicare Pan B,

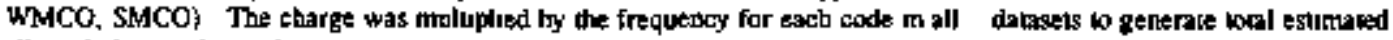
allowed charges for each eabegory

tt Code has tees deleked from the 1990 CPT. 4 mamul

** HCPCS = HCFA Comumon Procedural Codin: Sygued

CPT = Current procedure termunokgy 
Table 2. Rank Order Volume - High Volame Procedures Comprising the Top 20 Ranked Procedare Categories for the Combined Inpatient and Outpatient Report

\begin{tabular}{|c|c|c|c|c|c|}
\hline Number & $\begin{array}{l}\text { Caregory } \\
\text { Wevolu } \\
\text { Rank }\end{array}$ & $\begin{array}{l}3 \text { Digi } \\
\text { Procecture } \\
\text { Calepory } \\
\text { (CPT and } \\
\text { HCPCS } \\
\text { codes***) }\end{array}$ & $\begin{array}{c}\text { Abbreviaced } \\
\text { Trile }\end{array}$ & $\begin{array}{l}\text { Driver Procentares* } \\
\text { for Conegoty }\end{array}$ & $\begin{array}{l}\text { Approximati } \\
\text { Aggregate } \% * *\end{array}$ \\
\hline I & 1 & 992 & Patent Visis & 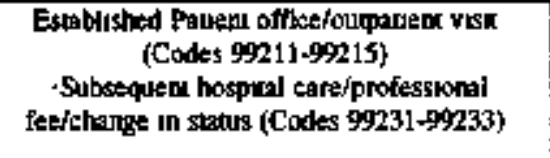 & $\begin{array}{c}561 \% \\
25.8 \% \\
\text { Suthotal }=81.9 \%\end{array}$ \\
\hline 2 & $\mathbf{2}$ & 310 & Chest X-Ray & 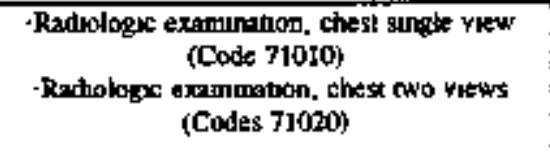 & $\begin{array}{c}464 \% \\
53.5 \% \\
\text { Sutbiotsl }=999 \%\end{array}$ \\
\hline 3 & 3 & 920 & $\begin{array}{l}\text { Optribalmoleggre } \\
\text { Services }\end{array}$ & 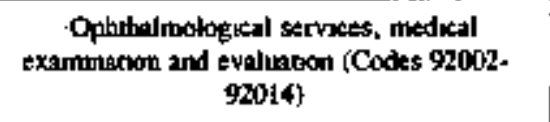 & $\begin{array}{c}87.1 \% \\
\text { Subtots[ }=87.1 \%\end{array}$ \\
\hline 4 & 4 & 930 & ECG & $\begin{array}{l}\text {-Electrocardjogrant (ECG), routhe ECG whith } \\
\text { at least i2 keads (Codes } 93000-93010 \text { ) }\end{array}$ & $\begin{array}{c}\text { \$.1\% } \\
\text { Subrosat }=\$ 5.1 \%\end{array}$ \\
\hline 5 & 5 & 760 & Maramogfam & $\begin{array}{l}\text { Mammography; biliteral } \\
\text { (Code 76991) } \\
\text { Screening Mammography, bolanerat } \\
\text { (Code } 76092 \text { ) }\end{array}$ & $\begin{array}{c}62.29 \\
3719 \\
\text { Sulbotel }=99.3 \%\end{array}$ \\
\hline 6 & 6 & $97 !$ & $\begin{array}{l}\text { Plyssical } \\
\text { Medreine } \\
\text { Treamentit }\end{array}$ & $\begin{array}{l}\text { Physocal medicine treatment on one eres } \\
\text { (Codtes } 97130 \text { and } 97128^{\circ} \text { ) }\end{array}$ & $\begin{array}{c}899 \% \\
\text { Subworal }=899 \%\end{array}$ \\
\hline 7 & $6^{+}$ & 993 & $\begin{array}{c}\text { Nursuts } \\
\text { Faciliny Care }\end{array}$ & $\begin{array}{l}\text {-Subsequent aursing facildy carcipro-fec } \\
\text { (Codes } 99311.99313 \text { ) }\end{array}$ & $\begin{array}{c}99.9 \% \\
\text { Subookal }=99.9 \%\end{array}$ \\
\hline 8 & 8 & 907 & $\begin{array}{l}\text { Influenza } \\
\text { Vocesne }\end{array}$ & $\begin{array}{l}\text { Imminzenon, active; influenza vinus } \\
\text { vaccine (Code 99724) }\end{array}$ & $\begin{array}{c}998 \% \\
\text { Sultotolat }=99.8 \%\end{array}$ \\
\hline 9 & 9 & 800 & $\begin{array}{l}\text { Laboratary } \\
\text { Blood Tests }\end{array}$ & 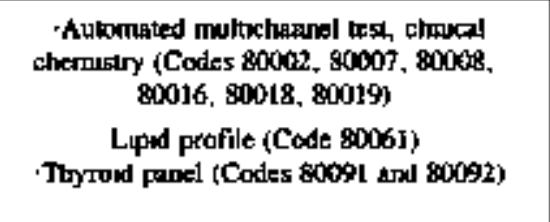 & $\begin{array}{c}77.8 \% \\
10.9 \% \\
11.3 \% \\
\text { Subtutal }=100 \%\end{array}$ \\
\hline 10 & 10 & 850 & Blood Count & $\begin{array}{l}\text { - Blood count; hemogram and platelet count, } \\
\text { aubmated (Codes B5023-85027) }\end{array}$ & $\begin{array}{c}92.2 \% \\
\text { Subuocal }-92.2 \%\end{array}$ \\
\hline 11 & 11 & sels & Psychodterapy & 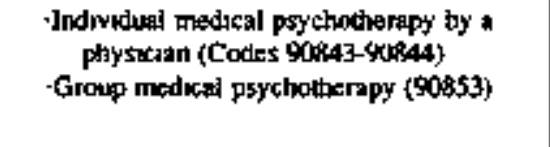 & $\begin{array}{c}6.8 \% \\
19.4 \% \\
\text { Subcout }=80.2 \%\end{array}$ \\
\hline 12 & 12 & gIO & Urmalyos & $\begin{array}{l}\text { Unnalysis, by reagent str ps } \\
\text { (Codes } 81000 \text { and } 8: 002 \text { ) }\end{array}$ & $\begin{array}{c}999 \% \\
\text { Subrotal }=99.9 \%\end{array}$ \\
\hline 13 & 13 & 730 & $\begin{array}{l}\text { Shoulder X- } \\
\text { Ray }\end{array}$ & 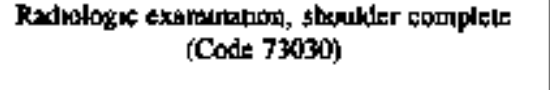 & $\begin{array}{c}9.5 \% \\
\text { Subtoul }=96.5 \%\end{array}$ \\
\hline
\end{tabular}




\begin{tabular}{|c|c|c|c|c|c|}
\hline 14 & 14 & 735 & $\underset{\text { Hip. Knee X- }}{\text { Rsy }}$ & 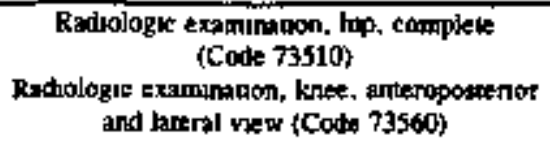 & $\begin{array}{c}587 \% \\
39.3 \% \\
\text { Suptotal }=98.0 \%\end{array}$ \\
\hline 15 & 15 & 736 & $\begin{array}{l}\text { Ankte, Foog } \\
\text { X-Ray }\end{array}$ & $\begin{array}{l}\mathrm{X} \text {-ray onlite, complote } \\
\text { (Code } 73610) \\
\mathrm{X} \text {-ray foos, complete } \\
\text { (Code } 73630 \text { ) }\end{array}$ & $\begin{array}{c}36.1 \% \\
48.8 \% \\
\text { Subtotsi }=84.9 \%\end{array}$ \\
\hline 16 & $15^{+}$ & 856 & $\mathbf{P T}$ & $\begin{array}{c}\text { Prothrombin Time (PT) } \\
\text { (Code 856L) }\end{array}$ & $\begin{array}{c}99.9 \% \\
\text { Sllowitil }=99.9 \%\end{array}$ \\
\hline 17 & $15^{\circ}$ & 994 & $\begin{array}{l}\text { Evaludioun ats } \\
\text { Merragement }\end{array}$ & $\begin{array}{l}\text { Unlisted evaluobon and mangogment } \\
\text { service (Code 99499) }\end{array}$ & $\begin{array}{c}100 \% \\
\text { Saboral }=100 \%\end{array}$ \\
\hline 18 & 18 & 844 & $\begin{array}{l}\text { Thyroxine, } \\
\text { TSH }\end{array}$ & $\begin{array}{c}\text { Thyroxine } \\
\text { (Code 84436) } \\
\text { Thyroud sumulaung hornoint } \\
\text { (TSH) (Code 84443) }\end{array}$ & $\begin{array}{c}43.2 \% \\
567 \% \\
\text { Subtol }=999 \%\end{array}$ \\
\hline 19 & 19 & 768 & Exhography & 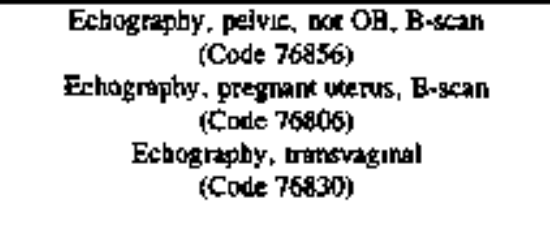 & $\begin{array}{c}38.3 \% \\
32.5 \% \\
185 \% \\
\text { Subrow }=893 \%\end{array}$ \\
\hline 20 & $19^{*}$ & $9 \$ 3$ & $\begin{array}{l}\text { Surgecal } \\
\text { Pathology }\end{array}$ & $\begin{array}{c}\text { Surtacal pathologyigross mictuscopti } \\
\text { (Codes } 88304 \text { and } 88305 \text { ) }\end{array}$ & $\begin{array}{c}100 \% \\
\text { Suboral } 100 \%\end{array}$ \\
\hline
\end{tabular}

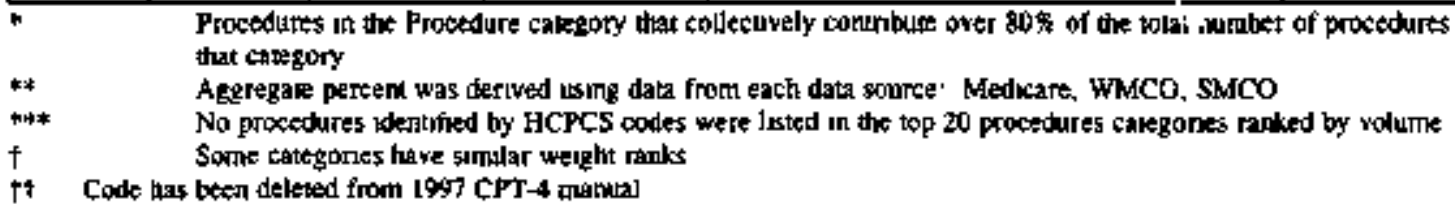

Outcomes data, both surrogate and definitive, were also collected. Surrogate measures acquired from administrative/claims databases included

- number and type of emergency room visits,

- number and type of hospitalizations,

- number of hospital readmisssions,

- number and type of clinic visits, and

- number and type of procedures performed.

Definitive outcome measures collected included

- patient functional status,

- patient satisfaction,

- mortality and morbidity rates,

- complication rates, and

- fit to work status, among others.

Definitive measures were identified both pre- and post-application of specific technologic intervention.

The outcomes team used standard tools that have been developed for the collection and quantification of outcome measures. As examples, the widely-used Short Form, 36-jtem 
(SF-36) and Dartmouth Project Cooperative (COOP) Charts for measuring patient functional status have been tested and validated [Nelson 1990, Ware 1992].

A key to the interpretation of potentjal outcomes variations are patient-specific characteristics that could confound the results and bias the interpretation of outcomes data. Several severity of illness indices were used by the outcomes team to assess the impact of severity on clinical outcomes.

For example, the Charlson index [Charlson 1987] was used Other indices, including the Index of Coexistent Disease (ICED) [Greenfield 1993] and the Kaplan-Feinstein Index [Kaplan 1974] were utilized for assessing comorbidity.

Although several other severity indices have been developed to assess cost of care, the previous indices were chosen for this task since they have been developed to assess clinical outcomes. For outcomes information derived from administrative/claims data sources that prohibited access to the medical records, risk adjustment was determined using indices such as the claims-based Charlson index [Deyo 1992] or the All Patient Reffned - Diagnostic Related Groups (APR-DRG) approach [Jones 1994].

\section{Interventional Focus Areas}

In order to quantify technology application in the U. S. health care systern, care pathway interaction models (CPIM's) were developed for two disease/disability states. The modeling effort was two pronged. An "artention focusing model" was developed with the goal of permitting the user to easily and conveniently vary input parameters and quickly assess results so that otherwise unappreciated relationships between variables and outputs could be identified. These attention-focusing models were developed utilizing Demos, a product of Lumina Decision Systems, for MacIntosh. The models were eventually imported into Lumina Decision Systems' commerciaf product: Analytica. When a personal computer version of the package became available, the models were imported into the Windows 95 version of Analytica. The second modeling effort involved the development of more detailed models utilizing the ARENA Windows 95 compatible system. The ARENA modeis are more difficult to manipulate and interrogate but are elemental in nature, providing the user with the ability to follow specific patient cohorts over time.

\section{Disease/Disability Conditions Assessed}

Because it was the goal of the team to develop a paradigm for the development of technological figures of merit which could be applied widely in the health care system, several criteria were established for the conditions which were to be modeled for this project. These conditions were designed to ensure that the analysis format which was 
developed as part of the project would be sufficiently robust to be widely utilized in future efforts by others to model health care costs. The criteria included the following:

- The technological intensity of the therapeutic modality. It was of considerable interest to Sandia to identify technologies (widely defined) which Sandia scientists and engineers could develop in order to lower costs. Therefore, the medical conditions chosen for modeling were deliberately technologically-intensive.

- The aggregate costs (dollar volume) of the condition should be large so as to provide national relevance to the issue of health care costs.

- The chosen conditions should be frequent (patient volume) to support the relevance of the analysis.

- Cost and outcome data should be available in the literature and elsewhere so as to improve the precision of the modeling.

- The chosen conditions should have a significant impact on individual patients so as to be viewed as non-trivial.

The first chosen condition was coronary artery disease of sufficient severity to consider vascular intervention. This disease can be treated by a technologically-intensive array of therapies, including coronary artery bypass grafting (CABG), percutaneous transluminal coronary angioplasty (PTCA, or balioon angioplasty), laser angioplasty, atherectomy, stents, and soon minimally invasive coronary artery bypass grafting (mini-CAB). Treatment of this disorder is expensive, amounting to $\$ 20$ billion annually. Coronary artery disease is the leading cause of death in the United States. In addition, two treatment procedures for coronary artery disease (CABG and PTCA) ranked in the top 20 procedures with the rank ordering task. Coronary artery disease is well studied both from the outcome and cost point of viewand is a major cause of morbidity, mortality, and hospitalization in the United States. Thus, coronary artery disease met all of the study criteria.

The second condition chosen was benign prostatic hypertrophy (BPH). Treatment of this condition is also technologically intensive and currently includes open prostatectomy, transurethral prostatectony, laser prostatectony, microwave therapy, transurethral needle ablation, and pharmacological therapy. The aggregate cost of BPH therapy is high, with procedures and pharmaceuticals estimated to cost over $\$ 3$ billion a year. The disease is common in the over- 60 age group. The primary surgical treatment for BPH (transurethral restenosis of prostate, or TURP) ranked in the top 50 procedures listed in the rank ordering task. Although there is not the abundance of outcome and cost data available for $\mathrm{BPH}$ that there is for coronary antery disease, adequate information exists in the literature and elsewhere for modeling purposes. Benign prostatic hypertrophy has a major impact on patients quality of life and sense of well-being. Thus, benign prostatic hypertrophy also met the criteria for the study.

In fact, the choice of benign prostatic hypertrophy complements the choice of coronary artery disease because, unlike coronary artery disease, BPH is in general not life threatening. Therefore, therapy is to a large extent optional. Indeed, the decision for 
procedural therapy is more dependent on the patient than the physician in many cases, which contrasts with coronary artery disease, where physician decisions dominate.

Finally, some have utilized information technology to impact patient choice regarding BPH therapy. Therefore, the inclusion of benign prostatic hypertrophy in this study offers the opportunity to model information technologies of this nature [Barry 1995].

The outcomes team collected data in conjunction with the Academic Medical Center Consortium (AMCC) for the Quality Measurement and Management Initiative on coronary artery disease. The data from this effort address a variety of outcomes, including

- baseline and follow-up functional status,

- satisfaction,

- adverse events and complications,

- repeat procedures, and

- death.

These data were merged with the Alton Ochsner Medical Foundation's (AOMF's) internal detailed charge file. This merged data set allowed the assessment of a large number of variables for economic analysis in developing the CPIM's.

The function of the models is essentially heuristic. The models clearly point out issues which bear on the nexus of technology and health care costs. Each of these issues is potentially worthy of future research.

First, the necessity to define health care cost is highlighted by the models. Each mode] recognizes that costs are both direct (payments for services rendered) and indirect (effects on society such as wages gained or lost). Therefore, it becomes clear that expenditures are not equivalent to cost. The models provide cost analysis from the point of view of the payer as well as from the perspective of the larger society. The results of simulations are dependent not only on the cost perspective assumed but also on the estimates of the costs themselves. In the case of establishing societal costs/benefits, the project tearn encountered the need for determining the dollar value of a life year. Appropriate economic literature was reviewed, and it was elected to estimate this value using a revealed preference methodology. The derived figure was utilized in the coronary artery disease model for calculations of societal cests/benefits.

A second major issue raised by the modeling was the growth of demand which a new procedure can produce. Based on literature review and a review of technology usage, it became clear that new technology often, if not always, stimulates increased demand for its use. Therefore, even technologies which may reduce unit costs often tend to increase aggregate direct costs. Various factors were identified as determinants of demand and were then included in the models so that they could be explored by analysts over time.

A third factor influencing the relationship of technology and health care costs is the assessment of quality-adjusted life years (QALY) and their economic impact. The 
theoretical arguments related to assigning economic value to QALY's were revjewed, including those arguments dealing with the increased late medical (and non-medical) costs to which life-extending therapies expose patients. As noted above, it was elected to empirically derive the value of a quality-adjusted life year (QALY). Therefore, longevity changes, discounted for quality of tife, were used in economic calculations of societad benefit in the case of coronary artery disease. In the case of benign prostatic hypertrophy, -where little impact on longevity is seen and the major irnpact of therapy is symptomatic, it was not felt that current theary is sufficiently developed to warrant establishing an economic value for the quality component of the therapy.

\section{Economic Analysis and Modeling}

Formal economic analysis was performed in this project in order to (1) properly define the direct cost of index procedures and (2) define the economic benefit of these index procedures. These issues are both important and complex. Just as wide variations in the use of medical technology occur in the United States, wide variations occur in the charges for the provision of that technology. Moreover, outcomes and charges are often poorly correlated. Therefore, it appears reasonable to attempt to define a true cost (as opposed to charge) for the index procedures after removing the effects of the severity of patient tllness and geographical price differences. These issues must be addressed in addition to those associated with the choice of an economic prospective on cost: the decision as to whether indirect or direct costs, broadly defined, are most appropriate to answer any specific question.

The economic analysis preserted here demonstrates methodologies for identifying costs and cost savings associated with the conversion of patients from one procedure to another, taking into account the severity of illness in these converted patients. Also demonstrated are means for identifying lowest-cost practice pattems. This analysis utilizes 'stochastic frontier' technology and attempts to identify that patter of inputs which produces an output of lowest cost. When corrected for quality of outcome, this kind of analysis assists the investigator in determining a benchmark cost ("lowest cost" or "best practice").

In the approach to the determination of the benefits of care, the economic anatysis reviewed the multiple means by which such benefit can be calculated, including (1) wage-based, (2) time trade-off, and (3) revealed preference methodologies. A revealed preference technique for identifying the value of time in the index populations was developed and employed in the models.

The modeling effort was approached in two ways. First, an "attention focusing model" was developed with the goal of perrnitting the user to easily and conveniently vary input parameters and quickly assess restuls so that otherwise unappreciated relationships between variables and outputs could be identified. These attention focusing models were developed utilizing Demos, a product of Lumina Decision Systems, for Macintosh. The 
models eventually were imported into Luming Decision Systems' commercial product Analytica and were then imported into the Analytics Windows 95 version for IBMcompatible personal computers. The second modeling effort involved the development of more detailed models utitizing the ARENA Windows 95 compatible system. The ARENA models are more difficult to manipulate and interrogate, but are elemental in nature and so provide the user with the ability to follow specific patient cohorts over time.

The economic analyses presented here were helpful in the development of the models for health care costs found in this report. However, their value extends beyond this project in that they serve as guideposis for economic analysis of health care technology of many sorts.

\section{Definitions}

When attempting to model health care quality and costs, several variables require precise definitions. Included among these are

- health care costs,

- technology, and

- demand for care.

\section{Health Care Costs}

When analyzing health care costs one can, in theory, utilize any one of several perspectives. First, one could focus on the direct unit cost of service: the cost of providing one procedure or the cost of treating one patient. Second, one could analyze direct aggregate cost: the total direct cost of all patients treated. Third, one could consider societal cost, which includes all direct costs as well as societal opportunity costs/savings (also denoted as "indirect costs" in the literature) derived from such factors as days lost from work. In the SNL/AOMF project, all of these costs are modeled, but the degree of precision of the modeling falls as one moves from direct costs to aggregate costs to societal costs. That is, more uncertainty exists with regard to the impact of a technology on societal costs than on the direct unit cost. Potential cost drivers inciude the following:

1. number of cases,

2. number of cases per physician,

3. occurrence of adverse events (need for additional technology, death, morbidity),

4. post-procedure length of stay,

5. institutions charges per admission,

6. variable costs,

7. fixed cost,

8. patient severity cost,

9. payment incentives, 
10. technology utilization.

11. willingness of physicians to provide services/technology, and

12. patient demand for services.

An additional problem associated with the definition of cost in a practical sense is related to the fact that the United States health system is administratively focused on charges, not on costs, because it is rooted in a traditional fee-for-service system. Yet, policy should properly be driven by cost considerations which eliminate effects of price distortions and rents (excess payments over those required to obtain a good or service). Recall that health care charges vary widely across the United States, often in ways unrelated to the outcome of care or to the volume of delivered care.

In the effort to develop direct cost data, two approaches were used:

- a "bottom-up" cost construction using time/work studies and supply costs, and

- cost-charge ratios derived empirically and from published literature.

The initial approach for the "bottom-up" cost constnuction effort was to utilize the recently implemented AOMF Cost Accounting System. However, inconsistencies between this system and the literature were sufficiently large that the investigators responsible for the project felt that it would be unwise to utilize this cost system as the sole arbiter of costs of health care for the indicated procedures. Not only was the system incomplete; its use as the sole deterninant of a cost function would be unwise from a theoretical point of viuN. In effect, even if optimaily functioning, the AOMF Cost Accounting System could provide information regarding the cost of medical care in only one health care system in only one geographical region of the country. Therefore, the AOMF Cost Accounting System was used to supplement the primary data sources: literature and published data (NIS, $\mathrm{HClA}$ ) containing cost/charge-detived information.

Three approaches were used to assess societal opportunity costs:

1. Wages were used to estimate the economic impact of a day spent out of the hospital or an extra day lived.

2. We assumed that both working and non-working indjuiduals contribute to the econorny. With that assumption, we determined an imputed economic benefit of a day (including non-wage earning activities) and multiplied that figure by the number of quality-adjusted life days gained thanks to the therapy under evaluation.

3. We utilized revealed preference techniques to identify the economic benefit of an extra year of life to a retired person.

Were revealed preferences not used, one would be required to catalog non-compensated but functionally usefil activities of retired persons and then ascribe to them a market value. This procedure has considerable shortcomings when compared to the revealed preference methodology. To see the importance of properly defining economic benefit (or alternatively of understanding the implications of the chosen cost definition for the interpretation of results) one need only to consider the impact of a changing retirement age on the calculated societal cost and benefits of a treatment for coronary artery disease. Because most patients with coronary artery disease are retired or near retirement, any 
societal costhenefit calculation which is based on the increase in Jifetime eatnings created by vistue of technology-driven patient salvage is immediately increased if retirement age increases. This issue is relevant given the fact that by the year 2001 the retirement age in the United States for maximum social security benefit will have increased from 65 to 67 years and will increase again thereafter.

Note that the cost of health care can be influenced by physician fees, which vary from region to region. Although physictan fees are a relatively modest component of total health care costs, in a fee-for-service system, physician ordering behavior (which may in part be influenced by physician fee structures) can influence the use of services and therefore costs. In addition, inefficjencies can contribute to health care costs, accounting for some of the variation in the utilization of services in different regions of the country as well as variation in health care charges. It must be noted that the "cost plus" system of reimbursement provided little incentive to hospitals or other providers to identify and reduce inefficiencies. The current SNL/AOMF proposal calculates costs with and without physician fees. The issue of efficient and inefficient providers is handled by using a distribution of costs in the model to reflect all causes of cost distribution. The investigators attempted to approach the issue of inefficiency using a novel method, stochastic frontier analysis, in an effort to define "lowest cost" or "best practice" behavior and to utilize this in the generation of cost functions. Although this methodology is potentially powerful, its utilization for modeling national health care would require detailed cost data from multiple providers. Therefore, cost data for this project were obtained from nationally available sources.

\section{Technology}

Technology itself requires an operational defintion for the purposes of the SNL/AOMF project. Clearly, medical handware and the associated procedures represent "technology," but so do information (including patient education), decision support tools (e.g. prevention programs), and office visits. The modeling paradigms developed by this initiative should ideally be robust enough to include these various forms of technology.

\section{Demand for Care}

Demand for care is perhaps the hardest issue to model or define. Demand is multifactorial and varies with procedure, patient, physician, and information provided. Of particular note are alterations in demand caused by new technology (the so-called "behavioral effects") or by payor class.

\section{Quality-Adjusted Life Years}

When modeling the impact of technology on health care costs, it is important to distinguish those reductions in costs which result from increased efficiency of care from those which result from reduction in the quality of received care. Further, when we 
attempt to quantify the benefits of therapy in order to compare the benefits of two competing therapies, the matter is potentially quite complex. The situation becomes more problematic when one wishes to develop a means for comparing quality of outcome, which can then be translated into societal economic value. Many attempts have been undertaken to arrive at methodologies for performing this kind of assessment, but the most prominent is based on Von Neumann-Morgenstern utility theory, which incorporates the so-called "standard ganble." This methodology permits the analyst to assess quality-of-jife-related attributes in addition to simple changes in longevity. The methodology requires that test subjects compare a specific health state with a gamble, the outcomes of which are immediate death (with probability p) and perfect health (with probability [1-p]). When the value of $p$ is varied, the point at which test subjects become indifferent to the outcome is determined. This permits an assessment of the desirability of any given health state. While a detailed description of the theory behind the standard gamble is beyond the scope of this discussion, this methodology has been used extensively in health care. When this approach is combined with estimates of longevity changes, the concept of a "quality adjusted life year" (QALY) emerges. The QALY concept enables comparisons and trade-offs to be made between interventions that have effects on outcome for both length and quality of life. The QALY concept also facilitates the calculation of cost-effectiveness ratios.

The QALY approach has been criticized for, among other things, the inability to assess the value of survival (e.g. the severity of moving from 0.3 to 0.0 on the quality of life adjustment factor scale). However, in the coronary artery disease model we have chosen to use QALY's as our measure of health outcome. This is because the revascularization strategies we are modeling produce approximately the same longevity of life. Therefore, questions relating to the character of the QALY scate over various intervals are less germane than they might be when comparing, for example, cosmetic surgery to renal dialysis. In the case of benign prostatic hypertrophy, we have not been able to ascribe QALY's to the various treatments available. Because longevity does not in genetal change, and the variation in symptoms does not in all cases parallel physiological parameters, it becomes difficult to quantitatively assess changes in QALY for BPH. Rather, we have chosen to examine changes in an arbitrary symptom score similar to that used by the American Urological Association.

\section{The Value of a QALY}

In analyzing the cost of heal th care, we considered not only the direct cost of providing care, but also such inditect costs as patients time lost from work, both during the immediate procedure and over the ensuing years. Similarly, a patient's ability to return to work could properly be counted as an offsetting opportunity which mitigates the societal costs of providing the care. The most straightforward means of estimating the value of these employment-derived opportunities and costs is to use ambient wage rate. However, these rates may be inaccurate for several reasons: 
- The prevailing wage rate is likely neither gender nor race neutral and therefore the cost/opportunity estimates derived would be distorted if based on average wage.

- Wage tends to overestimate the true value of employment since the wage is, in effect, the payment required by the least willing worker to perform the job. Presumably, more willing workers would have worked for less.

- The wage methodology completely ignores not-compensated value added to the society (e.g. from a housewife). This is a comparable problem to that faced by the Senate Committee on the Consumer Price Index.

This issue leads naturally into the question of the value of a day in the life of a retired person. Such people may provide uncompensated or compensated work to the society and may benefit the economy in other ways such as through the expansion of consumer demand. How are these factors to be taken into consideration? Ome view holds that, once a technology is demonstrated to produce an efíect on quality-adjusted life years, a conversion should in theory be possible for QALY scores for both employed and unemployed persons alike. One method which project economists have employed in making this estimate is based on revealed preference. In effect, economists look at the trade-off between retiring at 65 and retiring at age 62 . In the latter case, the retirement benefit is lower for several reasons, but the benefit is paid for a longer period of time, and the individual in question has additional leisure time by virtue of not working to age 65 . By analyzing the current value of each of these retirement options, economists estimate a value of approximately $\$ 170$ per day for the uncommitted time of the average 62 -yearold person.

\section{Cost-Benefit Analysis Applied to CAD and BPH}

In its simplest form, cost-benefit analysis attempts to measure the costs and benefits of particular economic actions. While this may be conceptually simple, its details can be quite difficult. In this part, we present some important conceptual ideas in cost-benefit analysis to issues of technological change in the health care industry.

As our results indicate, there are two general consequences of technological change: (1) the quality of treatment increases along a number of dimensions and (2) as the quality of treatment increases, the number of people who demand the treatment may rise. These two effects, together with the actual dollars needed to pay for the treatment, may lead to a substantial increase in the number of dollars that pass through the health care sector to pay for treating, for example, coronary artery disease (CAD) and benign prostatic hypertrophy (BPH). One may conclude from these data that net costs to society from these illnesses have increased. However, this may be a poor interpretation of the data. Before one can tell whether net costs are rising, one must answer two important questions:

- "What is the best measure of social costs (and benefits) in health care economics?", and 
- "How do we go about estimating the appropriate measure of social costs for this project?"

This part will address both of these issues.

Consistent with the well-established methodology of cost/benefit analysis in economics, we argue that when calculating the true social cost of inventing a new treatment modality, researchers must include the benefits that spring into existence due to the new technology as well as the costs associated with that technology. The "net benefit costs" are the difference between how mich more we benefit as a consequence of an innovation and how much more we have to spend because of that innovation.

\section{Appropriate Measure of Social Costs and Benefits}

In order to answer the question about what is the approptiate measure for social costs, we must briefly renum to first principles. In a competitive market, where outcomes are efficient, the consequence of any transaction is to raise social welfare. Hence, when we measure "social cost" what we are interested in measuring the degree to which welfare is not increased by market interaction. The welfare derived from an individual purchase is the difference between the value that a consumer places on the good purchased and the opportenity cost of actually producing the product. The relationship between the maximum value that a person, or group of people, assigns to a good and the amount of that good consumed is known as the Morginal Benefit (MB) or Demond relationship. The relationship between the opportunity cost of producing a good and the amount of the good produced is known as the Marginal Cost (MC) or Supply relationship. These relationships are plotted out in Figure 1. We can graphically illustrate the total arnount of welfare that society receives from consurning a particular good in a competitive market as the shaded area on the graph. 


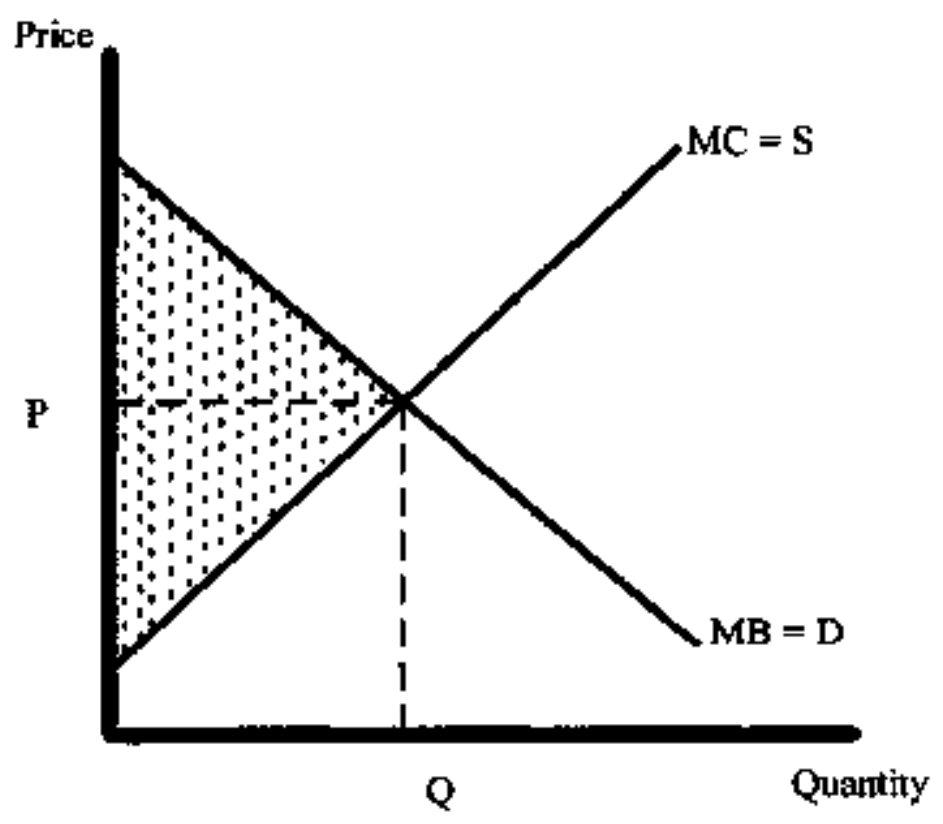

Figure 1. Fundamental supply/demand retationship in economics. (MC = Marginal Cost, S = Supply, MB = Marginal Benefit, D = Demand)

Note that in a normal, competitive market, where consumers are paying for all consumption conpletely out of pocket, we know that the consumer always purchases the good where the marginal benefit is exactly equal to the marginal cost. This implies that welfare is as large as it can be, and the market is efficient. Hence, if we want to know how much the last unit of the good is "worth" to society, we can simply look at how much was spent (price). However, in health care the consumer does not pay for all purchases completely out of pocket. In fact, in many circurnstances the consunner may pay nothing out of pocket. This teads to the well-known "moral hazard" problem of overconsumption, which refers to a circumstance in which a consumer does not pay the full cost of the goods he purchases and therefore does not take care of himself as he otherwise would. Here, marginal benefit does not equal marginal cost, and welfare is not maximized (dixe to over-consumption). In addition, since third-party payers are involved, the individual cannot frequently evaluate the benefit from a medical treatment across alt of its dimensions (e.g. quality). In this case, the observed willingness to pay may even be understated. Therefore, we cannot know the true value of a medical expenditure to society by simply observing transactions. Consequently, we must estimate the change in welfare directly. To do this we must estimate marginal resource cost and marginal value. If marginal costs are greater than marginal value, then social welfare is reduced and we have incurred positive net socjal costs.

\section{Measuring Costs}

For coronary artery disease (CAD), the primary costs involved are the costs of the various medical treatments. We obtained data for the charges of CAD patients at a large 
southeastem United States HMO. Our primary goal was to measure the cost savings avalable from switching patients from the generally more expensive CABG procedure to PTCA, assuming that the technology to make this possibie becomes available. This task required two steps.

1. First, we had to account for the severity of illness in the patients who have undergone CABG. Generally, CABG patients are "sicker" than PTCA patients. Thus, this group

- of patients would still be more costly to treat even if they were to undergo PTCA instead of CABG. Through multivariate regression analysis, we can adjust for these factors.

2. Second, we had to translate charges into costs.

In a perfectly competitive market, firms cannot affect the price received for their products by changing their quantity of output. They therefore maximize their profits by increasing their output until the marginal cost of that output equals the market price of the output. The hospital industry, however, is not perfectly competitive. We therefore expect that firms can alter the price they receive for their products by changing the amount of their output. Therefore, we expect that the charge for a particular good or service will be above the economic cost of providing that service. Further, hospitals provide a multitude of services jointly, and those have the ability to spread costs (and make profits) across numerous different charge items. Therefore, in our cost-benefit analysisit is necessary to convert charges into costs.

\section{Measuring Benefits}

The benefits of many advanced technologies are that they permit patients to become healthier sooner and more often. Higher quality treatments thus may allow patients to return to their "normal" state earlier than with current treatments. To measure the benefits of such innovation requires us to measure the value of a person's time, or the opportunity cost of time. Opportunity cost is discussed further in a later section.

To identify opportunity costs in health care, we must define what the next best alternative to health care is for a particular patient. Let us assume that without the health care treatment the patient would have continued on with the course of their life. The standard method of evaluating this cost is in lost wages. Wages represent the result of bidding for a person's services and therefore can be expected to be close to this person's economic value. Therefore, if health care treatment would take a person making $\$ 80$ per work day away from work for four days, the opportunity cost of that treatment would be $\$ 80 /$ day * 4 days $=\$ 320$.

The issue is made more complicated by the fact that patients also value their genetal recreational time. This problem is especially crucial for this project. In our data set of patients who had PTCA or CABG, the age of the median patient is 64 years. We can therefore expect that a large percentage of these patients are retired and therefore have no market wage. Stating that these patients have no opportunity cost is a mistake. Their opportunity cost is the value they place on their own leisure time. To address this 
problem, we later present a "revealed value" methodology for measuring the value of such time. The approach measures the value of a person's time by the implications of their actions (the value they place on their own time) rather than any arbitrary measurement.

\section{Application of Cost-Benefit Anglysis in This Study}

A significant result of our research is a model which predicts the effect of switching technologies on the casts of providing care for two important diseases: coronary artery disease (CAD) and benign prostatic hypertrophy (BPH). Both diseases have recently undergone a revolution in treatment methods. For CAD, this revolution was the implementation of balloon angioplasty (PTCA) atong with the introduction of arterial stents. For BPH, the revolution was the introduction of trans-urethral surgical techniques such as TURP, TULP, and TUNA. In both cases, the new technology involves a significant investment in medical devices and equipment.

Because of increases in the quality of treatment as well as in the number of people who demand the treatment, we are experiencing a substantial increase in the number of dollars that pass through the health care sector to pay for treatment of CAD and BPH. Before concluding that net costs to society from these conditions have increased, we must include the new benefits the technology offers as well as the costs. Again, social welfare is the difference between the benefit obtained from a productive activity and the opportunity costs of engaging in the activity. If the value of the activity is greater than the resource costs of the activity, then welfare has increased.

Health care consumers purchase services when the marginal value to them is below the true marginal cost. The prevalence of third party payers is widely viewed as a major distorting factor [Newhouse, 1992]. Such purchases represent a reduction in social welfare, and so must be counted as a true cost to society. Consequently, heaith economists are always suspicious that increases in raw expenditures truly represent costs.

Whi] suspicion may be the natura] tendency, Goddeetis [Goddeeris 1984a, 1984b] has demonstrated that increases in technology expenditures are not necessarily welfarereducing, even when there is widespread distortion from health insurance. Goddeeris builds a theoretical framework which allows him to evaluate the inpact of insuranceinduced technological innovation on welfare. As he notes, even with models tajlor-made to identify biases, it is not necessarily the case that welfare is reduced from innovation. The bealth care sector is characterized by various distortions, often conflicting. Therefore, whether a particular innovation has lead to a welfare reducing or increasing position for society is an empirical question. As Newhouse [Newhouse 1992] notes, rea] evidence on this issue is relatively scarce - despite its importance. Providing such evidence is a central mission of this study. 


\section{Opportunity Costs}

Providing health care is an expensive proposition for society. The most obvious costs of health care are explicit: the costs of supporting health care providers and facilities.

However, there are other less obvious costs which, because they are implicit in nature, can be more difficult to measure. Economists generally label such costs as "opportunity costs." In the provision of health care, there are a number of these opportunity costs. In particular, one opportunity cost which is quite problematic to estimate is the value of the patient's time taken up by a treatment regimen.

Currently, there are three alternative approaches in the economic literature to estimating the value of a person's time

1. the human capital (wage rate) approach,

2. the market value approach, and

3. the willingness to pay approach.

Because the last method is frequently prohibitively costly to administer, the first two are often utilized. Unfortunately, we theoretically expect that the first two methods will overestimate the value of the time of individuals in the work force because of rents (i.e. wages paid in excess of the minimum amount necessary to encourage the person to work) inherent in any labor market. Further, these approaches explicitly set the value of time of retirees at zero. This in turn may bias technological innovation away from treatments that could aid the elderly.

\section{Definition}

To understand how to measure such costs requires an understanding of the meaning of the phrase "opportunity costs." Opportunity costs are defined as the value of the relevant economic resource in its "next best" economic usage. Consider, for example, a star basketball player in the National Basketball Association. His nex1 best economic opportunity may be as a teller in a bank receiving a salary of $\$ 30,000$ per year. We would therefore say that his opportunity cost of playing basketball for one year is $\$ 30,000$. Often, opportunity cost is the largest part of the cost of using an economic asset.

Opportunity costs in health care work in a similar fashion. There are several specific opportunity costs involved here, though value of leisure time is the current concen. Note that opportunity costs we identify are likely to be among the benefits of using a new technology. We will want to identify those costs which would be incurred if the older technology is used but not incurred if the newer technology is used. These opportunity costs of old technology are costs saved when the newer technology is employed and consequently are a real social benefit from using the innovation. 


\section{Methodologies for Evaluating the Opportunity Cost of Time}

As mentioned above, three competing approaches exists when assigning a value to a day lost to medical treatment:

1. the human capital approach,

2. the "market value" approach, and

3. the willingness to pay approach.

Each has significant problems, which we discuss briefly below.

The most widely used approach is the human capital model fRice 1966 and Harrington 1991]. Fundamentally, the jdea is that competitive labor markets will estabtish a wage rate which exactly equals the reservation wage (i.e. opportunity cost) of the marginal worker. Since this competitive wage exactly compensates the marginal worker for the value he places on giving up one hour of leisure in order to work, it represents a good proxy for the opportunity cost of time. Implicitly, this model assumes that if the patient is not in the hospital, he would be working and the income that could be generated with this time reflects the value of the time.

There are a number of serious problems with this approach. For example, it is empirically observed that women tend to earn less in the marketplace than men. Similar problems occur for any other comparisons where market wages differ systematically (e.g. a day saved for a low income oerson would be worth less than a day saved for a high income person). Many implied differences such as these would be objectionable to policy makers and their constituents.

Another problem is that people engage in a number of activities which are not compensated in the market, but from which they derive value. For example, cooking dinner or mowing the yard are activities which generate value for society (and which heve potential markets) but are non-compensated when households undertake the activities directly rather than hiring them out in the market. The human capital/lost wages methodology does not capture these at all.

In response to this failure to incorporate non-market productive activities into measures of opportunity costs of time, the "market value" approach was utilized by Cooper and Rice [Cooper 1976]. This method involves estimating of the value of a basket of nonmarket productive activities. Specifically, Cooper and Rice cite a number of studies which involve time and motion analyses of the dajly activities of a group of housewives. A value is assigned to their time based upon what it would cost to hire a person from the labor force to replicate the services observed. In other words, market "equivalents" are assigned to a number of household activities and these equivalents are added to the lost wages measures generated by the human capital approach.

However, this method is also flawed. For one thing, it only measures certain activities and ignores other potentially important functions completely. Surveyors only account for the activities that they actualy observe the housewives undertaking. Other productive 
activities (for example, mowing the fawn) which the housewives in the studies might not be observed undertaking are excluded. This generates an unpleasant degree of

arbitrariness. Second, this method is incapable of reflecting the value of another class of activities for which there is no direct market compensation: pure leisure. This pleasure is perhaps highly valued, but neither of the previously mentioned methods can account for this value. However, for many populations this may be the dominant value of time. Retirees do not by definition work for wages. The value of their time is completely determined by the value they place on their productive and pure leisure activities, with the latter category perhaps constituting the large bulk of their "value of time." This problem with the retiree population is particularly significant for any study of PTCA vs. CABG where the average patient is retired or nearly so.

The final approach, first pursued rigorously by Schelling [Schelling 1965] is the "willingness to pay" methodology. It requires surveys to ask people how much they value certain gambles across possible states of the world. Unfortunately, many factors can bias the answers one gets from this approach. In particular, the values one imputes depend critically on the degree of risk aversion in the population, the homogeneity of preferences, and other issues which are difficult to address.

\section{The "Revealed Value" Approach}

The altemative that we propose is to extract information that workers reveal in their retirement decisions to estimate the revealed value of leisure time. Workers approaching retirenent today currently have the option of retiring at age 62 and receiving reduced social security benefits. The retirement income they receive from their pension plans would also be lower, since less money is saved in the shortened working time.

Altenatively, workers could continue to work until age 65 and receive full social security benefits, higher pension payments and the income that they eam from labor market activities.

This provides an excellent natural experiment. The cost to workers of continuing to work past age 62 is the leisure they do not get to consume. The benefit they receive from continuing to work ts the present value of their increased wealth dite to a longer period of savings. From first principles, we know that people should continue to work to the point that the satisfaction they receive from the increased consumption they will be able to undertake in the future equals the satisfaction they give up in consuming less leisure currently. Therefore, we can take the increase in the present value of wealth to be the dollar value of the leisure that is given up when the person decides to continue to work.

A complete discussion of this approach is beyond the scope of this document, but the results from this project analysis are displayed in Table 3. Table 3 spectifes the calculated total financial benefit from not retiring at age 62 to be $\$ 112,776.03$ in present value terms. To gain these additional funds, the average worker will work an additional 4.9 years. These years are discounted at a rate of $2 \%$ per year. This implies that the worker will work (in present value terms) 4.72 years to eam (in present value terms) 
approximately $\$ 113,000$. This in turn implies that one work year is worth $\$ 23.893 .23$. Assuming 250 work days in a year implies that each work day is worth $\$ 95.57$. If a work day consists of nine hours (eight actually working and another hourt in travel and preparation), one hour of time is worth $95.57 / 9$ or $\$ 10.62$. If a person sleeps eight hours a day, being released from the hospital a day early frees up 16 hours of leisure for retirees, worth $10.62 * 16=\$ 169.90$. Thus, reducing a patient's time spent in the hospital by one day creates $\$ 170$ worth of leisure time.

Table 3. The value of a day of leisure.

\begin{tabular}{|l|l|}
\hline Total Return From Not Retiring at Age 62 & $\$ 112,776.03$ \\
\hline $\begin{array}{l}\text { Total Work Years (Present value) from Age } \\
62 \text { to Age 62.9 }\end{array}$ & 4.72 \\
\hline Return Per Work Year & $\$ 23.893 .23$ \\
\hline $\begin{array}{l}\text { Return Per Work Day (Assuming 250 work } \\
\text { days/year) }\end{array}$ & $\$ 95.57$ \\
\hline $\begin{array}{l}\text { Retum Per Work Hour (Assuming 9 hours } \\
\text { wotk day) }\end{array}$ & $\$ 10.62$ \\
\hline $\begin{array}{l}\text { Value of One Leisure Day (Assuming I6 } \\
\text { bours of leisure in a day) }\end{array}$ & $\$ 169.90$ \\
\hline
\end{tabular}

\section{Stochastic Frontier Methodology Applied to CAD (PTCA vs CABG)}

Assessing of the impact of new technologies on health care costs is critical in today's economy. The health care sector is characterized by an extraordinary degree of innovation, perhaps more so than any other sector in the econony. Unlike many other areas, however, innovation in this sector is generally perceived as substituting newer technologies which require increased, rather than decreased, resource use: technological innovation appears fo be cost increasing. Clearly, we wish to understand whether this common perception is accurate. To do so, we must first understand the basic relationship between the medical care decisions required of existing and innovative technologies and how these medical "production functions" affect the cost relationships we observe.

This section addresses these issues by using stochastic frontier analysis to compare the costs of treatment for two competing interventions for coronary artery disease: coronary artery bypass grafting (CABG) and percutaneous transluminal coronary angioplasty. (PTCA, or balloon angioplasty). Exploiting a unjque data set, we examine costs at the patient level, allowing estimation of the cost savings that would be available if technological innovations in the less expensive PTCA procedure made that treatment regimen approprjate for all patients currently undergoing CABG. Previous studies of this type employed only data at the hospital level. 


\section{Further Information in the Appendices}

A detailed stumnary of the econometric approach to comparison of PTCA versus CABG is given in Appendix B. Appendix C contains a more complete treatment of stochastic frontiet methoxlotogy and is the primary source from which the content of this section was derived. Appendix D contains an analysis of PTCA vs. CABG across several hospitals, while Appendix $E$ contains a summary of a two-part model of the costs of treating BPH and the impact that new innovations could have on those costs.

\section{Estimating Costs in the Hospital Via a Physicians' Workshop Model}

Previous approaches to empirical examination of hospital production (either directly or through a cost function) have assurned one "global" production function for the institution, leading to models which are estimated with a high level of aggregation. In this work. we appeal to a different theoretical model of the hospital. On a conceptual level, health economists have considered hospitals to be "physicjans' workshops" since Pauly's [Pauly 1980] influential monograph. This model asserts that hospitals exist to provide necessary capital equipment to physicians, each of whom creates their own tean within the institution to treat patients. Each hospital is therefore not appropriately considered a "firm" in the traditional neo-classical sense. Rather, each hospital is a collection of "virtual firms," each defined by a unique provider team and production function. One can extend this analogy furtht: by recognizing that in most circumstances the actual team utilized will be unique for each patient. That is, when a patient is admitted to the hospital he travels through a treatment process which is tajlored to his particular medical needs and circumstances. A hospital is therefore a framework which supports a number of different production functions, and that the production function is best defined by using the patient as the unit of analysis.

Further, it seems reasonable to pool teams within an institution which are most closely related. For example, a team which is producing treatment for an acute myocardialinfarction (AMl) will face constraints more similar to those faced by another team treating an AMI patient than a team treating a patient for gall stones. Consequenty, a strategy to minimize the possibility of inappropriately pooling "prodtuction functions" is to define the production function for a specifsc treatment within a single institution. Only then is one likely to be able to estimate a production function which has meaning within the framework of hospital "workshops." This approach requires detailed data on single patients from jndividual hospitals. We suggest that only after researchers have explored medical production functions at their natural level (the patient) can work begin on expanding the analysis to include cross-institution similarities.

\section{Stochastic Frontier Model Formulation}

When observing estimated cost differences between two groups it can be difficult to tell whether one is more efficient than the other or whether one simply had "bad luck." For many issues, such as the impact that a new technology will have on costs, we want to 
explicitly control for inefficiency: we wish to estimate the cost mininization function for the two treatment groups and compare predicted costs using that rejationship. Otherwise, we run the risk of making policy recommendations based not on which technology leads to the towest cost, but rather which group happened to be behaving most efficiently when we observed them.

One techwique which can accommodate differences in efficiency is stochastic frontier estimation. This maximum likelihood technique has been carefully explored in the broader econometrics literature [Aigner 1977, Schmidt 1979, Kopp 1982, Kumbhakar 1987, Bauer 1990]. In general, the cost frontier relationship is of the form

$$
C=C(P, q)+\varepsilon,
$$

where $\mathrm{E}$ is assumed to consist of two components, $u$ and $v$, such that $\varepsilon=u+v$, where $u$ is a one- sided positive error and $v$ is a nomally distributed (two-sided) enror. The $u$ term corresponds to the measures of inefficiency for the specific cost frontiet, while $v$ represents the usual error term in econometric regression.

This basic formulation was enhanced to meet the needs of this study. First, in order to include patient behavioral factors in the analysis, a vector of regressors, $D$, was included to represent patient characteristics that contribute to uncertainty in the mathematical relationship. Additionally, total costs for observation $j$ are represented as the sum of costs from important sub-cost categories:

$$
C \equiv C_{1}+C_{2}+.,+C_{S},
$$

where subscripts $1 . N$ represent cost categories l through $N$. These cost categories represent "input prices" in this model. However, after augmenting this function with the behavioral variable vector $\mathbf{D}$ and estimating the model, $\mathbf{D}$ would clearly have no explanatory power given the identity shown for $C$ above. However, when $C_{l}$ are expressed as $N-I$ ratios of a normalizing cost (i.e. as $C_{i} / C_{N}$ ) then the identity above no longer holds and useful inferences can be drawn from the augmented equation.

In addition to the effect of the behavioral factors on cost, the parameters attached to $C_{i} /$ $C_{N}$ reveal the degree of substitution or complimentality that the two input categories have in cost. That is, if the parameter on $C_{j} / C_{N}$ is negative, this suggests that as $C_{i}$ becomes harger relative to $C_{N}$ then total costs fall. This would suggest that one could lower the total cost of providing the single treatment by relying more heavily on the $i^{\text {th }}$ input and less heavily on the $\mathrm{N}^{\text {th }}$. That is, the parameters on the input ratio variables will provide important information on the most cost-effective input mix and therefore most efficient production technique. Recall that each observation represents one unit of "output" so altering the input mix as suggested by the parameter signs would allow one to lower cost without changing output at all.'

${ }^{1}$ For example, assume the coefficient on the category representing the ratio of room cost to costs in the $\mathrm{N}^{\mathrm{s}}$ category is negative and significant. That would imply that if the hospital were to change its treatment regimes to aliow patients to stay in the hospital longer, the resulting changes in other treatments would, on average, reduce patient costs. 
We established a mechanisn to relate the charges for say, pharmacy, to the "price" of the pharmaceutical input. We decided to aggregate expenditures on pharmaceuticals and let the spending on that group of pharmaceuticals be the "price" for that "input." While there are some drawbacks to this approach, it is consistent with the relevant literature.

The final model formulation for the stochastic frontier analysis is of the form

$$
C_{j}^{k}=a+y_{t}^{k} P_{i, j}+\ldots+\gamma_{-}^{k} P_{y j}+\Gamma^{k} \mathrm{D}_{\mathrm{j}}+u_{j}^{k}+v_{j}^{k} .
$$

Here, the quantity is 1 for all observations, the $P_{i, j}$ represent relative input prices for the $j^{\text {th }}$ input and the $j^{\text {th }}$ patient (relative to the pharmacy costs), and $k=$ PTCA or CABG. This model reptesents the augmented charge or cost function for both PTCA and CABG, but each intervention requires its own set of model regression parameters. The likelihood function which estimates the parameters of the above model is

$$
\ln L=\frac{J}{2} \ln \left(\frac{2}{\pi}\right)-J \ln \sigma+\sum_{j=1}^{j} \ln \left[1-\Phi\left(\frac{-\varepsilon_{j} \lambda}{\sigma}\right)\right]-\frac{1}{2 \sigma^{2}} \sum_{j=1}^{t} \varepsilon^{2},
$$

where $J$ is the number of observations, $\varepsilon_{\mathrm{j}}$ is the estimated sum of $u$ and $v, \Phi($.$) is the CDF$ of a standard normal distribution, $\sigma=\sigma_{u}+\sigma_{v}$ and $\lambda=\sigma_{v} / \sigma_{v}$. The likelihood function is maximized across $\sigma_{u}^{2}, \sigma_{v}^{2}, \Gamma$, and $\gamma$ (where $\Gamma$ and $\gamma$ are the parameters for the equations represented in the model given above. Two important pieces of information can be obtained from this formulation:

- consistent estimates of the effect of patient covariates on the demand for the individual input shares, and

- technical inefficiency for each observation, found as

$$
u_{j}^{*}=\frac{\sigma_{x}^{*} \sigma_{r}^{*}}{\sigma^{*}}\left[\frac{\phi\left(\frac{\varepsilon_{j}^{*} \lambda}{\sigma^{*}}\right)}{1-\Phi\left(\frac{\varepsilon_{j}^{*} \lambda}{\sigma^{*}}\right)}-\frac{\varepsilon_{j}^{*} \lambda}{\sigma^{*}}\right]
$$

where starred terms mean estimated values and $\phi($.$) is the PDF of the standard normal$ distribution [Jondrow 1982]. These relationships suggest how well a particular patient is treated relative to all other patients in the specific institution, not relative to the industry (theoretical) cost.

\section{Patient Population}

The data for this study are taken from the internal records of a large hospital located in a major southem city. These data include $\$ 32$ observations representing all patients who were treated for some type of cardiac revascularization during 1994 (where a small number of observations were excluded due to missing data). The patients received ejther CABG or PTCA. The data are drawn from detailed charge information and medical chart abstracts. We estimate two classes of frontier: a charge frontier and a cost fromtier. The departmental charges are converted to costs using the cost-charge ratio for each department, as reported by the hospital to the Health Care Financing Administration in the hospital's cost reports. We therefore had access not only to the usual sorts of 
information obtained from discharge abstracts but also very detailed information about specific resource usage by each patient.

\section{Input Prices, Bebavioral Factors, and Health Factors}

Nine input categories exist for which charge or cost tepresent price. These include

1. pharmaceutical charges (the numeraire, or $\mathrm{N}^{\text {th }}$ input to which every other input price is relative),

2. room charge/cost (ROOM),

3. emergency room chirge/cost (ER),

4. lab charge/cost (LAB),

5. rehab charge/Cost (REHAB),

6. operating room charge/cost (OR),

7. catheterization lab charge/cost (CATH),

8. CV charge/cost (CV), and

9. miscellaneous charges/costs (MISC).

Again, each of these is divided by pharmaceutical charges (costs) before being entered into the regression equations above.

Behavioral variables used in the anatysis include the following:

1. COM, an index which (a) represents the degree to which comorbidities exist and (b) controls for variations in patient underlying health status prior to treatment,

2. ACUMI, whether the patjent was admitted with an acute myocardial infarction,

3. PRCABG, whether the patient has previously had bypass surgery,

4. PRPTCA, whether the patient has previously had angioplasty,

5. EF60, the patient's ejection fraction,

6. LEFT, if the blockage is on the left side of the heart, and

7. VES2 and VES3, whether there was blockage in two vessels, or three or more vessels, respectively.

Patient characteristics relevant to treatment of illness inciude

1. GENDER, a dummy variable indicating whether the patient is male, since men and women can respond differently to illness and medical treatment,

2. AGE, since responses and costs can vary significantly by patient age, and

3. SMOKER, whether the patient smokes cigarettes.

One additional important determinant of patient charges is the number of adverse events experienced by that patient. However, it is likely that the number of adverse events is a function of several of the other explanatory variables used in the charge equation. To control these dependent adverse events, we use Poission regression to predict the number of adverse events a patient should have based on his or her characteristics. The difference between actual and predicted values is then used as an explanatory variable in the charge and cost regressions. 


\section{Results}

\section{Charge Results}

Several patient characteristics significantly affect the total charges for providing a PTCA. These include:

- the presence of comorbidities,

- gender,

- having had a prior CABG or PTCA procedure,

- having left main arterial disease, and

- the likelihood of unanticipated adverse events.

With the exception of prior PTCA, each increases the charge (see Table 33 in Appendix C). Having had a prior PTCA appears to significantly reduce the charge associaled with the sampled PTCA procedure.

Recall that a significantly positive/negative value for one of the charge ratios indicates that using relatively more of that input will raise/lower the total charge of supplying the procedure. For PTCA procedures, three input ratios have significant positive effects:

- laboratory resourees (LAB),

- operating room (OR), and

- CV inputs.

These increase total charges without any "payoff." In contrast, patients who incur relatively higher room charges (relative to pharmaceutical charges) have significantly lower total charges.

Patient characteristics also significantly affect the total charges for providing CABG services. These include

- the presence of a higher comorbidity score,

- having had a prior $\mathrm{CABG}_{\text {, }}$ and

- increased unanticipated adverse events.

Each significantly increases the total charge of the CABG procedure. Unlike PTCA charges, a recent acute myocardial infaretion (AMI) and the number of vessels revascularized also significantly and positively affects total charge. A recent AMI raises total charges, as does having two vessels revascularized. Oddly, having three or more vessels blocked seems to decrease total charges. Since the "standard" approach for only one or two blockages would be to use PTCA rather than CABG, it may be that those in the one or two vesse] CABG group are relatively nore ill than those who have blockage in three or more vessets and hence require more intensive resource use in some areas.

For $\mathrm{CABG}$ patients, four charge ratios are significant in the frontier estimation:

- CV diagnostics,

- catheterization lab time,

- miscellaneous charges, and

- operating room time. 
Each of these raises relative charges in a non-productive manner except for the latter which, unlike PTCA, reduces total charges. That is, when the institution is using a larger proportion of its resources to actually provide the $C A B G$ procedure to a patient (which is done in the operating room), the charge to treat that patient falls.

Finally, recall that "jnefficiency" means how much more charge is generated for a given patient's treatment than the lowest charge possible in the hospital given the patient's characteristics. For PTCA patients, the average estimated inefficiency is $\$ 10,248$, which is $41 \%$ of the mean charge for the procedure. This suggests that the hospital is charging over $\$ 10,000$ more per patient than necessary given the lowest charge available in that institution. For CABG patients the average excess charges are approximately the same, at about $\$ 9,990$, though as a percentage of average charge the CABG inefficiency is smaller, at $22 \%$. Both of these numbers are relatively large and suggest that there may be room for significant charge (and so potentially cost) savings in the hospital by examining which patients are treated in the more cost effective manner and emulating this procedure with other patients.

Cost Results

The qualitative results in the PTCA cost regression with respect to the non-price effects are very similar to those in the charge regression. Costs are significantly affected by

- increased numbers of comorbidities,

- patient gender,

- having had a prior CABG or PTCA,

- suffering from left main artery disease, and

- having adverse events.

Unlike the charge estimates, an acute MI just prior to the procedure does significantly affect the costs of providing the PTCA.

In terms of hospital resources, the relative use the following resources significantly affects the total cost of providing a PTCA: (1) rehbbilitation and (2) CV diagnostics. The parameter estimates of these input ratios are positive, indicating that increasing the use of these inputs relative to pharmaceutical inputs will increase the total cost of the PTCA.

For $\mathrm{CABG}$, the following raise the cost of providing bypass surgery:

- comorbidities,

- a recent MI,

- a prior CABG, and

- unanticipated atverse events.

In addition, having multiple vessels involved is a significant predictor, as evidenced by the positive and significant effect of having two vessels stenosed and the negative and significant effect of having 3 or more vessels stenosed. While the sign patterns may seem somewhat cotmter-intuitive, they are actually what one would expect in the current state 
of the world. Currently, many patients who need two vessels repaired will have them done using PTCA technology. A person who is actualiy treated with a CABG instead is generally more sick than the average person needing two vessels reworked. However, a person who needs treatment in three vessels is not at all likely to receive PTCA.

Again, the parameter estimate on the relative use of OR resources is negative and significant. This suggests that a shift toward relatively more OR time per CABG (compared to pharmaceutical resources) may actually reduce the total cost of providing the service.

Finally, the absolute level of cost inefficiency for PTCA production is about $\$ 5,200$. This represents $41 \%$ of the total average cost of supplying PTCA to patients in the institution. The absolute level of cost inefficiency for CABG patients is $\$ 7,300$, or $29 \%$ of the total cost of the operation. These inefficiency estimates (at least in percentage terms) are reasonably similar to the estimates of charge inefficiency. While comparable levels of inefficiency have been found from research in other industries, this does indicate substantial room for inprovement in the average cost of treatment for the two procedures.

\section{Simulation of Changing Technology or Practice}

One issue that concerns the medical community and policy-makers alike is what effect shifting treatment standards will have on charges or costs: That is, as PTCA becomes a more mature technology, and new innovations such as stents are perfected, one coutd imagine shifting a number of patients from the CABG treatment path to the PTCA treatment path. On the surface this would appear to be a cost-saving move, since the average charge and cost of PTCA is much less than the average charge or cost of CABG. As discussed above, however, one would not want to take such a naive approach, since the patient populations have different characteristics, the two procedures may be currently provided with different levels of inefficiency, and the average PTCA patient has blockage in fewer vessels than the average CABG patient.

Part of the motivation for the analysis above is to provide an improved methodology for estimating the cost savings from switching patients from CABG to PTCA given that appropriate PTCA technology becomes available. Using the stochastic frontier results, we can control for the observable patient characteristics and the number of vessels treated. Further, since the maximum likelihood regression results produce the "minimum cost" frontier, we can predict cost savings without the presence of confounding inefficiencies (which may or may not persist through time).

To do this we divide the CABG patients into three groups:

- those requiring treatment in one vessel,

- those requiring treatment in two vessels, and

- those requiring treatment in three or more vessels. 
We then predict the charge and cost for giving each patient the CABG treatment regime. The predicted charge and cost for each group appears in the first column of Table 4. Once we have the estimated charges/costs for $\mathrm{CABG}$ patients under cost minimization, we then simulate what charges or costs would be required to give them PTCA. Each patient is analyzed using the PTCA frontier regression with their own personal characteristics and the charge or cost ratio values for the median PTCA patient in their group. We do this since the resource use observed for the CABG patients is clearly not the resource use we would observe if they received PTCA. The results of the predicted charge or cost of treating current CABG patients with PTCA technology appears in the third column of Table 4 .

The final column in Table 4 presents the estimated savings from treating various types of CABG patients with PTCA. The savings appear to be significant. Switching one-vessel CABG patients to PTCA would save an estimated $\$ 11,966$ in charges and $\$ 3,959$ in costs: switching two-vessel and three-or-more-vessel CABG patients to PTCA appears to result in $\$ 2 \$, 394$ and $\$ 17,156$ in charge savings and $\$ 16,387$ and $\$ 8,160$ in cost savings, respectiveiy.

Table 4. Predicted Savings from Switching CABG Patients to PTCA.

\begin{tabular}{|c|c|c|c|}
\hline $\begin{array}{c}\text { Number of Vessels } \\
\text { with Blockage }\end{array}$ & $\begin{array}{c}\text { Predicted Dollars } \\
\text { for CABG } \\
\text { T-atment for } \\
\text { Current CABG } \\
\text { Patient }\end{array}$ & $\begin{array}{c}\text { Predicted Dollars } \\
\text { for PTCA } \\
\text { Treatmeat for } \\
\text { Current CABG } \\
\text { Patient }\end{array}$ & $\begin{array}{l}\text { Imputed Savings } \\
\text { from Switching } \\
\text { Treatment from } \\
\text { CABG to PTCA }\end{array}$ \\
\hline \multicolumn{4}{|c|}{ CHARGES } \\
\hline IVESSEL & $28,715.07$ & $16,749.19$ & $11,965.89$ \\
\hline 2 VESSELS & $45,151.43$ & $19,757,92$ & $25,393.50$ \\
\hline 3 OR MORE VESSELS & $39,753.08$ & $22,596.72$ & $17,156.36$ \\
\hline \multicolumn{4}{|c|}{$\cos T s$} \\
\hline / VESSEL & 10.489 .68 & 6.530 .59 & $3,959,09$ \\
\hline $2 V$ ESSELS & $24,789.97$ & $8,402.71$ & $16,387.25$ \\
\hline 3 OR MORE VESSELS & $17,830.86$ & $9,670.52$ & $8,160.33$ \\
\hline
\end{tabular}

\section{Care-Pathway Interaction Models}

A more complete understanding of the drivers of health care costs can be obtained by means of a complete model of the pathways by which care is delivered to patients. The 
goal for development of these care pathway interaction models (CPIM's) is to identify areas where improvements in technology or the introduction of new technology could be applied to reduce costs and/or maintain or inprove outcomes. All resources relevant to each step in the care delivery process were addressed so that the impact of these inputs on cost and outcome could be established.

The modeling effort was approached in two ways. First, an "attention focusing model" was devejoped with the goal of permitting the user to easily and conveniently vary input parameters and qujckly assess results so that otherwise unappreciated relationships between variables and outputs could be identified. These attention focusing models were developed utilizing Demos, a product of Lumina Decision Systems, for Macintosh. The models eventually were imported into Lumina Decision Systems' commercial product Analytica and were then imported into the Analytica Windows 95 version for IBMcompatible personal computers. The second modeling effort involved the development of more detailed models utilizing the ARENA Windows 95 compatible system. The ARENA models are more difficult to manipulate and intertogate but are elemental in nature and so provide the user with the ability to follow specific patient cohorts over time.

\section{Diseases and Treatments Addressed by the Models}

For this study, the care pathway for two disease/disability (D/D) conditions was modeled, including diagnosis, treatment, and outcorne. These conditions were

- coronary artery disease (CAD) and

- benign prostatic hypertrophy (BPH).

Coronary Artery Disease (CAD)

Coronary artery disease (CAD) was chosen for several reasons. First and foremost it is currently the leading cause of death in America. Second, invasive treatment of heart disease is technologically intensive and has seen many innovations since it was first developed in the fate 1950's. It follows that heart disease is also very costly to treat, making it an excellent target for potential cost savings to healtheare providers and payers, as well as a target for monetary gain for investors in health care technologies. Simulation can be used to test the potential effects of new technologies on the cost of treatment as well as the potential benefits of treatment before actually having to bring such products to market.

\section{Treatment Alternatives}

As its name implies, $\mathrm{CAD}$ affects the arteries supplying the heart, restricting the flow of blood to the heart muscle. If untreated, heart disease may lead to chest pain, heart attack, and eventually mortality. The first treatment alternative is an array of medications. Medical treatment is the least invasive and the least expensive. However, many of those 
treated medically for $\mathrm{CAD}$ will eventually need more invasive treatment due to worsening symptoms or an emergency cardiac event. The benchmark invasive procedure for cardiac revascularization is coronary artery bypass grafting (CABG). During a CABG procedure the patient's stemum is broken and his or her chest is opened to expose the heart. The heart is themodynanically slowed and blood cireulation is achieved with a bypass machine, while the blocked arteries are bypassed using either sections of vein taken from the patient's leg or an artery taken from the patient's chest. CABG is a highly specialized, very invasive surgical procedure and is therefore very costly. However, to date it remains the "gold standard" treatment for coronary artery disease.

A less invasive alternative to $\mathrm{CABG}$ is percutaneus transluminal coronary angioplasty (PTCA), developed in the late 1970's. PTCA is a non-surgical procedure performed by a cardiologist in which a catheter is inserted through the femoral artery in the groin region and guided into the blocked artery, where a balloon is inflated to expand the blockage. PTCA has seen increased acceptance in the treatment of less severe cases of CAD as well as in stabilization of patients whose condition is too acute to risk bypass surgery. PTCA is performed during cardiac catheterization, which is also performed preliminary to bypass surgery. PTCA is less invasive than CABG and less costly, at least in the short term. The number of PTCA procedures being performed has surpassed the number of CABG procedures being performed.

There are significant technological advancements being made in medications as well as in both invasive procedures being used to treat CAD. Major improvements have been made in the guided catheters used in PTCA, increasing the operative success of the procedure. Also, in 1995 the FDA approved the use of coronary stents. Stents are wire mesh tubes that are expanded inside the artery when the balloon is inflated during an angioplasty. The stent adds support to the diseased artery, preventing immediate collapse and discouraging restenosis. According to publications on short term outcomes, stents do appear to reduce restenosis and heart attack rates [Fjebman 1994]. A minimally invasive CABG procedure has also been developed in which the arteries are bypassed using a laparoscope. By eliminating the necessity of breaking the sternum to expose the thoracic cavity, both the recovery time for CABG and the risk of post-operative infection has been greatly reduced.

\section{Definition of the Treatment Process}

The first step in modeling the treatment of coronary artery disease is to define the entire process, complete with every treatment alternative and all feasible outcome paths. The North American population forms the basis of our treament population. Most patients enter the treatment system either because they have experienced symptoms of heart disease or because they have had a major cardiac event. A small proportion of these patients will be completely asymptomatic. First, patients will have a carnpaign of less invasive screening tests. If screening is positive, a cardiac catheterization is perfonned by a cardjologist, who makes a diagnosis and an assessment of the severity and location of 
the disease. At this stage, the cardiologist makes the decision to perform a PTCA or to refer the patient to a surgeon for a CABG. This process is outlined in the flow diagram in Figure 2.

Treatment outcomes are divided into three time frames:

- short term, which covers the initial procedure and the first year post treatment,

- intermediate term, which is between one year and five years post treatment, and

- long term, which covers from five years post treatment until 25 years post treatment. Success in each time frame is defined as freedom from symptoms and freedom from major complications. Major complications include myocardial infarction, repeat revascularization (repeat $\mathrm{CABG}$ or PTCA) and death. If repeat revascularization becomes necessary, the patient will return to the treament decision and the process begins again. In the CAD model, the patient will remain in the system for 25 years after initial treatment or until death. 


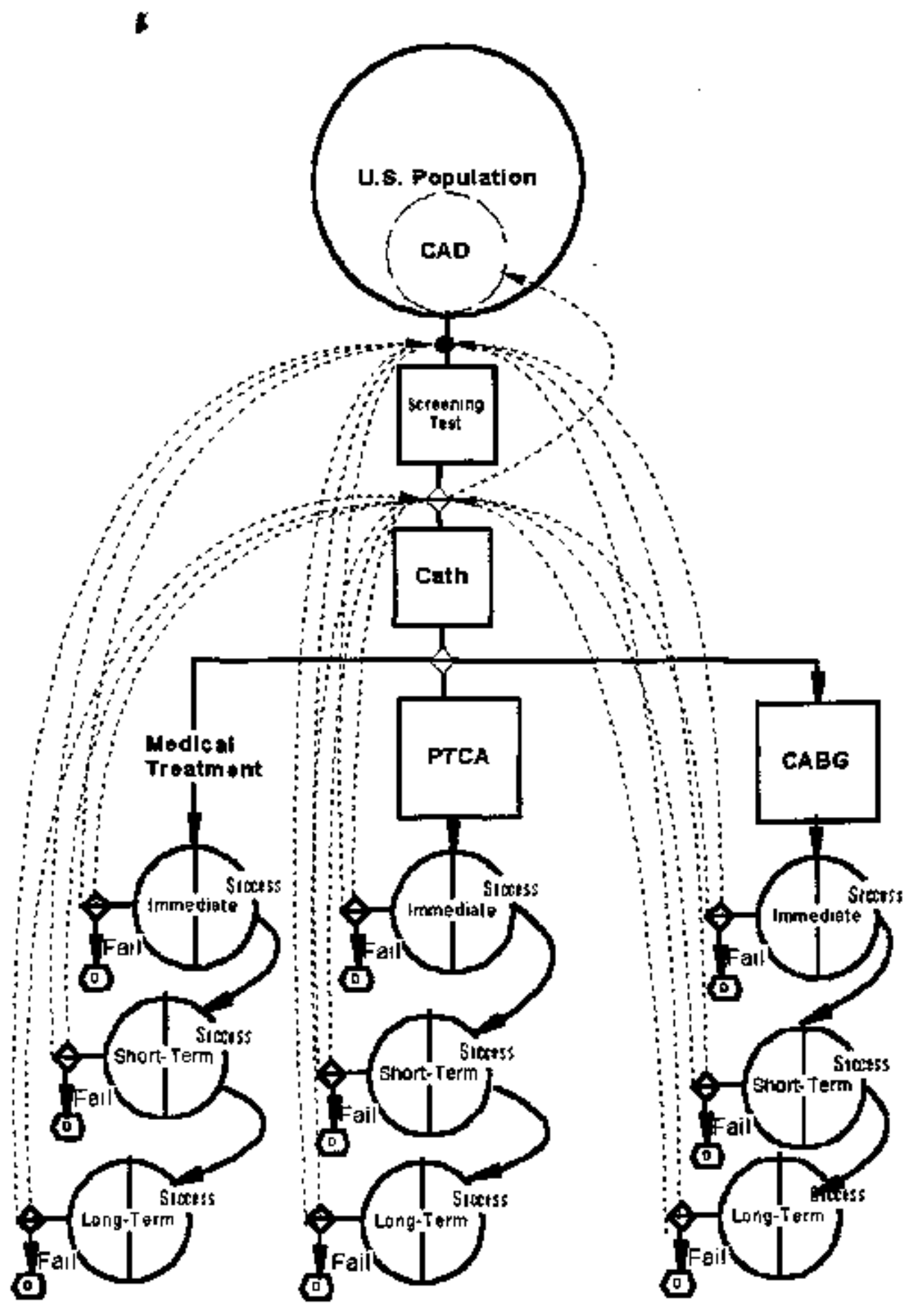

Figure 2. CAD treatment process flow diagram. 
Benign Prostatic Hypertrophy (BPH) was chosen for simulation for many of the same reasons as coronary artery disease. First, BPH affects a major proportion of the population. Studies of autopsy results have shown that BPH is present in almost all etderly men [AHCPR 1996]. Also, BPH is treated with a wide tange of very different technologies. The most significant difference between the two conditions chosen is that BPH is not life threatening. In fact, considering its widespread prevalence, it would probably not be inappropriate to consider BPH a natural part of the aging process for men. If untreated, BPH could potentially lead to bothersome urinary symptoms and perhaps even kidney disease.

\section{Types of Simulation Models}

There are many different types of computer simulation. Queuing models have been used for decades in manufacturing to model static production systens and static inventory systems. In this role, a model can be used as a tool to study the effects of hypothetical changes in dernand, process configurations and production capacity on throughput time, inventory levels and overall production output. Systems dynamics models have been used to study the interdependence between components of constantly changing systems, such as the relationship between predator and prey populations in tise field of wildlife management or the relationship between different social groups in the field of in urban planning. Markov models have been used to explain expected changes in mortality rates due to changes in risk factor prevalence in the population by simulating probabilistic changes of state over time. More recently, simulation models have been developed to emulate haman decision making behavior based on a fixed set of known rules. These models, known as expert systems, are used in mainly a diagnostic capacity. The most advanced simulation models make decisions based on feedback from model output while the model is running, much the same way that humans make decisions based on their own experience (artificial intelligence). The models that will effectively represent the relationships contained in the treatment of coronary artery disease (CAD) and benign prostatic hypertrophy (BPH) contain characteristics of each of these types of modets. However, the models could not effectively be created using any one of these methods alone, so it was necessary to incorporate several of these techniques into ots model.

\section{Modeling of CAD Treatment Using Analytica}

Again, the project tearn elected to approach the problem of modeling coronary artery disease through the creation of two distinct models. The first of these was to be an "atlention fixing" model which was telatively easy to use and which had the heuristic value of pointing out to the observer interrelationships between factors which might not be immediately apparent. The attention-fixing approach is discussed in this section. Once the analyst became comfortable with the general 
model for the treatment of coronary artery disease and had narrowed his areas of interest, it was envisioned he could tum to a more detailed model, capable of simulating the treatment of disease to a greater precision than that obtained through the use of the attention focusing model. The more detailed approach is discussed in the section summarizing the ARENA simulation models.

The Macintosh-compatible Analytica system was employed for the attention fixing model. This is a graphical decision/analysis system. The underlining statistical basis for this model and its methods of operation are to be found in the Analytica manual (Lumina Decision Systems Inc., Palo Alto California). The analyst has a variety of options regarding sampling techniques, sampling number, and choice of seed in the use of this model. The Analytica model is straightforward in its application and contains a variety of informational notes to aid the analyst in its use. It is important to note that the model consists of two parts: the Diagnosis Library and the CAD model. Both must be loaded for the model to function. The Analytica $\mathrm{CAD}$ and $\mathrm{BPH}$ models will run on the Windows 95 version of Analytica.

The attention focusing models employed in this project were developed on a beta release of the DEMOS graphical decision system developed by Lumina Decision Systems Incorporated. In August 1996, Lumina Decision lnc. released an improved commercial version of DEMOS-termed Analytica. Although the models utilized for this project were developed on DEMOS, they were imported into Analytica and run without problem on the Analytica system. Indeed, the Analytica system offers the analyst a more convenient means of refining the models. In July 1997, Lumina Decision Systems will introduce a version of Analytica for Windows 95 . The Windows 95 version of Analytica will read models generated on the Macintosh. Indeed, the project $\mathrm{CAD}$ and $\mathrm{BPH}$ models are both running without problem on an evaluation version of Analytica for Windows 95.

Note that the start-up screen for the coronary artery disease model is labeled "PTCA diagram." The initials refer to percutaneous treatment alternatives and should not be confused with PTCA or percutaneous transluminal coronary angioplasty.

The Analytica attention-focusing model must be run on a Power MacIntosh 6100/60 or higher supported by $16+$ megabytes of ram. For further specifications relating to Analytica models and more detailed information about the operation of Analytica itself, contact Lumina Decision Systems, Palo Alto, CA. 
Index To Important Input Variables In The Coronary Artery Disease Model

Interrelationship Diagran

Figure 3 below depicts the interrelationships between the variables used in the Analytica CAD model.

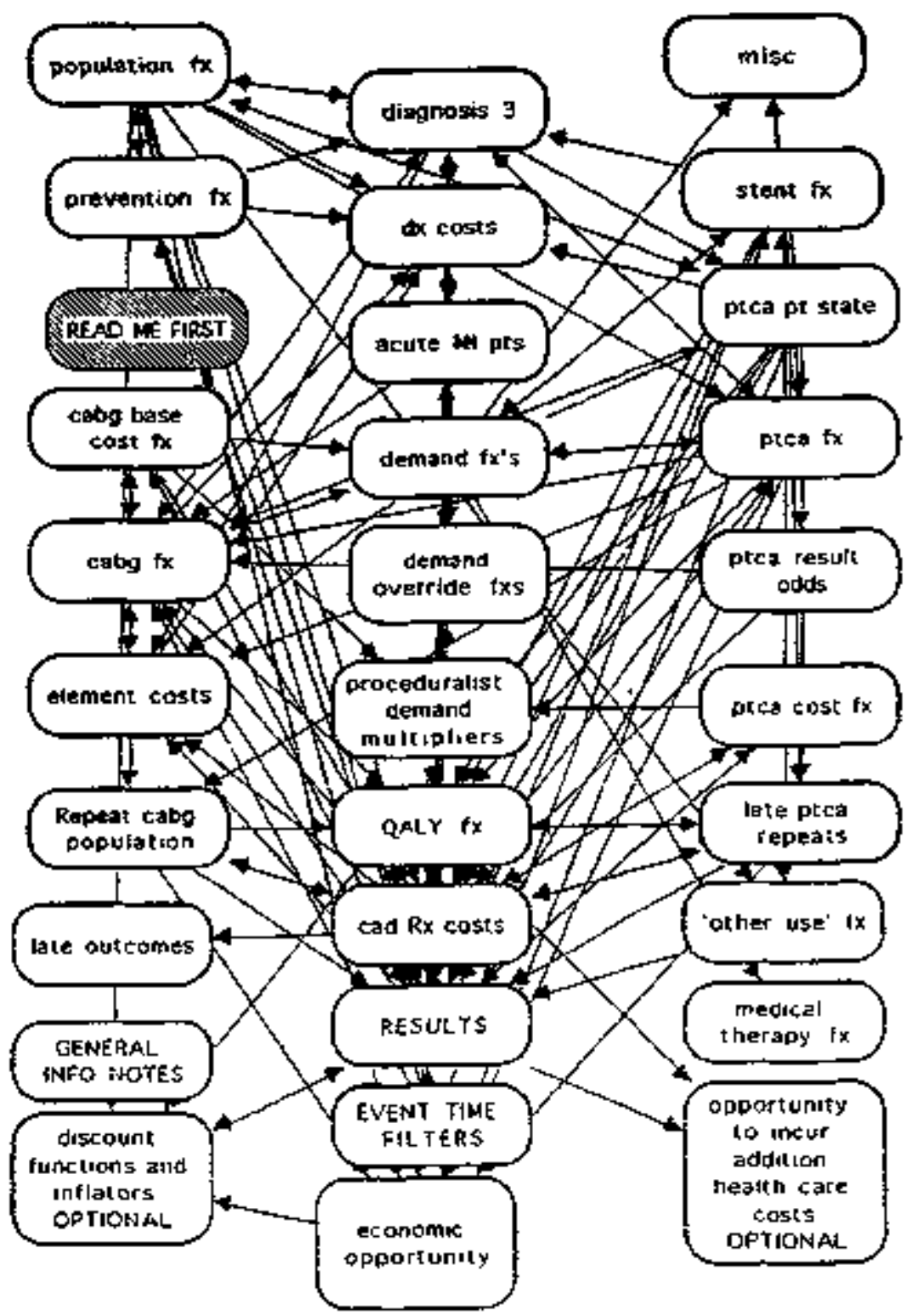

Figure 3. Depiction of the interrelationships used in the Analytica CAD model. 


\section{Stent-Related Variables}

All stent-related input variables can be found in the stent function module located on the first model screen.

- Stent efficacy: The stent effect input site is clearly marked in the stent function moduie. After clicking down to the stent effect function, it is necessary to move down to the procedure demand/time-filter in order to enter stent efficacy rates for each specific year. Stent efficacy should be input as a value ranging from 0 to 100 . Zero implies no stent effect on the restenosis rate, whereas 100 implies essentially the elimination of restenosis. Current stent technology is set at a value of 30 .

- Stent access: This function is input through "stent access: fraction lesions/vessels approachable by stent." Stent access assumes values from 1.2 to 2.0 , where 1.2 represents the current state of stent usage. As stents and angioplasty devices become smalfer in order to approach more distal lesions, and as physicians become more aggressive in treating angioplastable multi-vessel disease with stents, this function should rise accordingly. The range of the stent access function is from 1.2 to 2.0 .

- Unit stent cost: This value in the default mode is set at $\$ 3,000$, a value consistent with much of the literature. However, at least one major hospital has been found which purchases stents at $\$ 1,595$ per stent. Stent unit cost is likely to fall with time. It should also be recalled that stent unit cost is only one component of stent associated costs. Additional costs associated with hospitalization time and catheterization time are to be found in the "stent costs one vessel patients" function. Efforts to reduce the costs of stenting could focus either on unit stent cost or on associated hospital and catheterization laboratory cost. A similar situation pertains for multi-vessel patients and a "stent cost multi-vessel patient" input site can be found in the stent function module.

- Stent MI rate during PTCA: This variable determines the frequency with which myocardial infarction complicates angioplasty and stenting. It may fall with improved stent technology.

- Effect of stent on need for late revascularization: This function is also found in the stent function module and relates to any effect of stenting on the need for late revascularization. That is to say, stent efficacy deals with the revasctuarization rate in the first 24 months after procedure. Late recurrences occur. In the default mode a stent's ability to reduce late recurrences is assumed to be $1 / 2$ that of its ability to reduce recurrences in the first two years.

PTCA Costs

- PTCA 1V cost: This function estimates the cost of a single vessel PTCA. Based on the value of the repeat number, this function includes repeated PTCA's required in the 
first two years. The number of repeats in each patient who receives a repeat is assumed to be 1.34 , which compares with HCIA data. Going forward this factor becomes 1.07 tines the repeat number. The PTCA one vessel cost function also incorporates costs of those patients who require emergency $\mathrm{CABG}$ or $\mathrm{CABG}$ within the first two years following PTCA. It incorporates the cost of stents but does not include physician charges. This function drives the "PTCA multi-vessel cost"

. function and the "PTCA with lysis function," the latter applying to patients suffering from myocardial infarction.

- Repeat number: This is a derived function driven by stent efficacy and stent use. lt can be found in the PTCA function module and can be changed as necessary.

- Fraction of patients with multi-vessel disease: This function can be found in the PTCA function module. It is a function of the assumed baseline probabilities of multi-vessel disease in the population, the enrichment of multi-vessel disease in the PTCA population, and the effects of changing stent access and stent efficacy. The latter two functions are assurned to influence the number of patients with multi-vessel disease who present or are referred for PTCA.

\section{CABG Costs}

- CABG patient post-op condition: This function is found in the CABG function module. Once at this function, the user can migrate down to CABG-F-T which is the input site for this variable. The CABG patient post-op condition variable ranges from 0.3 to $\mathrm{l}$ (corresponding to a CAB-F-T input value of 1 to 10 ). This function is designed to estimate functional status and well being of patients during the first 6 weeks after a $C A B G$ procedure. The value of 0.3 reflects considerable morbidity. If laparoscopic CABG, for example, were to be undertaken and as a result reduce morbidity, then this value could rise. The $\mathrm{CABG}$ patient post-op condition variable is used to drive $C A B G$ demand and to influence the choice of PTCA versus CABG.

\section{Demand Override Functions}

The demand overide functions are found in the demand override functions module on the start up screen. The number of patients receiving catheterization in any given year and the number of patients presenting for a first PTCA (or first CABG) in any given year can be preset at this site. In order to preset a variable the first override function must be set at zero and the desired value of the function manually entered in the manual cath number, manual PTCA number, or manual CABG number function. The analyst may altematively fix the number of first-time $\mathrm{CABG}$ patients by altering the function $\mathrm{CABG}$ P2 directly, and he may alter the number of first time PTCA patients by changing the function TOTAL-PRIM. 
These functions assess the effect of physician reimbursement on choice of procedure and patient referral. These functions are to be found in the proceduralist demand multiplier module on the start up screen. Both the PTCA MD fee push function and the CABG MD fee push function are not likely to be operative during normal circumstances in that they do not become functional unless the reimbursement to cardiovascular surgeons for CABG falls bejow $\$ 1,000$ and reimbursement to cardiologists for PTCA falls below $\$ 750$. The analyst may change these threshold values.

\section{Repeat Patient Populations}

Both repeat $\mathrm{CABG}$ and repeat PTCA patients are modeled as are cross-overs between PTCA and CABG. Changes in these populations can be affected by working backwards from total CABG and total PTCA populations. In the case of total PTCA populations, one would go to total late PTCA populations and then alter any of the inputs of interest.

\section{Population Functions}

The population functions in the coronary artery disease model have been estimated from census bureau data. Risk rates have been obtained from the literature. These rates can be altered as required. The retirement age input site is also located in the population function module. In the default state, this value is set at 65 years and increases to 67.1 years after the year 2,000 , as is predicted to occur under current law. This may be low in that economic data suggest that the average person retires at approximately 67.9 years (i.e. he or she works after the formal retirement period). The analyst may wish to correct for this effect.

- The age-adjusted employment rate is to be found in the population function module and can be altered as economic circurnstances change.

- The fraction of patients with multi-vessel disease is set at 0.42 , the estimated fraction of disease in the procedure population. However, it must be noted that this is the prevalence of multi-vessel disease in all procedure patients. The prevalence is higher in CABG patients and lower in PTCA patients. Stenting could potentially increase the rate in PTCA patients as could recent data such as that generated by the BARI investigators, which show equivalence of outcome for multi-vessel disease patients treated with PTCA or CABG.

- Population age related complexity: This function is to be found in the population functions module. This function is designed to increase the severity of disease in presenting patients as the population ages. 


\section{Diagnosis 3 Library}

A submodel has been constructed to provide diagnostic information to the main coronary artery disease model. This tibrary is entitled Diagnosis 3 . It must be loaded with the main model for the main model to run. Included in the Diagnosis 3 Library is the presentation module. This module contains the characteristics of coronary artery disease patients who are candidates for revascularization. Input variables based on recent data include multi-vessel versus single vessel disease, dominant right coronary artery anatomy, the presence and absence of diabetes, the fraction of the population presenting for work-up, the mandated fraction (if any) of diabetics who are assigned directly to CABG as opposed to PTCA.

The remaining modules deal with symptom presentation and test results of patients undergoing work-up. The diagnosis module and the related diagnosis cost functions are based on less than adequate data in the literature. Best estimates of costs and decision trees are utilized. However, the coronary artery disease model is not sensitive to changes in the diagnosis evaluation modules per se because the number of patients presenting for catheterization does agree well with historical data and is the driver of revascularization procedures and costs.

\section{Prevention Function}

The prevention function module contains a variety of input sites dealing with the cost of primary and secondary prevention and the QALY's gained by drug prevention in one patient class or another. In addition, "prevention $\mathrm{RX}^{\mathrm{H}}$ functions are included. These deal with the use of such drugs as lipid lowering agents (which are deemed to be preventive measures) in the treatment of patients who would otherwise receive revascularization procedures. This kind of aggressive use of "preventive therapy" in patients who would otherwise be treated with a procedure is only now being explored. Should this activity expand, the prevention function module could accommodate it. For example, the analyst may choose to enter values other than the default values of zero into the functions "percent primary CABG patients amenable to drug prevention therapy" and in the "present primary PTCA patients amenable to drug/prevention therapy."

\section{Demand Functions}

The demand functions used in the default modes of the BPH and CAD models (based on disease prevalence, the frequency of "gate way" procedures such as cardiac catheterization, focus group derived opinions, and other factors) are relatively aggressive. As technology inproves, demand increases by $20 \%$ in the case of improved stent restenosis rates, $33 \%$ in the case of improved restenosis and enhanced access to lesions, and $45 \%$ in the case of the introduction of TUNA therapy for BPH. These figures are to be compared with a $26 \%$ increase in demand for cholecystectomy when laparoscopic 
cholecystectomy (with some health plans seeing much lower increases). The growth rates in the use of revascularization procedures and thrombolytic agents in patjents suffering from myocardial infarction, however, equal or exceed some of the default mode growth projections used here. For example, McClellan and Newhouse [McClelian 1997] have demonstrated that in the years between 1987 and 1990 certain cardiovascular technologies grew very rapidly. In relation to the treatment of myocardial infarction, the proportion of catheterized patients increased $41 \%$ (from $22.8 \%$ to $32.3 \%$ of patients) and the proportion of patients revascularized (PTCA and CABG) increased by $63 \%(8.1 \%$ different). Hospital costs also increased substantially, with nominal one year hospital costs increasing $34 \%$ (from $\$ 11,59 \$$ to $\$ 15,590$ ). Therefore, the analyst is advised to evaluate a range of demand increases when assessing a potential new technology.

\section{Results Module}

The results module contains those outputs which are believed to be of most use to the analyst. Most of these outputs are self-explanatory. It is important to note, however, that when interrogating the model for a cost or the cost of any unit item (such as the cost of a QALY), the analyst must be aware of the cost function being employed. Total direct procedure costs are those associated with the procedure, excluding physician costs. The total PTCA + CABG + procedure MD cost function includes physician fees. These physician fees can be varied, but at the extremes they can affect the "physician fee demand functions."

The "total PTCA + CABG costs - economic savings" function deducts from the total PTCA + CABG + procedure MD costs, those economic savings associated with early retum to work or increase longevity. This function in turn drives the "total cohort cost", but the "total cohort cost" also includes the diagnostic cost of all potential revascularization patients not simply those who actually received revascularization. That is, it reflects the increased push to diagnosis caused by improvements of technology whether or not that diagnosis leads to the use of the technology itself. In this regard it should be noted that the function "diagnosis push" increases the number of patients presenting for diagnosis of coronary artery disease and, while small in its effect, it is driven by improvements in stent technology.

"Net economic benefit" is driven by the estimates of QALY's gained from procedures multiplied by the value of a year in this patient population as assessed by the revealed preference method. This value of a life-year can be altered through the function "value of a quality life year," which can easily be entered through the "net economic benefit" function. Also important in the estimation of net economic benefit are the effects of technology on either the quality of the patient's life or the longevity of the patient's life. While most of these effects are preprogrammed (based on the available literature), the analyst is free to change these values in the net economic benefit module in order to assess the effects of anticipated technology improvements on the output. It must be 
emphasized that the "net economic benefit" function is strongly affected by the dollar value assigned to QALY. This vahue (V-qlf) can be modified by the analyst. Also, the discount function applied to future economic benefit can be modified as needed.

"Net economic benefit is also influenced by the QALY's assigned to each treatment group, as well as the reduced QALY's gained as treatment usage increases and less-ill patients are treated. The demand fanction can be altered to prevent the influx of less-well patients into the system. For exaniple, the "Dem-Multi" function can be made to prevent any dilution of the severity of multi-vessel disease in patients as stents are more widely used to treat that condition.

In assessing ratios, it is important to be mindful of the precise definition of both the numerator and the denominator. For example, the function "direct procedure costs per patient treated" reflects the direct procedure costs, including physician fees and the total number of patients treated with either PTCA or CABG (including repeat and crossover patients). The function "direct cost per primary revascular patient" is similar, but the denominator includes only first time procedure patients. As such, this ratio is a preferred estimator of costs per patient. To see this, note that all late patients detive from primary patients and therefore over time the cost per primary patient incorporates any changes in the cost per late or total patient population.

The demand override editor in the results r.odule is designed to warn the analyst if his patient population assumptions are flagrantly incompatible. More specifically, if the sum total of patients having procedures is greater than those being cathed, then the demand override editor activates and changes the output of "total PTCA procedures", "total PTCA + CABG cost", "total PTCA + CABG + procedure MD cost," and "total patients undergoing revascularization procedure" functions ail to zero.

\section{Simulation Issues}

The "demand influenced multi-yessel disease severity" function (DEM-MULTI) corrects for the lessening severity of multi-vessel disease which is expected to be seen in patients as stenting becomes more acceptable to patients. This is an extremely important variable insofar as it affects QALY-derived economic benefit. If the severity of multi-vessel disease falls, the QALY gained from either stenting or CABG declines, and the cost per QALY declines. If the multi-vessel disease severity is held constant (as would oceur if protocols required a certain level of disease before procedures could be considered), the true economic benefit of improved stents can be more easily be seen.

Functions dealing with physician fees have been included at Medicare allowable charges in the Analytica model. These levels are substantially less than the ambient charges of physicians in the United States today. As a result, total aggregate procedures costs are lower than might otherwise be expected. However, the project team betieves these 
estimates reflect the true proceduralist cost and that cost estimates are validated by the fact that low priced $C A B G$ s and PTCAs can be purchased in markets heavily penetrated by health maintenance organizations. Nonetheless, the analyst is worned that these physictan fees are substantially lower, both in the coronary artery disease model and in the BPH model, than fhe ambient charge figures in the United States. The analyst is advised to inflate these physician fees in order to get a more realistic estimate of the spectrum of costs which might be produced by any change in stent technology or BPH therapy.

Note that the economic models do not explicitly take into account the economic consequences of patient mortality during revascularization procedures. This is so because it is assumed that the QALY increments associated with revascularization therapy are compared with medical therapy, which in turn is compared with no therapy. Thus, the effects of mortality are included in the QALY gained estimate. Even if this were not the case, however, the econonic consequences of revascularization mortality are relatively modest. This is so becalse the overall mortality in revascularization patients is $1.5 \%$ or less. Even assuming 10 lost years of life at an annual value of a life of $\$ 62,000$, this mortality increases the value of a QALY by about $\$ 10,000$.

Note that as the variable "stent access" increases (i.e. as the percentage of multi-vesse] disease patients amenable to stenting increases), the simulation increases the number of stents used per person. However, the overall stent efficacy rate refers to tha ability of the stents to prevent restenosis in the patient rather than the effect of the stent on any given lesion. For example, if stent efficacy is set at 0.5 and stent access is set at 1.9 , this implies that a large percentage of multj-vessel patients are candidates for stenting and that the stent reduces the overall restenosis rate to $50 \%$ of the basal restenosis rate of $25 \%$. It does not imply that each stent carnes a restenosis rate of $12.5 \%$ but that the patient experiences an overall restenosis rate of $12.5 \%$. This would appear to be a reasonable default mode assumption given that it is unlikely that patients would be subjected to repeat PTCA for restenosis in one of multiple vessels treated with stents initially. Also, it is unlikely that the stents would be used if the cumulative restenosis rate rose signiftcantly higher than the restenosis rate now seen in single vessel disease. Nonetheless, should the analyst wish to model the circumstance in which repeat PTCA is driven by failure of each indjvidual stent, he need only adjust the "repeat number" function and the "probability of 12 month restenosis" function upward. Both functions are to be found in the "PTCA FX" module. Note that the repeat number drives the actual cost calculation whereas the probability of 12 month restenosis drives the demand functions primarily. Therefore, while their values are approximately equal, they are not exactly so.

The "opportunity to incur additional Health Care Costs" module contains functions designed to assess the effect on later health expenditures as a result of prolonging life. The theoretical underpinnings of this approach are only now being developed. The functions in the model indicate that the consideration of late health care costs could add between approximately $\$ 500$ and $\$ 2,000$ to the cost of each QALY gained by 
revascularization (baseline case). Meltzer [Meltzer 1997] argues that both medical and non-medical later expenditures should be considered if cost-benefit analysis is to be consistent with lifetime utijity maximization. This author estimates that the consideration of these later expenditures adds between $\$ 2,000$ and $\$ 3,000$ to the cost of each QALY gained through revascularization. A function representing this total late cost estinate is included in the modute. However, none of this late cost is incorporated into the costs generated in the results module. The analyst is free to use them when, and if, he becomes comfortable with the reliability of the estimates and the desirability of employing thern.

Note that alternative functions for a given output are sometimes found in the models. These alternatives are deemed to be inferior to the preferred output function, but are included to provide the substrate for possibie improvement as new data are presented in the literature. The assumptions underlying these alternatives ase included in the models.

\section{Basetine Simulations}

Total procedure costs for CABG and PTCA (including conservative estimates for physician fees based on Medicare allowable charges) are estimated to be $\$ 20.9$ billion in the year 2004. Were a near perfect stent (stent efficacy 0.9 , stent access 1.9 ) to be developed, the model predicts under baseline assumptions that total costs will rise by about $\$ 10$ billion to $\$ 30.11$ billion. This cost increase is driven by an assumed increase in patients treated from 744,000 to $1,050,000$. The cost of therapy when corrected for wages saved rises from $\$ 18.9$ billion dollars in the baseline circurnstance to $\$ 23.5$ billion with the near-perfect stent. That is, when wages are permitted to offset some of the increased costs associated with the treatment of more patients, the increase in aggregated costs associated with improved stent technology is somewhat blunted. Nonetheless, costs rise. When societal economic benefit is estimated based on the economic value of a QALY as assessed by the revealed preference method $(\$ 62,016)$, net economic benefit to the society is $\$ 32.5 \mathrm{~B}$ under baseline conditions and actually rises to $\$ 47.78 \mathrm{~B}$ with the adoption of the improved stents, assuming that the severity of multi-vessel disease in treated patients remains constant (Note that the default mode assumes a marked fall in multi-vessel disease severity with the introduction of the ideal stent such that total QALY's gained do not increase much. Holding severity constant or only slightly decteased is more realistic). This scenario indicates the importance of determining the frame of reference to be used in determining cost when attempting to establish technology policy. Clearly, the direct and indirect cost perspectives yield different conclusions regarding the economic impact of stent technology.

\section{Unit Costs}

In is possible for improvements in technology to lower the unit cost of a procedure or service or to lower the unit cost of therapy per patient. In the case of coronary artery stents, the unit cost per procedure is actually increased by virtue of the cost of the stents 
employed (typically in these models stent cost range from $\$ 750$ to $\$ 3,000$ ) as well as associated hospital and catheterization lab costs (typically in these modeis these costs tend to reflect historical levels, which perhaps will prove high as stents improve and competition increases). Thus, the use of stents increases the cost per PTCA procedure. However, stents have the capacity to reduce the need for repeat PTCA procedures and therefore have the capability of reducing PTCA costs per patient treated. Moreover, as stents improve so as to compete with higher cost $\mathrm{CABG}$ procedures (assuming total stents costs do not rise excessively) the total cost of treating a patient with a procedure (PTCA or $\mathrm{CABG}$ ) can also be shown to fall. In the case of interventional therapy for coronary artery disease however, it is perhaps more appropriate to consider direct costs per patient undergoing primary procedural therapy. This is because direct procedure cost per patient could fall due to more inexpensive stents, while the repeat rate for patients remains high. The direct procedure cost per primary patient treated would be expected to track not only the impact of unit procedure costs but also costs associated with repeat procedures.

ln the case of the baseline model (see Table 5), mean direct procedure costs per patient treated with a procedure (Mean \pm SEM) is $\$ 28,260 \pm \$ 780$ at a stent cost of $\$ 3,000$ per stent. This falls to $\$ 26,150 \pm \$ 8 \$ 5$ at a stent cost of $\$ 750$. With an ideal stent (stent efficacy $=0.9$, stent access $=1.9$ ) the comparable figures are $\$ 28,740 \pm \$ 503$ at a stent cost of $\$ 3,000$ and $\$ 24,260 \pm \$ 529$ at a stent cost of $\$ 750$. Thus, as stent costs fall, unit costs per procedure patient can be seen to fall. This results from the conversion of bigher cost CABG patients to lower cost PTCA/stent patients, and the effect increases as stent efficacy reduces the need for repeat procedures. In the case of procedure cost per primary patient treated, the baseline figure is $\$ 32,060 \pm \$ 903$ with a stent cost of $\$ 3,000$. This folls to $\$ 31,760 \pm \$ 555$ with the ideal stent. This is a statistically insignificant reduction. However, at a stent cost of $\$ 750$ the procedure cost per primary procedure patient in the baseline circumstance is $\$ 29,680 \pm \$ 931$, and this falls to $\$ 23,750 \pm \$ 568$ with the ideal stent. Thus, unit costs can fall even while aggregate costs rise, depending on assumptions regarding demand increase.

Thus, improvements in stent technology can reduce the unit cost per patient treated with a procedure. This cost-savings per patient is greater as stents become more effective in reducing restenosis rate following PTCA and as stents become less expensive relative to CABG costs. Moreover, if demand is assumed to be regulatable, aggregate cost-savings ate achievable. 
Table 5. Year 2904 results for the Analytica CAD stent simulations.

\begin{tabular}{|c|c|c|}
\hline & $\begin{array}{l}\text { Baseline } \\
\text { (MEAN } \pm \text { S.E.M.) }\end{array}$ & $\begin{array}{l}\text { Ideal Stent } \\
\text { (MEAN }+ \text { S.E.M.) }\end{array}$ \\
\hline Total Procedure Cost & $\$ 20.9 \mathrm{~B} \pm 0.56 \mathrm{~B}$ & $\$ 30.11 \mathrm{~B} \pm 0.49 \mathrm{~B}$ \\
\hline Cost-Wages Gained & $\$ 18.88 \mathrm{~B} \pm 1.26 \mathrm{~B}$ & $\$ 23.5 \mathrm{~B} \pm 0.57 \mathrm{~B}$ \\
\hline Patients Treated & $744 \mathrm{~K} \pm 5.75 \mathrm{~K}$ & $1.05 \mathrm{M} \pm 6.79 \mathrm{M}$ \\
\hline $\begin{array}{l}\text { QALY-Based Net } \\
\text { Economic Benefit }\end{array}$ & $\$ 32.50 \mathrm{~B} \pm 1.36 \mathrm{~B}$ & $\begin{array}{l}\$ 47.78 \mathrm{~B} \pm 2.42 \mathrm{~B} \\
\text { (if severity of disease remains } \\
\text { constant) }\end{array}$ \\
\hline $\begin{array}{l}\text { Total Procedaral Cost Per } \\
\text { Primary } \\
\text { Revascularization Patient }\end{array}$ & $\$ 32,060=903$ & $\$ 31,760 \pm 555$ \\
\hline Stent cost $\$ 750$ & $\$ 29,680 \pm 931$ & $\$ 23.750 \pm 568$ \\
\hline
\end{tabular}

These simulation results are dependant on the assumptions input to the model. For example, we have assumed relatively low physictian fee costs and based these primarily on Medicare allowable charges. In reality, many physicians charge higher fees to privately insured patients. It is not atypical for surgeons to charge $\$ 10,000$ for a CABG. Similarly, the BARI investigators report an estimated physician fee for multi-vessel angioplasty of $\$ 6,698$, higher than the Medicare allowable charge. Similarly, hospital charges for $\mathrm{CABG}$ and angioplasty in many cases far exceed the cost estimates which we have input in the model. The analyst is advised to vary these and other parameters (such as stent associated costs) so as to develop a level of comfort with what actual expenditures may be under specified conditions.

For example, if one were to (1) raise the physician fee for performance of single vesse] CABG from the defautt $\$ 1,432$ to a more realistic $\$ 7,000$, (2) raise the the fee for multivessel CABG from $\$ 2,033$ to the more market relevant price of $\$ 10,000$, (3) increase the PTCA physician fee from the default level of $\$ 1,105$ to $\$ 5,152$ in the case of single vessel angioplasty and $\$ 6,698$ in the case of multi-vessel angioplasty, and (4) increase CABG-associated hospital charges to an average of $\$ 31,000$, then a cost profile different from the default node energes. In particular, total procedure costs (including physician fees) rise to $\$ 27.6$ billion $\pm \$ 6.27$ billion. Cost per primary patient revasculasized increases to $\$ 43,460 \pm \$ 1,064$. Net societal economic benefit, however, remains positive at $\$ 24.28 \mathrm{~B} \pm \$ 1.39 \mathrm{~B}$, but cost per QALY increases to $\$ 33,910$.

This exercise demonstrates the juportance of defining costs before running a simulation.

Were the aralyst attempting to predict expenditures while using the default cost estimates, his predictions could vary considerably from the scenario he wished to simulate. 
Perhaps the most counterintuitive finding of the coronary entefy disease simulations is the result that the net social costs of interventional cardiological procedures is negative: these procedures in fact enhance social welfare and economic benefit. This conclusion is based on several inputs, including the economic value ascribed to a human life (more particularly to a quality-adjusted life year) and the costs of the various procedures. It is reasonable to explore how these values were derived.

As has been noted elsewhere, the economic benefit derived from medical care can be estimated by either the wage-based, the willingness to pay, or the revealed preference methods. Current economic thinking would argue that the revealed preference methodology is preferred. Note that this methodology is independent of employment status.

In the CAD model, the value of a quality-adjusted life year has been determined by the revealed preference methoo, utilizing the decision to voluntarily retire at age 62 as a natural experiment which reveals the economic value of a person's time. This approach is particularly appealing since it involves an experiment of nature dealing with the age group who participate in the therapies under consideration. As has been noted, this methodology produced a value of $\$ 170$ per day. This estimate equates to an annual value of $\$ 62,016$ per year. Is this figure realistic?

Cutler [Cutler, NBER WP 5750] considered a similar question. For their analysis, a value of $\$ 25,000$ per year was used, with an upper bound of $\$ 50,000$ per year and a tower bound of $\$ 10,000$ per year. Cutler mentioned that strvey evidence on the value of life for people around age 40 is $\$ 3,000,000$ to $\$ 7,000,000$ per 40 years of life, which equates to a considerably larger value for the value of an annual year of life. It is our belief that the figure of $\$ 62,016$ per year is appropriate given that it is derived empirically (as opposed to deduced from literature), is tailored to the population age group of interest, and falls within the boundaries of prior estimates.

In their study of patients treated for acute myocardial infarction, Cutler calculates a therapy-related change in the expected value of life ranging from $\$ 2,217$ to $\$ 25,994$. The first of these is driven by the assumption that a net value of a life here is $\$ 10,000$ per year, the latter value driven by the assumption that the net value of a life year is $\$ 50,000$. According to Cutler, when the expected net value of a life-year is assumed to be $\$ 25,000$ per year, the therapy-related change in the expected value of life is $\$ 11,133$. When this figure is adjusted by estimate of the improved life expectancy of the general population related to therapies other than acute myocardial infarction, the therapy related change in expected value of life (for the assumption that the net value of a life year is $\$ 25,000$ ) falls to $\$ 5,015$. This estimate is likely to be conservative for the reasons outlined by Cutler. 
The CAD model estimates that CABG and PTCA produce an economic benefit of $\$ 44,000$ per treated patient. Because these estimates are derived from treatmentgenerated increases in QALY's, they have already been corrected for other beneficial changes in society which would extend life. These figures have also been discounted at the rate of $2 \%$ per annum. Projected changes in the expected value of life caused by PTCA and CABG are higher than those reported by Cutler. However, several points stowld be made in this regard. The patients reported by Cutler bad suffered acute myocardial infarction, so the benefits of therapy in these patients were fewer, and their longevity was likely less relative to symptomatic patients who have not necessarify sustajned a myocardial infarction before receiving interventional therapy. Thus, one would expect the net benefit to be greater in the case of the patients represented in the $\mathrm{CAD}$ model. One could argue that these estimates are conservative given the differences in projected life span of elderiy patients who have sustained a heart attack (the population studied by Cutler) and all patients, young and old, who undergo PTCA and CABG (in large part prophylactically) to prevent future heart attack.

An additional point which speaks to the conservative nature of these predictions is that the CAD model makes no assumption of improvements in technology over time. This is clear when one realizes that the per-patient change in the value of expected life actually falls in the model between 1993 and 1996. (The CAD model does contain a function which will upgrade the change in quality of life years achjeved by PTCA as stent and other technologies improve, but these changes in QALY's can only increase to the "gold standart" level provided by today's CABG technology. Thus, the model's predictions are conservative even when stent and CABG technology are improved since no improvernent in optimal outcome is projected over current CABG capabilities.) This is of note given the fact that Cutler, et al have estimated a progressive decline in the cost of living index of about $1.1 \%$ per year and furthermore reported detectable technology driver increases in longevity after myocardial infarction. Thus, in the present model, both baseline simulations and simulations based on the changing of technology are likely to be conservative in respect to the societal cost of therapy.

At the same time it must be noted that these estimates of negative social cost are not robust when viewed against downward changes in the estimation of the value of a life year. Indeed with stent costs of $\$ 3,000$ or $\$ 1,500$, social costs become positive when the value of a life year approaches approximately $\$ 25,000$. In any event, the conclusion of a net social good derived from cardiovascular interventional therapies is not as robust as the argument in favor of newer myocardial infarction therapy. This points out the need for continued research in the effort to more rigorously define the value of a life year.

Sensitivity Analysis

When the value of a quality-adjusted life year is reduced below $\$ 27,000$, the societal benefits of interventional cardiovascular therapies turn negative (societal costs tum 
positive). This is different from the case outlined by Cutler for acute myocardial infarction, where the societal benefit was approximately $\$ 5,000$ under the assumption that a life-year was valued at $\$ 25,000$. If unit stent cost is set at $\$ 750$ per stent (recall that stent-associated costs in this circumstance may still be unrepresentatively high), societal break-even occurs at a quajity-adjusted life year value of approximately $\$ 25,000$.

It should be noted that all these estimates make no correction for improvements in longevity over and above those already associated with PTCA and CABG therapy in specific patient groups. Recent data suggest that longevity increases can be achieved even in a symptomatic patient with coronary artery disease when interventional therapy is utilized [Davies 1997]. Moreover, Cutler and colleagues have reported that between 1984 and 1991 the first year mortality rate of heart attack patients fell by $5 \%$. If this figure can be extrapolated to imply an improving survival rate of patients treated with interventional cardjovascular therapies after 1991 of between zero and $5 \%$, the benefits of treatment similarly increase. Nowhere in the current models is an outcome impact on life expectancy or quality of life better than that obtained by coronary artery bypass grating in 1990 inputed (these functions are avajlable in the nodel to be adjusted per the analyst, but are set to be inactive in the default mode). This again tends to make the societal estimates of cost and benefft conservative and gives further support to our view that in ret positive gain to society occurs when cardiovascular interventional technologies are employed as they curently are.

It is important to note however, that Viscusi [Viscusi 1993] reports a life year value of about $\$ 32,000,20 \%$ above the value associaled with a break-even societal benefit. Thus, this analysis (like other models of cardiovascular interventional therapy) suggests that the economics of this procedure may be poised close to the break-even benefit state, with considerable uncertainty surnounding the predicted true value of that economic benefit. Only enbanced research on outcomes and economic benefits will improve this circumstance.

If, as some have suggested, the value of a QALY is considerably greater than $\$ 25,000$ a yeas, the societal economic benefits increase dramatically. Under baseline circumstances, if the value of a QALY is $\$ 27,000$, the year 2004 net societal economic benefit is estimated to be $\$ 572$ million, or essentially the break-even point. If the value of a $\mathrm{QALY}$ rises to $\$ 50,000$, net societal economic benefit increases to $\$ 21.4$ billion, or about $\$ 29,000$ per patient treated. If the value of a QALY is further increased to $\$ 200,000$, net societal benefit exceeds $\$ 150$ billion, of more than $\$ 210,000$ per case.

Similar analysis can be undertaken regarding stent technology. At a stent cost of $\$ 3,000$ per stent, the baseline model predicts an economic benefit of $\$ 32.50$ billion. With a near ideal stent (stent access $=1.9$, stent effect $=0.9$ ), this figure rises to $\$ 47.78 \mathrm{~B}$ if the severity of disease in treated patients is held constant. If stent costs are set at $\$ 1.595$, net economic benefit initially under basal conditions is $\$ 32.50 \mathrm{~B} \pm \$ 1.36 \mathrm{~B}$, and this rises with the employment of the near ideal stent to $\$ 51.5 \mathrm{~B} \pm \$ 2.5 \mathrm{~B}$ if the severity of disease in treated patients is held constant. It should also be noted that the moded is capable of 
dissecting those changes in demand and cost associated with improved stent efficacy (that is reductions in restenosis rate), as opposed to those associated with expanded use of stents in the coronary anatomy (as is associated with the development of smatler stents and the willingness of physicians to see benefit in the stenting of mutti-vascular disease patients).

It is also of interest to determine the effect of increasing CABG and PTCA costs (including physician fees) on the analysis. The default mode estimates are based on Medicare-allowed physician charges and project team estimates of the time costs of revascularization procedures. Many facilities currently charge considerably more than these amounts. Thus, to the extent the analyst wishes to simulate expenditures (rather than estimated costs) the values of these cost inputs must approach current charges (prices).

If single vessel CABG hospital costs are raised to $\$ 31,000$, CABG surgeon fees are set at $\$ 7,000$ for single vessel patients $(\$ 10,000$ for multivessel), and PTCA physician costs are sel at $\$ 5152$ for single vessel disease ( $\$ 6698$ for multi-vessel disease), total procedure costs rise to $\$ 27.0$ billion, cost per primary patient increases to $\$ 43,460$ and cost/QALY rises to $\$ 36,110$. Net societal economic benefit remains positive at $\$ 24.24$ billion.

If the above physician costs hold but CABG cost rises to $\$ 40,000$, cost $/ Q A L Y$ is just over $\$ 36,000$. Net socic,al benefit remains positive.

Thus, the conclusion that revascularization provides a positive societal benefit is relatively robust in the face of variations in $\mathrm{CABG}$ and $\mathrm{PTCA}$ cost estimates. 
Table 6. Sensitivity analysis: net economic benefit as a function of QALY.

\begin{tabular}{|c|c|c|}
\hline Value of Time & Cost/QALY & Net Economic Benefit \\
\hline$\$ 100,000$ & $\$ 24,620$ & $\$ 66.18 \mathrm{~B}$ \\
\hline$\$ 71,367$ & $\$ 24,620$ & $\$ 40.37 \mathrm{~B}$ \\
\hline$\$ 62,016$ & $\$ 24,620$ & $\$ 32.50 \mathrm{~B}$ \\
\hline$\$ 60,000$ & $\$ 24,620$ & $\$ 30.12 \bar{B}$ \\
\hline$\$ 50,000$ & $\$ 24,620$ & $\$ 21.11 \mathrm{~B}$ \\
\hline$\$ 30,000$ & $\$ 24,620$ & $\$ 3.08 \mathrm{~B}$ \\
\hline$\$ 20,000$ & $\$ 24,620$ & $\$-5.93 \mathrm{~B}$ \\
\hline$\$ 10,000$ & $\$ 24,620$ & $\$-14.95 \mathrm{~B}$ \\
\hline
\end{tabular}

Table 7. Sensitivity analysis: net economic benefit as a function of CABG cost.

\begin{tabular}{|c|c|c|c|c|c|}
\hline \multicolumn{2}{|c|}{ Single Vessel Procedure Fees } & \multicolumn{3}{c|}{ Cost (Benefit) \$14.07B } \\
\hline $\begin{array}{c}\text { Surgical } \\
\text { Fee }\end{array}$ & $\begin{array}{c}\text { CABG } \\
\text { Hospital } \\
\text { Cost }\end{array}$ & $\begin{array}{c}\text { Cardiologist } \\
\text { Fee }\end{array}$ & $\begin{array}{c}\text { Procedure } \\
\text { Costs }\end{array}$ & $\begin{array}{c}\text { Cost/ } \\
\text { QALY }\end{array}$ & $\begin{array}{c}\text { Net } \\
\text { Economic } \\
\text { Benefit }\end{array}$ \\
\hline$\$ 1,432$ & $\$ 23,500$ & $\$ 1,105$ & $\$ 20.08 \mathrm{~B}$ & $\$ 24,620$ & $\$ 32.50 \mathrm{~B}$ \\
\hline$\$ 7,042$ & $\$ 31,000$ & $\$ 5,152$ & $\$ 27.6 \mathrm{~B}$ & $\$ 33,910$ & $\$ 24.28 \mathrm{~B}$ \\
\hline$\$ 7.042$ & $\$ 45,000$ & $\$ 5,152$ & $\$ 31.44 \mathrm{~B}$ & $\$ 38,000$ & $\$ 18.49 \mathrm{~B}$ \\
\hline$\$ 7,042$ & $\$ 55,000$ & $\$ 5,152$ & $\$ 33.65 \mathrm{~B}$ & $\$ 42,390$ & $\$ 14.24 \mathrm{~B}$ \\
\hline$\$ 7,042$ & $\$ 65,000$ & $\$ 5,152$ & $\$ 35.94 \mathrm{~B}$ & $\$ 46,380$ & $\$ 10.67 \mathrm{~B}$ \\
\hline
\end{tabular}


Cost-effectiveness anaiysis is a commonly-used methodology for comparing the ability of different technologies to reduce health care costs. In cost-effectiveness analysis, the researcher compares the cost per unit of benefit generated by two competing procedures. Cost-effectiveness analysis differs from cost-utility and cost-benefit techniques primarily in the measurement of benefits. Although this technique uses clinical outcomes (e.g. functional status and quality of life), it does not attempt to assign monetary measures to all outcomes generated by different medical technologies.

\section{Methodology}

Sloan [Sloan 1995] described a methodology for cost-effectiveness analysis as identified by the Department of Health and Human Services in 1992. The methodology is as follows:

1. Define the intervention. This includes specifying the nature of the intervention, the type of patient to be treated, and the alternative to the intervertion. In some cases, a medical intervention is compared to the natural history of the disease without treatment.

2. Identify relevant costs. Costs include direct (medical) costs as well as indirect costs such as patient time, Jost earnings, and social intervention costs.

3. Idenfify relevant benefits. Benefits include net bealth benefits to the patient (after removal of adverse side effects) as well as indirect benefits such as greater productivity.

4. Measure costs. This requires attaching a monetary value to all cost components, including medical inputs and an individual's time.

5. Measure benefis. This entails converting all benefits into a single metric (e.g. quality-adjusted life years, or QALY).

6. Account for uncertainties. This involves using Monte Carlo simulations or other methods to test the sensitivity of the conclusions to variations in perceived costs and benefits.

Again, the cost analysis team identified two commonly used coronary artery disease interventions as initial targets for this methodology. These are PTCA (percutaneous transluminal coronary angioplasty) and CABG (coronary artery bypass grafts). Both of these interventions, being technologically intensive, provided a tich set of issues to guide the development of a model for technology assessment.

\section{Cost Effectiveness Ratio}

The six steps of cost-effectiveness analysis can be summarized in the construction of a "cost-effectiveness ratio." This ratio is a calculation of the cost differences of alternative treatments weighted by outcomes measures. Determining a cost-effectiveness ratio 
includes generating an economically sound measure of the cost of the procedures or condition being analyzed. A weil-specified model of the cost of treating a condition could include measures of inputs used in the treatment, patient characteristics, input prices, and treatment mode (if different modes are being compared). A description of the cost measurement process is as follows:

Let $Z_{i r}=$ the amount of input $r$ used by patient $i$,

$X_{i}=$ patient characteristics,

$M_{i}=$ mode of treatment for patient $i$,

$P_{r}=$ price of input $r$,

$R=$ total number of types of inputs, and

$N=$ number of patients.

In this case, the cost of treating patient $i$ is

$$
C_{j}=\sum_{r=\}}^{R} P_{r} Z_{i r}
$$

The overall cost of treating the condition is then

$$
C=\sum_{t=t}^{k} C_{t}
$$

Important statistical issues exist regarding variation in the cost of treatment and how that variation is related to the type of treatment applied. In ordet to do this, a model is posed which relates input usage to patient characteristics and mode of treatment. Let $Z_{i}$ be the vector of inputs used to treat patient $i$. The vector of inputs chosen is affected by patient characteristics and mode of treatment, so $Z_{i}=F\left(X_{i}, M_{i}\right)$. Because of random variation or unobserved patient characteristics, these relationships include error: $Z_{i}=F\left(X_{i}, M_{i}\right)+e_{i}$ This forms the basis of the statistical model used to estimate costs. From this theoretical relationship, an estimated vector of input usage conditional on patient characteristics can be identified. From this estimated input vector, an estimated cost conditional on patient characteristics can be obtained.

\section{Cost-Effectiveness Analysis: Stent Technology}

A cost-effectiveness analysis would require that we determine the cost per QALY or similar measure of outcome. In the baseline state, the model predicts a cost of $\$ 25,150 \pm$ $\$ 680$ per QALY in the year 2004. With the introduction of a near-ideal stent (stent efficacy $=0.9$, stent access $=1.9$ ) this cost per QALY rises. This paradoxical increase in the cost of a QALY with improvement in stent technology can be shown to result directly from the assumption that as the stents improve, more patients with marginal indications for therapy (and therefore, patients who will derive less benefit per procedure) will be secruited into the population undergoing procedural therapy. In fact, if the severity of multi-vessel disease is held constont in the stented patient population, the cost per QALY actually falls slightly to $\$ 24,700 \pm \$ 370$. 
Moreover, if stent cost is reduced to $\$ 750$, the baseline cost per QALY falls to $\$ 23,790 \pm$ $\$ 700$. With the introduction of the near ideal stent and with the severity of multi-vessel disease held constant, cost per QALY falls dramatically to $\$ 19,630 \pm \$ 350$. This result indicates that improved stent technology can be demonstrated to improve the costeffectiveness of interventional therapy. Moreover, these simulations suggest that the cost of interventional therapy per quality of life year gained ranges from about $\$ 19,000$ to $\$ 25,000$.

McClellan and Newhouse [McClellan 1997] estinate that the average cost of each additional year of survival provided to acute MI patients by more intensive medica! treatment is at least $\$ 40,000$ in 1987 dollars; more plausible estimates are $\$ 70,000$ or more. This estimate is based on rather elaborate cortections for severity of iliness and treatment pattems. Absent these corrections, the cost per year of life gained falls to approximately $\$ 30,000$. Interestingty, these authors contend that what benefit enhanced technology has provided to the treatment of myocardial infarction patients is not necessarily associated with revascularization itself, but perhaps with better overall cardiological care. This conclusion is based on their observation that the majority of benefit obtained in interventional cardiology centers is obtained in the first day survival rate, a time during which few patients had yet received therapy. This conclusion appears counterintuitive and does not appear consistent with data indicating that time to revascularization is an important predictor of result. Thus, the conclusion is suspect as it relates to the benefit of current revascularization technology.

However, comparing this paper with Nationa! Bureau of Economic Research Working Paper 5750 by the same authors, it would appear that (1) the treatment cost of acute myocardial infarction from a societal point of view appears to have fallen between 1988 and 1993, (2) the treatment cost of an acute myocardial infarction appears to be about $\$ 70,000$ per life-year gained in 1990 (figures based on 1987 dollars), and (3) the benefit of aggressive treatment appears to be unrelated to revascularization procedure. This study predales modern revascutarization strategies, and its conclusions may not be applicable today.

As has been demonstrated (see thesection on cost-effectiveness), the CAD model predicts that the cost per QALY under baseline assumptions ranges from about $\$ 19,000$ to $\$ 25,000$. As noted above, McClellan and Newhouse have estimated the treatment of acute myocardial infarction cost at $\$ 40,000$ to $\$ 70,000$ or more per QAL Y achieved. This estimate gives some support to the CAD model predictions. Medical experience teaches that patients who have sustained myocardial infarctions are significantly more itl than those who simply suffer with angina and coronary artery disease, and their prognosis both in terms of longevity and function after therapy is diminished compared to those who have not sustained a myocardial infarction. The loss of ventricular muscle mass following a myocardial infarction is associated with a wide variety of complications, not the least of which is ventricular dilatation and enhanced susceptibility to congestive heart fajlure and arthythmia. Thus, it would appear reasonabie to assume that the cost of a quality life-year gained by the treatment of acute myocardial infaretion would be higher 
than that for the treatment of a patient with coronary artery disease who has not sustained an infarction. One could argue that this would not be the case, were the treatment of myocardial infarction to restore the patjent to near perfect health, but sadly this is not the circumstance. Thus we can assume that the 40,000 to $70,000+$ figure per QALY should represent an upper bound for the cost per QALY associated with the procedural treatment of coronary artery disease. Indeed, the relative magritudes of our $\$ 19,000$ to $\$ 25,000$ figure and McClellan and Newhouse's $\$ 40,000$ to more than $\$ 70,000$ figure seems reasonable.

\section{Coronary Artery Disease Laparascopic CABG Simulation}

Coronary Artery Bypass (CABG) grafting is an effective means of restoring blood flow to ischemic myocardium and thereby improving the symptomology of patients (in many instances extending their life spans). Recent data (Davies RF et al Circulation 95: 20372043,1997 ) suggest that re-vascularization may be effective in preventing morbidity and mortality even in asymptomatic patients: patients who are not now considered candidates for re-vascularization therapy. Thus, the demand for coronary bypass and angioplasty therapy will likely increase with time.

A major impediment facing patients who wish to under go a coronary artery bypass graft procedure is the significant morbidity and mortality associated with the procedure. CABG can only be described as a major procedure with a prolonged time to full recovery. Because stemotomy is required, patients cannot exert themselves or return to work for six weeks. Because of the morbidity associated with coronary artery bypass grafting surgeons have sought alternative means of approaching the coronary arteries so as to provide the same benefits as current-day CABG procedures with less morbidity. To this end, minimaly invasive CABG procedures are coming under development. These procedures are known also as PORT-ACCESS heart surgery or even laparoscopic CABG. In general, two approaches have been developed thus far. One involves placing the patient on heart lung bypass as is customary in the present CABG, while the other involves operating on the beating heart. Currently both procedures appear to be promising, although given constraints of access, it appears that at the present time only about 20 to $25 \%$ of patients could be candidates for this procedure. This is because the posterior aspect of the heart is difficult to access. However, we anticipate that with continued development the procedure will become more widely applicable.

The coronary artery disease model has been developed to simulate potential laparoscopic CABG procedures. To this end one can enter the CABG function module, scroll down to "CABG-PATIE" (a finction which reflects the post-operative state of well-being of a CABG patient), and then scroll down further to the function CABG-F-T. This function in the default position is set at one. Should it reach 3.33 the implication would be that the patient experiences very little (if any) mortidity following the procedure. In order to simulate the port access minimally invasive heart surgery of the future, this function was 
set at 2.5 after the year 1998. Next, the inpatient CABG cost were reduced to reflect the shorter time thatminimally invasive CABG patients will spend in the hospital. "Inpatient $-2^{N}$ can be entered through the CABG function module. From there one can drill down to "inpatient $\cdot^{n}$. In order to simulate the effects of a laparoscopic CABG procedure, room costs, ICU room costs, and supply costs were all multiplied by $0.5 ;$ other costs were left unchanged. This had the effect of reducing "inpatient $2^{\text {th }}$ the in-hospital CABG cost to about $\$ 20,800.00$.

Next, the function "value-of-w3" which can be reached in the economic opportunities module, was adjusted so that the function "CABG days lost" (the number of days a CABG patient loses from work) was multiplied by 0.33 , reflecting the fact that, in the case of minimafly invasive CABG, work days lost fall from 42 to 14 . Finaliy, it shouid be noted that because no reduction was made in "CABG post-operative patient condition," "the cost", or in the value of work days lost, this formulation assumes that virtually all CABG patients are candidates for the minimally invasive feature.

When this simulation is run, the total number of CABG patients increases to 601,000 , with the total PTCA patients remaining at about 400,000 . The total number of revascularization procedtures climbs to 1.2 million. This increase in procedure number reflects the increased demand for CABG which would be associated with a marked decrease in CABG morbidity, "Total procedure and physician cost" increases from $\$ 20.9$ \pm 0.56 billion in the baseline state to $\$ 25.7 \pm .71$ billion after the introdiction of minimally invasive CABG. That this increase in aggregate cost is almost totally accounted for by the increased demand for procedures can be seen from the fact that while total revascularization cost per primary revascularization patient was approximately $\$ 32,000 \pm 903$ in the baseline state, this falls to $\$ 29,000 \pm 905$ dollars following the introduction of minimally invasive coronary artery bypass grafting. That is, the introduction of the new procedure actually lowers unit cost per patient treated but stimulates a sufficient increase in demand $(744,000$ patients in the baseline circumstance, one million after the introduction of the new technology) to increase aggregate costs.

Total direct costs minus wages gained ("total cohort cost") are projected to rise (from $\$ 18.66 \pm 1.26$ billion to $\$ 22.32 \pm 2.10$ billion) following the introduction of the new technology. However, when these figures are expressed on a per-patient-undergoingrevascularization basis, the direct cost minus wages gained per revascularization patient fall from $\$ 25,080.00$ in the baseline case to $\$ 22,250.00$ following the introduction of the new technology.

Net societal economic benefit after the introduction of the new technology is also projected to rise. However, this result and the QAL Y-derived estimates below result in large measure from the fact that no diminution in the severity of multi-vessel coronary artery disease is assumed following the introduction of mininally invasive CABG. It is left as an exercise to the reader to set the "dem-multi" finction to a lower level than its default value of 9542 and apply it to CABG derived QALY's in order to reflect any diminution of disease severity. However, assuming no such diminution occurs, the cost 
per QALY falls to $\$ 20,840 \pm 595.00$ following the introduction of the technology. However, it must be repeated that net societal economic benefit, net societal economic benefit per procedure patient and cost per QALY all are criticaliy dependient on the value selected for the diminution for the severity of multi-vessel disease.

In summary, this exercise demonstrates that the introduction of a minimally invasive CABG technology can be expected to increase the mumber of revascularization procechures performed and the total cost of canying out those procedures. However, if the minimally invasive $\mathrm{CABG}$ procedure is as effective as the current procedure, the total cost of revascularization per primary patient is likely to falt, indicating that the new technology has provided a means to more efficiently treat the individual patient. Net societal economic benefit also seems to increase under these circumstances, but this conciusion is dependent on assumptions regarding the seventy of multi-vessel disease in the expanded CABG population. The study of the sensitivity of these results to the severity of milti-vessel disease in the CABG population is left as an exercise. 


\section{Modeling of BPH Treatment Using Analytica}

\section{Summary of the Benign Prostatic Hypertrophy Anadytica Model}

The benign prostatic hypertrophy (BPH) model is designed to permit the simulation of the costs and outcomes associated with the introduction of a variety of therapies for prostatic hypertrophy. Currently in the United States, the predominant mode of therapy for symptomatic benign prostatic hypertrophy is the transurethral prostatectomy (TURP). This procedure has generally superseded the open prostatectomy for benign prostatic hypertrophy. However, over recent years a variety of procedures, including laser technologies, microwave prostatic ablation, and transurethral needle ablation of the prostate have been developed. These procedures vary considerably in their costs. While the outcomes of these procedures are largely unknown at this time, it can be reasonably anticipated that these outcomes will vary both in the quality of symptomatic relief and the durability of that relief. Moreover, during recent years a variety of medical therapies (including five alpha reductase inhibitors and alpha adrenergic blocking agents) have come on the market to provide symptomatic relief for prostate patients. At the same time new educational efforts have been developed which inform the prostate hypertrophy population of the true risks and benefits of interventional therapy. Because the interventional therapy of prostatic hypertrophy is in large measure directed at providing symptomatic relief to patients, as opposed to improving longevity or general health (since it is now relatively rare for patients to be permitted to develop significant renal insufficiency without a procedure), the treatment of benign prostatic hypertrophy is directed increasingly by the patient as opposed to the physician, and the success of that therapy is jncreasingly determined by the subjective improvements which patients perceive. Thus, the treatment of benign prostatic hypertrophy is a complex process in which procedural technology, economic forces, and patients' desires interact in a complex fashion.

The BPH model consists of two portions. The first is a library entitled "Base Population." Here, data deal with the United States population at risk for BPH. This library drives the remainder of the model and the main BPH model cannot be operated without it.

The presentation screen of the BPH model consists of several clearly identified modules. Important among these is the presentation module in which is entered the prevalence of various forms of prostate-related symptoms and signs (clinical findings). The "therapy outcomes" probability module houses the literature-derived best estimates of complications and outcomes of interventional therapy for prostate disease. In most instances, these outcomes probabilities are driven by the module "UCNA surgical Rx outcomes". The latter module incorporates the surgical outcomes results published in the Urological Clinics of North America (UCNA). Other therapy outcome probabilities are derived from the "UCNA medical $\mathrm{Rx}$ outcomes" function which similarly reports Urological Clinics of North America estimates for medical therapeutic outcomes. 
The diagnostic module outlines a variety of diagnostic tests which can be used in patients with benign prostatic hypertrophy. However, this module (with the exception of cystoscopy in patients about to undergo procedure) does not drive the main model to any significant extent because in recent years diagnostic testing has been scaled back for patients with benign prostatic hypertrophy. However, should one wish to estimate the impact of the reintroduction of these tests, this module conld prove helpfin.

A "QALY" module appears on the first screen, and this is something of a misnomer. Because benign prostatic hypertrophy therapy has little impact on longevity, any estimate of QALY changes will be largely driven by changes in symptomatology. While a variety of symptom scores are available, it is not possible at this time to convert these changes in symptoms to a true change in QALY. Therefore, the labeling of this module as "QALY" is more a hope or plan for the future based on future research than a reality for today. As noted in the QALY module, symptom score estimates are derived from a variety of sources including the work of Dr. Clause Roehubom of the University of Texas. It is important to note however that no economic benefit is associated with change in symptom score or QALY in this model.

The "procedure functions" module contains the cost data associated with a variety of procedures as well as the number of procedures which are likely to be prefomed. The procedural MD demand muttiplier is a module which attempts to estimate how physicians will respond to changing reimbursement for procedures. That is, as one procedure is favored over another in terms of reimbursement, physicians may be tempted to perform it more ofter.

The "patient education" modute permits the analyst to introduce estimates regarding the impact of patient education on the use of procedural therapies. In the baseline mote it is assumed that were education to be widely available, the rate of TURP would fall by $28 \%$. Therefore, the effect of education on TURP function is driven by the availability of education, and the analyst can set this function as he wishes. In the default mode, this function is scaled up from $10 \%$ in 1992 to $60 \%$ in 1994 . Similar educational availability and effect functions are found for other technologies, and the analyst is advised to be aware of this because in many cases the educational impact and availability functions mirrot those assumed to be present for TURP.

The remainder of the modules on the start-up page are self explanatory. The analyst is advised to read the "info notes" carefully. In particular, it is important to note that baseline BPH population data prior to 1995 were derived from HCIA, and these data were used to extrapolate the 1996 baseline TURP population and cost.

In the case of benign hypertrophy, the project team again created two models. The first "attention focusing model" is designed to provide the analyst an easy-to-use tool having the heuristic value of pointing out to the observer interrelationships between factors which might not be immediately apparent. The second, more detailed model is 
constructed utilizing ARENA. Again the ARENA model is elemental in that individual patients or small cohorts of patients can be tracked over time. Just as a library model (Diagnosis 3) is required for operation of the coronary artery disease model, so too is the library "base population" required for the operation of the BPH model. The "base population" model must be loaded for the BPH model to run.

Index To Important Input Variables In The Benign Prostatic Hypertrophy Model

\section{Interrelationship Diagram}

Figure 4 below depicts the interrelationships between the variables used in the Analytica BPH model.

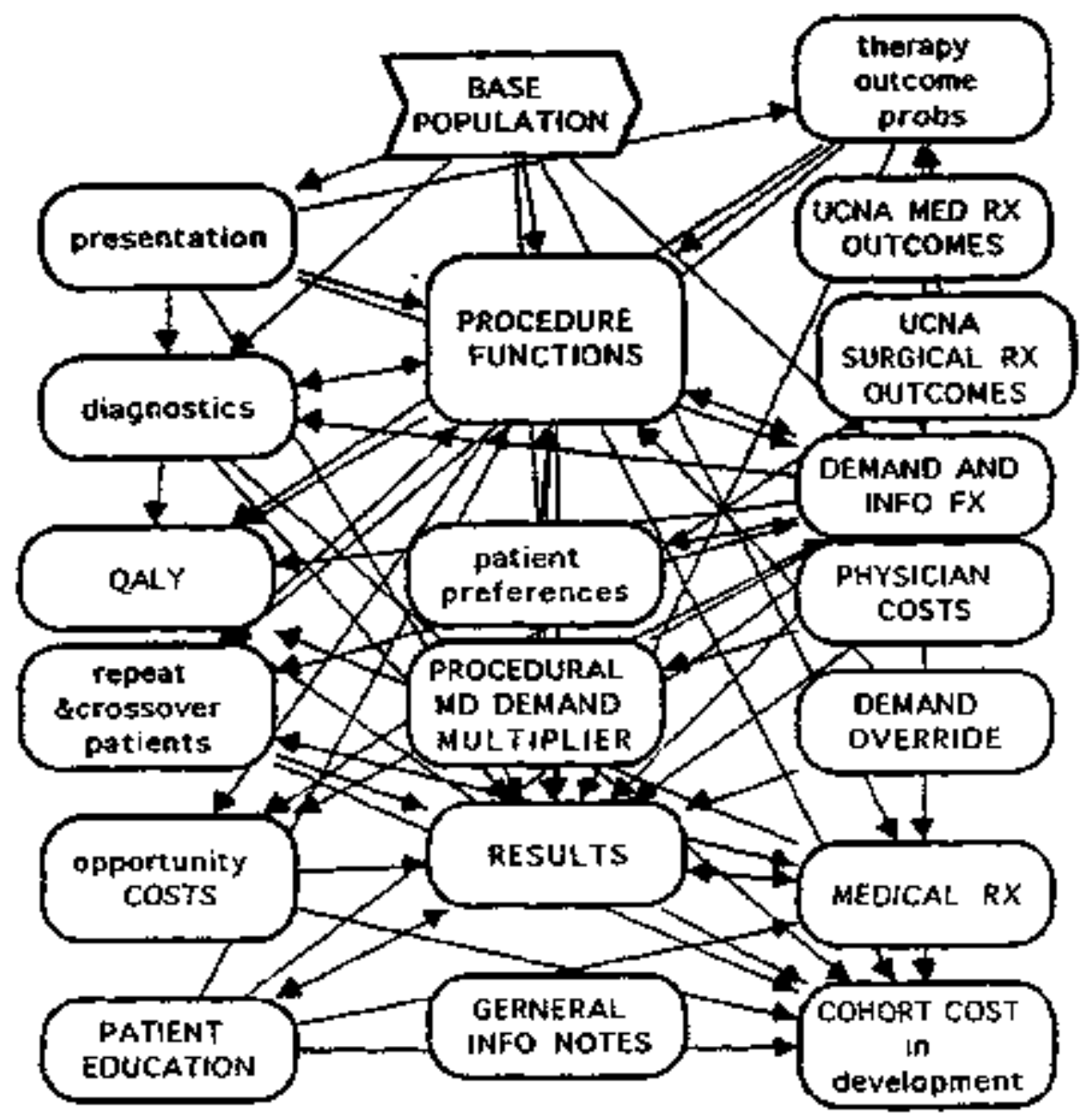

Figure 4. Depiction of the interrelationships used in the Analytica BPH model. 


\section{Poptlation Related Yariables}

All population-related input variables are to be found in the "based population 7/8" library.

Male population at risk. The male popukation at risk is derived from census figures and an age-adjusted risk for BPH. Both these variables can be modiffed by scrolling down through the function module in base population 7/8.

\section{Yariables Related to Repeat Procedures and Patients Crossing Over From One Procedure to Another}

The "repeat and crossover patients" module contains important variables which influence the rate of repeat procedures as well as the rate at which patients having repeat procedures switch from one type of procedure to another. In general, both first-year repeat rates and five-year repeat rates can be individually entered. In the case of transurethral prostatectomy, data from Urology 44:692-699, 1994 is employed to jndicate an average first-year repeat rate for TURP of $1.3 \%$. Repeat functions for years four through five (and later if desired) can be entered directly through the "therapy outcome probabilities" module. In the case of transurethral prostatectomy five year repeat rates ranging from about 12 to $6 \%$ for BPH are reported. This repear ate appears to be changing with time and its value can influence results of the simulation significantly. The andyst is to pay careful attention to the literature in regard to the true value of this parameter at any given time, and the analyst is further advised to perform sensitivity analysis around any chosen repeat rate. The one-year and five-or-more-year repeat rate for newer technology (e.g. TUNA and microwave) are as yet unknown and can only be estimated. In the BPH model default mode, estimates derived from focus groups have been used, but again the analys is advised to update these in an ongoing fastion.

\section{Relief Of Symptoms}

The "therapy outcome probabilities" module contains the various outcomes of procedural therapy for BPH. This module includes functions which bear on the relief of "irritative symptoms" by various procedures. Because the irritative symptoms of prostatism (for exarnple nocturia) are particulariy bothersome to patients and appear to be differentially affected by therapies, these input values must be carefully considered. 
A complication in modeling the procedure therapy of benign prostatic hypertrophy results from the fact that some transurethral prostatectomies are performed for reasons other than benign prostatic hypertrophy. For example, some patients with prostate cancer undergo TURP in order to relieve symptoms. These transurethral prostatectomies should not properly be modeled as an element of the therapy of benign prostatic hypentophy. Similarly, some patients who undergo transurethral prostatectony for benign prostatic hypertrophy are subsequently found to have prostate cancer. These patients are considered in the simulation to be BPH patients. In other words, the model assumes an "intention to treat" perspective. In general, approximately $87 \%$ of TURPs are done for benign prostatic hypertrophy. This variable must be followed over time and the analyst must be aware of its potentjal significance, particularly when he attempts to compare results of the simulation with actual TURP rates. The cost of therapy for patients who are incidentally determined to have prostate cancer at the time of TURP is given in the "cost of malignant disease" function, which is found in the "results" module. Based on literature support, (cited in the "cost of malignant disease" function) an incidental rate of prostate cancer of $10 \%$ is assumed. Further, the cost of therapy for a patient so detected is assumed to be $\$ 10,000$. Should the analyst wish to change either of these variables, he can do so directly by accessing the "cost of malignant disease" function. No economic benefit is ascribed to the treatment of incidentally detected prostate cancer, but the analyst may choose to make such an addition if subsequent data makes that a reasonable assumption. Finally, the "cost of malignant disease" function does not consider those patients whose prostate cancer is detected by PSA screening. These patients are in general sent directly for open prostatectomy. Screening is rapidly becoming common place. Therefore, it was not elected to consider PSA-detected cancets as part of the BPH simulation. However, should the analyst wish to assume that the work-up for BPH drives a percentage of PSA detected cancers, he is free to enter this assumption in the "cost of malignant disease" function.

The analyst is again advised to review the definition of cost functions and functions in which cost is to be found as an element in a ratio. This is so because, depending on what one wishes to include in the definition of "cost," results can vary. The BPH model presents many variants for calculating cost-benefit and other cost-related functions, and the analyst is advised to pay particular attention to the definition of any function he or she interrogates.

\section{Simulation Results}

Results from these simulations are summarized in Table 8. In the default mode, the modes describes a fall in the total number of procedures for benign prostatic bypertrophy from approximately 330,000 in 1992 to approximately 270,000 in 1995 , with a slight 
increase to 298,000 by 1997 . Thereafter, demographic pressures continue to increase the number to about 320,000 in the year 2005. This is still below the 1992 figure. This relative fall off in procedures is ascribed to improved patient education and the availability of pharmacological therapy. It can also be assunned that, as more patients present for radical prostatectongy (because of PSA screening induced demand), urologists may choose to perform that procedure in preference to TURP. The approximately 320,000 procedures which are expected to occur in the year 2005 will carry a cost of about $\$ 3.3$ billion. At the same time it should be noted that, in the year 2005 , the model in the default mode estimates that approximately 660,000 patients will be under treatment (either medically or surgically) for benign prostatic hypertrophy.

The availability of transuretbral needle ablation (TUNA) technology can be simulated by scaling up availability from zero in 1996 to 0.9 in 2001 in the "TLNA availability" function and also increasing the "info TUNA" function to .91. Both these functions are found in the "demand and info FX" modules. The TUNA information function is designed to simulate the degree to which knowledge about the TUNA procedure and its outcomes is available to physicians and patients, while the TUNA availability function is designed to permit the sirnulation of the availability of the technology itself. If the 5-year repeat rate for TUNA is assumed to be $20 \%$, then the total number of procedures for BPH predicted to occur in the year 2005 rises to approximately 444,000 . Of these, 296,000 are projected to be TUNA proceduses. Thus TUNA is anticipated to not only increase the total dernand for procedures, but to displace.to some extent transurethral nostatectomy. It should also be noted that in the case of TURP, repeat procedures over 5 years are less frequent than in the case of coronary artery disease. The model also suggests that the total number of patients under medical and surgical therapy will increase to 769,000 by the year 2005. This obviously assumes that TUNA is not only capturing some patients who previously would have received TURP but also has induced additional patients into the treatment paradigm including medical treatment. In effect, the model predicts a $16 \%$ increase in the total symptomatic BPH poptation presenting for procedure therapy. This data is not inconsistent with data from Israel and elsewhere suggesting there is a large untapped population with symptomatic BPH.

The total cost of procedure patients in the baseline simulation is $\$ 3.30 \pm .306$ billion (Mean \pm S.E.M.) in the year 2005. With the introduction of the TUNA procedure, this cost is expected to fall insignificantly to $\$ 3.28 \pm .256$ billion. However, this is an aggregate cost of therapy. The total cost per procedure in the baseline state is $\$ 10,213$, and this falls to $\$ 7,382$ after the introduction of the TUNA. When per-patient costs are calculated, the per-patient procedure cost is $\$ 10,928$ in the baseline case and $\$ 8,180$ after the introduction of TUNA. Therefore, TUNA clearly produces a unit cost-saving, whether that unit cost is calculated per procedure or per patient. Because BPH therapy is in large degree "optional", the control of patient volumes is perhaps more easily achieved in the therapy of $\mathrm{BPH}$ than in the therapy of a life-threatening disease such as coronary artery disease. Therefore, any tendency to constrain demand increase following the introduction of TUNA could be expected to decrease aggregate procedure costs. 
Estimates of costs in the BPH model are sensitive to the assumed cost of a TUNA as well as to its repeat rate. Of particular importance is the value assigned to the cost of physician time. This is an extremely difficult value to obtain, and physician charges vary widely. Nonetheless, the model uses a reasonable estimate based on Medicare-allowable charges and ambient charges in the community.

If.one cajculates the aggregate symptom score improvement following procedure therapy, one sees that this score increases from $3.48 \pm 0.38$ million units to $4.60 \pm 0.17$ million units. That is, the introduction of TUNA is associated with a net improvement in symptomatology score of about $30 \%$. If one calculates the symptom score improvement per total dollars spent on procedures, this value rises from $1.04 \pm .11$ mil units per dollar to $1.40 \pm .51$ mil units per dollar. That is to say, the value obtained in terms of symptomatic relief per procedure dollar spent increases after the introduction of TUNA.

In summary, this simulation, albeit sensitive to estimates regarding TUNA repeat rates, physician- associated fees, and demand, predicts that the introduction of TUNA will hold aggregate costs constant while reducing unis costs. In addition, it will increase aggregate symptomatic improvement.

Table 8. Benign prostatic bypertrophy baseline simnlation year 2000 results.

\begin{tabular}{|l|l|}
\hline $\begin{array}{l}\text { Total Costs of Patients Treatedwith a } \\
\text { Procedure }\end{array}$ & $\$ 3.23 \overline{\mathrm{B}} \pm .0269 \mathrm{~B}$ \\
\hline Aggregate Number of Procedure Patients & $298,400 \pm 2,756$ \\
\hline $\begin{array}{l}\text { Aggregate Number of Procedures } \\
\text { Aggregate Number of Patients Treated } \\
\text { Pharmacologically or with a Procedure }\end{array}$ & $315,900 \pm 2,901$ \\
\hline $\begin{array}{l}\text { Aggregate Improvement in Symptom Score } \\
\text { Produced by Procedures }\end{array}$ & $\begin{array}{l}3 . \overline{401} \pm . \overline{369} \text { million } \\
\text { units }\end{array}$ \\
\hline $\begin{array}{l}\text { Improvement in Symptom Score Produced } \\
\text { by Procedures Divided by Total Cost of } \\
\text { Procedures }\end{array}$ & $\begin{array}{l}1 . \overline{043} \pm 10.112 \text { milli } \\
\text { units/dollar }\end{array}$ \\
\hline $\begin{array}{l}\text { Improvement in Symptom Score by } \\
\text { Medical Therapy per Dollar Spent on } \\
\text { Medical Therapy: }\end{array}$ & $\begin{array}{l}1.598 \pm .0264 \text { milli } \\
\text { units/doliar }\end{array}$ \\
\hline
\end{tabular}

Sensitivity Analysis of TURP Repeat Rate

Evidence indicates that the rate of repeat transurethral prostatectomy for benign prostatic hypertiophy is falling. The analyst might properly wish to perform sensitivity analysis on the value of this rate. Historically, the eight-year repeat rate for TURP following an initial TURP for benign prostatic hypertrophy has ranged from about $20 \%$ in 1987 
[Wennberg 1987] to a 1994 value of about 5.5\% [Lu-yao 1994]. Lu-yao et al report a first year TURP repeat rate for BPH of about $1.3 \%$ and a five year rate of $5.3 \%$.

In performing sensitivity analysis one must note that the default position of the BPH model is set at a first-year repeat rate of $1.26 \%$ and a five-year repeat rate of $12.6 \%$. In the default mode the simulation predicts year 2004 total procedure costs of $3.23 \pm .03$ biltion dollars. This cost is driven by $316,000 \pm 3,219$ procedures. If the Lu-yao figures are used (first-year repeat rate of $1.26 \%$, five-year tepeat rate of $5.5 \%$ ) the total cost of procedures falls to $\$ 3.03 \pm .025$ billion. This figure is driven by a total of $295,000 \pm$ 2,730 procedures. See Table 9 for a summary of these results.

Thes, the estimate of procedure cost and number of procedures is sensitive to the TURP repeat rate. Two conclusions can be drawn from this observation. First, the falling TURP rate (likely caused by increased education of the population regarding the cost and benefits of the procedure), coupled with the availability of pharmacological therapy has also been associated with a decrease in TURP repeat procedures (with additional savings). Second, this analysis confirmed that those technologies or interventions which reduce the need for repeat procedures (i.e. those that produce a durable result) have the potential to reduce costs.

Table 9. Sensitivity analysis of transurethral prostatectomy repeat rate: year $\mathbf{2 0 0 5}$ results.

\begin{tabular}{|l|l|}
\hline $\begin{array}{l}\text { Total Cost of Patients Treated with a } \\
\text { Procedure }\end{array}$ & $\begin{array}{l}\text { Aggregate Number of Procedures } \\
\text { Performed }\end{array}$ \\
\hline (Assuming a TURP first year repeat rate of 0126 and a repeat rate years 4-5 of 0.113$)$ \\
\hline$\$ 3.234 \mathrm{~B} \pm .031 \overline{\mathrm{B}}$ & $\overline{316,300 \pm 3,219}$ \\
\hline (Assume a Year-One TURP Repeat Rate of 0126 and Year 4-5 Repeat Rate of 0.042$)$ \\
\hline$\$ 3.028 \mathrm{~B} \pm .025 \mathrm{~B}$ & $295,200 \pm 2,037$ \\
\hline
\end{tabular}

Note that when changing the five-year TURP repeat rate, one should also consider altering the "TURP redos" function in the "procedure functions" module. This is because the "TURP redos" contains preset repeat TURP numbers for the first six years of the simulation. Should the analyst wish to systematically change past and future estimates of TURP redo rates, he should consider changing the historical repeat rates included in this function. Also note that this function corrects the TURP five-year repeat rate to a sixyear value.

The defaut mode of the benign prostatic hypertrophy model includes a gradual but modest phase-in of both TUNA and microwave procedures. This phase-in is accompanied by default mode repeat rates for each procedure. The analyst may prefer to zero out the introduction of these new technologies and use that state as baseline. 
The distinction between aggregate number of procedures and aggregate numbers of procedure patients prinarily reflects the number of patients who bave mote than one procedure in a year. If a patient returns for a repeat procedure in a subsequent year, he is counted as a procedure patient. If he has two procedures in a year, he is counted as one patient in the function "number of procedure patients" and as two procedures in the "number of procedure" function.

The symptom score calculations ascribe benefit to each patient who receives a procedure irespective of whether it is a repeat procedure or a primary procedure. In other words, the duration of the symptom relief is not included in the symptom score calculation. This correction could be made by simply multiplying the improvement in symptom score for each treatment modality by a number equal to one minus the fraction of patients who will have repeat procedures in the time span under consideration. This has not been done in this function for two reasons. First, the correction is small. Second, the inprovement in symptom score is derived from subjective judgments in the literature which vary considerably from study to study and indeed from patient to patient. Also, whether the negative value arbitrarily ascribed to those few patients who undergo procedural death is appropriate or not is debatable. For all these reasons the project team believes that future research will be required to further refine the changes in symptomatology associated with the treatment of benign prostatic hypertrophy, and it was elected not to elaborate on this point any further in the model. However, if an analyst wishes to model duration of symptom relief or a varjety of utilities associated with the relief of particular symptoms, the rodel offers the opportunity to do this.

\section{A Representative Simulation of the Introduction of Microwave Therapy}

It is assumed that microwave therapy becomes avajlable in the year 1996 and that its availability increases to a maximum of $90 \%$ in the year 1999 and thereafter. The first year repeat rate for microwave therapy is assumed to be 0.1 , and the rate over years 2 through $S$ is assumed to be 0.2285 . With these assumptions, the year 2005 resuts of the simulation are as shown in Table 10 . 
Table 10. BPH simulation results from the introduction of microwave therapy.

\begin{tabular}{|c|c|}
\hline $\begin{array}{l}\text { Total Cost of Patients Treated with } \\
\text { Procedure }\end{array}$ & $\$ 3.689 \mathrm{~B} \pm .0254 \mathrm{~B}$ \\
\hline Aggregate Number of Procedures & $507,600 \pm 3,738$ \\
\hline $\begin{array}{l}\text { Aggregate Number of Patients Treated } \\
\text { with Procedure }\end{array}$ & $467,100 \pm 3,234$ \\
\hline $\begin{array}{l}\text { Total of Patients Treated with Either a } \\
\text { Procedure or Pharmacological Therapy }\end{array}$ & $822,100 \pm 3,508$ \\
\hline $\begin{array}{l}\text { Aggregate Improvement in Symptom } \\
\text { Score Produced by Procedures }\end{array}$ & $5 . \overline{961 \pm} . \overline{16} \overline{3}$ million units \\
\hline $\begin{array}{l}\text { Improvemeat in Symptom Score } \\
\text { Divided by Total Procedure Cost }\end{array}$ & $\begin{array}{l}1.641 \pm .0420 \text { milli units per } \\
\text { doilar }\end{array}$ \\
\hline $\begin{array}{l}\text { Total Improvement in Symptom Score } \\
\text { in Pharmacologically Treated Patients } \\
\text { per Dollar Spent }\end{array}$ & $\begin{array}{l}593 \pm .0263 \text { milli units per } \\
\text { dollar }\end{array}$ \\
\hline
\end{tabular}

Simulation of the Introduction of Transurethral Needle Ablation (TUNA) as Therapy for Benign Prostatic Hypertrophy

In this simulation it is assumed that information regarding TUNA is available to $91 \%$ of patients and physicians. It is further assumed that the TUNA technology itself is available to no one in 1995 , to $1 \%$ of the population in 1996 , to $20 \%$ in 1997 , to $70 \%$ in 1998 , and to $90 \%$ of the population thereafter. The one-year TUNA repeat rate is assumed to be 0.068 and the repeat rate in years 2 to 5 is assumed to be 0.20 . Year 2005 results are shown in Table 11 below.

Table I1. Simulation results from the introduction of transurethral peedle ablation (TUNA) as a therapy for benign prostatic hypertrophy.

\begin{tabular}{|c|c|}
\hline $\begin{array}{l}\text { Total Costs of Patients Undergoing a } \\
\text { Procedure }\end{array}$ & $\$ 3 . \overline{326} \pm .02 \overline{49}$ \\
\hline Aggregate Number of Procedure Patients & $408,200 \pm 3,050$ \\
\hline Aggregate Number of Procedures & $451,200 \pm 3,620$ \\
\hline $\begin{array}{l}\text { Aggregate Improvement in Symptom Score } \\
\text { Produced by Procedures }\end{array}$ & $4.6 \overline{\mathrm{I}} \pm . \overline{166} \mathrm{mi} \overline{\mathrm{l}} \mathrm{i} i \mathrm{on}$ units \\
\hline $\begin{array}{l}\text { Improvement in Symptom Score by } \\
\text { Procedures per Dollar of Total Procedure } \\
\text { Cost }\end{array}$ & 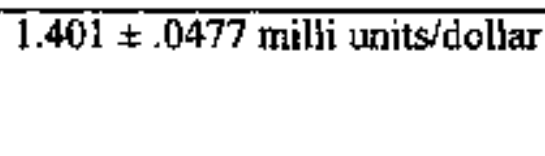 \\
\hline $\begin{array}{l}\text { Improvement in Syaptom Score by } \\
\text { Medical Therapy per Dollar Expended on } \\
\text { Medical Therapy }\end{array}$ & $1.595 \pm .0263$ milli units/dotlar \\
\hline
\end{tabular}


These data indicate that the introduction of TUNA is associated with an increase in total procedure costs driven in large measure by an increase in total procedure patients. Both cost per patient and cost per procedure fall significantly. Cost per patient falls from $\$ 10,839$ to $\$ 8,137$, for example. Thus the introduction of the TUNA technology clearly reduces unit cost while producing a modest increase in aggregate cost based on a large increase in the number of procedural patients. Symptom improvement per dollar expended on procedural care similarly tises, although it does not equal the benefit per dollar spent on those patients who are amenable to pharmacological therapy.

If the TUNA repeat rate is set to approximate the TURP repeat rate in the default mode, a slightly different pattem emerges. Specifically, when the first year TUNA repeat rate is set at 0.0131 and the repeat rate during years 2 to $S$ is set at 0.113 , the total cost of procedures falls to $3.099 \pm 0.022 \mathrm{~J}$ billion doliars. The number of procedure patients falls slightly to $390,400 \pm 2,990$. This is because procedure patients in any one year includes some repeat patients from prior years, and as the repeat rate falls, the number of patients presenting for therapy in any year's cobort of patients declines. The number of procedures performed similarly declines to $416,700 \pm 3,225$.

This sensitivity analysis of the effective TUNA repeat rate clearly indicates that if TUNA repeat rate approaches thar of TURP in prior years (recall TURP repeat rate appears to be falling), aggregate costs as well as unit costs will fall.

This analysis states that the durability of a procedurally-derived result (i.e. the lack of the need for repeat procedures) can save money even in the aggregate. This occurs principally because patients are removed from the system and do not reqquire follow-up therapy for the diagnosis in question. 


\section{Modeling of CAD Treatment Using ARENA}

The platform chosen for the more detailed model was the Windows 95 compatible ARENA system. This is an elemental modeling system, meaning that one or a small cohort of patients of various composition are repetitively introduced to the model and outcomes determined on the basis of probabilistic methods. While relatively cumbersome to operate, the model has the advantage of providing fine detail. The fates of individual patients or patient cohorts can be interrogated and the status of patient cohorts at any given time can be leamed. This is different from the Analytica system, which will only produce aggregate probabilistic outcomes for the entire population or define subsets of the population.

The goal of the ARENA modeling postion of this project was to define the system of relationships between the critical factors involved in the treatment of coronary artery disease (CAD) and to develop a simulation model to provide infomation to decision makers concerning the potential impact of changes to the system such as the introduction of new treatment technologies. A simulation model is a mathematical representation of a real world system that should imjtate the behavior of the real system as long as all of the assumptions on which the model has been developed hold. Simulation is best suited for systems that are too complex for basic analytical tools, or for systems in which the interactions within the system are the focus of study. The study of the treatsnent of coronary artery disease fis both of these criteria. Although data analysis forms the foundation of any model, there are simply too many relationships involved to grasp overall behaviors and the impact of changes using analytical methods alone.

Furthermore, many of the intricate relationships within the system are not exactly known but may be uncovered by the model itself while under development.

The product chosen for this modeling task was ARENA. It is a discrete event modeling package that has been actively developed by Systems Modeling Corp since the mid eighties. It runs under either Windows 95 or Windows NT on a $486+$ computer with $16+$ MB of RAM. ARENA was developed mainly for modeling manufacturing systems. However. it is very flexible and can be used for any modeling application. ARENA is basically a $\mathrm{C}$ shell that allows the programmer to write large complex routines by simply clicking on one of an extensive library of icons and then filling in the required blanks. ARENA also accepts user-written routines in $C$ and in FORTRAN and has the ability to communicate directly with Microsoft database and spreadsheet applications. ARENA contains an extensive animation facility that allows the modeler to view displays of output while the model is running. This allows for constant monitoring of all model components, an effective aid during model development. It also contains facilities to generate most known mathernatical functions and probability distributions and has an input analyzer that can develop distributions to be used in the model directly from raw data.

Project models are designed to forecast demand for treatment, make treatment decisions and then forecast treatment outcomes and future demand based on these outcomes. 
ARENA allows the user to represent each individual patient by creating a database file to store unique demographic and clinical characteristics as well as complete treatment history. This allows us to simulate treatment decisions as well as forecast outcomes based on the complete set of significant factors as they simultaneously change over time. It also allows us to make technological changes that affect a very specific patient group. The model calculates the costs and the benefits of treatment and performs economic analysis of the treatment alternatives and the impacts of technology.

Modeling Methods

\section{Population Demographics}

The next step in modeling the treatment of $\mathrm{CAD}$ is to generate the population at risk. Analysis of nation-wide projections for invasive treatment of heart disease (not all of which is ischemic heart disease) revealed that over $90 \%$ of those currently being treated in the United States were above the age of 40 . Therefore, we restricted our study to this portion of the popu]ation [HCIA NIP 1996]. Demographic tables were extracted from U.S. Census data to get the historical distribution of age of the American population [U.S. Bureau of Census 1994]. Aging chain theory was then used to forecast the population demographics until the year 2005. Calculations were verified against 5 year interval forecasts from the Census Bureau with minimal error $(<0.05$ for any given five-year interval). This analysis revealed that the surge in the birthrate between the years 1946 and 1965 was clearly visible in the data. This finding not only verified that we are faced with a changing distribution of age in the U.S., but it also gave us very accurate estimates regarding its magnitude. The surface plot in Figure 5 jllustrates these findings. 


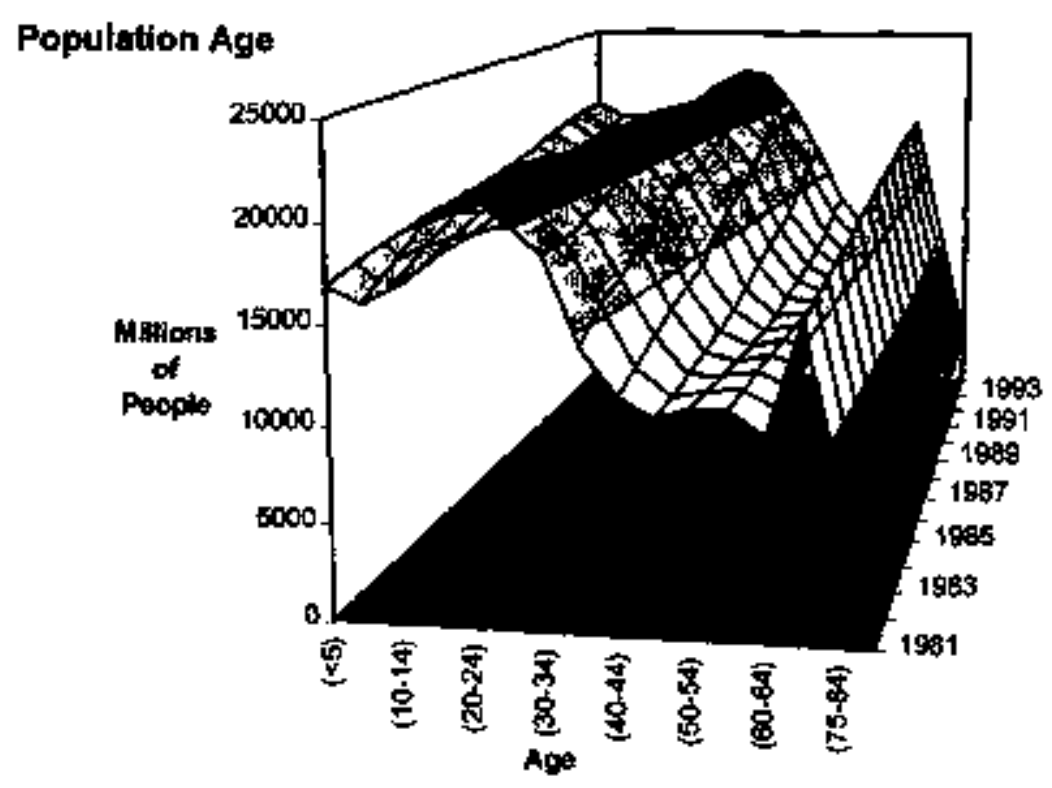

Figure 5. Distribution of age between 1980 and 1994.

The darker area represents the aging of the "Baby Boomers." From the historical trend. it is not difficult to see impact that this group has on the population. Furtheimore, the eldest members of this group are just beginning to enter the high risk age groups for heart disease. During the next twenty years the number of people at risk for heart disease will grow by $50 \%$ (by conservative estimates). Although changing social attitudes toward low fat diets, regular exercise, and cigarette smoking will at least offset the progression of heart disease, the surge in the at-risk population will still have a significant impact on demand for treatment.

The age characteristics of the population have been incorporated into the model in the form of an 8X15 variable array named PopulationDemographics. The at-risk population (40+) has been divided into eight age groups: 40-44, 45-49, 50-59, 60-64, 65-74, 75-84 and $85+$. The array contains the number of people in each age group, reported in thousands, from the years 1992 until 2006. The number of patients requiring treatment for heart disease that the population will generate is calculated based on this array.

\section{Demand for Current Treatment Methodologies}

\section{Historical Analysis}

Currentiy, experts speculate that 13 million people in the U.S. have coronsary artery disease and that between 600,000 and 700,000 are being revascularized annually with CABG or PTCA. In order to determine the historical behavior of demand, a time series for the number of procedures performed was fashioned using three data sets (see Figure 6): 
- RAND (1982-1987),

- National In-Patient Sample(1988-1991), and

- H.C.I.A. National Inpatient Profile (1992-1994).

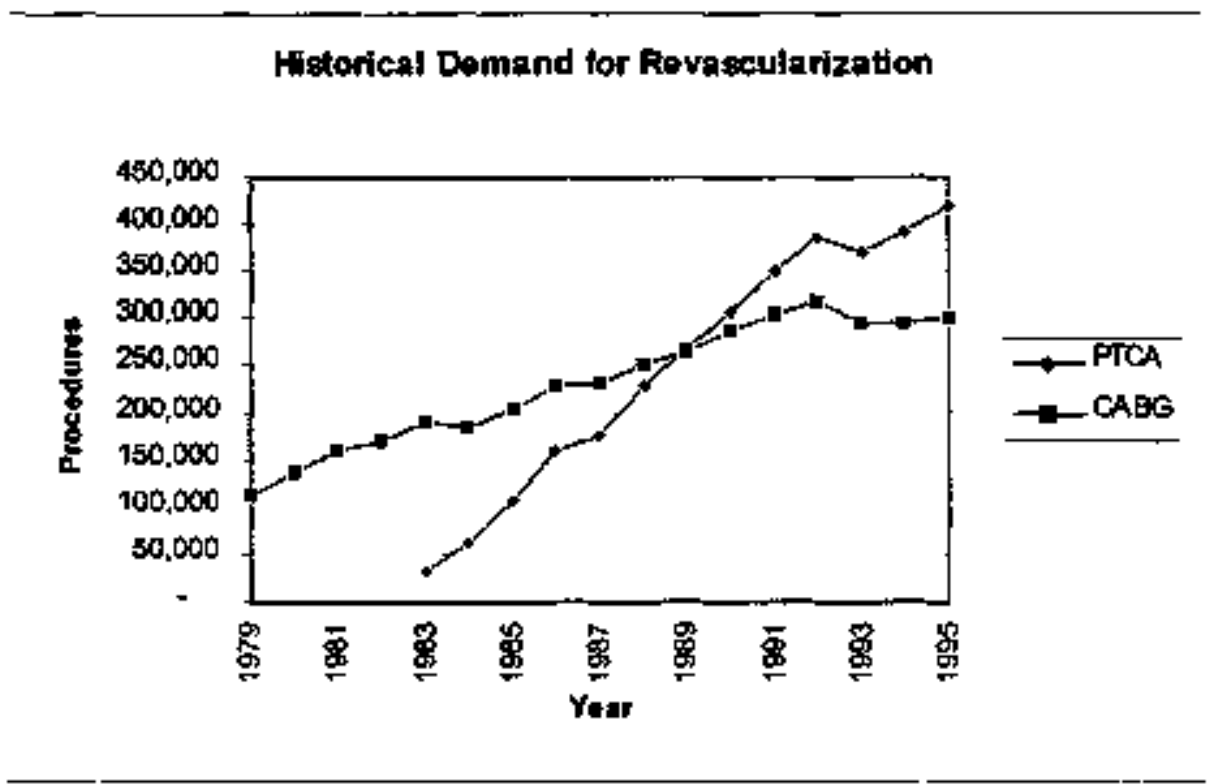

Figgure 6. Historical demand for revascularization.

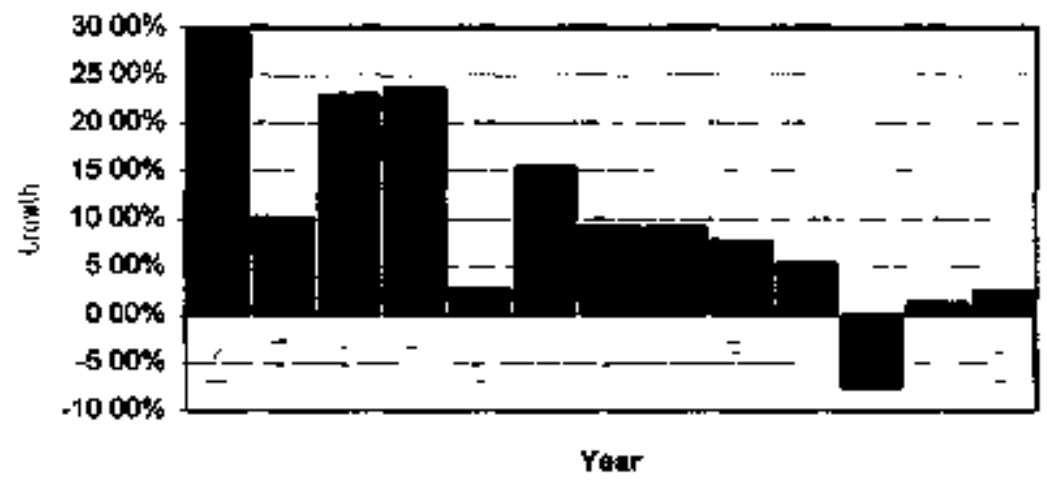

Figure 7. Growth of the PTCA market share.

Next, we controlled for population growth and compared the annual change in the growth rate of demand. This technique is more typically called a market share analysis. Some interesting patterns began to emerge for both procedures. First, as shown in Figure 7, the rates of change for demand for PTCA plotted from 1983-1995 follow a growth pattem which is extremely similar to the growth section of a standard product or technology cycle as it reaches maturity. Also, we know that the first PTCA was performed in 1976, so we can see that it has taken roughly 20 years to reach a point near market saturation. 
This analysis gave us feasibility ranges for both the market growth pattern and the time until market saturation for a newly introduced, invasive, and technologically-intense health care product.

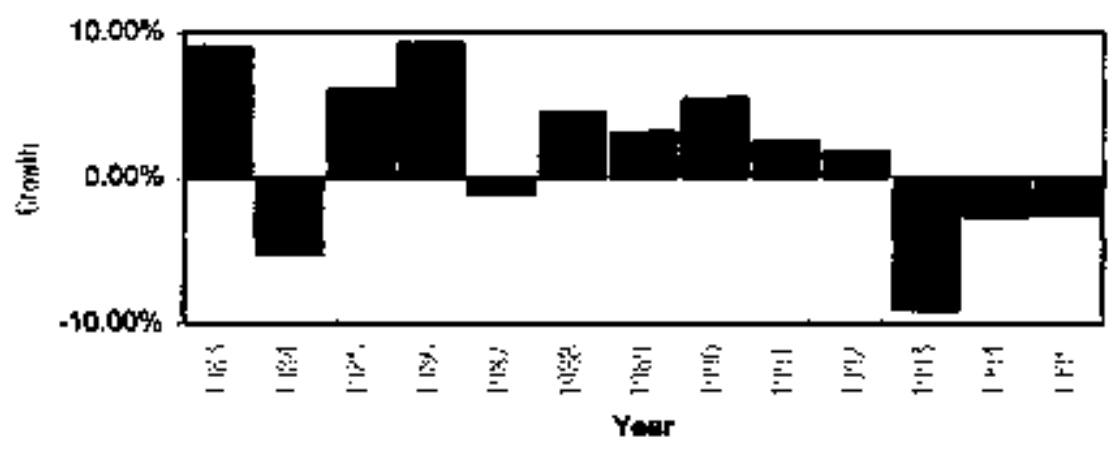

Figure 8. Growth of the CABG market share.

The same analysis was performed on the number of CABG procedures, and the rate of growth remajned between $+10 \%$ and $-10 \%$ over the entire interval (see Figure 8 ). This is very similar to the range of growth at the end of the interval for PTCA shown above. Therefore, it appears reasonable to assume that this random pattem represents random market variation around a baseline level of saturation for these types of procedures. Also, during this period, PTCA and CABG (with very little variation) comprised all cardtac revascularization procedures, making them mutually exclusive and collectively exhaustive choices for treatment at any one time (rare patients will require an emergency CABG immediately following a failed PTCA). Furthermore, if we assume no inappropriate use of these procedures due to supply induced demand, we can then say that their combined usage represents the rate of baseline necessity for invasive cardiac revascularization. This is used as a baseline for modeling future demand.

\section{Modeling}

Modeling demand is a twe step process. In the model, demand is ultimately determined by the decision module and by functions of the individual technologies. However, it is also necessary to first be able to control the number of patients entering the system within a reasonable range. The baseline necessity is calculated and then adjusted with linear combinations of a series of growth functions that mimic the historical pattems of PTCA and $C A B G$. Baseline rates are adjusted for first year failure rates for both procedures to avoid double counting. Three functions were written to represent changes in demand using uniform probability distributions with parameters within a certain feasibility range:

- StableMarketGrowth increases demand randomly between $10 \%$ and $20 \%$,

- MarketSaturation exactly imitates the behavior of CABG growth shown above, and

- StableMarketDecline decreases demand randomly between 0\%-10\%. 
The parameters of each of these three functions can be redefined by the user and they can be combined with logical expressions to represent an infinite number of demand scenarios.

We thought that, in order to more accurately predict potential changes in future demand it was necessary to determine what makes these changes occur. At this stage, the model will give us accurate estimates of future demand. However, the model lacks the level of detail necessary to predict changes in demand from factors other than changes in population number and the effectiveness of the procedures themselves. Although these two factors are a major proportion of demand increase, we must decompose the components of demand further. There are several underlying factors driving the nationwide demand for invasive healthcare procedures. First, there are regulations that constrain the demand for procedures prior to each state approving the technology. Next, there are the organizational factors within the hospital that determine whether each facility will acquire the new technology once it has been approved. Organizational factors include the number of specialists working within the hospital that desire the new technology and the capital budgeting policy of the owners concerning the requisition of new equipment. Competition from other area hospitals that possess the new technology as well as fear of malpractice suits for not using technologies (that may now be considered the most appropriate) will influence these capital budgeting decisions. Another factor that has a serious impact on demand is the method of payment for the new technology, which in most cases is based on the generosity of insurance coverage. When reimbursement for a technology is generous and prompt, the procedure will be used much more readily than a technology whose reimbursement is regulated by insurance companies or where reimbursement may be unsure due to lack of insurance coverage [Cutler 1996].

The current economic situation in the treatment of heart disease is quite complex. First, the growth in the number of hospitals acquiring PTCA as a new technology seems to have slowed with very similar behavior to the growth of total utilization of PTCA. Governmental regulation is no longet an issue, as PTCA has been avajlable in the marketplace for long enough to be approved in all states where its use in desired. It is possible that PTCA has simply reached a ievel of total saturation; but it is also likely that the growth of PTCA is being slowed by economic pressures. Managed care organizations are applying extensive pressure to the level of reimbursement by scrutinizing hospital costs and by competitively shopping heath care products. At first, one might assume that these factors when combined will cause a definite decline in the number of PTCA procedures. However, there are more confounding factors involved. The number of cardiovascular specialjst practicing in the United States has grown at twice the rate of other specialties and, according to our consultants, has quite probably grown to a level beyond necessity [U.S. Bureau of Census [995]. Although the over-saturation of cardiologists may be accepted as fact, the impact that this phenomenon will have on future demand is still unclear. Many of these specialists will simply retire early, and many will be retrained. However, the clear issue is that the number of practicing cardiologists is going to decrease gradually over time until a more appropriate 
equilibrium is reached. Therefore, it has been realized that it may be more appropriate to test the model under linear combinations of the various market condition functions written from the historical demand analysis rathet than to attempt to mathematically predict this complex and definitely ambiguous set of relationships.

\section{Treatment Deciston Module}

When cardiac revascularization becomes necessary, the decision of which treatment will be used is much more complex than it may appear on the surface. It depends a great deal on the demographic and clinical characteristics of the individual patient as well as their complete treatment history. The treatment decision must also be dynamic, having the ability to represent changing attitudes toward altemative treatments from the patient point of view and the physician's point of view. It must also be able to reflect the knowledge that will be gained from long-term clinical outcomes research. The decision whether to treat with CABG or PTCA is made using an adaptation of proportional hazards theory [Marshall 1994]. Many of the beta coefficients are calculated as a functions of time, and several coefticients are calculated based on the outcomes of the model itself. The probability of the individual patient having CABG vs. PTCA once revascularization becomes necessary is calculated using the following equation:

$$
\begin{aligned}
P(C A B G \mid X)= & \frac{\exp \left(\alpha+\beta_{1} x_{1}+\beta_{2} x_{2}+\beta_{3} x_{3}+\ldots \beta_{n} x_{n}\right)}{1+\exp \left(\alpha+\beta_{1} x_{1}+\beta_{2} x_{2}+\beta_{3} x_{3}+\ldots \beta_{n} x_{n}\right)} \\
\text { Where } \quad & \\
& X=\left\{x_{1} x_{2} x_{3} \ldots x_{n}\right\} \\
& X \text { is assumed to be the complete set of factors affecting this decision }
\end{aligned}
$$

$$
\exp \left(\beta_{i}\right)=\frac{a_{i}^{*} d_{i}}{b_{i}^{*} c_{k}}
$$

\begin{tabular}{|l|c|c|}
\hline & \multicolumn{2}{|c|}{ Patient Charsteristic } \\
\hline Outcome & Present & Absent \\
\hline CABG & $a_{1}$ & $\bar{b}_{1}$ \\
\hline PTCA & $c_{i}$ & $\bar{d}_{1}$ \\
\hline
\end{tabular}


Static and Dynamic Trentment Decision Factors

Table 12. Static and dynamic treatment decision factors.

\begin{tabular}{|c|c|c|}
\hline \multicolumn{3}{|c|}{ STATIC TREATMENT DECISION FACTORS } \\
\hline Patient Demographics & Odds Ratio & B \\
\hline Age (40-59) & 0.65 & -0.43 \\
\hline Age $(60-64)$ & 1.01 & 0.01 \\
\hline Age $(65-69)$ & 1.20 & $0.1 \overline{8}$ \\
\hline Age $(70-74)$ & $1 . \overline{35}$ & 0.30 \\
\hline Age $(75+)$ & 1.25 & 0.22 \\
\hline Patient Clinical Characteristics & Odds Ratio & $\beta_{i}$ \\
\hline Male Gender & 1.20 & 0.19 \\
\hline Single Vessel Disease & 0.02 & -3.78 \\
\hline Double Vessel Disease & 5.98 & 1.79 \\
\hline Triple Vessel Disease & 11.52 & $\overline{2.44}$ \\
\hline Four or More Vessels & 16.44 & 2.80 \\
\hline Left Main Disease & 9.79 & 2.28 \\
\hline$\overline{\mathbf{N Y}}$ Angina Class I \& II & $0 . \overline{87}$ & -0.14 \\
\hline NY Angina Class III \& IV & 0.69 & -0.37 \\
\hline Ejection Fraction $>\mathbf{5 0} \%$ & 3.06 & $1.1 \overline{2}$ \\
\hline Comorbid Conditions & Odds Ratio & $\mathrm{B}$ \\
\hline Diabetes & 1.24 & $0.2 \overline{1}$ \\
\hline PVD & $1 . \overline{06}$ & 0.06 \\
\hline COPD & 1.00 & 0.00 \\
\hline TIA & 1.32 & 0.28 \\
\hline Hypertension & 1.18 & 0.16 \\
\hline Hypercholesterolimia & $0.8 \overline{5}$ & -0.17 \\
\hline \multicolumn{3}{|c|}{ DYNAMJCTREATMENT DECISION FaCTORS } \\
\hline Treatment History & Odds Ratio & B. \\
\hline Previous MI & 4.89 & 1.59 \\
\hline Recent MII (30days) & 1.00 & \\
\hline Acute $\overline{M I}(\bar{C}$ arrently) & $1 . \overline{00}$ & \\
\hline Prior PTCA & 0.54 & -0.61 \\
\hline Prior CABG $<=1$ & 0.26 & -1.34 \\
\hline Prior $\mathrm{CABG}=2$ & & \\
\hline Prier CABG $=3$ & & \\
\hline
\end{tabular}




\section{Abstract Trestment Decision Factor Routines}

\section{Level of Invasiveness of Treatment}

This variable was developed to emulate the patient's aversion to invasive treatment. Using a focus group of two cardjologists and a thoracic surgeon, a simple scoring system was developed so that treatment alternatives could be compared from the patient's point of view. CABG was given a score of 10 , which was decided would be the maximum. PTCA was given a score of 4 , and Mini-CAB, a minimally invasive bypass procedure currently being initiated, was given a score of 7 . These scores are manipulated into the logistic regression format (by comparing their magnitudes), and a coefficient is calculated to influence the treatment decision toward the less invasive procedure. It should also be noted that the patients probably gauge the level of invasiveness for a procedure by the average length of the hospital stay. If all other factors are equal, every patient will desire the least invasive procedure. Therefore, there must be a factor to be used as a counterweight to effectively represent reality. (Every patient does not choose the recommendation to have a PTCA). The other half of the treatment trade-off is the knowledge of the long term effectiveness of the procedure in the individual patient. In most basic terns: "How much is it going to hurt?" vs. "How well is it going to work?"

\section{Knowledge of Long-Term Treatment Outcomes}

It was necessary to incotporate components into the model so that the treatment chosen would be influenced by the results of the long term success rates of the procedures. This is done by incorporating a variable into the treatment decision that is based on the results of the model itself. Ten-year event-free survival rates of PTCA and CABG are logistically regressed, and the coefficient is used in the initiat treatment decision as weil as in the treatment decisions contaired in the outcomes modules. The magnitude of this coefficient has been constrained to reflect the presence of the learning curve. (The results of a ten year cohor study would not be available for 10 years. However, there would be preliminary reporting that would give some indication of the final results.) Because the treatment decision is in many different places in the modet which represent different points in history. it has been written as a function of time so that each decision module will make the appropriate decision for its particular point in the future.

\section{Potential Changing Practices in the Treatment Alternatives}

Until recently, the use of PTCA was considered appropriate only in cases of a single blockage and in cases in which the patient was not suitable for surgery because of acute myocaritial infarction or comorbid conditions. An analysis of the 1994 HCIA National Inpatient Profile showed that $85 \%$ of PTCA procedures coded were perfotmed on a single 
artery. Furthermore, partially tue to the fact that CABG is not considered appropriate to treat a single blockage except in the case of the left main coronary artery, we found that $90 \%$ of procedures performed on single vessel disease were PTCA. More recently, PTCA has gained acceptance for use in multiple vessel disease. This potential change in practice may be evolving for several reasons. First, the catheters used in PTCA have seen technological advancements, giving cardiologists the ability to reach more arteries. Second, because PTCA is much less invasive than CABG, it is a very attractive alternative to the patients when presented with the options. It may be due to the growth in the ntmber of cardiologists in America. No matter what the reason, the current literature on the treatment of coronary artery disease is replete with randomized clinical trials comparing the outcomes of PTCA and CABG in multiple vessel disease.

The coefficients for the number of diseased arteries bave been made variable and are recalculated annually. Routines have been written that will bring PTCA and CABG usage to a user-defined equilibrium over a user-defined period of time. Each year, the regression coefficients are driven asymptotically closer to 0 , making the treatment decision indifferent to the number of vessels diseased. This gives us very accurate emulation of the phenomenon that will take place if PTCA becomes more accepted in the treatment of multiple vessel heart disease. We performed logistic regression of the HCLA Patient Level Data from All-Payer States [HCIA PLD 1996]. The results revealed the number of vessels diseased to be the mosi statistically significant of all of the independent factors as well as the coefficients with the largest values. This analysis verified that the number of arteries diseased is the most important factor in the decision whether PTCA or CABG is chosen as a treatment.

\section{Treatment Outcomes Module}

\section{Basic Structure}

There were many issues involved with modeling medical treatinent outcomes. The first issue concerned the length of the time frame that would be used. When modeling population dynamics, it is necessary to be able to represent the entire lifetime of each individual, and therefore their complete lifetime of treatment. The amount of time between the age of the average heart disease patient and average "all cause" mortality in America is about 25 years. There was no shortage of detailed information on long-term outcomes for both PTCA and CABG in the medical literature. However, the longest study for CABG was 15 years [Weintraub 1994] and the longest for PTCA was 12 years [Mick 1994]. Fortunately, event rates for both procedures were extremely regular and fell well within the limits of what couid be considered mathematically predictable. Also, plots of outcome curves for both PTCA and CABG were uniform across many studies. 


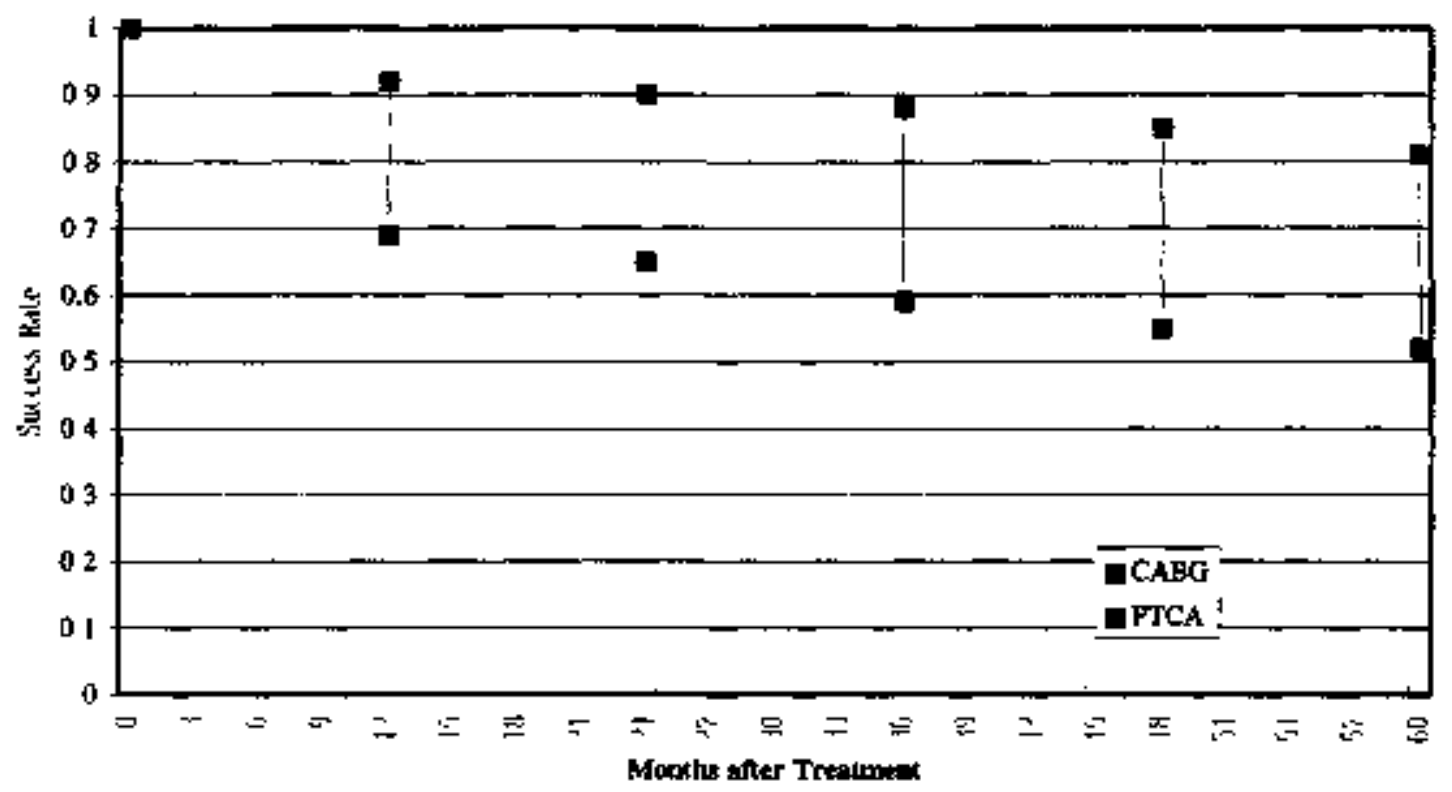

Figure 9. Event-free survival after treatment.

At this point several differences in the outcomes for theșe two procedures became apparent. First, the rate of myocardial infarction after both procedures is very similar. Second, the rate for repeat procedures after PTCA and the rate for repeat procedures after CABG are very different. The first year failure rate for PTCA is consistently reported between $20 \%$ and $30 \%$, and for $C A B G$ it is between $5 \%$ and $10 \%$ (see Figure 9 ). By 5 years, the probability of failure for PTCA has risen to over $50 \%$ in most studies, and the probability for failed CABG has remained below $20 \%$. The standard reporting method for procedure outcomes monitors the proportion of the treatment population of the population free from major post treatment events, which exactly defines the inverse of the "first failure" event rate. For PTCA and CABG, post treatment events are defined as myocardial infarction, repeat PTCA, repeat CABG and death. The difference in the points plotted above represents the difference in effectiveness between CABG and PTCA, or from a purely mathematical viewpoint, the proportion of post treatunent cardiac events that could be avoided if CABG were used exclusively.

Many of the studies provided data (for each of the four post procedural events) for the population broken down by many of the patient characteristics of interest. This allowed us to again use proportional hazards theory to more accurately predict outcomes given the characteristics of the individual patient. The modeling theory used for the outcomes module was designed to be identical to the cohort studies used in its development. At certain tine intervals, each patient is checked for status and, based on historical cohort studies and their given set of characteristics, they will either remain free from cardiac events or they will not (dichotomy). A standard decision tree process is used to represent this consept. The one drawback of proportional hazards theory is that it is based on a 
terminating event. The theory does not necessarily hold for multiple events, probebly because with multiple events there is some level of dependence that must be defined [Blackstone 1996]. There has been exceilent work in this area. However, no exact solutions are known. We handled this situation by runing the model (assuming independence) and constraining the risk of future events until a verifiable distribution of lifetime events prior to mortality was reached. It should be noted that this could be a way to determine the level of dependence between multiple cardiac events and may warrant further investigation.

\section{Effects of Technology on Treatment Effectiveness}

Since the long tem outcomes of various technological improvements for PTCA and CABG are still unknown, it is most appropriate to let the user define the desired level of improvement in effectiveness using the curves of the basic known technology as a baseline. There are several dimensions that must be considered when analyzing the impact that a new technology will have on treatment outcomes. First, there is the maximum potential reduction in the cardiac event rate that new technology will have. Second, this potential must be constrained to effectively represent infusion of the technology into the marketplace. Third, it must also be constrained by the learning curve to represent the fact that more experienced specialists produce better outcomes results. Logistic growh equations using the maximum potential effect as a threshold were used. Examples are givan below for the impact of cardiac stents.

\section{Calculation of Treatment Cost}

Treatment cost for both PTCA and CABG are estimated using the HCIA data set which provided discrete distributions of charge (quartiles) for each ICD-9 procedure code [HCIA PLD 1996]. These discrete distributions were then converted to continuous charge functions in an attempt to create a more accurate representation of the original data. Cost must be calculated from charge using global cost-to-charge ratios. It was necessary to use a bottom-up order in our analysis because health care research report findings in terms of charge, not cost. Charge is simply much easier to verify than cost. The model is set to use the global cost-to-charge ratio of 0.67 . However, this variable can be changed at the user's discretion to reflect potential cost savings.

Analysis of CAD Model Output

\section{Generating Output with the ARENA Model}

The CAD model automatically generates output reports in Microsoft Excel file format so that they be easily analyzed using a spreadsheet tool. A report template has also been inciuded so that data can be cut and pasted from a raw data file into an easily readable report. The report contains annual figures on demand, hospital charges and costs, professional fees, QALYs and net benefit. The report is divided into 8 sections: Primary 
CABG, Repeat CABG, Total CABG, Primary PTCA, Repeat PTCA, Total PTCA, Total Procedures and Dissection of Demand. A report template has also been included that will automatically generate the means and $95 \%$ confidence intervals for the entire output report.

\section{Baseline Restlts and Confidence Intervals}

The ARENA model was developed using studies from a certain technological era. Therefore, in its baseline state, it reflects the outcomes from that era. All of the routines that affect the treatment decision and the outcomes are deactivated. This scenario addresses the question, "Given zero change in technology, where will the system be in 2005?" Twenty replications of this "baseline scenario" were run and $95 \%$ confidence intervals were calculated on the output. The results are represented in the following figures.

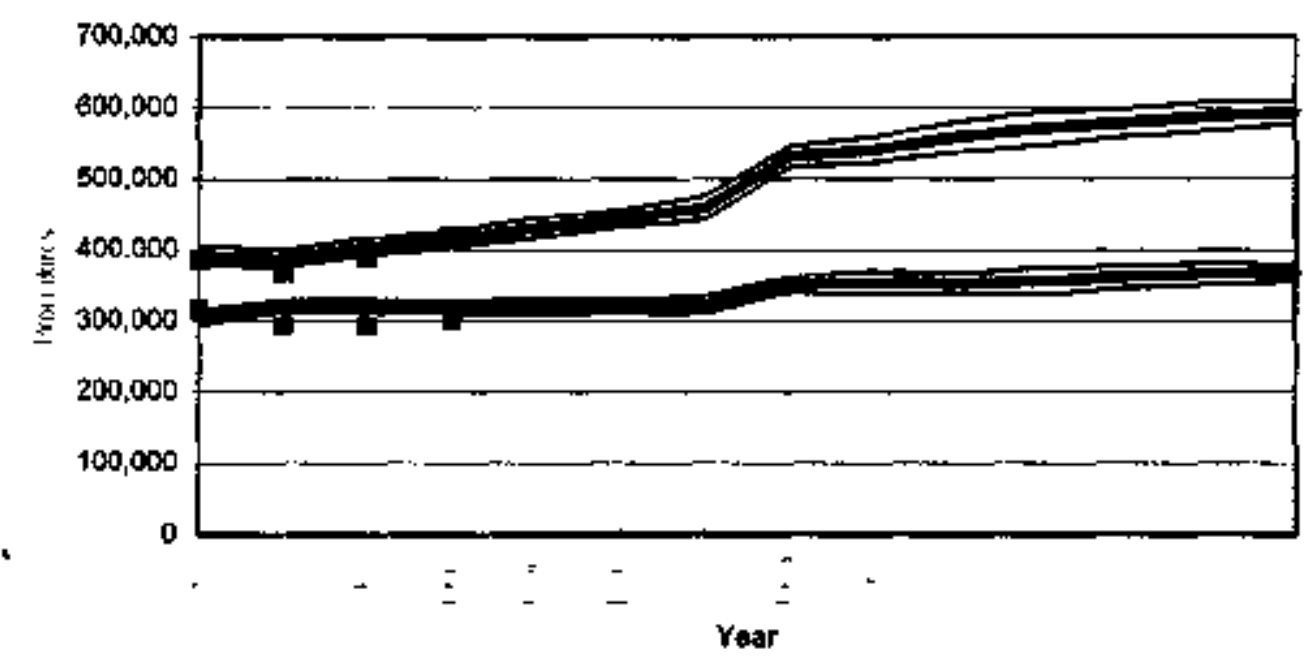

Figure 10. Demand for revascularization.

As shown in Figure 10, the model indicates that by year 2005 demand for revascularization procedures will grow to $960,153+8634$ procedures, comprised of $593,733+15,256$ PTCA (upper) procedures and $36 \overline{6}, 6+2+10,910$ CABG (lower) procedures. The plotted points represent the number of procedures taken from the historical demand analysis for the years data were available. These data verify that, at least during the period of known history, the model is working well. The thin lines, which represent the $95 \%$ confidence interval around each mean (thick tine) show how little vartation the model generates between replications. It should be noted that, at the baseline, demand is assurned to be fully saturated at 1992 rates and that increases in demand are due exclusively to population growth. 
Total Hotpplal Costs (95\% C.l.)

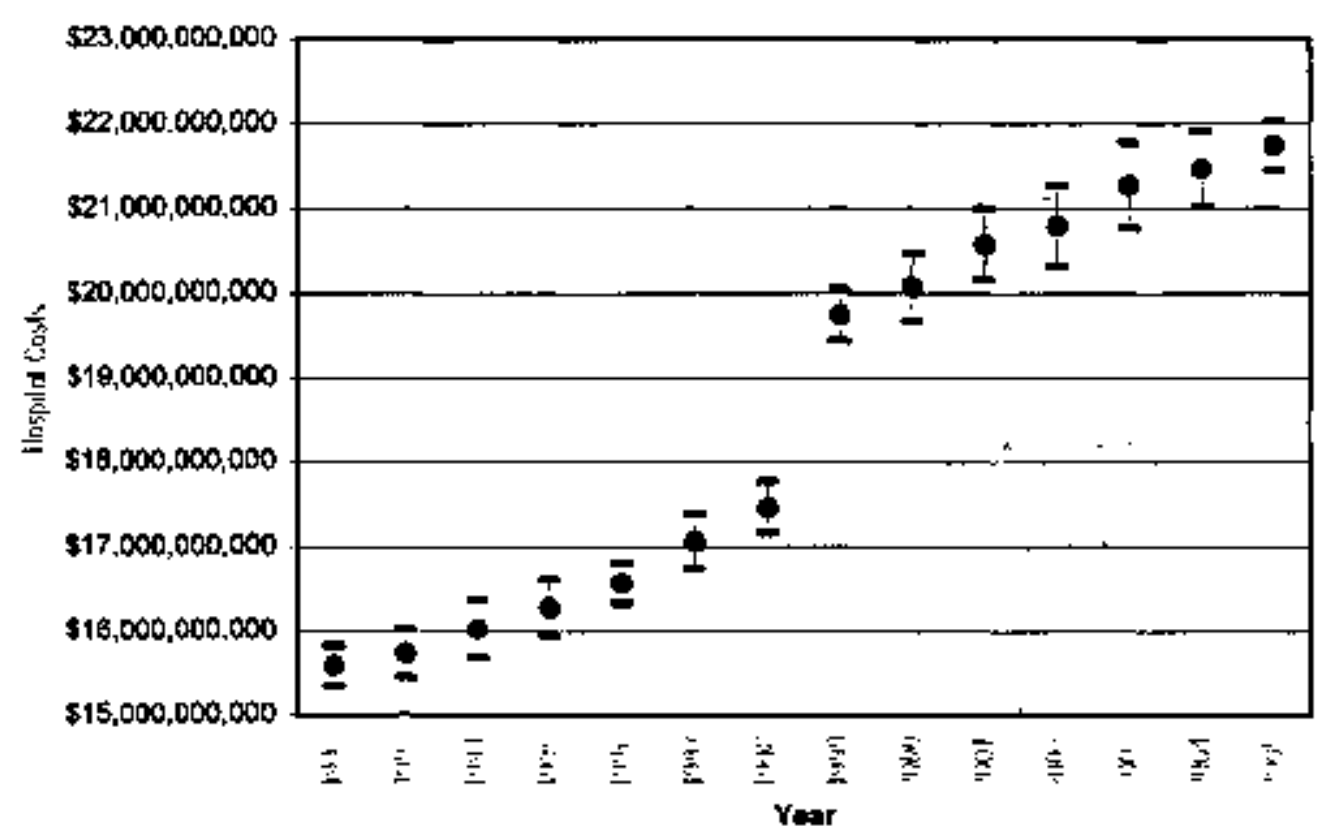

Figure 11. Hospitel costs as a function of time.

The diagram in Figure 11 illustrates the mean and $95 \%$ confidence interval on total hospital costs at the baseline. According to the model, hospital costs will rise from a current level of $\$ 17.1 \pm 0.161$ billion to $21.7 \pm 0.144$ billion by the year 2005 if technology and demand rates remain at current levels.

We have leamed from history that a new technology will increase demand for treatment and therefore increase total costs. However, if this technology has the ability to decrease treatment failure rates by a magnitude greater than the increase in denand, and retrealment is a major portion of demand, then such a technology has the potential to actually decrease demand and have a negative impact on total treatment costs. This may be the case with PTCA. Approximately $25 \%$ of all PTCA procedures performed will fail in the first year, generating demand for another procedure in the same year.

Sensitivity Analysis

\section{Potential Effects of Coronary Stent}

The literature shows that coronary stents have the potential to decrease PTCA failure rates and therefore constrain demand [Fichman 1994]. To test the impact of the introduction of the coronary stent, the following scenario was produced. We assumed that the near-perfect coronary stent would have the potential of reducing the failure rate 
of PTCA by $30 \%$. Demand was fixed at baseline rates and the model was nun, decrementing the failure rate of PTCA in $2 \%$ intervals until the near perfect $30 \%$ reduction was reached. Saturation level was set at $85 \%$, to be reached within 10 years. The learning curve was also set to 10 years and the price for the stent to $\$ 3,000$. The surface plot in Figure 12 below illustrates the impact that this scenario would have on total demand for revascularization.

\section{Impact of Stent Ettectiveness on Demand for Revascularization}

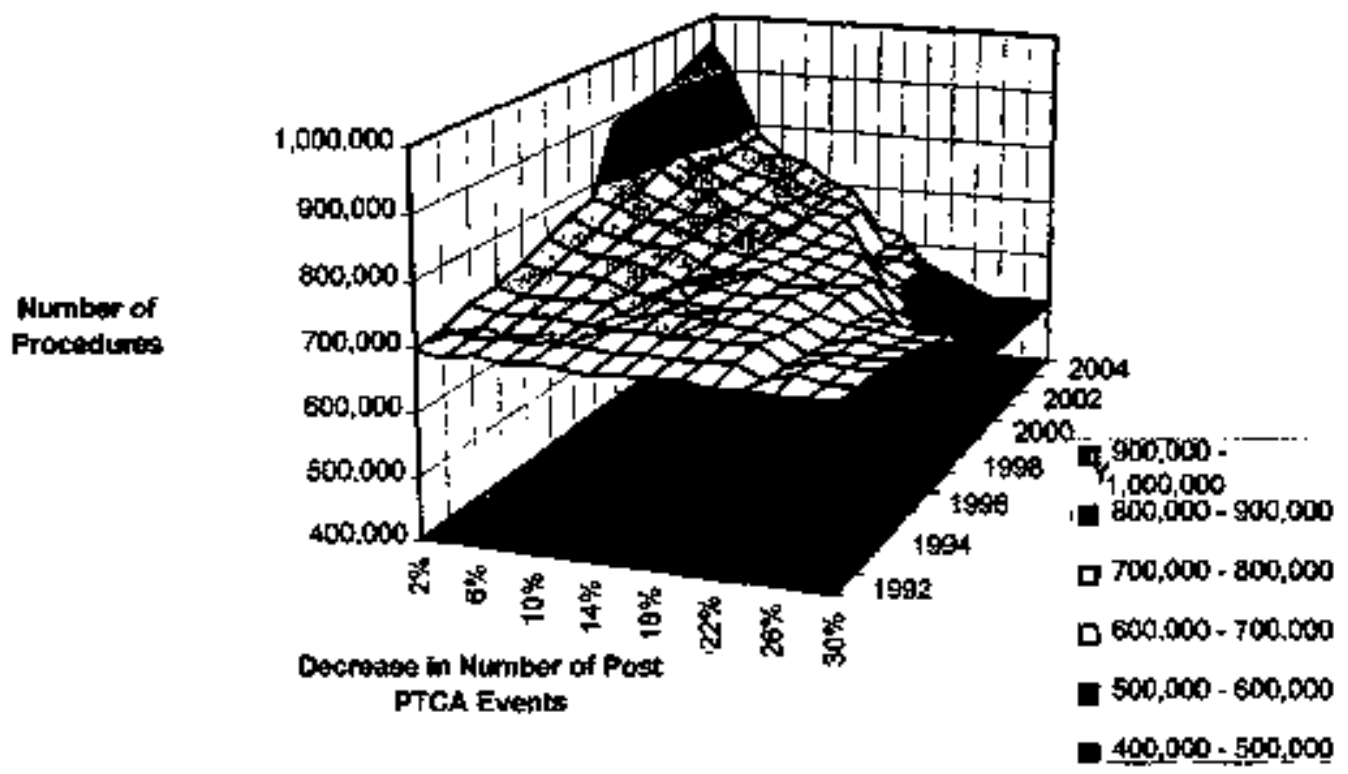

Figure 12. Impact of stent effectiveness on demand for revascutarization.

The model indicates that, by the year 2005 , demand for revascularization could be reduced to 513,000 procedures at a total cost of around $\$ 13.15$ billion. This is quite a significant decrease in demand, and cost is actually reduced from present vahues. In reality, demand cannot be constrained at current levels, and market factors will tend to obstruct the level of cost savings. Therefore, these numbers should only be viewed as indicating the potential for cost reduction along with the general magnitude of that reduction.

Sensitivity analysis was also done to test the impact of the price of the coronary stent on total cost. The stent price was reduced from $\$ 3000$ to $\$ 1500$ in increments of $\$ 200$, holding demand and current levels of effectiveness fixed. The price of the stent will have very little impact on overall cost when compared to the other factors. In fact, the average PTCA bas a mean price of $\$ 17,000$ and professional fees of $\$ 6700$, so a total unit change of $\$ 1500$ yields little savings, and incremental changes of $\$ 200$ have little effect The situation is different if multiple stents per patient are used. 


\section{Potential Effects of Laparoscopic CABG}

According to expert panel members, the Laparoscopic CABG will be very similar to a normal $\mathrm{CABG}$. It will cost virtually the same, and the average hospital stay will be decreased by only a few days (not accounting for outliers from increased hospital stays due to complications). The major difference is in the time it takes to retum to normal activity and to work. The stemum is divided during a $C A B G$ ptocedure, and it takes 6 weeks for bone to completely heal. Because the laparoscope eliminates the necessity to divide the sternum, full recovery will be achieved much sooner for most patients.

Although the Mini- $\mathrm{CAB}$ is still more invasive than $\mathrm{PTCA}$, it offers the superior outcome results of CABG. A sensitivity analysis was rum, introducing the Mini-CAB, with a 10year infusion period to reach an $85 \%$ market saturation point. Like the cardiac stent, we assumed a maximum potential to reduce post procedural events by $30 \%$ and a learning period for the new technology of 10 years. The model shows that the Mini-CAB has the potential to reduce demand to 726,900 procedures at a total cost of $\$ 17.9$ billion. (This assumes that all patients are candidates for Mini-CAB, which is currently not the case.) The impact on both demand and total cost was much less than that of cardiac stents. This was true for a number of reasons. First, because CABG has significantly lower faiture rates than PTCA, the impact made by the same rate of reduction is significantly less. Demand is 200,000 procedures lower than baseline by 2005 because a more effective substitute has been offered for PTCA, not because CABG has becone more effective. Mini-CAB requires fewer repeat procedures than PTCA, but it is more expensive.

\section{Modeling of BPH Treatment Using ARENA}

Modeling Methods

\section{Population Demographics}

The population at risk of BPH falls within the same age demography as those for heart disease. However, BPH only affects tnales. The proportion of males in the population was determined, and the base population through the year 2006 was calculated from the base population calculated for the CAD model. It should be noted that an update of the Statistical Abstract contained new tables with the level of detail necessary for our model. However, because our calculations were well within the accepted error of the forecasts produced by the Census Bureau, we left the tables unchanged.

The patient characteristics of interest in the model are the symptoms which are commonly accepted by the American Urological Association (AUA) when evaluating prostate function. These symptoms include

- nocturia (frequent urination during the night),

- dribbling,

- hesitancy,

- straining, urgency, 
- stopping and starting,

- incomplete emptying, and

- weak urine stream.

Using these characteristics, the model catculates the AUA symptom score and the AUA obstractive score [Garraway 1994].

Patient characteristics that directiy affect patient quality of life are also accounted for in the model. These include

- sleeplessness,

- the necessity of limiting fluids before bedtime and travel,

- "imiting travel to 2 hours, and

- avoidance of certain activities.

These characteristics are used to generate the AUA bothersome score, which is a widely used gauge for quality of life of patients with urinary conditions. Clinical variables of interest include the size of the prostate, the peak urinary flow rate, and the maximum urinary volume that can be retained. Estimates of the prevalence of these characteristics in the population were extracted from published population-based studies [Chute 1993].

Patient generation routines used in the BPH model are more advanced than those used the CAD model. The BPH model generates the entire male population of North America (1=1000 scale), urinary symptoms are assigned, and logistic regression is used to determine if each indjxidual has BPH. Because we are modeling the entire diseased population, prevention can now be represented, at least in terms of potential changes in urinary symptomology.

\section{Demand for Current Treatment Methodologies}

Analysis of current utilization for treatment of $\mathrm{BPH}$ was much more complex than for $\mathrm{CAD}$. Open prostatectomy and transurethral resection of the prostate are used to treat prostate cancer as well as BPH. Therefore, it was necessary to determine exactly what proportion of these procedures were being performed exclusively for BPH. An analysis of patient level data from HCIA [HCIA PLD 1996] revealed that $87 \%$ of TURP's are performed on patients for BPH only, but only $5 \%$ of Open Prostatectonies are performed on patients with BPH only (see Figure 13). A similar situation was discovered when investigating the drug treatment, because the alph-adrenergic blocking drugs (e.g. Hytrin) are aiso used as a treatment for hypertension. Utilization for both Hytrin and Proscar were determined from analysis of a report of pharmaceutical utilization ordered from IMS America, Inc. This analysis revealed several things. There has been a major decrease in utilization of the more invasive treatments for BPH. This is due in part to increased levels of education concerning the adverse outcomes associated with invasive treatment and the likely outcomes of non-procedural therapy. Medical treatments have become $\mathbf{a}$ weicome alternative, seeing growth in utilization over the same study period. In fact, the growth in drug use more than compensates for the decline in surgical procedures. 


\section{Treatunent of EPH}

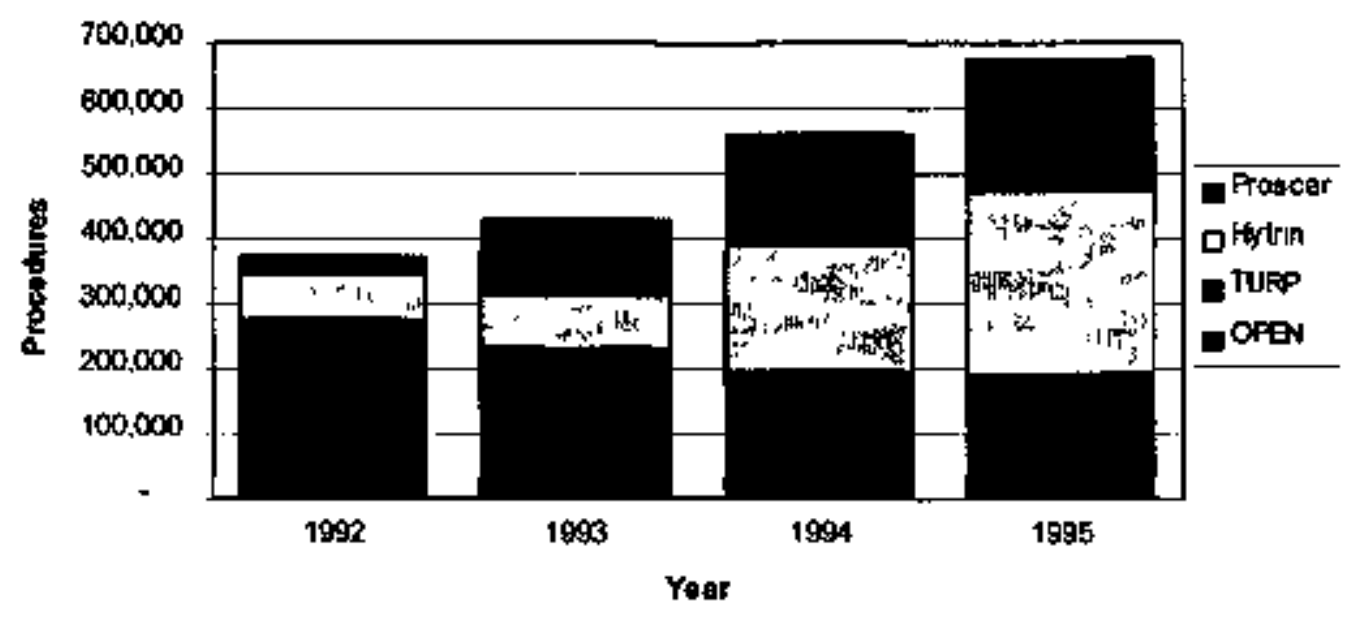

Fignre 13. Procedure distribution for the treatment of BPH.

\section{Treatment Decision Module}

Treatment selection for the BPH model differs from the CAD model in several ways. First, because BPH is not life threatening, the decision to treat becomes an issure of quality of life rather than necessity. Because of this fact, the choice of treatment (or whether to treat at all) is to a large extent determined by the individual priorities of the patient as opposed to being solely deternined by the physician (critical pathways). Also, the BPH model has eight alternatives. These include five invasive treatment options: open prostatectomy, transurethral resection of the prostate (TURP), transurethural incision of the prostate (TUIP), transurethral needle ablasion (TUNA), and transurethral microwave therapy (TUMT) as well as two drug treatment options: an alpha adrenergic blocking agent (c.g. Hytrin) and an o-reductace inhibitor, Proscar. The final alternative is to monitor the patient for worsening symptoms, but not to treat at the current time (watchful waiting). Because the treatment decision for BPH is not a dichotomous decision like the choice between PTCA and CABG, logistic regression theory does not apply. The method used is an adaptation of benefit regret analysis taken from widelyaccepted decision theory.

First, the expected benefit for each treatment altemative is calculated using the potential for beneficial outcome and the magnitude of the potential benefit. The unit measure for benefit of treatment in the BPH model is a reduction in the AUA symptom score. Next, expected regrets are calculated using the probabilities of adverse events and post treatment urinary complications for each treatment alternative. Because each individual patient has a different set of priorities, benefits and regrets are then weighted using a system developed from a ranked list of patient preferences. These scores are then constrained to reflect the level of actual knowledge (Education of Fact) available for each treatment. Benefit scores and regret scores are then combined to create a composite 
expected outcome score for each treatment. The treatments are then ranked according to score and checked for availability for each individual patient. The treatment with the highest score that is currently available is chosen.

\section{Treatment Outcomes Module}

The treatment outcomes module in the BPH model is very similar to the treatment outcomes module in the CAD model, with a few exceptions. Because there are not definite events associated with BPH, we have defined treatment failure as no change or an increase in the AUA symptom score. The time frame has also been shortened to 15 years because the average patient treated for BPH is 10 years older than the average patient treated for $C A D$. The analyst using the BPH model should be aware of the fact that long term clinical results for many of the treatments studied were unavailable. Therefore, the long-term risk of failure was mathematically extrapolated from short term studies. As long-term clinical data becomes available, the model should be updated to increase the accuracy of the results.

\section{Analysis of BPH Model Output}

Figure 14 below illustrates the number of procedures that the BPH model predicts along with the historical data (singie points of the same shape) taken from our demand analysis.

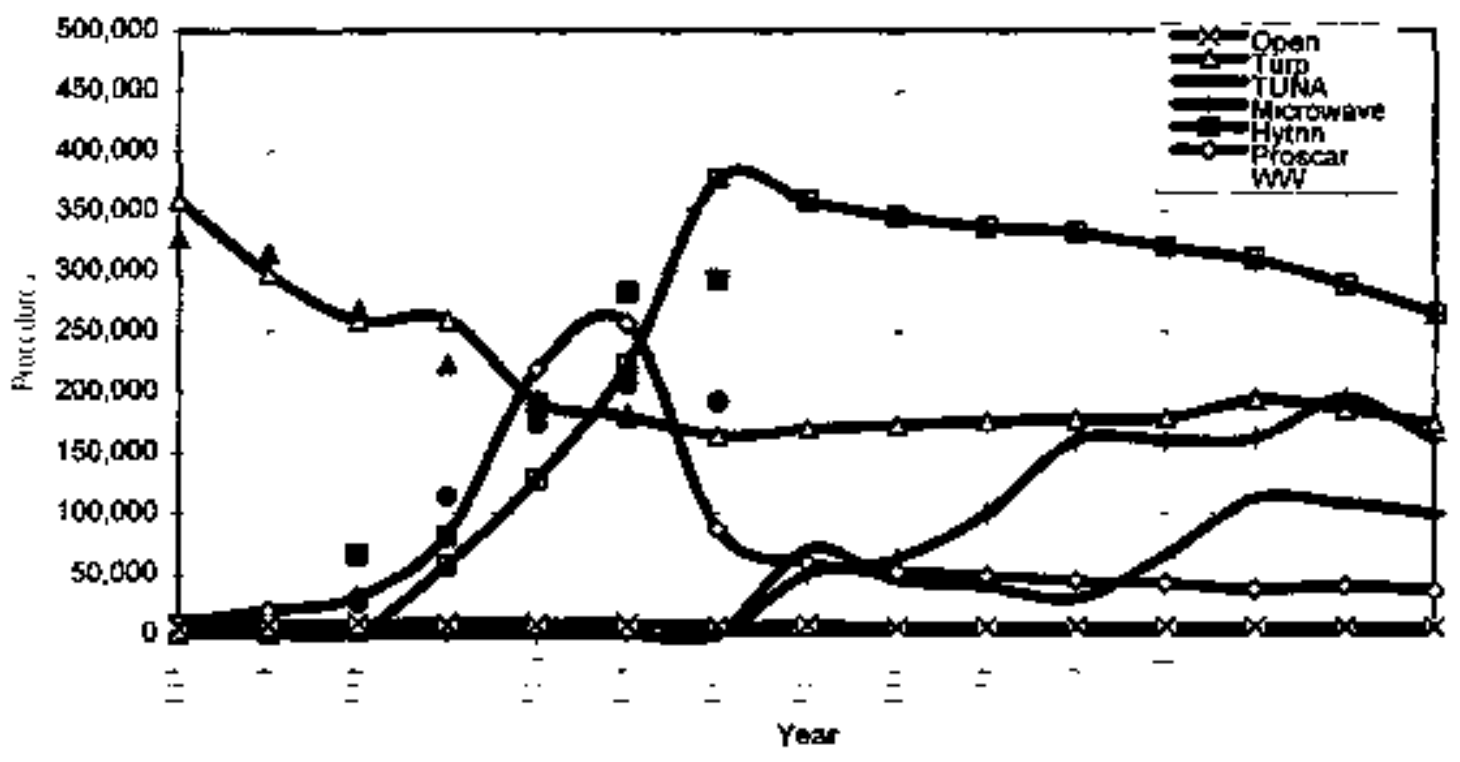

Figure 14. Validation of BPH model data.

The model predicts demand for the invasive treatments (TURP, TUIP and open prostatectomy) with excellent accuracy. The demand for the drug treatments is not quite 
as accurate, but acceptable for modeling purposes. The objective was to create the current morket framework so that the introduction of TUNA and TUMT can be stadied in this multiple alternative environment.

The model prediets that, by 2004, total demand for treatment of BPH will reach 582,300 procedures at a total cost of $\$ 1.56$ billion. Although demand for treatment has increased from a predicted 324,800 in 1990 , total cost has decreased from the predicted $\$ 1.95$ billion in 1990. This is dae in part to the introduction of cost saving TUNA and Microwave treatments. However, the majority of the savings are due to the introduction of drug treatments as an alternative to invasive procedures. With the introduction of Proscar and Hylrin, the number of TURP is reduced. This is predicted by the model and verified by the historical data. The model does not directly indicate that the potential benefits of TUNA and TUMT will decrease the number of TURP procedures further. Instead, they will become a more attractive alternative for those already being treated with drugs. It should be noted, however, that without the introduction of medical therapy for BPH, the number of TURP procedures would have continued to rise. Also, medical treatment for many patients is only temporarily effective in reducing symptoms.

Therefore, the patients being drawn from drug treatment in the latter part of the time frame to have a TUNA or TUMT are patients that would be having a TURP if the TUNA and TUMT were not available. Furthernore, they would have had a TURP originally if the drug treatments were not available. 


\section{Chapter 3 - Technology Road Mapping}

\section{Description of the Top-Down Approach}

This study's Top-Down Approach developed Btomedical Technology Roadmaps for eight innovative biomedical technology areas with the pofential to reduce U.S. health care delivery costs while maintaining (or improving) care quality.

The Top-Down Approach to the study used Prosperity Games to identify eight areas where Technology Roadmaps could be developed. Prosperity Games are executive-level interactive simulations that explore complex issues in a vartery of economic, political and social arenas. The simulation provided particjpants (about $70-80$ total) with an understanding of some of the obstacles and opportunities associated with current and proposed technologies. For example, problems and opportunities faced by doctors and other health care providers, patients, technology developers, the military, regulators, legislators, insurance agencies, lawyers, and other stakeholders in the biomedical engineering field were explored.

The Biomedical Prosperity Game was co-sponsored by the US Amy Research and Materiel Command, the Department of Defense Advanced Research Projects Agency (ARPA) and the Koop Foundation, Inc.. These co-sponsors are leaders in advancing the development and introduction of biomedical technologies. Their co-sponsorship was an important means for pooling resources to achieve each organization's similar goals for lowering the cost of and improving the quality of future biomedical technologies.

The product resulting from the Prosperity Game was a Biomedical Technology Outline along with development objectives for eight innovative biomedical technology areas with the potential to reduce care delivery costs while maintaining (or improving) care quality. The Gane's atmosphere rejinforced a consensus about the important technologies and their development objectives. It also helped develop relationships, partnerships, and a cooperative spirit among the stakeholders of the major biomedical technology and techno-policy related areas.

The Prosperity Game was followed by a Technology Roadmap workshop. The workshop was held March 1996 and was attended by about 150 persons with particular expertise in the identified biomedical technology areas. Participants in the Workshop developed the Biomedical Technology Roadmaps, which are considered to be the important deliverabte from this study's Top-Down Approach. 
The Biomedical Technology Roadmaps identified those technology advances that are needed to "leapfrog" present concepts, reduce health care costs and maintain or increase present levels of quality. The essential components of Technology Roadmaps address

- Reguisite resources,

- Cost goals,

- Quality goals,

- Time goals, and

- Critical infrastructure and core competency needs

(annong other importamt parameters) for the introduction and application technologies in the US health care system.

The Sandia tean that developed the Biomedical Technology Roadmaps has a broad, technical systems background. To date, the members of the team have addressed roadmaps for other complex issues in U.S. Infrastnucture, electronics manufacturing, environmental technology, global economic competitiveness, university business school education, the restructuring of the Department of Energy and its National Laboratories, petroleum drilling technologies, and Department of Defense sensor systems.

The broad acceptance and buy-in gained in the development of the Roadmaps by the participating stakeholders will be important for lamching the partnerships and alliances necessary for carrying out the Roadmaps. Ownership by the broader biomedical industry is key to deriving wie full benefits of the Roadmaps. Each participant in this development process has been encouraged to support consortiums and work groups that can provide the execution and follow-up of the Roadmaps. In addition, the Roadmajs could provide a framework for organizing a national initiative in biomedical engineering technology.

The following sections provide additional detail on these concepts related to the development of the Biomedical Technology Roadmaps.

\section{Introduction to the Biomedical Prosperity Game Concept}

\section{Prosperify Games simulate and explore complex isstacs.}

A Prosperity Game is a new type of forum for simulating and exploring complex issues in a variety of areas including economics, politics, sociology, environment, education, research, health care, etc. The issues can be examined from a variety of perspectives ranging from a global, macroeconomic and geopolitical viewpoint down to the details of customer/supplier/market interactions in specific industries. The concept originated in meetings with the staff of New Mexico Senator Jeff Bingaman, with Lee Buchanan of the Advanced Research Projects Agency (ARPA), and with other government and industry leaders. The conceptual implementation has been further developed by fomer Sandia National Laboratories employees, J. Pace Vandevender and Marshall Berman, to address a wide variety of applications. 
Prosperity Games are an outgrowth of move/countermove and seminar war games. They are executive-level interactive sinulations that encourage creative problem solving and decision-making, and explore the possible consequences of those decisions in a variety of economic, political and sociat arenas. The simulations are high-level exercises of discretion, judgment, planning and negotiating skills; they are not conputer games. They explore the challenges and opportunities faced by businesses, government, laboratories, universities and the public.

Ten previous Prosperity Games have explored environmental issues, economic competitiveness in electronics manufacturing and information technology, university business education, the business case for diversity, and the relationships of the Department of Energy National Laboratories. This was the first Game designed to address biomedical technologies. A recent Prosperity Game also explored national security jssues affecting U.S. Infrastructure

\section{Gaming Theory}

In mathematics, game theory is the study of strategic aspects of situations of conflict and cooperation. Game theory approaches conflicts by asking a question as old as games themselves: "How do people make 'optimal" choices when these are contingent on what other people do?" (see Brams 1993). Game theory originated with the mathematician John von Neumann as early as 1928 . The collaboration of von Neumann on theory and Oskar Morgenstern on applications to economic questions led to the seminal book The Theory of Games and Economic Behovior (see von Neumann) that first appeared in 1944, and was later tevised in 1947 and 1953. Game theory is an approach to developing the best strategies to beat a competitor or enemy.

\section{The Bionedical Prosperity Game involved look-ahead strategies}

A game is defined by a set of rules that specify the players, their desired goals, allowed interactions, and a method of assessing outcomes. There can be one or more goals with different levels of inportance. The players adopt strategies, and the interactions of the "moves" based on those strategies lead to outcomes which may or may not be consistent with the players" goals. Complex games involve look-ahead strategies that address the different possible moves that an opponent could make. It is important to try 10 understand an opponent's goals in ordet to maximize the probability of a favorable outcome. Games can be sequential, with player interaction allowed between moves.

\section{Objectives of the Biomedical Prosperity Game}

The Biomedical Prosperzty Garne ${ }^{\circ}$ produced the following specific and general accomplishments: 
Identify critical technology issues that affect the cost and quality of health care.

SPECIFIC ACCOMPLISHMENTS:

- Identified advanced/critical technology issues that affect the cost and quality of health care.

- Explored the development, patenting, manufacturing and licensing of needed technologies that would decrease costs while maintaining or improving quality.

- Identified policy and regulatory changes that would reduce costs and improve quality and timeliness of health care delivery.

- Identified and applied existing resources and faciitities to develop and implement improved technologies and policies.

- Developed a Biomedical Technology Roadmap for industry and government cooperation.

\section{GENERAL ACCOMPLISHMENTS:}

- Developed partnerships, teamwork, and a spirit of cooperation among health care consumers and providers, researchers, regulatory agencies, industry, government, and other staketolders in the heaith care system.

- Increased awareness of the needs, desires and motivations of the different stakeholders.

- Brought conflict into the open and managed it productively.

- Explored long-term strategies and policies.

- Provided input for possible future legislation.

- Stimulated thinking.

- Provided a potentially life-altering learning experience.

The Game explored biomedical technology simulaneously from three points of view, that of consumers, providers and the nation. The consumers represented patients and their problems (including diseases and disabilities), costs for services as well as insurance, treatment options, and overall quality of care and quality of life. Al providers and related organizations involved in health care were represented including doctors, hospitals, research organizations, manufacturers, and the problems they encourtered such as costs, delivery systems, regulations, research and development, etc. Since health care costs constme $14.1 \%$ of US gross domestic product and $18.5 \%$ of total public spending, this area is of utmost importance to the nation. Health care costs are also reffected in the costs of all products and services, and affect our ability to compete internationally. Hence, private and public representatives of national stakeholders (including legislators, insurers, government customers and payers, lawyers, etc.) where included in the Game.

Over the course of the Game, patients developed diseases, disabilities, and aging problems that where treated by doctors and nurses using available technologies, and new technologies developed during the Game. Suppliers, manufacturers, congressional 
representatives, researchers, national laboratories, regulators, lawyers, insurance companies, finance, and news media played their real-life roles.

Resuls of the Game were combined with the expertise of a large group of health care professionals and stakeholders to create Technology Roadmaps for the future of the health care system in biomedical engineering.

\section{Biomedical Prosperity Game Description}

\section{Biomedical Prosperity Game Teaming Groups}

The Garne incorporated eleven basic teams:

- Consumers representing patients from ail demographic groups in the US.

- Two Provider teams. One representing independent physicians and hospitals and IPAs (Independent Practice Associations) who bill on a fee-for-service basis, and the other representing Health Maintenance Organizations (HMOs).

- Insurance Payers representing private and public (Medicare, Medica:d) insurance organizations. Large companies were also represented in their role of insurance providers.

- Legislators representing the US Congress and State legislatures.

- Suppliers/Manufacturers representing companies that make and sell biomedical devices and equipment.

- US Food and Drug Administration and State Regulators

- Planning/Funding Organizations representing the private and public (including the Department of Defense, National Science Foundation, private foundations, etc.) organizations that provide resources to fund research and development of new biomedical technologies and that perform strategic planning.

- Universities/Laboratories that perform the research and development of new technologies.

- Lawyers that provide consulting and legal assistance to all parties.

- A Control Team that directed the conduct of the Game, resolved all disputes, and played all other roles required in the Game including that of financial institutions, news media, scientific publications, foreign countries, polling, computing, etc.

It should be noted that every Prosperity Game is unique because the outcomes depend on the players. Players were selected to represent their real-life roles as faithfully as possible. Their creativity and commitment to the simulation determine the success of the Game. 


\section{Technology Areas Addressed by the Biomedical Prosperity Game}

The players were encouraged to develop innovative technologies across a broad set of biomedical technology areas. These areas were grouped into the following preliminary categories as a starting point for the ptayers' consideration:

1. Advanced diagnostics

2. Assistive technologies for the elderly and disabled

3. Energy delivery devices (lasers, ultrasound, etc.)

4. Health Informatics

5. Mieroelectronics and sensors

6. Minimally invasive therapies

7. Outcomes research tools

8. Telemedicine

Technology includes the results of engineering analysis, design, and materials; and product development entailing hardware (electronic, mechanical, electro-mechanical), software, and systems approaches. Drugs were not specifically investigated in the Game. However, if a team decided that drugs were the only viable approach, it was noted in the Game records.

\section{Policy Areas Addressed by the Biomedical Prosperity Game}

Our goal was not to reform the entire medical system. Rather, these policies address ways to improve the processes involved in funding, developing, testing, approving, and marketing new technologies with special emphasis on reducing costs while increasing the quality of care. A list of Biomedical Technology-Related Policy areas includes:

1. Legislative changes, regulatory improvements and reforms

2. Government incentive programs

3. Information surety and security

4. Tort liability reform

5. Metrics and systems for evaluating the costs and increases in health care quality resulting from the introduction of new technologies

6. Funding allocation systems

\section{Biomedical Prosperity Game Execution}

The primary Game objective was to explore existing and future biomedical technologies, with emphasis on lowering costs and maintaining quality. This exploration required highly skilled players with a strong krowledge of the biomedical field, the ability to read and digest a significant amount of information, and the confidence to make decisions, observe their consequences, and alter their decisions accordingly.

The design of the Game guided the assembled stakeholders from the broader US Health Care System to improve care delivery through improved technology, as demonstrated by: 
- Cost reduction through the introduction of cost-effective technology,

- Unacceptable physical consequences of inadequate technology,

- Political pressure on the Legislative Team to reduce the cost of health care and increase care delivery productivity, and

- Rewarding cooperation for the development of innovative biomedical technologies.

The Game's play ran in four sessions on the first day of the Game event. The four sessions addressed the future time epochs from January, 1996 to the end of 2003, a compression of eight years into one and a half days. This time compression of 2000:1 (1 Game minute -1.5 days) means that many aspects and issues were treated very approximately. The Game's design was intended to qualitatively capture these concepts to assist decision makers in tunderstanding today's environment and the possibilities of significant future improvements. This learning process was used to build a Biomedical Technology Roadmap which incorporates vechnical and policy changes that will ultimately benefit the nation with lower costs and high quality health care.

The central theme of the Game, as in real life, was the relationship between the patients (Consurner Group) and health care delivery professionals (Providers Group) in the event of accident, illness, disability or aging. The patients were provided with

Disease/Disability (hereafter denoted as D/D) cards that described their assigned age and symptoms. The D/D cards listed:

- Treatment options that are avaitable in the year(s) designated by particular Game session,

- Placeholders for new technology-based treatments that may be developed during the play,

- Various possible outcomes and associated probabilities, and

- Estimates of direct treatment costs and long-term costs to society by either dying, remaining ill, or completely recovering and returning to the workforce.

As the Game progressed in time, additional technology treatment options were created to update the technology treatment placeholders on the cards.

Several diseases and/or disabilities (due to illness, accidents, battlefield casuatties, or aging) were defined for each of the technology areas, and these provided the basis for the D/D cards. The cards addressed at most four possible generic outcomes with associated probabilities and returns on investment for working life up to age 65 (these outcomes being modified according to the particular D/D). Life expectancy was assumed to be 75 for all patients. D/D cards were given to individual consumers describing their condition and treatment options. In addition, the Provider teams were given "team" D/D cards representing global health care problems that needed to be solved by their team (e.g., breast cancer sereening or disaster evaluation and triaging).

For the initial Game sessions, only current technologies were available as treatment options. All new technologies had to be developed either through Technology and Policy Toolkit Options or through the natural processes of the Game (i.e., research, 
development, patenting, licensing, clinical testing, regulatory approval, manufacturing, marketing, gaining insurance coverage, etc.). During play, the care providers delivered care to their patients, choosing among the available treatment options, taking into consideration the patient's insurance and income, overall health, and any other considerations deemed important.

For the latter Game sessions, the Control team kept the providers abreast of the newly developed and licensed technologies, including costs, and possible outcomes and their probabilities. All new technologies included costs associated with research and development.

The Game simultaneously explored two dynamic systems: the health care delivery system and the technology development and marketing system. The delivery system encompassed three tightly knit teams: consumers, providers and insurers. The consumers had discretionary income that could be used to purchase health insurance and save for personal expenses such as premiums or copayments. The private insurers spread the risk among the mix of bealthy and sick people and sought to make a profit. Government insurers covered a segment of the population including the elderly and the poor. Providers delivered health care directly to their patients and also sought to profit from their labors.

The technology system encompassed the researchers and those who funded research, the suppliers and manufacturers, and the regulatory agencies. Their objectives were to create new technologies and products that are safe and effective, and deliver them to the health care providers.

The legislators strongly influenced both systems. They provided a large fraction of the money needed in health care delivery/consumption. They also supported research and development of new and improved tectnologies. They could also set national objectives and policies for a large fraction of the health care expenditures.

Lawyers also played roles in both systems. They could be involved in litigation between any of the stakeholders (e.g., malpractice suits, product liability litigation, etc.). They could also assist in securing and defending intellectual property rights, lobbying, and mediating disputes.

The primary "move" in the Game was represented by an agreement or contract. These agreements were negotiated among two or more teams and had to represent an exchange of value for value. If the agreements involved uncertain future outcomes, these were determined probabilistically by the Control team. The agreements had to be accompanied with money that was transferred between partners. Two secondary "moves" included investments in Toolkit options, and D/D cards with their associated outcomes, costs, and quality evaluations. 
All tearns were provided with a list of near-term and long-term challenges. This information, coupled with the experience and expertise of the players, launched them into the real-world simulation of the Game. The Game was "won" by successfully meeting the prescribed challenges and accomplishing the long-term objectives of the teams and individual players. Players sought to accomplish their goals following the most realistic altematives available.

Figure 15 illustrates some (but certainity not all) of the possible interactions that could occur during the Grame execution. This experiential process developed the relationships and provided the inputs and innovative thinking that were used in the development of the Biomedical Technology Roadmap.

Figure 3.1. Schematic of Some Possible Team Interactlons

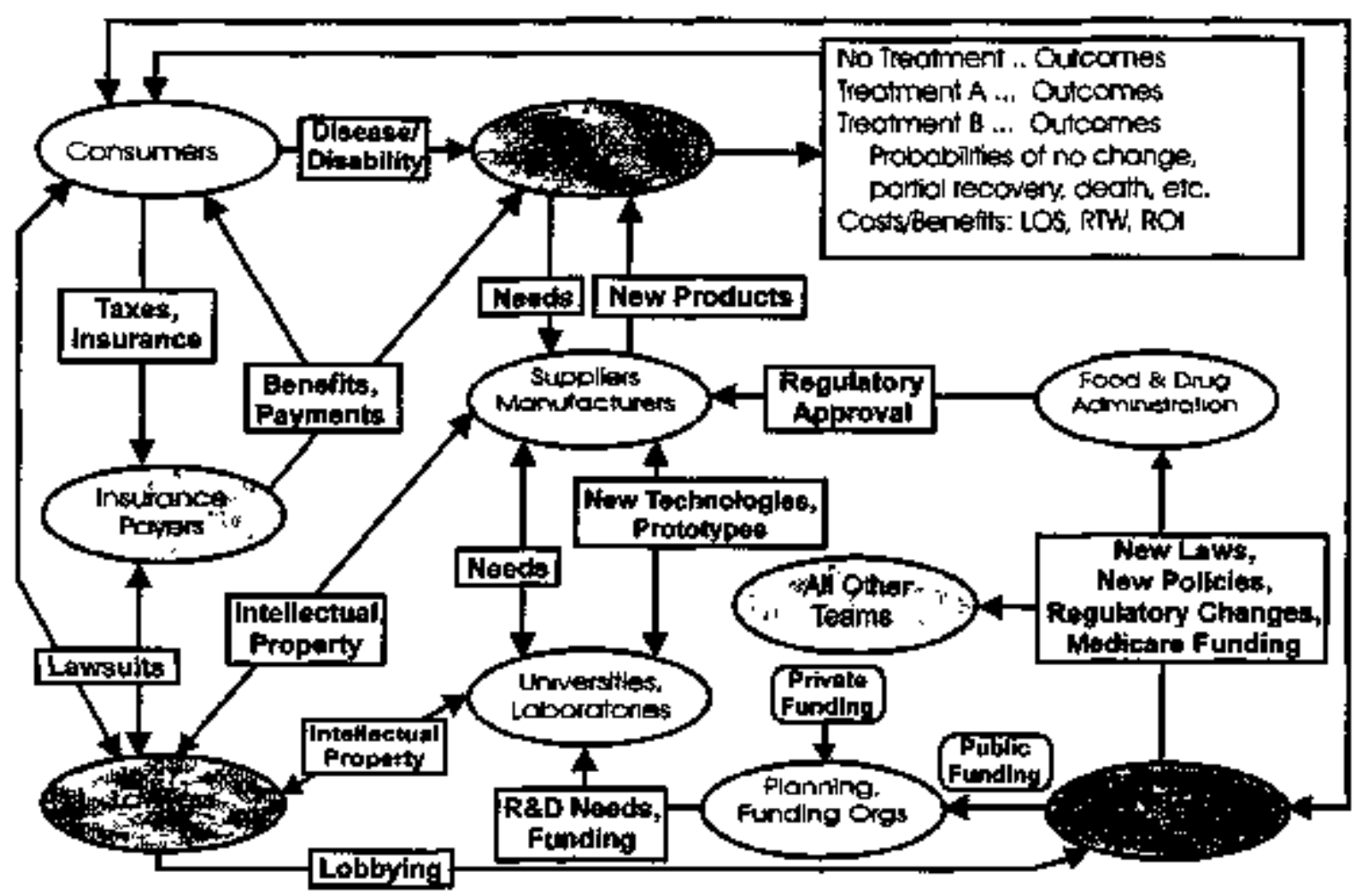

Mamontzistas

Figure 15. Schematic of some possible team interactions.

\section{Technology Development Process}

Table 13 iliustrates the full process for technology development, licensing and marketing as it currently exists. Changes and improvements in this process were accomplished in the Game by negotiating agreements among all affected stakeholder teams. Al] determinations of future results (e.g+, successful research, successful clinical testing, etc.) were decided probabilistically after assigning a mean investment and mean time. In the 
context of the Game, all specified long-duration events (such as conducting clinical trials) were assumed to have already been accomplished in the event of a successful outcome. Representatives from all negotiating parties had to bring the agreements and money to Control for acceptance, probabilistic determinations, and confirmation.

Table 13. Standard Process for Technology Development

\begin{tabular}{|c|c|c|}
\hline Action & Affected Teams & Move \\
\hline $\begin{array}{l}\text { Funding agencies get } \\
\text { money for desired } \\
\text { R\&D }\end{array}$ & $\begin{array}{l}\text { Legislators, Funding Orgs, } \\
\text { Universities/Labs, et al. }\end{array}$ & $\begin{array}{l}\text { Agteernents - money } \\
\text { transfer }\end{array}$ \\
\hline Disburse funds & $\begin{array}{l}\text { Funding Orgs, Universities/Labs, } \\
\text { et al. }\end{array}$ & $\begin{array}{l}\text { Agreements - money } \\
\text { transfer }\end{array}$ \\
\hline Perform R\&D & $\begin{array}{l}\text { Universities/Labs, } \\
\text { Suppliers/Manufacturers }\end{array}$ & $\begin{array}{l}\text { Agreements - } \\
\text { probability assigriment } \\
\text { and dice roll; possibly } \\
\text { money transfer }\end{array}$ \\
\hline $\begin{array}{l}\text { Secure intellectual } \\
\text { property rights }\end{array}$ & $\begin{array}{l}\text { Lawyers, Universities/Labs, } \\
\text { Suppliers/Manufacturers, Control } \\
\text { tearn }{ }^{\text {II }} \text { patent office }\end{array}$ & $\begin{array}{l}\text { Agreements - money } \\
\text { transfer }\end{array}$ \\
\hline $\begin{array}{l}\text { Negotiate terms (time, } \\
\text { cost, etc.) of clinical } \\
\text { testing and conduct } \\
\text { trials }\end{array}$ & $\begin{array}{l}\text { FDA, Universities/Labs, } \\
\text { Suppliers Manufacturers }\end{array}$ & $\begin{array}{l}\text { Agreements - } \\
\text { probability assignment } \\
\text { and dice roll; possibly } \\
\text { money transfer }\end{array}$ \\
\hline Ge1 FDA approval & $\begin{array}{l}\text { FDA, Universities/Labs, } \\
\text { Suppliers/Manufacturers }\end{array}$ & $\begin{array}{l}\text { Agreements - possible } \\
\text { money transfer }\end{array}$ \\
\hline $\begin{array}{l}\text { Manufacture } \\
\text { technology and } \\
\text { products }\end{array}$ & $\begin{array}{l}\text { Suppliers/Manufacturers, Control } \\
\text { teaun }\end{array}$ & $\begin{array}{l}\text { Agreements - money } \\
\text { transfer }\end{array}$ \\
\hline $\begin{array}{l}\text { Sell tecknology to } \\
\text { providers }\end{array}$ & $\begin{array}{l}\text { Suppliers/Manufacturers, } \\
\text { Providers }\end{array}$ & $\begin{array}{l}\text { Agreements - money } \\
\text { transfer }\end{array}$ \\
\hline $\begin{array}{l}\text { Convince insurers to } \\
\text { cover treatment costs }\end{array}$ & $\begin{array}{l}\text { Suppliers/Manufacturers, } \\
\text { Providers, Insurers }\end{array}$ & $\begin{array}{l}\text { Agreements - money } \\
\text { transfer }\end{array}$ \\
\hline
\end{tabular}

\section{Measure of Game's Care Quality}

In the Gane, the quality of care was measured by a short questionnaire supplied to the patients and their care delivery professionals. The questionnaire was incomporated on the back side of each D/D card and addressed the following topic areas:

- the reasonability of cost,

- the efficiency of treatront,

- the appropriateness of treatment.

- the minimization of risk, 
- the adequacy of technology utilized,

- overall patient satisfaction, and

- whether the treatment improved the quality of life.

Each player answered the questions independently, and the results were tabulated and identified for each D/D state and treatment option.

\section{Measure of Game's Care Cost}

A simple algorithm was developed that incorporated information from the D/D cards into estimates of costs as a function of time in the Garne. Costs included initial treatment, hospital stay, other costs and retum on investment. The costs to develop and introduce "new" technologies were also included. The algorithm was intended only to provide a rough qualitative estimate, and perhaps guide further, much more comprehensive econometric research

\section{Disease/Disability Card Description}

The D/D cards were developed by Dr. Fidel Davila of the Scott \& White Clinic, Texas A\&M College of Medicine, Temple, TX. In addition, Drs. David Rattner, Steven Dawson, and Elizabeth Mort from the Massachusetts General Hospital (MGH) provided card design suggestions conceming coverage of pervasive disease states, potential treatment uptions and probabilities, and outcomes considerations. Sandia National Laboratories constructed a basic set of Technology and Policy Toolkit Options, which, when chosen for development during Game execution by a single or collection of Game Tean(s), were added to the D/D cards' available treatment options. A later section provides further details on the initial set of Technology and Policy Toolkit Options. These Toolkit Options were reviewed and augmented by Drs. Davila and Rattner.

The D/D cards served the following functions in the game:

- Introduced the players to the pervasive diseases and disabilities addressed by the health care delivery system,

- Listed the costs of conventional and advanced treatment options,

- Estimated the costs to develop new technologies,

- Illustrated probabilities of positive and negative patient outcomes and how these outcomes might improve with advanced technologies, and

- Estimated the potentiat return on investment which is dominated by the ability of the consumer to return the productive working population or to reduce the fiscal drain on the health care system.

There were $32 \mathrm{D} / \mathrm{D}$ cards available in the game, as shown in Table 14 . Twenty four of these applied to individual consumers (patients) and eight to the provider teams. DID cards 6, 7, 8, 21, 22, 25, 27, and 30 applied to the Provider teams. These cards focused on the potential benefits of diagnostics and prevention in the early detection of diseases 
(e.g., cancer screening). They also explored the process for adopting new procedures in a conservative $\mathrm{HMO}$ system, and the approach to desling with majot disasters.

Table 14. D/D Cards, Insurance Type, and Patient Descriptions

\begin{tabular}{|c|c|c|}
\hline DDO01 & Private & Adverse Drug Reaction \\
\hline $\mathrm{DDO} 2$ & Private & Diffiuse Atherosclerosis \\
\hline DD03 & Gov. & $\begin{array}{l}\text { Massive Battlefieid } \\
\text { Injuries }\end{array}$ \\
\hline DDO4 & Private & Knee Osteoarthuitis \\
\hline DD05 & Gov. & Blindness \\
\hline DD06 & Provider & Breast Cancer Screening \\
\hline DDN7 & Provider & $\begin{array}{l}\text { Cancer Screening } \\
\text { Interpretation }\end{array}$ \\
\hline DD08 & Provider & Colon Cancer Screenting \\
\hline DD09 & Private & Heart Replacement \\
\hline$\overline{\text { DD10 }}$ & Private & $\begin{array}{l}\text { Insulin Dependent } \\
\text { Diabetes Mellitus }\end{array}$ \\
\hline DD11 & Gov. & Hearing Loss \\
\hline DD12 & Gov. & Hip Fracture \\
\hline DDI3 & Gov. & Home Bound Patient \\
\hline DD14 & Private & $\begin{array}{l}\text { lschemic Heart Disease } \\
\text { Diagnosis }\end{array}$ \\
\hline$\overline{\mathrm{DD}} \overline{5}$ & Private & $\begin{array}{l}\text { Jschemic Heart Disease } \\
\text { Treatment }\end{array}$ \\
\hline$\overline{\text { DD16 }}$ & Gov. & Kidney Faidure \\
\hline DD17 & Gov. & Liver Replacement \\
\hline$\overline{\mathrm{DDl} 8}$ & Private & Lung Cancer \\
\hline DD19 & Private & Lung Replacement \\
\hline$\overline{\mathrm{D}} 20$ & Gov, & $\begin{array}{l}\text { Medication } \\
\text { Compliance/Monitoring }\end{array}$ \\
\hline$\overline{\mathrm{DD} 21}$ & Provider & $\begin{array}{l}\text { New Information } \\
\text { Dissemination }\end{array}$ \\
\hline DD22 & Provider & New Procedure A toption \\
\hline DD23 & Private & Paraplegic \\
\hline$\overline{\mathrm{DD} 24}$ & Private & Premature Birth \\
\hline DD25 & Provider & Prostate Cancer Screening \\
\hline$\overline{\mathrm{DD} 26}$ & Gov, & Quadriplegia \\
\hline DD27 & Provider & Skin Cancer Screening \\
\hline$\overline{\mathrm{D} D} 28$ & Gov. & Tissue Diagnosis \\
\hline DD29 & Private & $\begin{array}{l}\text { Unknown Critical } \\
\text { Information }\end{array}$ \\
\hline DD30 & Provider & $\begin{array}{l}\text { Disaster Evaluation and } \\
\text { Triaging }\end{array}$ \\
\hline DD31 & Gov. & Burn debridement \\
\hline DD32 & Gov. & Threatened tarly delivery \\
\hline
\end{tabular}


For individual patients, the following represented a typical set of outcomes:

\author{
Outcone \\ None (death ot no change) \\ Poor (invalid; unable to work) \\ Partial (able to work part time) \\ Complete (full recovery)
}

\author{
Return on Investment \\ $\$ 0$ \\ $-\$ 20,000$ per year for expected \\ remaining lifetime \\ $+\$ 10,000$ per year until age 65 \\ $+\$ 30,000$ per year until age 65
}

These outcomes and returns were used for post-game analysis of the impact of technology on medical casts. They illustrate the potential benefits to society of returning patients to the work force or reducing costs for long-term care. An example of a D/D card for "Diffuse Atherosclerosis" is shown in Figure 16.

An examination of the "Diffuse Atherosclerosis" card reveals the return-on-investment and treatment option potentials by advancing biomedical technologies. The estimated frequency of the atheroscletosis condition is about 100,000 cases per year in the US. Currently available treatments include balloon angioplasty and bypass surgery. There is a significant probability of no change or death for both of these procedures. Furthermore, patjents may be required to return for additional treatment or surgery in a few years, even if the surgery is successful. Optien T33 is a laser device that completely removes atherosclerotic lesions (see Toolkit Option T33). The development of this technology posed the potential for reducing total treatment costs by a factor of five, and tripled the probability of complete recovery for about eight years. The expected return on investment (sum of the products of probability times total return on investment per outcome) for bypass surgery was $-\$ 78,000$ per patient. With the laser technology, the return was $+\$ 64,000$. Hence, over the time span of interest ( 1 to 8 years), the net return to society for the laser treatment (assuming 100,000 patients) would be $\$ 6.4$ billion

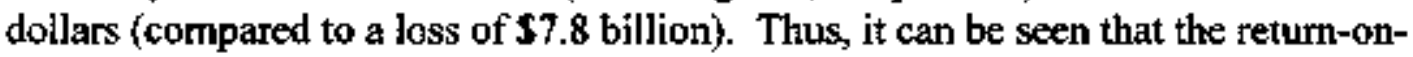
investment far exceeds the assumed initial technology development cost of $\$ 80$ million. 


\begin{tabular}{|c|c|c|c|c|c|c|c|c|}
\hline $\operatorname{CARD} 2$ & \multicolumn{5}{|c|}{ DIFPUSE ATHEROSCLEROSIS } & \multicolumn{3}{|c|}{ 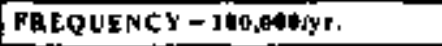 } \\
\hline \multicolumn{9}{|l|}{ 15 your old, pronte ingurnate } \\
\hline Pupleni: & \multirow{4}{*}{\multicolumn{8}{|c|}{ 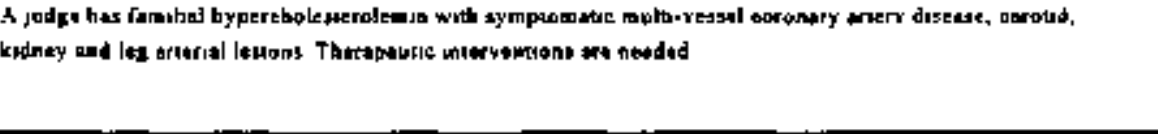 }} \\
\hline \multirow[t]{3}{*}{ Q } & & & & & & & & \\
\hline & & & & & & & & \\
\hline & & & & & & & & \\
\hline \multirow{2}{*}{ Tronoment opirone } & $\begin{array}{c}\text { Tout } \\
\text { tratainent }\end{array}$ & $\begin{array}{l}\text { Teehrology } \\
\text { developnitemd }\end{array}$ & & & babaliny & $\begin{array}{l}\text { Length of } \\
\text { Iecoyery }\end{array}$ & Produclat ltyi & $\begin{array}{c}\text { Total nturn } \\
\text { on }\end{array}$ \\
\hline & $\cos \pi$ & 七लम & Ounedme & H & Rerage & $0065 \quad 10 \pi 01$ & yripment & mresimeni \\
\hline \multirow[t]{4}{*}{ Balloon angerplewats } & $\pm 15,000$ & MA- & None (death) & 030. & $000+90$ & 0 & $\theta$ & $(115,000)$ \\
\hline & & & Poor & D我 & $031-069$ & 1 & (\$弓冫)_000) & $(535000)$ \\
\hline & & & Partial & 050 & $066-195$ & 2 & 510,000 & 55,0000 \\
\hline & & & Compdetr & 005 & 096.100 & 3 & 530,000 & 875.000 \\
\hline Coronxy antents bypath sarety. entetid & $\$ 100,000$ & $N_{A}$ & None (denlh) & 020 & $000<020$ & 0 & 0 & $\{\$ 100.000)$ \\
\hline \multirow{3}{*}{ and odomapal surgery } & & & Potr & 030 & 021010 & \pm & $(\$ \geq 0,000)$ & $(5140,000)$ \\
\hline & & & Purtial & 040 & 051090 & 1 & 510,000 & (560,000) \\
\hline & & & Complori & 010 & $091-100$ & 6 & 590,000 & 580,000 \\
\hline Nols eltromly avaluble & 520,000 & $580 \mathrm{~m}$ & Nọnę (deuilh) & 010 & 000.010 & 0 & 0 & $(530,0,001$ \\
\hline \multirow{3}{*}{ See opion T33 } & & & Poor . - & 820 & $011-60$ & 3. & $1520,000)$ & [5s0 óna] \\
\hline & & & 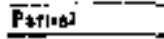 & 040 & 03100.00 & 6 & 51000 & $\$ 40,000$ \\
\hline & & & Ţ冖onplese & 650 & $0 \overline{110}$ & $\bar{\varepsilon}$ & 550,000 & $\$ 20000$ \\
\hline Nos currentiy avenable & $\$ 25,000$ & $\$ 120 \mathrm{Mr}$ & Kont (de:ah) & Dos & 0004005 & 0 & D & $(573,000)$ \\
\hline \multirow[t]{3}{*}{ Set apson T34 } & & & Poar & 020 & 006015 & + & $(520,000)$ & (\$105,000 \\
\hline & & & Partal & 035 & $26-060$ & 8 & 310,000 & 355.000 \\
\hline & & & $\overrightarrow{\text { Complate }}$ & 040 & $061+163$ & 10 & 334000 & 5275,600 \\
\hline Not currenuly gvaglabale & 525,000 & $3320 \mathrm{M}$ & None (denth) & $N A$ & & 0 & 0 & $\mathrm{NA}$ \\
\hline \multirow[t]{4}{*}{ Sed opien T9 } & & & Paor & 010 & 0.00 .010 & 5 & $(520000)$ & [3115.000] \\
\hline & & & Partio! & 030 & $0 \longdiv { 1 1 0 4 0 }$ & 10 & 510.000 & 533000 \\
\hline & & & Compiese & 060 & 041.100 & 13 & 530,000 & 5425,000 \\
\hline & & - & & & & & & \\
\hline
\end{tabular}

Figure 16. Patient Disease/Disability Card

\section{Technology and Policy Toolkit Options}

The Game Players had two ways in which they could advance the available biomedical technologies as treatment options. One means was a conventional approach that involved realjstic processes of negotiations and contracts among stakeholders. Another means presented in the context of this Game was through direct investment of options through the Toolkit Options.

The Toolkit Options were composed of a list of technology and policy options that teans and ptayers could invest in. The control team created an initial list of potential options and assigned a total resource investment required to yield a $50 \%$ probability of success to develop and introduce the option. Tearns were encouraged to determine which of these or other technology and policy options were important to address their future priorities. Investments were made by individual Teams, however, the Teams were encouraged to partner with other Teams according to mutual priorities. For newly identified options not on the iritial list, "experts" from the Game Control team assigned the amount of mean investment required to yield a $50 \%$ probability of a successful outcome. The total investments from all teans were processed and the success or failure was determined by 
random number genexation. It should be noted that investments made in unsuccessful options were permanently lost.

The outcomes of the Toolkit investments were determined probabilistically as shown by the example in Figure 17. The baseline probability increased with increasing investunent following a normal distribution with mean $x$ and standard deviation $* x$. Hence, from the example, an investment of twice the mean, $\$ 200 \mathrm{M}$, would yield a success probabitity of 0.84. To take into account factors other than total investment, a uniform distribution is superimposed on the normal distribution to reflect uncertainties and risks in the real world for accomplishing major technology or policy breakthroughs. This uniform distribution can increase or decrease the baseline probabjlity by as much as $16 \%$.

Toolkit Options provided an indication of some possible advances in technology, or policy changes that might significantly improve health care quality and tower costs. These Options were meant to encourage collaboration among the many stakeholders and to indicate the highest priority technology and policy objectives of the players.

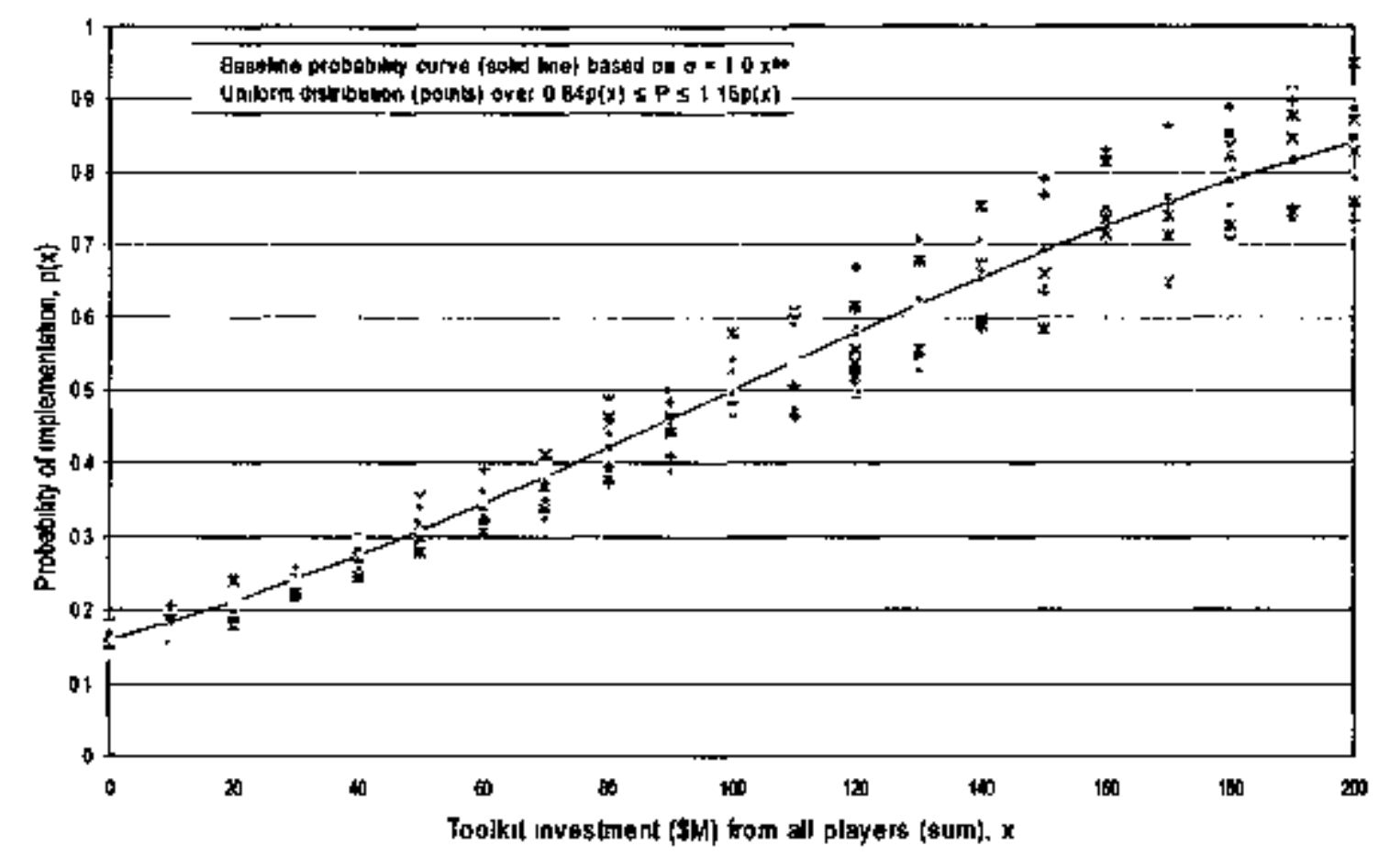

Figure 17. Probabilistic Determination of Toolkit Investments Outcomes 


\section{Gaming Dollars}

The function of money in the Game is to introduce the concept of finite resources. This forced the players to create options and assign priorities that simulated real life.

However, this Game was complicated by the fact that it dealt with individual patients and their treatments together with national issues related to government appropriations, research funding and performance, and overalt industry income and outflow. A single currency definition could not apply to all these situations and simultaneousiy provide the players with value measures that simulated reality. Hence, the Sandia Game design team designed the following system to accommodate these diverse objectives.

All the bills circulating in the game were denominated in gane dollars - \$G. Game dollars came in two colors: green and yellow. Green dollars circulated primarily among the health delivery triad - consumers, providers, and insurers. Yellow dollars circulated exclusively within the national technology development system. Conversion factors, as shown in Table 15, were assigned for crossovers.

Table 15. Conversion Descriptors for Game Dollars

\begin{tabular}{|l|l|l|}
\hline \multicolumn{1}{|c|}{ Team } & \multicolumn{1}{|c|}{ Dollar Type } & \multicolumn{1}{c|}{$\begin{array}{c}\text { Conversion for agreements, } \\
\text { contracts }\end{array}$} \\
\hline Consumers: & Green & $\$ 1=\$ 200$ \\
\hline Provider 1: lPAs, individuals & Green & $\$ 1=\$ 200$ \\
\hline Provider 2: HMOs & Green & $\$ 1=\$ 200$ \\
\hline Insurance Payers: & Green & $\$ 1=\$ 200$ \\
\hline Legislature & $\begin{array}{l}\text { Green and } \\
\text { Yellow }\end{array}$ & $\begin{array}{l}\$ 1=\$ 1 \text { for appropriations to } \\
\text { heslth insurance } \\
\$ 1=\$ 0.5 \text { million for all other } \\
\text { apptopiations }\end{array}$ \\
\hline Suppliers/Manufacturers & Yellow & $\$ 1=\$ 0.5$ million \\
\hline US FDA, Other Regulators & Yellow & $\$ 1=\$ 0.5$ million \\
\hline Planning/Funding Organizations & Yellow & $\$ 1=\$ 0.5$ million \\
\hline Universities/Laboratories & Yellow & $\$ 1=\$ 0.5$ million \\
\hline Lawyers & Green and & Depends on customer \\
& Yellow & \\
\hline
\end{tabular}

Green dollars were used by consumers and insurers to pay for treatments and insurance policies (and any legal expenses related to an individual). If green dollars were used for any expense other than treatments (e.g., providers wishing to purchase products from suppliers or invest in research), each green dollar was worth $\$ 200$.

Yellow dollars represented national expenses (research, manufacturing, etc.). In that environment, one game dollar represented $\$ 0.5$ million. The two types of dollars allowed 
the game to accurately estimate both the real costs to the patients for treatments and the real costs of research, developing, testing and manufacturing new technologies and profucts.

Table 16 indicates the funding (i.e., income) that was provided to each Team for each Game session.

Table 16. Team andi Player External Income Per Session

\begin{tabular}{|c|c|c|c|c|}
\hline Team & $1996-1997$ & $1998-1999$ & $2000-2001$ & $2002-2003$ \\
\hline $\begin{array}{l}\text { Consumers: Each player receives } \\
\text { this amount. }\end{array}$ & & $\$ 45,000$ & $\$ 48,000$ & $\$ 52,000$ \\
\hline \multicolumn{5}{|l|}{ Provider 1: IPAs, individuals } \\
\hline Provider 2: HMOs & . & & & \\
\hline $\begin{array}{rr}\text { Insurance Payers: } & \begin{array}{r}\text { Private } \\
\text { States }\end{array} \\
\text { Medicare, Other Federal }\end{array}$ & $\begin{array}{l}33.8 \% \\
64.7 \% \\
\end{array}$ & $\begin{array}{l}\text { TBA } \\
\text { TBA }\end{array}$ & $\begin{array}{l}\text { TBA } \\
\text { TBA } \\
\end{array}$ & $\begin{array}{l}\text { TBA } \\
\text { TBA } \\
\end{array}$ \\
\hline $\begin{array}{ll}\text { Legislature: } & \text { Federal }(66.2 \%) \\
& \text { States }(33.8 \%)\end{array}$ & & $\$ 180,000$ & $\$ 192,000$ & $\$ 208,000$ \\
\hline Suppliers/Manufacturers & & $\$ 800$ & $\$ 900$ & $\$ 1600$ \\
\hline $\begin{array}{l}\text { US FDA } \\
\text { Other Regulators }\end{array}$ & $0.1 \%$ & TBA & TBA & TBA \\
\hline $\begin{array}{l}\text { Planning/Funding Organizations: } \\
\text { Governument (DoD, NSF, Koop, etc.) } \\
\text { Private Foundations }\end{array}$ & $1.4 \%$ & $\begin{array}{l}\text { TBA } \\
\$ 200\end{array}$ & $\begin{array}{l}\text { TBA } \\
\$ 200\end{array}$ & $\begin{array}{l}\text { TBA } \\
\$ 200\end{array}$ \\
\hline \multicolumn{5}{|l|}{ Universities/Laboratories } \\
\hline Lawyers & & & & \\
\hline
\end{tabular}

TBA: To be appropriated by the legislators

\section{Biomedical Technology Issues and Potential Solutions}

The second day of the Game was devoted to initiating the development of Biomedical Technology Roadmaps for the technologies (and policies) promoted by execution of the Game. During the opening session on the second Game day, each Game Team identified the most important issues and potential solutions for employing technologies and related policies in reducing costs and increasing quality. The areas identified were based on reallife and Game experiences from the first Game day. Issues wete prioritized and the top one or two issues and solutions were presented to the entire group of Game participants in a plenary session. Isstres not addressed by an identified technology or policy area promoted a new technology or policy area for roadmapping. 


\section{Biomedical Technology and Policy Roadmapping}

Following the initial issues session on day two, the Game players reassembled according to gaming tables arranged by Biomedical Technology and Policy areas of primary interest. The reassembled players created a vision statement for the future of the specific technology or policy area, and then outlined the key elements for Biomedical Roadimaps. The resulting coliection of Biomedical Technology Outlines (along with key development objectives) for each important biomedical technology area became important products for further development in the Technology Roadmap Workshops.

Table 17 shows a sample template for a Btomedical Technology Outline. Following this are definitions of key terms for developing a Roadmap outline:

\section{Roadmap Development Definitions}

Vision

Champions

Objectives

Drivers

Sub-rechnologies

Sponsoring organizations

Attributes
A high-level view of the purpose of the particular technology area in health care.

People who lead, provide guidance for and participate in roadmapping exercises.

Goals identifying the future advances in the particular technology area.

Specific characteristics of technologies that must be available to achieve the desired objective.

Classes of technologies that hold promise in enabling the objective.

Potential funders, researchers, etc., related to the subtechnology classes or technology drivers.

Specifics related to the objective, such as cost, size, speed, policy, technical requirements, etc. 
Table 17. General Technology Area

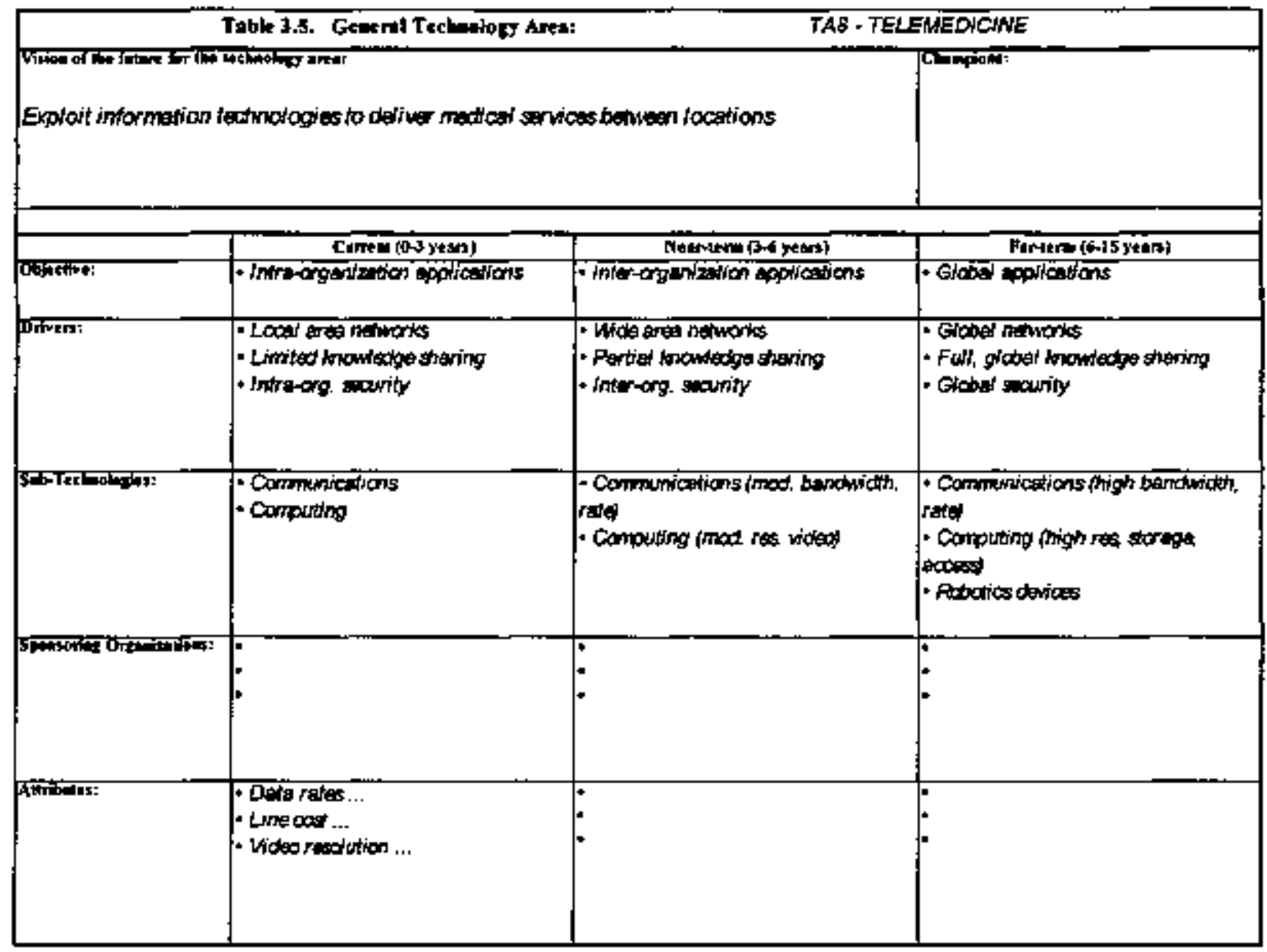




\section{Biomedical Technology Roadmap Description}

\section{Summary Goal}

This study's Top-Down Approach developed Biomedical Technology Raadmaps for each innovative biomedicat technology area with the potential to reduce U.S. health care deliveny costs while maintaining (or improving) care quality.

\section{Rationale for Technology Roadmap Development}

These Roadmaps provide important planning and forecasting gujdelines for the development and introduction of biomedical technologies with the stated cost and quality characteristics. It is intended that these Roadmaps be used to provide consensus in the research and development of the identified technologies by:

- Providing a unique tool for coordinating necessary development and application activities,

- Reducing duplication of effort in research and development efforts,

- Addressing biomedical technology challenges that may be too expensive or risky for a single organization to solve, and

- Ensuring that the broader US biomedical industry addresses the basic technology options to ensure that funure care delivery needs are met.

It is also intended that these Roadmaps provide a long range view of the future product and technology needs of the broader US Health Care delivery system. Each Roadmap is designed as a working document and may be updated as required.

Sandia National Laboratories' several roles in this Roadmapping effort were as follows:

Motivator Sandia was very committed to this effort in the national interest,

Catalyst

Builder of consensus as a quasi-governument, quasi-business entity,

Consultant Sandia's technology core competencies are compatible with the broader biomedical area,

Facilifator Sandia managed the development process, the participants owned the content, and as

Porticipont Sandia maintains unique facilities and capabilities on a "neutral" ground. 


\section{Roadmapping Methodology}

The Roadmaps developed in this study addressed the broad range of innovative technologies required to meet the health care delivery products and services of the future with the stated goals for cost and quality. Speciffe Roadmaps were developed for:

- advanced telemedicine,

- health and healthcare informatics,

- information and network surety,

- integrated predicative diagnostics,

- minimaliy invasive therapy, imaging, and energy delivery systems,

- performance measurement and outcomes research,

- preventive medicine and incentive programs, and

- rehabilitative science and assistive technologies

The following methodology presents a broad outiine that was, in some part, addressed by the roadmap development activities of this study:

1. Identify care delivery products, services, and needs,

2. Identify requirements for these needs,

3. Identify technology drivers that address these requirements,

4. Quantify these drivers' attributes (e.g., performance, cost, characteristics, etc.)

5. Establish a timeline required for achieving the attributes,

6. Determine critical infrastracture (e.g., resources, core competencies, etc.) required

7. Identify potential show-stoppers (i.e., obstacles) as weil as opportunities

8. Determine priorities for each preceding area

9. Implement within a working group, consortium, or other alliance process.

Technology development and application requirements are derived by addressing the technology user pull and the technology developer push. Eventual cost-effective products that promote quality outcomes depend on forecasting future product capabilities and the technologies required to realize those capabilities. The user is essential to forecasting the future required capabilities. Likewise, the developer is essential to identifying a comprehensive evaluation of technologies required in meeting the users' desired products.

\section{Roadmapping Events}

The events for the development and implementation of the Roadmaps took place from November 1995 through September 1996. These primary events included:

- Biomedical Prosperity Game $(B P G)$

- Technology Roadmap Workshop 1 (TRI)

- Completion of Individual Technology Roadmaps

- Completion of edit and format of Final Biomedical Technology Roadmap

Document
November 1-3, 1995

April 22-24, 1996

August 1,1996

October 15, 1996 
- Completion of print of Final Document;

November 11, 1996

Dissemination of Final BTR Document

to Individuals, Organizations and Consortiums

The Biomedical Prosperity Game initiated this process on November 1-3, 1995 at Atbuquerque, NM. Its unique format addressed the following steps of the roadmap development process:

WHO Identified leaders, sponsors, and participants, and

WHAT Established high level needs of the care delivery system and potential technology solutions atea.

The principal output of the Game, Biomedical Technology Outlines encapsulated this information.

A Techrology Workshop event was held April 22-24 1996 to advance the first drafts of each Roadmap. This first Technology Workshop event (and working groups) addressed the following steps of the process:

WHAT Provided details of high level seeds and solutions

HOW Determined infrastructure, resources, etc. required to accomplish

WHEN Established the timelines

Each of the Roadmap Champions and Work Groups submitted the final versions of the Biomedical Techusology Roadmaps by August 1, 1996. The Roadmaps were edited and formatted for final document presentation consistency. Printing of the final Biomedical Technology Roadmap document was completed by the end of November. Copiers of the final document have been disseminated to health care technology and policy stakeholders. lt is also available electronically on the DoD Telemedicine World Wide Web site at: http://www.matmo.org/news/sections/civprog/sandia.html. 


\section{Chapter 4 - Conclusions}

Modem medicine is characterized by the use and refinement of an ever-expanding array of technologies. The interrelationship of technology and medicat costs depends upon the definition of cost on the one hand and the characteristics (figures of merit) of the technologies on the other. In addition, a variety of societal factors, most particularly the demand for innovative therapy, can powerfully impact aggregate expenditures for health care. The health care planner must be aware of these often complex interrelationships.

As a first step to understanding these relationships, Sandia National Laboratories applied a systems approach to identifying innovative biornedical technologies with the potential to reduce U.S. health care delivery costs while maintaining care quality. This study was conducted by implementing both top-down and bottom-up strategies. The top-down approach used prosperity gaming methodology to identify furture health care delivery needs. This effort provided roadmaps for the development and integration of technology to meet perceived care delivery requirements. The bottom-up approach identified and ranked interventional therapies employed in existing care delivery systerns for a host of health-related conditions. Economic analysis fomned the basis for development of care pathway interaction models for two of the most pervasive, chronic disease/disability conditions: coronary artery disease (CAD) and benign prostatic bypertrophy (BPH). Soxietal cost-benefit relationships based on these analyses were used to evaluate the effect of emerging technology in these treatment areas.

The following general conclusion was reached based upon these top-down and bottom-up analyses. In general, technologies which

- produce durable results and therefore lessen the need for repeat procedures,

- limit unnecessary or less-than-optimal use of procedures (as in the case of information given to patients or phystcians),

- produce quality results at markedly reduced costs, or

- render positive both patient lifetime utility and its related economic societal benefit can reduce health care costs varjably defined. The definition of "health care cost" and the perspective from which it is defined are important in this scenario. Health care "expenditures" need not be equal to heath care "costs." When technologies currently in use are rank-ordered by dollar using Medicare-allowable charges for services, it is apparent that office visits, chest $x$-rays, ophthalmologic services, mammography, EKG, and a variety of other medical technologies are used at high cost and therefore present targets for cost reduction by the innovative use of technology.

This work indicates that additional research is required in critical study areas if the relationship between technology, health care expenditures, and bealth care costs is to be understood. Prominent among these are the nature of the increase in demand (which occurs following the introduction of a new technology), the economic value of time (both of an employed and unemployed person), the refinement of the definition of a quality- 
adjusted life year (QALY) with sufficient theoretical underpinnings to permit an economic value to be placed on a QALY, methods to accurately assess the effect of medical therapies on patient QALY's, and the exploration of the potential of managed care to direct technology usage and control demand. The following sections present concluding thoughts specific to the bottom-up and top-down economic approaches.

\section{Bottom-Up Approach: Cost-Effectiveness Analysis for Selected Disease/Disability States}

\section{Econometric Analyses}

The functionality of the models used in this study was essentially heuristic. The models clearly point out three issues which bear on the nexus of technology and health care costs. Each of these issues is worthy of future research.

First, the necessity to define health care cost is highlighted by the models. Each model recognizes that costs are both direct (payments for services rendered) and indirect (effects on society such as wages gained or lost). Therefore, it becomes clear that expenditures are not equivalent to cost. The models provide cost anatysis from the point of view of the payer as well as from the perspective of the larger society. The results of simulations are dependent not only on the cost perspec.ive assumed but also on the estimates of the costs themselves. In the case of establishing societal costs/benefits, the project team encountered the need for detemining the dollar value of a life year. Approptiate economic literature was reviewed, and team members elected to estimate this value using a revealed preference methodology. The derived figure was utilized in the coronary artery disease model for calculations of societal costs/benefits.

A second major issue raised by the modeling was the growth of demand which a new procedure can produce. Based on literature review and a review of technology usage, it became clear that new tectuology often, if not always, stimulates increased demand for its use. Therefore, even technologies which reduce unit costs often tend to increase aggregate direct costs. Various factors were identified as determinants of demand and were then included in the models so that they could be explored by analysts over time.

A third factor influencing the relationship of technology and health care costs is the assessment of guality-adjusted life years (QALY) and their economic impact. The theoretical arguments related to assigning economic value to QALY's were reviewed, including those arguments dealing with the increased late medical (and non-medical) costs to which life-extending therapies expose patients. As noted above, it was elected to empirically derive the value of a QALY. Therefore, longevity changes, discounted for quality of life, were used in economic calculations of societal benefit in the case of coronary artery disease. In the case of benign prostatic hypertrophy, where little impact on longevity is seen and the major impact of therapy is symptomatic, it was not felt that 
current theory is sufficiently developed to warrant establishing an economic value for the quality component of the therapy.

Using cost models in a heuristic fashion, the following summary conclusions were reached:

- Technologies now under development can lower the anit cost of therapy, whether that unit cost is calculated per procedure or per patient treated. If demand growth is vigorous, aggregate costs are likely to increase.

- Even if aggregate costs increase with the introduction of new technology, societal costs remain negative in many instances (i.e. societal benefit is positive). A more strict economic evaluation of a technology would require that the positive societal benefit outweigh any additional health care costs experienced by the patient prior to a terminal illness. Note that this prediction of a positive societal benefit is dependent in some instances on pricing distortions in the health care market.

- Technologies which produce more durable resuits and thereby lessen the need for repeat procedures have the potential to further reduce cost by effectively removing patients from further interaction with the health care system. This can be seen in the use of stents (by reducing restenosis rate) and in the use of transurethral needle ablation for BPH. Similarly, prevention of disease lowers costs.

- Information technology that reduces unnecessary procedures (e.g. patient education for treatment of benign prostatic hypertrophy) can tower health care costs because it reduces demand (albeit inappropriate demand).

- Technologies which produce the same result as an alternative technology, but at tower cost per unit, can reduce aggregate cost because they tend not to increase demand.

- Estimates of societal cost/benefit derived from technology usage are sensitive to the econtomic value ascribed to a quality life year gained. Further research in this area is recommended.

- Mathematical modeling techniques such as stochastic frontier analysis offer novel ways to identify "lowest cost" practices and thereby identify a true cost baseline for the provision of medical care.

- The rank ordering task revealed that the office visit, when defined as a technology, ranks high in cost when compared to other technologies. This suggests that more research is warranted for determining ways to reduce the number and/or expense of office visits while maintaining quality of care.

In many cases, technology can be shown to lower health care costs if the societal response to technology is undexstood and the societal costs/benefits associated with technology are fully considered and understood.

\section{Care Pathway Integration Modeling}

The following sumnary conclusions were reached based on multiple simulations using the CAD and BPH models: 
- In the treatment of CAD or BPH, technological improvements can be expected to raise aggregate expenditures for care.

- Unit costs can be lowered by technological innovations.

- In general, technologies which produce satisfactorily dirable results (thereby lessening rework) have the opportunity to reduce aggregate and societal costs.

- Improvements generated as a result of technology use can increase demand for use of the technology.

- Societal costs/benefits of innovative technology were calculated by one of two methods. The first centered on the use of wage rates to estimate aggregate economic benefit provided by therapy (wage-based method). The second method determinex the value of a day of average life to patients in the near retirement age by studying retirement tradeoffs and decisions of the American population (the revealed preference method). When the wage-based method was empioyed, the cost of treating a disorder such as $\mathrm{CAD}$ could be seen to vary with societal policy, such as an increase in the retirement age. An increase in the retirement age tended to decrease the total cost for interventional therapy of CAD by virtue of extending the work life of patients benefiting from this therapy. Nonetheless, the analysis predicted a net cost to society for these therapies. However, when the revealed preference method was used, projections indicate that the cost of therapy is negative and will remain negative through the year 2004 .

- Information technology which limits unnecessary technology use through patient and physician education can lower costs because it directly lowers demand. Although this kind of information technology lowers costs, it also appears in the simulations to lower aggregate relief of symptom score. This conclusion must be further explored since some BPH patients have chosen less invasive therapies such as pharmacological therapy over procedural therapy, which might in theory provide a more durable relief of symptoms, albeit with increased short-term risk.

- The models showed that if sufficiently severe cost controls are imposed on technology, aggregate costs can fall. Unfortunately, the impact of such cost controls on the development of new technologies can be anticipated to be negative. From the revealed preference economic view, this effect can be detrimental to social wellbeing. Strategies designed to mitigate any influx of less-ill patients as a result of technological improvement can mitigate cost increases (or produce cost reductions) with variable effects on societal benefit.

- The models also show that utilization controls will lower aggregate costs, but quality or symptom relief will likely be lowered in the process. An exception would be those cases in which therapy is inappropriate and where, in effect, utilization control reduces waste.

- The simulations pointed ort the effect of patient demand on aggregate costs. The advent of a new technology can increase patient demand for that technology in multiple ways. lndeed, a new technology may also find application to totally unexpected areas of care, thereby increasing demand further. Also, indirect increases in demand can occur in that a new technology can prompt more patients to seek 
diagnostic testing, thereby enhancing the detection of a second disease. Finally, by permitting patients to live longer, technological advances permit patients to be exposed to the risk of developing subsequent disorders accompanied by additional treatment costs.

\section{Methods By Which Technology Can Reduce Societal Health Care Costs}

Although it is relatively easy to envision technologies which reduce the unit cost of delivered service, it is more difficult to envision ways in which technology can reduce aggregate costs given the push to demand which a new technology causes. However, based on project simulations, there are several ways in which cost reductions can occur.

The first is the deliberate limitation of the expansion and use of the technology. In effect, this methodology equates to a form of rationing in that not all patients who are desirous of using the technology will have access to it. However, this strategy can maintain or enhance the quality of care while lowering costs. This strategy is increasingly being considered by prepaid health care delivery systems, state governments, and others. The present modeling effort can accommodate this strategy and simulate the effects of various strategies to limit access to care.

The cost lowering impact of proposed technology could be so great that even in the face of increased demand.and of increased utilization of the technology for unanticisated purposes, the aggregate cost falls. In general, this would require a major reduction in costs and possibly a quanturn leap in technological development.

New technology could increase socjetal productivity by enhancing the aggregate productivity of the citizens. For example, the prevention of prenature mortality in a working population would enhance the Gross Domestic Product. As mentioned in the economic analysis section of this report, the prevention of morbidity and mortality even in unemployed patients can have a salutary economic effect. It is important to note however, that this opportunity cost of societal activities appears only when the cost benefit analysis is done from the societal point of view and not from that of the health care payor.

\section{Top-Down Approach: Technology Roadmapping Efforts}

Biomedical technology roadmaps were a major result of this effort. The primary goal of development of these roadmaps was to focus on areas where technology can have a major impact on cost reduction in the health care industry. The roadmaps, or strategic plans, identify a common vision for tinely solution of fundamental system problems that are "needs-driven" rather than "solutions-driven." These roadmaps provide consensus in the development and introduction of innovalive technologies by jedixing duplication of essential research, development and application activities among stakeholders. The major benefits of these strategic plans are (1) they address technology challenges that may be 
too expensive or too risky for a single organization to solve and (2) they provide a comprehensive viewpoint for addressing solutions to broad health care system problems.

The roadmap areas are

- advanced telemedicine,

- heath and healthcare informatics,

- information and network surety,

- integrated predicative diagnostics,

- minimally invasive therapy, imaging, and energy delivery systems,

- performance measurement and outcomes research,

- preventive medicine and incentive programs, and

- rehabilitative science and assistive technologies.

These areas include U.S. health care system resources, costs, quality and time goals, critical infrastructure requirements, and core competency needs. In order to ensure the credibility of each roaxmap, the working group champions for the technology areas obtained critiques from a wide variety of organizations and individuals with recognized expertise in each particular field. More than 75 organizations and 150 individuals have participated in the biomedical technology roadmap development process. Concurrence from this broad spectrum of participants valjdates the usefulness of the roadmaps. To begin the address future health care technology and technology-related policy, the prosperity game brougbt together stakeholders representing 44 organizations having expertise in the broad spectrum of heajth care technologies. The roadmaps should serve as tools to help make decisions on future health care activities. They have been widely distributed, and we are continuously receiving requests for additional copies. The complete roadmap document is available electronically on the DoD Telemedicine world wide web site at

http:/www.matmo.org/news/sections/civprog/sandia.html 


\section{References}

Agency for Health Care Policy and Research. Assessing Therapies for Benign Prostatic Hypertrophy and Localized Prostate Cancer (PORT). Chapter 3: Federal Medical Treatment Effectiveness Research. 1997 MEDICAL OUTCOMES \& GUIDELINES SOURCEBOOK. Faulkner \& Gray's Healthcare Infomation Center, Washington, D.C., 1996, pp. 273-288.

Agency for Health Care Policy and Research. 1997 Medical Outcomes \& Guidelines Sourcebook. "Benign Prostatic Hyperplasma: Diagnosis and Treatment."

Ahern, M. "The softness of medical production and inplications for specifying hospital outputs." Journal of Economic Behavior and Organization. 20(1993): 281.294.

Aigner, D.J. et al. "Formulation and estimation of stochastic production function models." Journal of Econometrics. 6(1977): 21-37.

Bary MJ, Fowler FJ, Mulley AG, Henderson JV, Wennberg J. Patient Reactions to a Program Designed to Facilitate Patient Participation in Treatment Decisions for Benign Prostatic Hyperplasia. Medical Care 33;(8) 771-782, 1995.

Bauer, P.W. "Recent developments in the economic estimation of frontiers." Journal of Economerrics, 46(1990): 39-56.

Benedict, M. E. and K. Shaw. "The impact of pension benefits on the distribution of earned income." Industrial and Labor Relations Review. 48(4): 740-757, 1995.

Blackstone, E.H. "Outcome Analysis Using Hazard Function Methodology," Ann Thorac Surg, 1996, 61:\$2-7.

Bradford, W.D. and C. Craycraft. "Prospective payments and hospital efficiency." Review of Industrial Organization. Forthcoming, 1996.

Brams, S.J., "Theory of Moves," American Scientist, pgs. 81, 562-570, NovemberDexember 1993.

Bureau of the Census. Statistical Abstract of the United States, 1995. (Washington, D.C.: U.S. Governunent Printing Office, 1995).

Carey, $\mathbf{K}$. and T. Stefos. "Measuring inpatient and outpatient costs: A cost-fumction approach." Heallh Care Financing Review. 14(1992): 115-124. 
Charison, ME, Pompei $P$, Ales $K L$, MacKenzie $C R$. "A new method of classifying prognostic comorbidity in longitudinal studies: Development and validation," $J$ Chronic Dis 40:373-383, 1987.

Chute, C.G., L.A. Panser, C.J. Girman, J.E. Oesterling, H.A. Guess, S.J. Jacobsen, and M.M. Lieber. "The Prevalence of Prostatism: A Population-Based Survey of Urinary Symptoms," J Urol, 1993, 150:85-89.

Clawson, Marton, and Jack Knetsch, Econornics of Outdoor Recreation (Baltimore: Johns Hopkins University Press for Resources for the Future, 1966).

Conrad, R.F. and R.P. Strauss. "A multiple-output, multiple-input model of the hospital industry in North Carolina." Applied Economics. 15(1983): 341-352.

Cooper, B.S. and D.P. Rice. "The economic cost of illness revisited." Social Sectrity Bulletin, February, pp. 21-36, 1976.

Cragg J.G. "Some Statistical Models for Limited Dependent Variables With Application to the Demand for Durable Goods." Econometrica. 39(1971): 829-844.

Cutler, et al. National Bureau of Economic Research Working Paper Series 5750.

Cutler, David M., and Mark McCletlan. "The determinants of technological change in heart attack treatment." NBER Working Paper 5751, 1996a.

Cutler, D.M. and M. McClellan. "The Determinants of Technological Change in Heart Attack Treatment," Working Paper 5751, NBER Working Paper Series, National Bureau of Economic Research, September 1996.

Dahistrand C., et al. "Transurethral Microwave Thermotherapy Versus Transurethra] Resection for Symptomatic Benign Prostatic Obstruction: A Prospective Randomized Study With a 2-Year Follow-up." British Journal of Urology. 76(1995): 614-618.

Davies RF, Goldberg AD, Forman S, Pepine CJ, Knatterud GL, Geller N, Sopko G, Pratt C, Deanfield J, Conti R. Asymptomatic Cardiac Ischemic Pilot (ACIP) Study Two-year follow-up. Circulation 95: 20037-2043, 1997.

Department of Commerce, Bureau of Labor Statistics. Work life Estimates: Effects of Race and Education. (Washington, D.C. : U.S. Government Printing Office, 1986).

Deyo, RA, Cherkin DC, Ciol MA. "Adapting a clinical comorbidity index for use with ICD-9 CM administrative databases," J Clin Epidemiology 45:613-619, 1992.

Dor, A. "Non-minimum cost functions and the stochastic frontier: On applications to health care providers." Journal of Health Economics. 13(1994): 329-334. 
Dranove, D., "Measuring Costs," in Valuing Health Care: Costs, Benefits, and Effectiveness of Pharmaceuticals and Other Medical Technologies, ed. Frank Sloan, Cambridge Univ. Press. New York, 1995.

Dnummond, M., Brandt, A., Luce, B., Rovira, J., "Standardizing Methodologies for Economic Evaluation in Health Care: Practice, Problems, Potential," International Journal of Technology Assessment in Healh Care, I993, pg. 26-36.

Duan N., et al. "Choosing Between the Sample-Selection Model and the Multi-Part Model." Journal of Business and Economic Statistics." 2(1984): 283-289.

Fíchman, D.L., M.B. Leon, D.S. Baim, R.A. Schatz, M.P. Savage, I. Penu, K. Detre L. Veitn, D. Ricei, M. Nobuyoshi, M. Cleman, R.Heuser, D. Almond, P.S. Teirstein, R.D. Fish, A. Colombo, J. Brinker, J. Moses, A. Shaknovich, J. Hirshfeld, S. Bailey, S. Ellis, R. Rake, and S. Goldberg. "For the Stent Restenosis Study Investigators. A Randomized Comparison of Coronary-Stent Placement and Balloon Angioplasty in the Treatment of Cotonary Artery Disease," $N$ Engl J Med, 1994, 331:496-501.

Foulkes RL etal. "Parametric Modeling of Stroke Recurrence," Neuroepidemiology 13: 19-27, 1994.

Gartaway, W.M., and R.S. Kirby. "Benign Prostatic Hyperplasia: Effects on Quality of Life and Impact on Treatment Decision," Urology, 1994, 44+629-636.

Goddeeris, John H. "Insurance and incentives for innovation in medical care." Southern Economic Journal. 51(2):530-539, 1984a.

Goodman, C. Assessment of Health Core Technologies: Case Studies, Key Concepts, and Strategic Issues. Chapter 7: The Moving Target Problem and Other Lessons from Percutaneous Transluminal Coronary Angioplasty, pp. 123-140, John Wiley and Sons, Ltd., 1996.

Granneman, T.W. et ał. "Estimating hospital costs: A multiple-output anatysis." Joumal of Health Economics. 5(1986): 107-127.

Greene, W., Econometric Analysis, 2nd Edition. Macmillan. New York.

Greenfield, S. Apolone G. MoNej BJ, Cleary PD. "The importance of co-existent disease in the occurrence of post-operative complications and one year replacement in patients undergoing total hip replacement. The Health Institute." Medical Care 31: 141-154, 1993.

HCIA Inc. National Inpatient Profile from the HCIA's Projected Inpatient Database (PIDB). Baltimore, MD, 1994, 1995, 1996. 
HCIA Inc. Patient Level Data from All-Payer States - Detail Data from CA, CO, FL, MD, NJ. Baltimore, MD, 1994, 1995, 1996.

Harington, W. et al. Economics and episodic disease: the benefits of preventing a giardiasis outbreak. (Washington, D.C : Resources for the Future, 1991).

Hay J.W., et al. "Ordinary Least Squares and Sample-Selection Models of HealthCare Demand." ." Journal of Business and Economic Statistics. " S(1987): 499+506.

Healthy People 2000. National Health Promotion and Disease Prevention Objectives. Washington, DC. DHHS Publication Number (PHS) 91-50212, 1991.

Hecknan J., "Varieties of Selection Bias." American Economic Association Papers and Proceedings. 80(1990); 313-318.

Hodgson, TA. "The State of the Art of Cost-of-Illness Estimates," Adv. in Heallh Economics and Healfh Services Research, 4: 129.164, 1993.

Hornberger, J., Garber, A., and Chernew, M., "Is High-Flux Dialysis Cost-Effective?" International Journal of Technology Assessment in Health Care, 1993, pg. 85-96.

Jacobsen S.J., "Community-Based Population Studies on the Natural History of Prostatism." Curren Opinion in Urology. S(1995): 13-17.

Jennett, B、 "Assessment of clinical technologies," International Jotirnal of Technology Assessment, 4:435-445, 1988.

Jondrow, J, et al. "On the estimation of technical inefficiency in the stochastic frontier production function model." Journal of Econometrics, 19(1982): 233-238.

Judge, George G., W.E. Griffiths, R. Carter Hilt, Helmut LutikepohJ, Tsoung-Chao Lee, The Theory and Practice of Econometrics, Wiley, New York (1985).

Kaplan, MH, Feinstein, AR. "The importance of classifying initial comorbidity in evaluating the outcone of diabetes mellitus," J Chronic Dis 27:387-404, 1974.

Keejer, E., "Decision Trees and Markhov Models in Cost-Effectiveness Research," in Valuing Health Care: Costs, Benefits, and Effectiveness of Pharmaceuticals and Other Medical Technologies, ed. Frank Sloan, Cambridge Univ. Press. New York, 1995.

Kiefer, N., "Economic Duration Data and Hazard Functions," Journal of Economic Literature, 1988, pg. 646.79. 
Kopp, R.J. and W.E. Deiwert. "The decomposition of frontier cost function deviations into measures of technical and allocative efficiency." Journal of Econometrics. 19(1982): 319-331.

Krousel-Wood, MA, McCune, TW, Abdoh A, Re, RN. "Predicting work status for patients in an occupational medicine setting who report back pain," Archives of Family Medicine, 3:349-355, 1994.

Krueger, A.B. ad J.S. Pischike. "The effect of Social Security on labor supply: a cohort analysis of the notch generation." Jotrnal of Labor Economics, 10(4): 412-437. 1992.

Kumbhakar, S.C. "The specification of technical and allocative inefficiency in stochastic production and profit frontiers." Journal of Econometrics. 34(1987): 335-348.

Lepor H., "The Efficacy of Terazosin, Finasteride, or Both in Benign Prostatic Hyperplasia." The New England Journal of Medicine. 335 (August 22, 1996): 533538.

Leung S.F., Y. Shihiti "On the Choice Between Sample-Selection and Two-Part Models."

Journal of Econometrics. 72(1996): 197-229.

Lu-yao GL et al. Urology, 44:692-699, 1994.

Maddala G.S. "A Survey of the Literature on Selectivity Bias as it Pertains to Health Care Markets." Advances in Health Economics and Health Services Research. $6(1985) \div 3-18$.

Manning, W.G., et al. "The demand for alcohol: The differential response to price." Journal of Health Economics. 14(1995): 123-148.

Manning W.G., et al. "Monte Carlo Evidence on the Choice Between Sarnple Selection and Two-Part Models." Joumal of Econometrics. 35(1987): 59-82.

Marshall, G., L.W. Shroyer, F.L. Grover, and K.E. Hammermeister. "Bayesian-Logit Model for Risk Assessment in Coronary Artery Bypass Grafting," Ann Thorac Surg, $1994,57: 1492-1500$.

McClellan and Newhouse. "The Marginal Cost Effectiveness of Medical Technology: a Panel Instrumental-Variables Approach," Journal of Econometrics, 77: 39-64, 1997.

McCullough D.L., et al. "Transurethral Ultrasound-Guided Laser-Induced Prostatectomy: National Human Cooperative Study Results." The Journal of Urology. 150(1993): 1607-1611. 
Meltzer. J. Health Economics, 16:33-64, 1997.

Menke, T. "Impacts of PPS on Medicare Part B expenditures and utilization for hospital episodes of care." Inqutry. 27(1990): 114-126.

Mick, M.J., M.R. Piedmont, A.M. Arnold, and C. Simpfendorfer. "Risk Stratification for Long-Term Outcome After Elective Coronary Angioplasty: A Multivariate Analysis of 5,000 Patients," J Am Coll Cardiol, 1994, 24(1):74-80.

Milroy E.J.G. "Prostatic Stents." Current Opinion in Urology. 5(1995): 25-29.

Mullahy, $J_{+}$, and Manning, W., "Decision Trees and Markhov Models in CostEffectiveness Research," in Valuing Hedth Care: Costs, Benefits, and Effectiveness of Pharmaceuticals and Other Medical Technologies, ed. Frank Sloan, Cambridge Univ. Press. New York, 1995.

Nelson, EC, Landgraf, JM, Hays, RD, Wasson, JH, Kirk, JW, "The Functionat Status of Patients," Med Care 28:1111-26, 1990.

Newhouse, J.P. "Toward a theory of nonprofit institutions: An economic model of the hospital." American Economic Review. 6.? 1970): 64-74.

Newhouse, Joseph P. "Medical care costs: How much welfare loss?" Joumal of Economic Perspectives. 6(3): 3-21, 1992.

Newmark, C.M. and M. Walden. "Should you retire at age 62 or 65 ?" Association for Finoncial Counseling and Planning Education working paper. 1995.

Nue , C.R. "Individual preferences for life and health: misuses and possible uses." in R.L Kane and R.A. Kane (eds .) Valtues and long-term care, (Lexington, MA: Lexington Books, 1982), pp.261-276.

Pauly, M. V. Doctors and Thelr Workshops: Economic Models of Physician Behavior. (Chicago: University of Chicago Press, 1980).

Re, Dr. Richand, et al. Alton Ochsner Medical Foundation. The Role of Technology in Reducing Health Care Costs, Q1997, May 1997.

Roehtborn, Claus G. "The newly established guidelines for the diagnosis and management of benign prostatic hyperplasia." Current Opinion in Urology. 5(1995): $30-34$. 
Roehrborn, C.G. "The Agency for Health Care Policy and Research. Clinical Guidelines for the Diagnosis and Treatment of Benign Prostatic Hyperplasia, Urol Clin North Amer, $1995,22: 445-453$.

Rice, D.P. Estimating the cost of illness. PHS Pub. No. 947-6. Public Health Service, Washington, U.S. Government Printing Office, May 1966.

Sandia National Laboratories. The Role of Technology in Reducing Health Care Costs, SAND 60-2469, O1996, DOE Distribution Category UC-900, November 1996.

Schelling, T.C. "The life you save may be your own." in S. Chase (ed.), Problems in public expenditure analysis. (Washington, D.C.: Brookings institute, 1968), pp. 127176.

Schmidt, P. and C.A.K. Lovell. "Estimating technical and allocative inefficiency relative to stochastic production function and cost frontiers." Journal of Econometrics. 9(1979): 343-366.

Schulman C.C., Alexandre R. Zlotta. "T ransurethral Needle Ablation of the Prostate: A New Treatment of Benign Prostatic Hyperplasma Using lnterstitjal Low-Level Radiofrequency Energy." Current Opinion in Urology. 5(1995): 35.38 .

Sirls L.T., et al. "Transurethral Incision of the Prostate: An Objective and Subjective Evaluation of Long-Tern Efficacy." The Journal of Urology. 150(1993): 1615-1621.

Skinner, J. "What do stochastic frontier cost functions tell us about inefficiency?" Journal of Health Economics. 13(1994): 323-328.

Sloan, F., "Introduction," in Valuing Health Care: Costs, Benefits, and Effectiveness of Pharmaceuticals and Other Medical Technologies, ed. Frank Sloan, Cambridge Univ. Press. New York, 1995.

Thorpe, K.E. "The use of regression analysis to determine hospital payment: The case of Medicare's indirect teaching adjustment. ${ }^{n}$ Inquiry. 25(1988): 219-231.

Tietenberg, Tom, Environmental and Natural Resource Economics (New York: HaperCollins, 1992).

U.S. Bureau of the Census. STATISTICAL ABSTRACT OF THE UNITED STATES: THE NATIONAL DATA BOOK, 1995 (115 ${ }^{\text {th }}$ Edition), Washington, D.C., 1995.

U.S. Bureat of the Census. STATISTICAL ABSTRACT OF THE UNITED STATES: THE NATIONAL DATA BOOK, 1994 (114 ${ }^{\text {b }}$ Edition), Washington, D.C., 1994. 
U.S. Department of Health and Human Services. Healthcare Financing Administration. Bureau of Data Management and Strategy. Public Use Files Catalog as of July 1, 1996. Washington, D.C., 1996.

Viscusi WK. The Value of Risks to Life and Heatth: A Comparison of Three Statistical Cost Frontier Models . Journal of Economic Literature 31(4):1912-1946, 1993. ...

Von Neumann, J. and O. Morgenstern. "The Theory of Games and Economic Behavior", 1944, 1947, 1953.

Wagstaff, A. "Estimating efficiency in the hospital sector: A comparison of three statistical cost frontier models." Applied Economics. 21(1989): 659-672.

Ware, JE, Sherbourne, CD. "The 36-Item Short-form health survey (SF-36): I. Conceptual Framework and Item Selection," Med Care 30:473-81, 1992.

Weintraub, W.S., E.L. Jones, J.M. Craver, and R.A. Guyton. "Frequency of Repeat Coronary Bypass or Coronary Angioplasty After Coronary Artery Bypass Surgery Using Saphenous Venous Grafts," Am J Cardiol, 1994, 73:103-112.

Wennberg JE et al. JAMA 257:933-936, 1987.

Wolf, Frederic M., Meta-Analysis: Quantitative Methods for Research Symthesis. (Beverly Hills, CA: Sage Publications, Inc. 1986).

Zuckerman, S. et al. "Measuring hospital efficiency with frontier cost functions." Journal of Health Economics. 13(1994): 255-280.

, et sl. "Are medical prices declining?" NBER Working Paper 5750, $1996 \mathrm{~b}$.

$\overline{56-67}, 1984 b$.

. "Frontier estimation: How useful a tool for health economics?" Journal of Health Economics. 13(1994): 317-322.

and C.E. Phelps. "Regulatory intensity and hospital cost growth." Journal of Health Economics. $9(1990)$ : 143-166. 


\section{Appendix A - Derivation of Rank Order Data}

\section{Data Sources}

A systematic approach to addressing the data sources used for the rank ordering task was adopted. The project team specified inclusion criteria for the data sources, formulated a plan for searching the data sources, collected and analyzed the data.

The inclusion criteria were as follows: data was to be recent (1992 to present); data was to be reflective of the U.S. population (neonate to elderly); data was to be reflective of different payer groups (e.g. Medicare, managed care, fee for service); data was to be procedure code-oriented; data was to reflect utilization and dollar amount of services. The most recent uniformly available data at the onset of this project was from calendar year 1994. Therefore, we reviewed the 1990 U.S. Bureau of Census Data projected to 1994 to assess the demographic breakdown of the U.S. population. (Of note, review of the trend data (1992 - 1995) did not reveal any major changes in demographic breakdown of the U.S. population over this 4 year time period). This information together with variation in healthcare delivery indicated the need for data from multiple sources. Thus, several data sources were included in this project: Medicare data (inpatient and outpatient), data from a Western Managed Care Organization (MCO), data frorr a Southem MCO, and National lnpatient Sample (NIS) data.

The Medicare population consists of potentially high utilizers of healthcare services. To review health care utilization in inpatient and outpatient settings, the project team obtained the top 200 procedures (predominantly captured by CPT-4 codes) by allowed services from HCFA (Health Care Financing Administration) Part B Medicare files (1). The Part B files include non-instinutional services: physician; clinical laboratory; durable medical equipment/supplies; prosthetics and orthotics; facility charge for freestanding ambulatory surgical centers; blood; outpatient speech, occupational and physical therapy; monthly ESRD (end stage renal disease) capitation; parenteral and enteral supplies; ambulance; immunosuppressive drugs, pneumococcal vaccines. The Part B files reflect procedures occurning in both inpatient and outpatient settings. The Medicare Part B data is based on the Health Care Financing Administration's Common Procedure Coding System (HCPCS). The HCPCS codes are required when providers report services and procedures provided to Medicare beneficiaries. HCPCS is a three-level coding systen. The first level is based on the CPT codes that are published and updated annually by the American Medical Association (2). It is five digit systern that describes procedures, and services physicians provide to patients but does not include non-physician procedures, services and specific supplies. The second level of this coding system is referred to as National Codes, or sometimes by the acronym, "HCPCS" (3). These codes are published and updated yearly by the Health Care Financing Administration, and these codes supplement CPT. Codes are included for non-physician services and procedures such as 
ambulance services and durable medical equipment. The codes are 5 digit alphanumeric codes. The third level of the HCPCS system is based on tocal codes that are used to note new procedures or specific supplies for which there is no national code. These codes, like the level two codes are five-digit ajphanumeric codes (an alphabetic character followed by fou digits). For the healthcare occurring in short-stay hospital facilities only, characteristics of inpatient billing practices resulted in our use of rank ordering by DRG (Diagnostic Related Group) to assess technology utilization in short-stay hospitals. We obtained data that was generated from the $100 \%$ MedPAR file (Medicare Provider Analysis and Review file) from HCFA. HCFA provided aggregated data regarding procedures and conditions by DRG code that resulted from inpatient discharges from short-stay hospitals. The following information was provided: DRG, charges/DRG (total, covered and Medicare rejmbursed), number of discharges, and average length of stay. Descriptions for DRG's can be found in St. Anthony's DRG Guidebook (4).

The westen MCO provided information regarding its 1994 enrollees (over 2.4 million). For hospitalizations in 1994, data was provided on the top 200 principal procedures (ICD-9 procedure code) by volume (high to low) for all inpatient and outpatient (i.e. same day surgery) procedures. The top 200 office visit procedures (CPT-4 codes) ranked by volume (high to low) for one representative month in 1994 was provided. These codes were translations of an appointment reason code; the coding process was not designed to capture all procedures performed in the office. In addition, the top 200 radiology procedures (predominantly CPT-4 coding) were provided rank-ordered by volume for on: representative month in 1994. Prior to analysis, the ICD-9 codes were translated into CPT 4 coding; the one month data was used to estimate 1 year data; and the individual data files were integrated with the other data files from the MCO.

The southern MCO provided data on approximately 63,000 enrollees in calendar year 1994; Medicare patients were not included in the MCO in 1994. A composite list of the top 200 procedures (CPT-4 and HCPCS codes) for 1994, rank-ordered by volume, was obtained. The report included inpatient and outpatient hospitalizations, office visits, radiology and laboratory utilization. A separate list of the top 200 procedures rank ordered by "amount paid" by the SMCO was also obtained. This was done in an effort to determine correlation of rank order by volurne versus rank order by dollar.

Data regarding inpatient utilization was obtained from the Agency for Healthcare Policy and Research (AHCPR) Healthcare Cost and Utilization Project (HCUP-3) (5). The HCUP-3 Nationwide Inpatient Sample (NIS) contains data from approximately 900 U.S. Hospitals (approximately 20 percent sample of U.S. community hospitals). It contains data from records for all stays in the sample hospitals. The NIS Release 1 for 1992 was drawn from a sample of hospitals in 11 states: Arizona, Califormia, Colorado, Florida, Illinois, Iowa, Massachusetts, New Jersey, Pennsylvania, Washington and Wisconsin. The sample is a stratified probability sample designed to be representative of the universe of U.S. community hospitals. (The American Hospital Association (AHA) designates community hospitals as all non-Federal, short-term general hospitals (open to the public) and specialty hospitals.) The HCUP-3 sample available at the onset of this project (1995) 
spanned the period from 1988 to 1992 . From these patient-level records, we derived the top 200 inpatient procedures (ICD-9 coding) by volume for 1992. When the 1993 data became available in 1996, we generated a top 200 list for 1993. Correlation analysis of the rank ordered lists from 1992 versus 1993 revealed that the lists were highly correlated (Spearman rank correlation $=0.90$ for the ranks; Pearson correlation $r 0.87$ for the frequency counts). This paper reports on the 1992 data because it was the initial data set available for this analysis. In the spring of 1997 , the 1994 NIS data was released. From these inpatient records, we derived the top 200 DRG codes for hospitalizations. This was done in an effort to obtain a comparable dataset to the Medicare short-stay hospital data; the two data sets were used to generate a weighted rank-order list of the top DRG's in the U.S. short-stay hospitals.

\section{Demographics}

From the 1994 projections of the 1990 U.S. Bureau of Census Data, the demographic breakdown of the U.S. Population was as follows: of the approximate 260 million people in the U.S. in $1994,51 \%$ were women, $58 \%$ were between $20-64$ years of age $(13 \%$ are greater than 64 years old), $74 \%$ white non-Hispanic, and $85 \%$ were insured (13\% with Medicare). Of note, the proportion of the U.S. population that is insured by managed care organizations is increasing.

The demographic breakdown for the unique populations from the different data sources used for this project is provided below. The Medicare population in 1994 consisted of approximately 37 million beneficiaries (over $13 \%$ of the U.S. Population): $57 \%$ women, $89 \%$ aged (vs $11 \%$ disabled), and $84 \%$ white. The Western MCO 1994 enroliees included over 2.4 million patients: $51 \%$ women, $62 \%$ between the ages of $21-65$ years of age ( $11 \%$ greater than 65 years old), $70 \%$ white, (data on race available for enrollees 20 years of age and older). The Southern MCO provided data on over 63,000 enrollees for 1994. The population consisted of $48 \%$ women, $66 \%$ persons aged $20-64$ years $(17 \%$ were greater than 65 ). No data was available regarding race/ethnic origin. The HCUP-3 NIS 1992 data set included approximately 6,195,744 patient hospitalizations. The following reveals the demographic breakdown: $42 \%$ women, $58 \%$ white, $34 \%$ Medicare, $46 \%$ persons aged $21-65$ years ( $32 \%$ persons greater than 65 years old).

In attempting to jdentify leading procedures that should be assessed for potential technological innovation, some investigators may only seek to identify leading highvolume or leading high-dollar procedures. In order to assess the impact of using one rank ordered list over another (dollar vs volume), we used rank ordered reports generated from the 1994 Medicare Part B (over 36 million enrollees) and the 1994 SMCO data (over 64 thousand enrollees) to determine correlations between rank order by volume of procedures vs. rank order by dollar amount (8). For the Medicare Part B, the conrelation between the rank order by volume vs by "allowed chargen for the top 200 procedures was as follows: $r=0.27, \mathrm{p}=$ less than .00005 . For the $\$ M C O$, the correlation between the rank order by volume vs the "amount paid" for the top 200 procedures was as follows: $r$ 
$=0.48, \mathrm{p}=$ less than .00005 . Although significant, the relatively poor correlations jdentified in this analysis between rank order by volume of procedure vs dollar anount indicated the need to assess these two aspects of the procedures (volume and dollar) independently when selecting procedures for study. Based on this analysis, it was decided that we would pursue separate lists ranked by volume and dollar for both the combined report and the inpatient report.

\section{Dollar Data}

The data obtained from the various data sources reflected utilization of procedures or the number of procedures performed by code category in a given period of time. Obtaining meaningful and comparable data regarding cost, charge, and/or expenditures for various procedures was a complex task. First, there is noted geographic and payer variation in charges per procedure $(6,7)$. Second, there is no universal cost accounting system in place that can provide accurate cost estimates for procedures that are representative of all U.S. practices. In addition, charges for intividual procedures performed in the hospital are difficult to isolate from the confounding effects of other procedures performed during the same admission and length of stay. Consequently, identification of a source for dollar estimates that would altow unifom reranking of the high volume procedures by dollar amount required different approaches. For those procedures identified by CPT -4 and HCPCS procedure codes, we utilized HCFA Part B allowed charges averaged across the U.S. for each code. The data was obtained from the HCFA Public Use File (i.e. Part B Procedure File (1)) for calendar year 1994. This file provided an array of every Part B procedure. In addition, it showed the related frequency and submitted and allowed charges for services processed by carrier. The dollar figure generated with this approach for each code was applied to each data set used for the combined report. For the inpatient report only, we used the average covered charge for each DRG generated from the 1994 MedPAR file for those procedures occurring in the hospital. This average charge obtained from the MedPAR file was applied to the DRG's identified in the 1994 NIS database.

\section{Data Preparation And Assessment}

The data sets obtained for this project were used to generate two types of rank-ordered lists: rank-ordered by volume (ROV) and rank-ordered by dollar (ROD). Although the initial goal was to generate two (2) lists (ROV and ROD) that would combine both inpatient and outpatient procedures, additional lists (ROV and ROD) containing only inpatient procedures were also generated. This was considered important in light of the fact that there are different drivers of techuology utilization in the inpatient vs the outpatient setting; such a report could provide useful information for targeting technology innovation in hospitalized settings. Therefore, the data was assessed and presented as follows: ROV list for combined inpatient and outpatient procedures as well as inpatient 
procedures only; ROD list for combined inpatient and outpatient procedures as well as inpatient procedures only.

\section{Rank Order By Volume (ROV)}

For the combined inpatient and outpatient report (Combined Report), the following data sources were used: Medicare Part B, WMCO, SMCO. The majority of the procedures identified were captured primarily by ICD- 9 or CPT-4 procedure codes. These 2 coding systems were developed independently; this, there was no direct "map" between the 2 coting systems. For the Combined Report, it was necessary to translate the ICD-9 procedure codes to CPT -4 codes. This was a tedious task involving effort from personnel in the medicat records department. They translated the codes and provided a "map" between the 2 coding systems for the procedure codes identified in the rank-ordered lists for this project. Two primary issues were identified in this process: one, for some ICD-9 codes, there were nultiple CPT-4 codes that were related; two, there was overlap in the code descriptions. In an effort to minimize the potential effect of these two issues overestimating the rank-ordered status of some procedures, we grouped the data using CPT 4 codes collapsed to the first 3 digits. For the few procedures captured by HCPCS codes, we grouped the data using the alphanumeric codes collapsed to the first 3 digits. (The complete procedure codes in the category that collectively constituted over $80 \%$ of the procedures for the top 20 categories were reported). For each data source used for the ROV Combined Report, a rank-ordered list by collapsed code (CPT and HCPCS) was generated. In an effort to provide a single rank-ordered report (ROV) for the combined inpatient and outpatient procedures, the procedures were reranked based on the weighted rank calculated with the inverse of the mean rank of each procedure grouping from each data source. The steps are summarized as follows: data on the top 200 procedures jdentified by the 5-djgit procedure codes were entered into a d-Base III plus file. After a new field was created for the procedure category based on the first three digits of the procedure code, a new file was created for each data source that aggregated the volume over the category code. Procedures were ranked in descending order based on the aggregared voltume of the categories. A weight for each category man was calculated based on the inverse average of the three original ranks. For those categories with a missing rank (the procedure did not fall into the top 200 ranked procedures) they were given the highest rank for the data set (i.e. 200). Based on the calculated rank weights, the procedure categories were re-ranked in descending order. Once the highest volume procedure categories were identified using the process described above, we itemized the individual procedure codes making up each of the top 20 procedure categories. The individuat procedure codes making up at least $80 \%$ of the procedure code category are provided in Table 18 .

The ROV Inpatient Report was generated using 2 sources: 1994 HCUP-3 NIS and the 1994 MedPAR file. Because inpatient discharge files (the source of this data) contain conditions and procedures by DRG code, we generated the list based on DRG codes. For the two data sets used for this Inpatient Report, a rank-ordered list by DRG code was 
generated. In an effort to provide a single rank-ordered report (ROV) for inpatient procedures, the procedures were retanked based on the weighted rank calculated with the inverse of the mean rank of each procedure code from each data source. The following steps summarized the methodology used. A weighted national estimate for the total number of discharges for each DRG was estimated using the 1994 NIS data. (The estimated total discharges for all DRGs was $34,622,203$ ). The top 200 DRG's were extracted and placed in a separate file together with the estimated total number of discharges for each DRG and the ranks that were assigned based on the number of discharges in descending order. Data obtained from HCFA (that was based on the MedPAR file) was provided in a format that aggregated the DRGs from short-stay hospitals in the MedPAR file and ranked them in descending order by number of discharges per DRG. The two data sets (NIS and MedPAR) were merged together by the DRG code while retaining the original rank in each unique data set. A weight for each DRG rank was calculated based on the inverse average of the original ranks. Any DRG code that bad a missing rank (i.e. a specific DRG code was ranked in the top 200 codes for 1 data set but not for the other data set) was given the highest rank for the data set (i.e. 200). Therefore, if a DRG ranked top in both data sets, it would be given a higher weight. Based on the rank weights, the merged data were reranked in descending order.

\section{Rank Order By Dollar (ROD)}

For the Combined Report containing CPT -4 and HCPCS codes, the average national HCFA Medicare Part B allowed charge itemized per code was used. For the Inpatient Report using DRG codes, the average national covered charge itemized per DRG-code was used. This data was obtained from a HCFA download of the MedPAR file from calendar year 1994.

In rank ordering the procedures by dollar for the Combined Report, similar steps were followed as with the rank ordering by procedure volume described above.

However, the average HCFA allowed charges multiplied by volume replaced the volume for each procedure in caiculating the ranks and the weight ranks for the different categories. The average allowed charge for each category had to be weightel by the volume (combined for the three data sets) of the procedures making up the category. This was necessary because using only the simple averages of the charges making up the three digit procedure category would have over-estimated the average since many of the more expensive procedures had low volumes. In addition, it was necessary to use the weighted average so that the total estimate of charges for each category would match the sum of total estimates of the procedure charges making up that category. In rank ordering the procedures by dollar for the inpatient report, similar steps were followed as with the rank ordering by DRG volume described above. However, the average HCFA covered charge was multiplied by the number of discharges which resulted in a number that replaced the number of discharges for each DRG in the steps outlined above. 


\section{ROV and ROD Results}

Using the data sources described in the methods section; we generated rank ordered lists: Combineo Report: ROV and ROD; Inpatient Report: ROV and ROD. We report the procedures comprising the top 20 procedure categories generated for each list. (Table 18 through Table 23).

\section{Discussion}

The goal of this project was to obtain information regarding utilization of current health care technologies; the high volume and/or high cost technologies identified could guide future efforts for technology development and for assessing the potential of existing and future technologies potential to reduce health care cost while maintaining or improving quality of healthcare. From the three data sets (Medicare, WMCO, SMCO), used for the Combined Reports, we reported the leading procedures ranked by volume and by dollar for combined inpatient and outpatient encounters. In addition, the leading DRGs (diagnostic related groups) in hospital short-stay facilities have been identified and ranked by dollar and volume using two data sources: HCUP 3-NIS and MedPAR.

\section{Rank Ordering Of Combined Inpatient And Outpatient Procedures}

The top five procedure categories ranked by dollar and volume are the following: patient visits (inpatient and outpatient), chest $x$-rays, mammograms, ophthalmological services, and electrocardiograms (9). Patient visit (inpatient and outpatient) was the leading procedure category for both dollar and volume rankings. Although this was not unexpected, it provides quantitative information that may support the need and/or use of telemedicine or similar technology in the evaluation and management of patients.

Although the rank ordering of procedures by volume and dollar for the combined inpatient and outpatient report (Table 18 and Tabte 19) are similar (Spearman Rank Order correlation coefficient $=0.67 \mathrm{p}<.001$ ), there are notable differences. Procedure categories that were listed in the high-volume ranking, but not in the high-dollar ranking included: influenza vaccine, urinalysis, shoulder $\mathrm{x}$-rays, ankle and foot $\mathrm{X}$-rays, prothrombin time, and thyroxin and thyroid stimulating hormone tests. Procedure categories that were ranked in the high-dollar list but were not included in the highvolume rank ordered list are as follows: sigmoidoscopy/colonoscopy, ambulance services, CAT-scan of the head, radjotherapy, and abdominal echography. Identifying procedure categories that are defined by high-volume and high-dollar rankings provides a basis for evaluation of technologies that may potentially reduce healthcare cost while maintaining or improving quality of care. However, it is important to assess high-volume and high-dollar procedures separately. For those procedures that are identified as highvolume, hypotheses could be generated regarding appropriate utilization of these procedure services. Implementation of information transfer systems among healthcare 
providers and between healthcare providers and their patients may facilitate appropriate utilization of some procedures (e.g. sigmoidoscopy/colonoscopy, thyroid testing, breast cancer screening (mammography)). For high-dollar procedures (that are deemed to be appropriately utilized), efforts could be targeted at technological innovation that could result in less invasive and/or tess expensive ways of delivering these services/procedures. For example, new technologies that would allow the assessment of blood count and/or . blood chemistry evaluation without having to collect the blood sample intravenously may ultimately result in a less expensive approach to performing these blood tests.

Conversely, procedures currently ranked as high-dollar may "lose their ranking" if the operative payment mechanism is implemented. For this project, Medicare "allowed" and "covered" charges were used to rank the procedures across data sources in descending order. Application of another payment scheme might result in a change in rank of some or all procedures.

\section{Rank Ordering Of Inpatient Procedures}

Because of inpatient billing practices that result in grouping procedure charges in an effort to generate a single bill for the hospitalization, it was not feasible to determine specific charges for individual procedures that occur in the hospital. This was particularly an issue with the smaller, "low cost" procedures such as venipuncture, $\mathrm{X}$ rays, spinal taps. Therefore, inpatient utilization was assessed using DRG's, a system for billing for hospitajizations put forth by HCFA. Although the correlations between the rated ranks by the number of discharges and the weighted ranks by total covered charges for the DRGs assessed was considered good (Spearman rank comrelation coefficient $=$ $0.8226 ; \mathrm{P}<0.001)$ there are differences in the DRGs listed in Table 21 and Table 22 which provide information on the top $20 \mathrm{DRGs}$ that are ranked by dollar and by volume respectively. DRGs that were present in the rank order by volume top 20 list but not present in the rank order by dollar top 20 list are as follows: major joint and limb reattachment procedures of the lower extremities (DRG 209), angina pectoris (DRG 140), esophagitis, gastroenteritis and miscellaneous digestive disorders (DRG 182), nutritional and miscellaneous metabolic disorders (DRG 296), cardiac arthythmia and conduction disorders with complications (DRG 138), chest pain (DRG 143), kidney and urinary tract infections (DRG 320), chemotherapy without acute leukemia as a secondary diagnosis (DRG 410). DRG's appearing in the top 20 rank order by dollar but not in the top 20 rank order by volume are as follows: tracheostomy except for face, mouth and neck diagnosis (DRG 483), coronary bypass with cardiac catheterization (DRG 106), respiratory system diagnosis with ventilator support (DRG 475), coronary bypass without cardiac catheterization (DRG 106), other vascular procedures with complications (DRG 478), extensive operating room procedures unrelated to the principal diagnosis (DRG 468), and major cardiovascular procedures with complications (DRG 110). In reviewing the data that combined both the National Inpatient Sample Data and the Medicare data, it is interesting to note that the top $5 \mathrm{DRG}$ 's that are ranked by number of discharges are predominantly medical diagnosis: heart failure and shock (DRG 127), simple preumonia and pleurisy (DRG 89) cerebral vascular disorders (DRG 14), chronic obstructive 
pulmonary disease (DRG 88) and psychoses (DRG 430). Of note, the top 5 DRG's tanked by total covered charges are predominantly surgical in nature: major joint and limb reattachrnent procedures of the lower extremity (DRG 209) tracheostomy (DRG 483), coronary bypass with cardiac catheterization (DRG 106), and major small and large bowel procedures with complications (DRG 148) with the exception of heart failure and shock (DRG 127). In selecting conditions/procedures for further evaluation and potential technological innovation, assessing botk high volume and high dollar conditions/procedures would be appropriate.

The authors noted that in combjining the Medicare and National Inpatient Sample data, this may have biased the data to reflect more of the hospitalizations for Medicare patients than for the U.S. population as a whole. Of note, the National inpatient Sample reflects all payers and therefore includes Medicare as well as non-Medicare patients.

Therefore, we also assessed the top $20 \mathrm{DRG}$ 's that were ranked for the National Inpatient Sample both by volume and by dollar of note, the Spearman correlation between volume and charges for the 1994 NIS data was $0.78, p<0.001$ (the 4 DRGs with missing charges were excluded from this analysis). The most noted difference between these tank ordered lists (Table 22 and Table 23) and Table 20 and Table 21 are the inclusion of procedures/conditions related to birth: vaginal delivery without complicating diagnosis (DRG 373), nommal new born (DRG 391), neonate with other significant problems (DRG 390), cesarean section without complication (DRG 371), vaginal delivery with complicating diagnoses (DRG 372), full-term neonate with major problems (DRG 389).

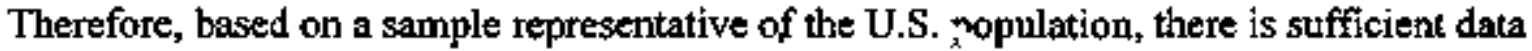
regarding volume and dollars expended on hospitalizations related to birth; this information could provide a foundation for program planning as well as technological innovation.

A potential limitation of this study's conclusions is that administrative data was used as the primary source of information. The results of any study using administrative data are dependent on accurate and reliable coding of the procedures and/or conditions that are under study (10). Procedures or conditions can be miscoded and/or can not be coded (missing data). The experience of several authors (MK-W, RNR, AA) revealed that coding for procedures was reliable (11). In addition, the accuracy of procedures coded was better than that of some diagnoses coded (unpublished data). Nevertheless, adtninistrative data-bases were designed to predominantly track utilization of services for billing purposes; therefore, the use of administrative databases to address the goal of rank ordering technologies utilized in the U.S. was appropriate. With the use of administrative databases, issues regarding patient confidentiality are important. Sometimes, administrative databases do not allow for the assessment of procedures by patient. The unit of analysis for this project was the number of procedures/services utilized and not the number of patients undergoing procedures.

Administrative databases use coding systems that are updated annually. In using the results reported in this paper to compare with subsequent data that becomes available from similar sources, one should be to be aware of the potential impact of coding changes and technology changes on documentation of procecture frequency (12). For example, in trending the HCUP-3 NIS data (1990 - 1993) there was a noted change in rank (15 to 2708 ) and frequency $(512,178$ to 30 ) over the 4 years for mechanical ventilation 
procedures captured by ICD-9 code 93.92. Although one might conclute that utilization of mechanical ventilation is decreasing over time in U.S. short-stay hospitals, this conclusion would be erroneous based on the data provided. The change in rank and irequency for mechanical ventilation resulted from the ICD-9 code 93.92 becoming obsolete in 1991. Follow-up regarding the changes in coding would be necessary to fully assess trend changes in mechanical ventilation use or any other procedure. Misunderstanding of coding and technology/practice changes may lead to erroneous conclusions regarding technology utilization in the U.S. hospitals.

Table 18. Rank Order Volume - High Volume Procedures Comprising the Top 20 Ranked Procedure Categories for the Combined Inpatient and Outpatient Report

\begin{tabular}{|c|c|c|c|c|c|}
\hline Number & $\begin{array}{l}\text { Cangory } \\
\text { Weighir } \\
\text { Rank }\end{array}$ & $\begin{array}{l}3 \text { Digir } \\
\text { Procedinte } \\
\text { Caterory } \\
\text { (CPT and } \\
\text { HCPCS } \\
\text { cadesentm. }\end{array}$ & $\begin{array}{l}\text { Abbtevated } \\
\text { Tule }\end{array}$ & $\begin{array}{l}\text { Dnver Procedtures* } \\
\text { for Cansogury }\end{array}$ & 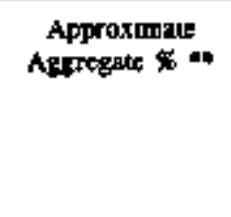 \\
\hline $\mathbf{I}$ & $\mathbf{J}$ & 992 & Papent Verit & 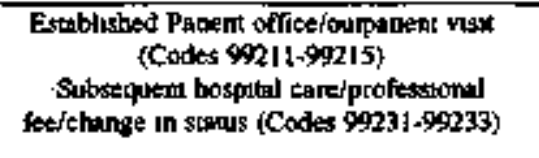 & $\begin{array}{c}561 \% \\
25.8 \% \\
\text { \$uttoul }=81.9 \%\end{array}$ \\
\hline 2 & 2 & 710 & Chest X-Ray & 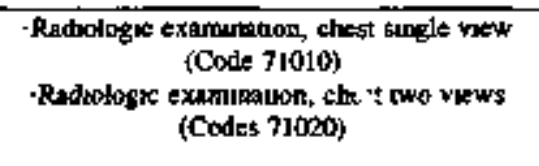 & $\begin{array}{c}46.4 \% \\
535 \% \\
\text { Subboral }=99.9 \%\end{array}$ \\
\hline 3 & 3 & 920 & $\begin{array}{l}\text { Ophutaimoloes } \\
\text { c Services }\end{array}$ & 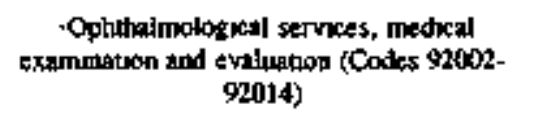 & $\begin{array}{c}87.1 \times \\
\text { Subtoral }=87.1 \%\end{array}$ \\
\hline 4 & 4 & 930 & ECG & $\begin{array}{l}\text { Electrocardiogram (ECG), routune ECG wuh } \\
\text { it least I2 ketals (Codes 93000-93019) }\end{array}$ & $\begin{array}{c}951 \% \\
\text { Subtotal }=951 x\end{array}$ \\
\hline 5 & 5 & 760 & Mammogram & $\begin{array}{l}\text { Mammography; bulawral } \\
\text { (Code 76001) } \\
\text {-Screening Mammography; bitaveral } \\
\text { (Code 76692) }\end{array}$ & $\begin{array}{c}62.2 \% \\
37.1 \% \\
\text { Subtotal }=99.3 \%\end{array}$ \\
\hline 6 & 6 & 971 & $\begin{array}{l}\text { Physical } \\
\text { Meducine } \\
\text { Treatinein }\end{array}$ & 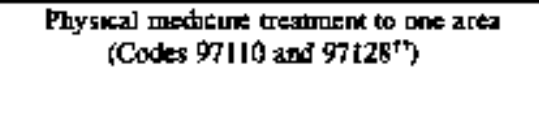 & $\begin{array}{c}\text { g9 9\% } \\
\text { Subtott }=89.9 \%\end{array}$ \\
\hline 7 & $6+$ & 993 & $\begin{array}{l}\text { Nursing } \\
\text { Faculy Care }\end{array}$ & $\begin{array}{l}\text {-Subsequent murseng facility carefpro-fec } \\
\text { (Codes } 99311-99313 \text { ) }\end{array}$ & $\begin{array}{c}999 \% \\
\text { Subtotol }=9999\end{array}$ \\
\hline 8 & 8 & 907 & $\begin{array}{l}\text { Influerza } \\
\text { Vaccint }\end{array}$ & $\begin{array}{l}\text { Immunzzatron, acave; influenzo vinus } \\
\text { vaccine (Code } 90724 \text { ) }\end{array}$ & $\begin{array}{c}99.8 \% \\
\text { Subtotel }=998\end{array}$ \\
\hline 9 & 9 & $g x$ & $\begin{array}{l}\text { Labornory } \\
\text { Blood Tests }\end{array}$ & 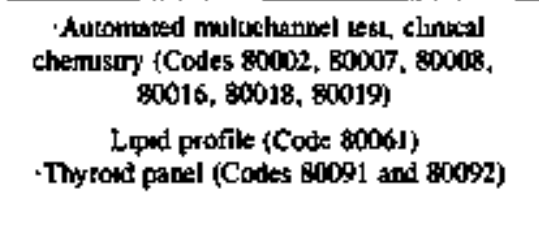 & $\begin{array}{c}77.8 \% \\
10.9 \% \\
113 \% \\
\text { Subtom }=100 \%\end{array}$ \\
\hline 10 & 10 & 850 & Blood Count & 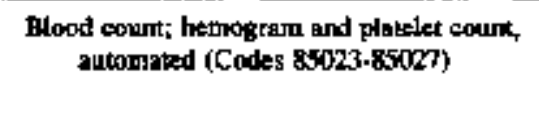 & $\begin{array}{c}922 \% \\
\text { Subtotal }=92.2 \%\end{array}$ \\
\hline
\end{tabular}




\begin{tabular}{|c|c|c|c|c|c|}
\hline 11 & 11 & 908 & Psycheothetrapy & 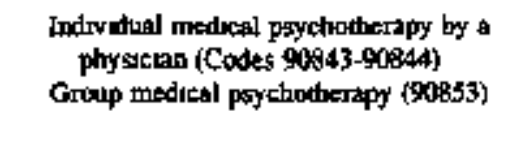 & $\begin{array}{c}668 \% \\
134 \% \\
\text { Subtool }=802 \%\end{array}$ \\
\hline 12 & 12 & 810 & Unaalysis & $\begin{array}{l}\text { Urtinalyss, by reagent sinps } \\
\text { (Codes } 81000 \text { and } 81002 \text { ) }\end{array}$ & $\begin{array}{c}999 \% \\
\text { Subtotel }=999 \%\end{array}$ \\
\hline 13 & t3 & 730 & $\begin{array}{l}\text { Shoulder X: } \\
\text { Ray }\end{array}$ & $\begin{array}{l}\text { Radiologe exammatron, shoulder complete } \\
\text { [Code } 73030]\end{array}$ & $\begin{array}{c}965 \% \\
\text { Subtotal }=965 \%\end{array}$ \\
\hline 14 & 14 & 735 & $\begin{array}{l}\text { Hip. Knee X. } \\
\text { Ray }\end{array}$ & 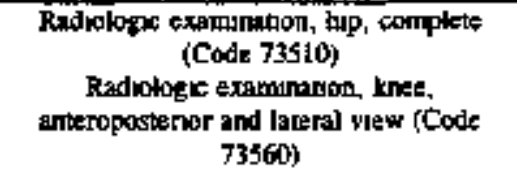 & $\begin{array}{c}587 \% \\
393 \% \\
\text { Sutututi }=980 \%\end{array}$ \\
\hline I5 & 15 & 736 & $\begin{array}{l}\text { Andkle, Foot } \\
\text { X-Ray }\end{array}$ & $\begin{array}{l}\text { X-ray ande, coumplete } \\
\text { (Code } 73610 \text { ) } \\
\text { X-riy foct, Complete } \\
\text { (Code 73630) }\end{array}$ & $\begin{array}{c}361 \% \\
488 \% \\
\text { Subwel }=849 \%\end{array}$ \\
\hline 16 & $1 s^{t}$ & 856 & PT & $\begin{array}{c}\text { Protbrombin Tme (PT) } \\
\text { \{Code 85610 }\end{array}$ & $\begin{array}{c}999 \% \\
\text { Subtotal }=999 \frac{9}{x}\end{array}$ \\
\hline 17 & 15 & 994 & $\begin{array}{l}\text { Evaluagon and } \\
\text { Manageanetre }\end{array}$ & $\begin{array}{l}\text { Ualisned evaluanon and managemenx } \\
\text { servxe (Code 9949) }\end{array}$ & $\begin{array}{c}100 \% \\
\text { Subtom }=100 \%\end{array}$ \\
\hline 18 & 18 & 844 & $\begin{array}{l}\text { Thyroxine, } \\
\text { TSH }\end{array}$ & $\begin{array}{l}\text { Thyroxune } \\
\text { (Code } 84436 \text { ) } \\
\text { Thyroud stimularme botmone } \\
\text { (TSH) (Code 84443) }\end{array}$ & $\begin{array}{c}432 \% \\
567 \% \\
\text { Sub_tw1 }=999 \%\end{array}$ \\
\hline 19 & 19 & 768 & Echooraphy & 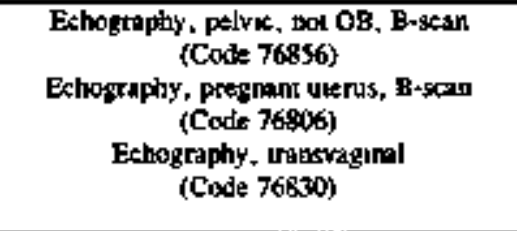 & $\begin{array}{c}385 \\
325 \% \\
18 \$ \% \\
\text { Subcoal }=893 \%\end{array}$ \\
\hline 20 & $19^{r}$ & 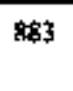 & $\begin{array}{l}\text { Surgical } \\
\text { Patholoray }\end{array}$ & $\begin{array}{l}\text { \$urgecal pethology' (7005s microsedpic } \\
\text { (Codes } 88304 \text { and } 88305 \text { ) }\end{array}$ & $\begin{array}{c}100 \% \\
\text { Subtatal 100\% }\end{array}$ \\
\hline
\end{tabular}

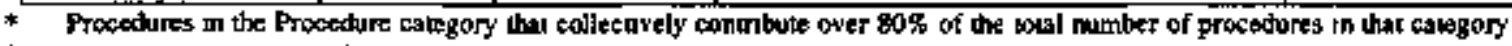

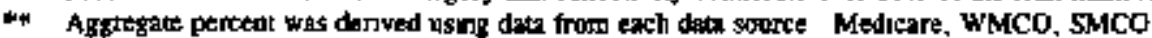

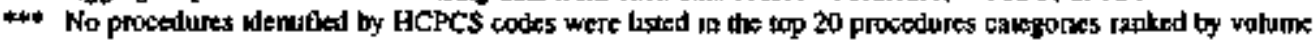

t Some cavegones have similar weight ranks

it Code has been detered from 1997 CPT 4 mathual 
Table 19. Rank Order Dollar - High Dollar Procedures Comprising the Top 20 Procedure Categories (Ranked by Total Estimated Allowed Charges*) for the Combined Inpatient and Outpatient Report

\begin{tabular}{|c|c|c|c|c|c|}
\hline Number & $\begin{array}{l}\text { Causpory } \\
\text { Weighe } \\
\text { Rank }\end{array}$ & 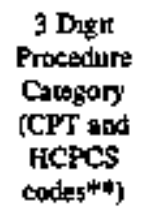 & $\begin{array}{l}\text { Abbrevared } \\
\text { Tude }\end{array}$ & $\begin{array}{l}\text { Donves Procedures * } \\
\text { for Category }\end{array}$ & $\begin{array}{l}\text { Approximate } \\
\text { Apregate } \% \\
\text { of Dollors per } \\
\text { Catogary }\end{array}$ \\
\hline $\mathbf{1}$ & $\mathbf{I}$ & 992 & Pauent Visit & 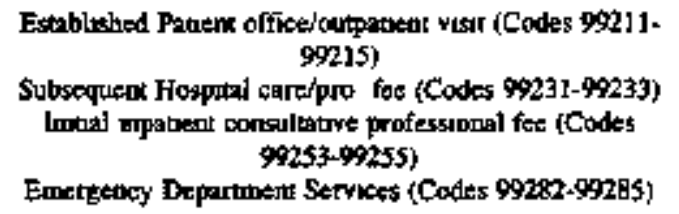 & $\begin{array}{c}416 \% \\
243 \% \\
73 \% \\
70 \% \\
\text { Subutai }=502 \%\end{array}$ \\
\hline 2 & 2 & 710 & Chest X-Ray & $\begin{array}{l}\text { Radiologe examination, chest, sugle view (Code } 71010 \text { ) } \\
\text { Rathologic exammothon, chest, two vesws (Codes } 71020 \text { ) }\end{array}$ & $\begin{array}{c}384 \% \\
616 \% \\
\text { Subtoxal }=1000 \%\end{array}$ \\
\hline 3 & 3 & 760 & Mommogram & $\begin{array}{l}\text { Mamiocosaphy, bJateral (code 76091) } \\
\text { Screeruns Mammogaphy, balateral (Code 76092) }\end{array}$ & $\begin{array}{c}633 \% \\
361 \% \\
\text { Subtod }=994 \%\end{array}$ \\
\hline 4 & 4 & 920 & $\begin{array}{l}\text { Ophatmalmologer } \\
\text { Servbes }\end{array}$ & 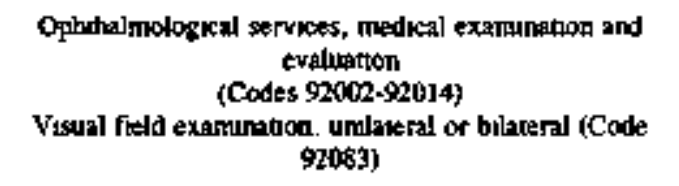 & $\begin{array}{c}88 \$ \\
111 \% \\
\text { Subrotel } \pm 996 \%\end{array}$ \\
\hline 5 & 3 & 930 & ECG & 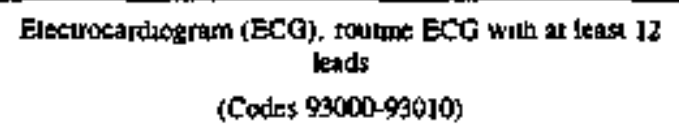 & $\begin{array}{l}97 \% \\
\text { Sobtovl }=97 \%\end{array}$ \\
\hline 6 & 6 & $\$ 8$ & Psyctorherapy & $\begin{array}{l}\text { Individual modxal psychotherapy by a physician } \\
\text { (Codes 90o43-90844) } \\
\text { Group medikal psychotherapy (Code } 900353 \text { ) }\end{array}$ & $\begin{array}{c}769 \% \\
75 \% \\
\text { Subcoul }=844 \%\end{array}$ \\
\hline 7 & 7 & 933 & 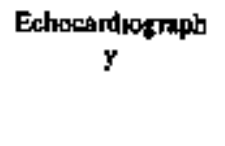 & 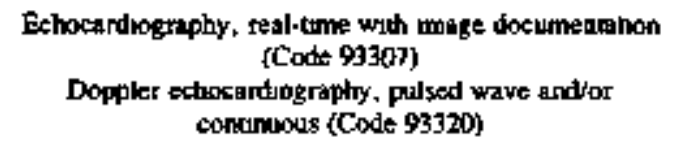 & $\begin{array}{c}574 \% \\
231 \% \\
\text { Subtotal }=805 \%\end{array}$ \\
\hline B & B & 971 & $\begin{array}{l}\text { Ptysical } \\
\text { Medicine } \\
\text { Treabmenx }\end{array}$ & $\begin{array}{c}\text { Physkesl medicune treatment to ano area (Codes } 97110 \\
\text { and } 97128^{74} \text { ) }\end{array}$ & $\begin{array}{c}874 \% \\
\text { Submtal }=874 \%\end{array}$ \\
\hline 9 & 9 & 993 & $\begin{array}{l}\text { Nursmg Faciluy } \\
\text { Care }\end{array}$ & $\begin{array}{l}\text { Subsequent nursing faculicy canefpro-fee (Codes } 9931]- \\
99313 \text { ) }\end{array}$ & $\begin{array}{c}9998 \\
\text { Subtobl }=999 \%\end{array}$ \\
\hline 10 & 10 & 768 & Echotrapty & 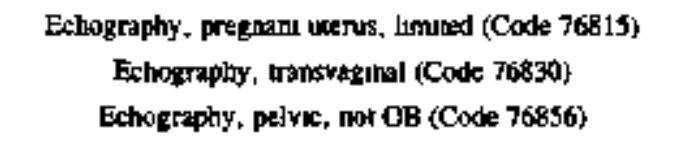 & $\begin{array}{l}393 \% \\
165 \% \\
353 \% \\
\text { Suboral }=911 \%\end{array}$ \\
\hline 11 & $10^{*}$ & 890 & $\begin{array}{l}\text { Laborawory } \\
\text { Blocd Tess }\end{array}$ & 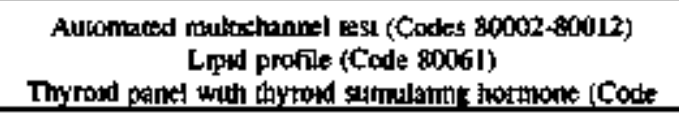 & $\begin{array}{l}632 \% \\
143 \% \\
178 \% \\
\end{array}$ \\
\hline
\end{tabular}




\begin{tabular}{|c|c|c|c|c|c|}
\hline & & & & $80092)$ & Sultotol $=953$ \\
\hline 12 & 12 & 994 & $\begin{array}{l}\text { Evaluntion and } \\
\text { Mantentement } \\
\text { Service }\end{array}$ & $\begin{array}{l}\text { Unlesiod avalmahon and mankgemem servies (Code } \\
9 \% 4 \% \text { ) }\end{array}$ & $\begin{array}{c}100 \% \\
\text { submol }=100 \%\end{array}$ \\
\hline 13 & 13 & 453 & $\begin{array}{l}\text { Sigmondosicopyl } \\
\text { Cotonoscopy }\end{array}$ & 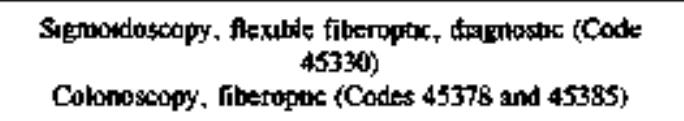 & $\begin{array}{c}601 \% \\
399 \% \\
\text { Subrowl }=160 \%\end{array}$ \\
\hline 14 & 14 & 735 & $\begin{array}{l}\text { Hip, Kines } X- \\
\text { Ray }\end{array}$ & 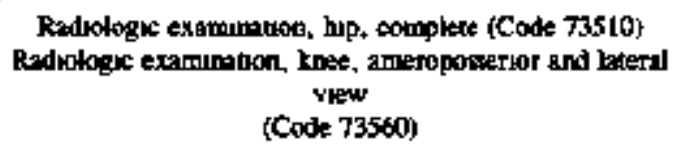 & $\begin{array}{c}600 \% \\
379 \% \\
\text { Subtuat }=979 \%\end{array}$ \\
\hline 15 & $34^{4}$ & 850 & Blood Coont & 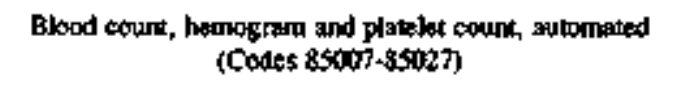 & $\begin{array}{c}959 \% \\
\text { Subtotal }=9598\end{array}$ \\
\hline 16 & 16 & 883 & $\begin{array}{l}\text { Strogical } \\
\text { Patholoty }\end{array}$ & 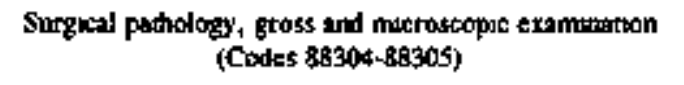 & $\begin{array}{c}200 \% \\
\$ \text { subtotal }=100 \%\end{array}$ \\
\hline 17 & $16^{\prime}$ & $402 * * *$ & Ambulanct & $\begin{array}{l}\text { Ambulance service and supplits (Codes A0215, } 10220 . \\
\text { A0222) }\end{array}$ & $\begin{array}{c}100 \% \\
\text { Suboul }=100 \%\end{array}$ \\
\hline 18 & 18 & 704 & $\underset{\text { Heat }}{\operatorname{CATSan}}$ & $\begin{array}{l}\text { Conmputerzed axpal tomography (CAT) scan, head or } \\
\text { breun (Code } 20450 \text { ) }\end{array}$ & $\begin{array}{c}986 \% \\
\text { Subtotal }=586 \%\end{array}$ \\
\hline 19 & $18^{+}$ & 774 & Radiodherapy & $\begin{array}{l}\text { Weldy sadwotherapy manigemem, compkex (Code } \\
77430)\end{array}$ & $\begin{array}{c}999 \% \\
\text { Subcotal }=999 \%\end{array}$ \\
\hline 20 & 20 & 767 & $\begin{array}{l}\text { Abdomunal } \\
\text { Echography' }\end{array}$ & 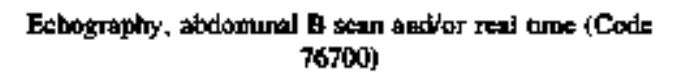 & $\begin{array}{c}990 \% \\
\text { Subcotod } 990 \%\end{array}$ \\
\hline
\end{tabular}

t Some cakgories have similar weighi ranks

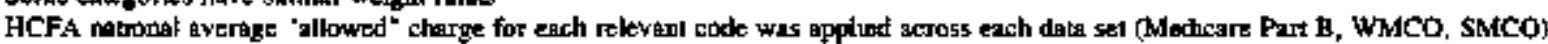

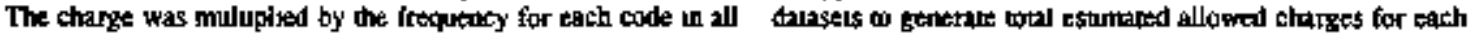
calogory

it Code has been deleted from the 1997 CPT-4 mantal

*. HCPCS = HCFA Common Proceduril Coding System

CPT $=$ Curnen procecture tertumalogy

* HCPCS siphanumenc code 
Table 20. Rank order volume: weighted ranks for the top 20 DRG's ranked by number of discharges for inpatient data* only

\begin{tabular}{|c|c|c|c|}
\hline NUMBER & $\begin{array}{l}\text { WT } \\
\text { RANK }\end{array}$ & DRG & DESCRJPTION \\
\hline 1 & 1 & 127 & FEART FAחURE AND SHOCK \\
\hline 2 & 2 & os & \$IMPLE PNEUMONIA AND PLEURISY AGE GREATER THAN IT WITH COMPLICATHONLS \\
\hline $\mathbf{3}$ & 3 & 14 & SPECIFIC CEREBROVASCULAR DISGRDERS EXCEPT TKANSIENT ISCHEMIC ATTACK \\
\hline 4 & 3 & 88 & CHRONIC OBSTRLCTIVE PULMONARY DISEASE \\
\hline 5 & 3 & 430 & PSYCHOSES \\
\hline 6 & 6 & 209 & MAJOR JOINT AND LIME REATTACHMENT PROCEDURES OF LOWER EXTREMTTY \\
\hline 7 & $\mathbf{T}$ & 140 & ANGINA PECTORIS \\
\hline 8 & 7 & 182 & $\begin{array}{l}\text { ESOPHAGITIS, GASTROENTERTIS AND MISCELLANEOUS DIGEST DISOFDERS AGE } \\
\text { GREATER THAN I T WITH COMP }\end{array}$ \\
\hline 9 & 9 & 112 & PERCUTANEOUS CARDIOVASCULAR PROCEDURES \\
\hline 10 & $\mathbf{g}$ & 174 & OASTRONTESTENAL HEMORRHAGE WITH COMPLICATIONS \\
\hline II & II & 296 & $\begin{array}{l}\text { NUSRTTIONAL AND MUSCELLLANEOUS META AOULIC DHSORDERS AGE OREATER THAN } \\
\text { I W WITH COMPLICATIONS }\end{array}$ \\
\hline 12 & 12 & 138 & CAROLAC ARRFYTHMLA AND CONDUCTION DISORDERS WTTH COMPLICATIONS \\
\hline I3 & 13 & 143 & CHEST PAN \\
\hline 14 & 14 & 79 & $\begin{array}{l}\text { RESPIRATORY INFECTKONS AND INFLAMMATIONS AGE GREATER THAN IT WITH } \\
\text { COAFPLICATIONS }\end{array}$ \\
\hline 15 & 14 & 416 & \$EPTXCEMA AGE GREATER THAN 17 \\
\hline 16 & 16 & 462 & REHABILITATION \\
\hline 17 & 17 & 148 & MAKOR SMAL AND LARGE BOWEL PROCEDURES WTTH COMPLICATIONS \\
\hline JB & 18 & 121 & $\begin{array}{l}\text { CIRC. DISORDERS WITH ACUTE MYOCARDUAL DNFARCTION AND CARDIOVASCULAR } \\
\text { COMOPLCATIONS DISCHARGED ALIVE }\end{array}$ \\
\hline 19 & 18 & 320 & $\begin{array}{l}\text { KIDNEY AND URNARY TRACT INFECTIONS AGE GREATER THAN IJ WITH } \\
\text { COMPLKATIONS }\end{array}$ \\
\hline 20 & 18 & 410 & CHEMOTHERAPY WIJHOUT ACUTE LEUKEMIA AS SECONDARY DIAGNOSIS \\
\hline
\end{tabular}


Table 21. Rank order dollar: weighted ranks for the top 20 DRG's ranked by total covered charges' for inpatient data" only

\begin{tabular}{|c|c|c|c|}
\hline NUMBER & $\begin{array}{l}\text { WT } \\
\text { RANK }\end{array}$ & DRG & DESCRIPTION \\
\hline I & l & 209 & MAYOR KONT AND LIMB REATTACHMENT PFOCEDURES OF LOWER EXTREMTY \\
\hline 2 & $\mathbf{I}$ & 483 & TRACHEOSTOMY EXCEPT FOR FACE, MOUTH AND NECK DIAGNOSES \\
\hline 3 & 3 & 106 & CORONARY BYPASS WTTH CARDUAC CATHETERIZATJON \\
\hline 4 & a & $\$ 27$ & HEART FAILURE AND SHOCK \\
\hline 3 & 5 & 148 & MAOR SMALL AND LARGE BOWEL PROCEDURES WITH COMPLICATIONS \\
\hline 6 & 6 & 89 & SIMPLE PNEUMONIA AND PLEURISY AGE GREATER THAN I 7 WITH COMPLICATIONS \\
\hline 7 & 6 & 430 & PSYCHOSES \\
\hline 8 & 6 & 112 & PERCUTANEOUS CARDIOVASCULAR PROCEDURES \\
\hline 9 & 9 & 14 & SPECIFIC CEREBROVASCULAR DISDRDERS EXCEPT TRANSIENT ISCHEMIC ATTACK \\
\hline 10 & 10 & 462 & REHABILTATION \\
\hline II & II & 475 & RESPIRATORY SYSTEM DIAGNOSLS WTIH VENILATOR SUPPORT \\
\hline 12 & 12 & 88 & CHRONIC OESTRUCTIVE PULMONARY DISEASE \\
\hline$\$ 3$ & 12 & 79 & $\begin{array}{l}\text { RESPIRATORY JNFECTIONS AND INFLAMTMATIONS AGE GREATER THAN IT WITH } \\
\text { COMPLICATLONS }\end{array}$ \\
\hline 14 & 12 & 107 & CORONARY BYPASS WITHOUT CARDIAC CATHETERIZATON \\
\hline 15 & 15 & 478 & OTHER VASCULAR PROCEDURES WITH COMPLICATHONS \\
\hline 16 & 16 & 416 & SEPTICEEMIA AGE GREATER THAN IT \\
\hline 17 & 16 & 468 & EXJENSIVE OPERATING ROOM PROCEDURE UNRELATED TO PRINCIPAL DHAGNOSIS \\
\hline 18 & 16 & 110 & MAJOR CARDHOVASCULAR PROCEDURES WTH COMPLICATIONS \\
\hline 19 & 19 & 121 & $\begin{array}{l}\text { CIRCULATORY DISORHERS WITH ACUTE MYOCARDIAI. DNFARCTION AND } \\
\text { CARDIOVASCULAR COMPLICATHON, DISCHARGED ALIVE }\end{array}$ \\
\hline 20 & 20 & 174 & GASTROINTESTINAL HEMORRHAGE WITH COMPLICATIONS \\
\hline
\end{tabular}

* Inpatient data - 1994 Medicare (MedPAR) and 1994 Nesicasl lapatlent Simpte

+ Total covered charge was gevierated using the national average Medicare "covered ${ }^{n}$ tharge per DRG time the fitequency of uhe relevant DRG 
Table 22. Rank Order Volume: top 20 DRGs ranked by the weighted national estimates of the total number of discharges for 1994 National Inpatient Sample Data

\begin{tabular}{|c|c|c|c|}
\hline RANK & DRt & DESCRFMTION & $\begin{array}{l}\text { WETCHFED } \\
\text { ESTOMATE OF } \\
\text { TOTAL } * \text { OF } \\
\text { DISCRARGES }\end{array}$ \\
\hline $\mathbf{a}$ & 373 & $\begin{array}{l}\text { VAGINAL DETHEAY WITHOUTT COMIPLCATING } \\
\text { DAACNOSES }\end{array}$ & $2,408,55$ \\
\hline 2 & 3is & NORMAL NEWHOTNN & $2,4, \overline{317}$ \\
\hline 3 & 127 & HEART FAMURE AND SHOCK & 951.821 \\
\hline 4 & 30 & REONATE WTIH OTHEA SIGNIFICANT PROBLEME & 619.99 \\
\hline 5 & $\mathbf{4 3 0}$ & PSYCFOSES & $73,5,316$ \\
\hline 6 & 89 & $\begin{array}{l}\text { STMLE PVUIMONIA AND PLEURISY AGE GREATKR } \\
\text { THAN I7 WTTH COMPL, ICATIONS }\end{array}$ & 615,274 \\
\hline 7 & 37 & CESAREAN SECTION WTTHOUT' COMIPLKATION & 563,507 \\
\hline$\overline{8}$ & 14 & $\begin{array}{l}\text { SFECEFIC TERCBROVASCULAR DISORD SRS EXCEPT } \\
\text { TRANGSIENT ISCHEMAC ATTACK }\end{array}$ & 534,237 \\
\hline 9 & 88 & CHRONIC OBSTXUC:TYE PULMONARY DHSEASE & 511,64 \\
\hline 10 & 209 & $\begin{array}{l}\text { MAJOR FONNT AND LMB REATTACFMENT PROCEDURES } \\
\text { OF LOWER EXTREMITY }\end{array}$ & $5 \times 0,46$ \\
\hline 11 & 112 & PEACUTANEOUS CARDIOVASCULAR PROCFDURES & 44,14 \\
\hline$\overline{12}$ & 18Z & $\begin{array}{l}\text { ESOPHAGITS, GASTROENTERITS AND } \\
\text { MISCELLANEOUS DIGESTIVE DISORDERS AGE GREATER } \\
\text { THAN 17 WITH COMPLICATIONS }\end{array}$ & 450.576 \\
\hline 13 & 140 & ANGINA FLCTORIS & 445,797 \\
\hline 14 & 143 & CHEST PADN & 430,976 \\
\hline$\overline{15}$ & 174 & $\begin{array}{l}\text { GASTROINFESTINAL HEMORRHAGE WTH } \\
\text { COMPLICATKONS }\end{array}$ & $400, \$ 43$ \\
\hline 16 & 359 & $\begin{array}{l}\text { UTERINE AND ADNEXA PROCETLIRES FOR NON- } \\
\text { MALJGNANCY WTHHOUT COMPLICATIONS }\end{array}$ & $341, \overline{961}$ \\
\hline 17 & $\bar{m}$ & VAGINAL DEWVERY WTHH COMIPLCATING DIAGNOSES & 328,331 \\
\hline 18 & 309 & FULL TERM NEONATE WTTH MAVOR PROBLEMES & 323,689 \\
\hline 19 & $2 \% 6$ & $\begin{array}{l}\text { NUTRITONAL ANID MHSCELLANEOUS MIETABOLIC } \\
\text { DSORDERS AGE GREATER THAN IT WITH } \\
\text { COMPLICATTONS }\end{array}$ & 320,202 \\
\hline (3) & 138 & $\begin{array}{l}\text { CAROLAC ARPHYTHML AND CONDUCTION DISORDERS } \\
\text { WFTH COMPLICATIONS }\end{array}$ & 314,685 \\
\hline
\end{tabular}




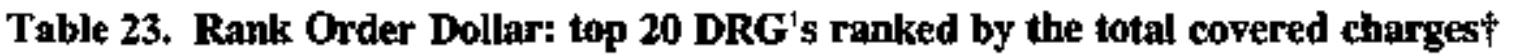
For the 1994 National Impatient Sample (NSS) Data

\begin{tabular}{|c|c|c|c|c|c|}
\hline RANT & DRG & DESCRIPTION & $\begin{array}{l}\text { AVRRAGE } \\
\text { COV HCFA } \\
\text { CHARGES }\end{array}$ & $\begin{array}{l}\text { WEIGETED } \\
\text { EST * OF } \\
\text { Disch }\end{array}$ & $\begin{array}{l}\text { TOYTAL } \\
\text { COVERED } \\
\text { CHARGES }\end{array}$ \\
\hline$\overline{\mathbf{1}}$ & $\mathbf{4 8 3}$ & $\begin{array}{l}\text { TRACHEOSTOMY EXCHPT FOR FACE, } \\
\text { MOUTH AND NECK DIAGNOSES }\end{array}$ & $\$ 152,190.60$ & 71,385 & $\$ 10,864,126,001$ \\
\hline 2 & 259 & $\begin{array}{l}\text { MUOR JOLNT AND LWAS REATTACFHENT } \\
\text { PHOCEDURES OF LOWER EXTHEMITY }\end{array}$ & $\$ t 9,76 * 4 \$$ & 50,476 & $\$ 9,894,358,667$ \\
\hline 3 & $1 \mathbf{1 8}$ & $\begin{array}{l}\text { CORGNARY BYPASS WITH CARDIAC } \\
\text { CATRETERIZATION }\end{array}$ & $\$ 51,476.88$ & 176,187 & $59,469,522,569$ \\
\hline 4 & 369 & $\begin{array}{l}\text { FULL TERM NEONATE WTTH MAJOR } \\
\text { FROELESS }\end{array}$ & 527,425 & 323,68 & $\$ 9,057,649,027$ \\
\hline $\mathbf{5}$ & 410 & PSYCHONOS & $\$ 11,299.10$ & $7 \times 3,316$ & $\$ 4,997,634,247$ \\
\hline 6 & 127 & HEART FAILURE AND SHOCK & $\$ 9,016,47$ & 951,821 & $\$ \mathrm{a}, 50 \mathrm{~L}, 583,405$ \\
\hline 7 & 112 & $\begin{array}{l}\text { PXRCUTANEOUS CARDIOYASCELAR } \\
\text { PROCEDUR'S }\end{array}$ & $518,516.73$ & 454,142 & $58,469,223,461$ \\
\hline$\overline{8}$ & 373 & $\begin{array}{l}\text { VAGINAL DELJVERY WTTHOU' } \\
\text { COMPLCATLNG DAGNOSSS }\end{array}$ & $5 \longdiv { 3 , 3 2 4 , 6 }$ & $2,488,5$ & $59,273,26,258$ \\
\hline 5 & 148 & $\begin{array}{l}\text { MAJOR SMALL ANT IAARGE BOWEL. } \\
\text { PROCEDURES WTTH COMPLICATIONS }\end{array}$ & $\$ 29,145.64$ & 274,396 & $\$ 7,497,447,481$ \\
\hline 16 & 89 & $\begin{array}{l}\text { STMFLE FTEUMONA AND PLEURISY AGE } \\
\text { GREATRR THAN IT WITH COMPI,1CATIONS }\end{array}$ & $\$ 9,494,51$ & 615,274 & $55,835,573,680$ \\
\hline $\mathbf{1 1}$ & 14 & $\begin{array}{l}\text { SPECIFIC CERERROVASCULAR DISORTRRS } \\
\text { EXCEFT TRANSIENT WCHIMIC ATTACK }\end{array}$ & \$ 10,695.51 & 534,237 & $\$ 5,713,956,653$ \\
\hline $\mathbf{1 2}$ & 30 & $\begin{array}{l}\text { NEONATE WTH OTHER SIGNIFICANT } \\
\text { PRODIEMS }\end{array}$ & $\$ 6,707, \$ 1$ & 819,659 & $\$ \$, 4,4,116,446$ \\
\hline i3 & 475 & $\begin{array}{l}\text { RESPIRATORY SYSTEM DIAGNOSIS WTTH } \\
\text { VENTILATOR SUPPORT }\end{array}$ & $\$ 33,367,58$ & 160,178 & $55,344,752,387$ \\
\hline $\mathbf{1 4}$ & 107 & $\begin{array}{l}\text { CORONARY BYPASS WTTHOUT CARDIAC } \\
\text { CATHETERIZATION }\end{array}$ & $\$ 39,645.84$ & 124,828 & $54,948,911,258$ \\
\hline 15 & $4 \sqrt{4}$ & REFABLITATION & $\$ 16,982,44$ & 268,745 & $\$ 4,563,945,341$ \\
\hline $\mathbf{1 6}$ & 88 & $\begin{array}{l}\text { CFRONIC ORSTRUCTIVE FULAONARY } \\
\text { DISEASE }\end{array}$ & 5 B.489.62 & 511,064 & $\$ 4,338,737,177$ \\
\hline$\overline{17}$ & 468 & $\begin{array}{l}\text { EXTENSIVE OPEALTING ROOM } \\
\text { PROCBDURE UNRELATED TO PRINECTPAL } \\
\text { DLAGNOSTS }\end{array}$ & $\$ 31,439,48$ & $130,52 \%$ & $54,102,536,3,5$ \\
\hline$\overline{18}$ & 79 & $\begin{array}{l}\text { RESPIRATORY INFECTIONS AND } \\
\text { INFLAMMATONS AGE GREATER THAN } 17 \\
\text { WTIH COMPLICATIONS }\end{array}$ & $\$ 14,303.48$ & 273,835 & $\$ 3,916,794,448$ \\
\hline 19 & 110 & $\begin{array}{l}\text { MANOR CARDTOVASCULAR FROCEDURES } \\
\text { WTH CONIPLICATIONS }\end{array}$ & $\$ 37,637.83$ & 109 독 & $\$ 3,89,661,010$ \\
\hline 20 & 48 & $\begin{array}{l}\text { OTAIRR VASCULA PROCEDURTS WTTH } \\
\text { COMPLICATJONS }\end{array}$ & $\$ 21,024.77$ & 180,894 & $\$ 3,815,917,656$ \\
\hline
\end{tabular}

$\uparrow$ Total covered charges was gencrpted using the national averge Medicare "covered" charpe per DRG limes the frequertey of the releverm DRG identified in the NIS dats 
Intentionally Left BJank 


\section{Appendix B - Econometric Analysis of Savings Available from PTCA Innovation: The Nine Category Approach}

\section{Introduction}

There are two competing technologies for the treatment of Coronary Artery Diseases (CAD), PTCA and CABG. It is generally recognized that for those patients for which it is appropriate, PTCA is the less expensive treatment, at least for the initial intervention. For many patients, however, PTCA is not an appropriate treatment. The goal of this part, as well as the next, is to determine the amount of savings available if new technologies could make PTCA viable for the patients who currently undergo CABG treatment.

This amount cannot be calculated by simply taking the average CABG treatment costs and subtracting it from the average PTCA treatment cost. The reason is that CABG patients have systematically different characteristics than PTCA patients. In particular, CABG patients may be "sicker" and thus require more intersive treatment. This requirement would continue to be true even if it were possible to treat those patients with PTCA.

Thus, we attempt to conduct a hypothetical "thought exercise": How much would be saver if we could treat CABG patients with PTCA technology? A special feature of this test is that we are able to break down costs by nine separate areas in the hospital. Thus, not only ane we able to predict the relevant cost savings, but also to predict where in a hospital those cost savings would occur.

\section{Data Sources}

Our data comes from a large hospital in a major city in the Southern part of the United States. We have in our data every patient who underwent either CABG or PTCA at that hospital during 1994. We also have data on detailed charges for each patient Thus, for one patient we could conceivably have thousands of individual charges items in our data set. We will conduct our analysis on both charges and costs. We will generate costs by employing detailed cost to charge ratios reported by that hospital for Medicare cost reports.

We have taken the numerous charges per patient and aggregated them into nine calegoties. The nine categories are

1. room charges, 
2. intensive care,

3. laboratory and radiology,

4. pharmacy,

5. rebabilitation,

6. operating room,

7. catheterization laboratory,

8. cardiovascular diagnostic, and

9. miscellaneous.

Due to the differences in procedures, CABG and PTCA patients are likely to have different intensities of uses across several of the categories. For instance, PTCA treatments make intensive use of the catheterization laboratory and Jittle use of the Operating Room. For CABG, the reverse is true. This presents estimation issues that we will deal with below in Section III.

We also have detailed data on patients' health conditions, and use it as explanatory variables in our regressions. The patient characteristics are:

1. Treatment type. (Abbreviated below as TREAT) The treatment the patient underwent, $\mathrm{CABG}=1, \mathrm{PTCA}=0$;

2. Comorbidity (COM). The comorbidity score of the patient, which indicates the severity of illnesses other than CAD that the patient might heve;

3. Gender. Whether or not the patient was a man (Gendes=1) or a woman (Gender=0);

4. Smoker. Equals 1 if patients smokes, 0 otherwise;

5. Age. Age of the patient in years;

6. Acute myocardial-infarction within 24 hours of admission (AMI=1 if occurred, 0 otherwise);

7. If the patient had prior $\mathrm{CABG}$ treatment (PR_CABG=1 if treated with $\mathrm{CABG}$ previously, 0 otherwise);

8. If the patient had a prior PTCA treatment (PR_PTCA=1 if previously treated, 0 otherwise);

9. The ejection fraction of the patient's heart (EF60). We note that many patients had missing data for this entry. Consultations with clinicians indicated that this is likely to occur when the patients has a normal ejection fraction of 60 . We therefore set the EF 60 of patients with unknown values to 60 ;

10. Whether the patient's heart had stenosis of two or more vessels (VES2);

11. Whether the patient's heart had stenosis of three or more vessels (VES3);

12. Whether the patient's heart had stenosis of the left main artery (LEFT);

13. The number of umpredicted adverse events that occurred to the patient while in the hospital (UNADV). We describe how this variable is derived below in Subappendix B 1. Table 24 presents the variable means, broken down by CABG and PTCA patients. 
Table 24. Variable Means (Standard Deviations in Parentheses)

\begin{tabular}{|c|c|c|c|}
\hline Variable & CABG Patients & PTCA Patients & All Patients \\
\hline Comorbidity & $1.78(1.86)$ & $1.43(1.56)$ & $1.53(1.65)$ \\
\hline Gender & $0.20(0.40)$ & $0.32(0.47)$ & $0.28(0.45)$ \\
\hline Smoker & $0.55(0.50)$ & $0.35(0.48)$ & $0.41(0.49)$ \\
\hline Age & $62.56(9.95)$ & $64.50(11.60)$ & $63.96(11.2)$ \\
\hline AMI & $0.09(0.26)$ & $0.10(0.30)$ & $0.10(0.29)$ \\
\hline Prior CABG & $0.12(0.33)$ & $0.28(0.45)$ & $0.24(0.43)$ \\
\hline Prior PTCA & $0.18(0.39)$ & $0.38(0.49)$ & $0.33(0.47)$ \\
\hline EF & $52.18(15.00)$ & $55.70(13.50)$ & $54.73(14.0)$ \\
\hline VES2 & $0.94(0.25)$ & $0.67(0.47)$ & $0.74(0.44)$ \\
\hline VES3 & $0.83(0.38)$ & $0.37(0.48)$ & $0.50(0.50)$ \\
\hline LEFT & $0.29(0.46)$ & $0.06(0.25)$ & $0.13(0.33)$ \\
\hline UNADV & $-0.16(2.79)$ & $-0.14(2.04)$ & $-8.15(2.27)$ \\
\hline Room Charges (\$) & $5720(4717)$ & $2019(1826)$ & $3038(3354)$ \\
\hline Intensive Care Charges (\$) & $8349(17623)$ & $2831(5077)$ & $4351(10,48)$ \\
\hline Laboratory/ Radiology Charges (\$) & $4285(10,146)$ & $1579(2508)$ & $2365(4) 62)$ \\
\hline Phamacy Charges (\$) & $4284(10,147)$ & $1018(2586)$ & $1917(5931)$ \\
\hline Rehabilitation Charges (\$) & $628(680)$ & $105(227)$ & $249(459)$ \\
\hline Operating Room Charges (\$) & $21,340(6427)$ & $527(1945)$ & $6259(10,03)$ \\
\hline Catheterization Laboratory Charges (\$) & $2427(3174)$ & $15,822(6419)$ & $12,133(827)$ \\
\hline Cardiovaseular Diagnostic Charges (\$) & $647(2100)$ & $571(3795)$ & $592(3412)$ \\
\hline Miscellaneous Charges (\$) & $12,050(20344)$ & $1984(5641)$ & $4756(12,51)$ \\
\hline Total Charges (\$) & $59,917(63,154)$ & $26,457(20,898)$ & $\begin{array}{c}35,672 \\
(40,408)\end{array}$ \\
\hline Number of Observations & 141 & 37 & 512 \\
\hline
\end{tabular}




\section{Econometric Issues}

One of the things we wish to accomplish is to predict the savings associated with switching a CABG patient to PTCA. To do so requires that we apply the proper econometric modeling. In this context, we face two important econometric issues: sample selection bias and censoring.

\section{Sample Selection Bias}

Sample selection bias may result because trearment type is a function of many of the same variables that determine charge (or cost). If selection bias does occur to a high degree. Ordinary Least \$quares (OLS) regression is not the appropriate estimation procedure. For example, consider whether or not a particular patient is a smoker. This variable will influence both charge and treatment type. The question arises as to how smoking effects charge. Does smoking increase charge because it increases the resources necessary for care, or does it increase charge because it increases the probability of the patient receiving a CABG, which is a more expensive procedure? Because treatment is not necessarily determined in a linear way, the question of selection bias is both important and complex.

In an attempt to determine if selection bias is important to the charge equations, we first performed the estimation of a model where each regression is allowed to have a different set of coefficients and then a regression where both sets of coefficients were restricted to be the same. First we will explain the structure of the model, and then we will explain the econometric results

We start by assuming a model of the choice made between PTCA and CABG.2 We assume that the probability of a CABG treatment for patient (i) is $\Phi\left(\gamma Z_{i}\right)$, where $\Phi()$ is the cumulative normal density function, $\gamma$ is a set of estimated coefficients, and $Z_{i}$ is the set of explanatory variables. In Subappendix B2 we report the results of this "Probit" estimation for our data set.

Given this choice, we have two potential econometric models. For CABG patients, we have

Charge $=b_{0}{ }^{\prime} X_{1}+b_{\text {ad }}$ if $\gamma Z_{1}<\varepsilon_{1}$ t.e., if CABG treatment (see Subappendix B1) and for PTCA patients;

Charge $=b_{p}{ }^{\top} X_{j}+u_{p i}$ if $\gamma Z_{i}<\varepsilon_{i}$ i.e. if PTCA treatment. (2)

\footnotetext{
2 For the most part this model comes from: G.S. Maddala, Limited Dependent and Qualitative Variables in Econometrics, Econometric Society Monographs, Cambridge University Press, 1983, pp 223228.
} 
In these equations, $b_{c}$ and $b_{v}$ represent the estimated coefficients on the CABG and PTCA costs functions, $X_{i}$ represents the set of explanatory variables described above, and $v_{c i}$ and $\mathrm{u}_{\mathrm{pt}}$ represent the nomally distributed error terms on each charge equation.

In order to estimate the model in a way which allows us to test the validity of the assumption of different coefficients, we must reformulate the model. If we take the expected value of Charge we get:

$$
\begin{aligned}
& \mathrm{E}(\text { Charge })=[\mathrm{E}(\mathrm{Charge} \mid \mathrm{TREAT}=\mathrm{CABG})] \cdot[\mathrm{Prob}(\mathrm{TREAT}=\mathrm{CABG})] \\
& \left.+[\mathrm{E}(\text { Charge|TREAT }=\text { PTCA })]{ }^{\circ} \text { Prob(TREAT=PTCA }\right) .(3)
\end{aligned}
$$

Here $E$ is the expected value operator and "|" is read as "given that". The expected value of Charge is equal to the expected value of Charge given that Treatment is CABG times the probability that Treatment is CABG plus the expected value of Charge given that Treatment is PTCA times the probability that Treatment is PTCA.

If we put the equation for $\gamma \mathrm{Z} i$ into probit form, we can recover the results of the probit estimation of PTCA vs. CABG. The probability of individual $i$ receiving a CABG is given by $F\left(\gamma Z_{j}\right)$ which is the $C D F$ of a normal zero-one randon variable. Because patients only arrive in our sample if they undergo either CABG or PTCA, if the probability of CABG is $F_{i}$ it implies the probability of PTCA is $1-F_{i}$.

Each of the charge equations (1) and (2) is a truncated regression. A truncated regression is a regression which has some of the useable observations removed based on some criteria, here treatment type. This type of truncation results in an expectation of the form. $\mathrm{E}(\mathrm{Charge})=\mathrm{b}^{\prime} \mathrm{X}_{\mathrm{i}}-\mathrm{s}\left(\mathrm{f} / \boldsymbol{F}_{\mathrm{i}}\right)$ (Maddala equation 8.12) for truncation "from below " (CABG equation) and $\mathrm{E}(\mathrm{Charge})=\mathrm{b}^{\top} \mathrm{X}_{i}+\mathrm{s}\left(\mathrm{f}_{i} / 1-\mathrm{F}_{i}\right)$ (Maddala equation 8.13$)$ for truncation "from above " (PTCA equation), where $f_{i}$ is the PDF of a nomal zero-one variable.

The term on the end of the equations, $s\left(f_{i} / F_{i}\right)$ or $s\left(f_{i} / 1-F_{i}\right)$ accounts for the truncation. The $\mathbf{S}$ variable is the standard deviation of the equation, implying there is a different $\mathbf{s}$ associated with each equation. The variable $s_{\mathrm{cm}}$ is the standard error of the CABG only (equation (1)) and $s_{p o}$ is the standard error from the PTCA only (equation (2)). Though $s$ is a defined parameter it can be treated as a coefficient to be estimated, because asymptotically (as our data set becomes systematically larger) the estimated value will equal the true value.

Filling in the values for each of the pieces of equation (3) yields:

$$
\begin{array}{r}
E(\text { Charge })=\left\{b_{c}{ }^{\prime} X_{i}-s_{c a}\left(f_{f} / F_{i}\right)\right]^{\prime}\left[F_{i}\right] \\
+\left[b_{p}{ }^{\prime} X_{i}+s_{p u}\left(f_{i}\left(1-F_{i}\right)\right)\right]^{\prime}\left[1-F_{i}\right] .
\end{array}
$$


Multiplying this out gives us

$$
E(\text { Charge })=b_{\varepsilon}{ }^{\prime} X_{i} \Phi_{i}-s_{q u} f_{j}+b_{p} X_{i}\left(1-\Phi_{i}\right)+s_{p u} t_{i} .
$$

Rearranging equation (5) eventually yields

$$
E(\text { Charge })=b_{p}{ }^{\prime} X_{i}+\left(b_{c}{ }^{\prime}-b_{p}{ }^{\prime}\right) X_{i} F_{i}+f_{i}\left(s_{p u}-s_{c y}\right) \text {, }
$$

where $F_{i}$ and $f_{i}$ are from the probit of PTCA vs. CABG.

This form has several advantages. $X_{i}$ is known and both $F_{i}$ and $f_{i}$ are estimable via the Probit procedure discussed in Subappendix B2. Therefore the model can be expressed as a simple linear regression with $b_{p}{ }^{\prime},\left(b_{c}{ }^{\prime}-b_{p}{ }^{\prime}\right)$, and $\left(s_{p u}-s_{e u}\right)$ as coefficients to be estimated. It is straightforward to test whether the individual coefficients are significantly different between the CABG and PTCA equations. It is accomplished for one coefficient by a simple t-test on the appropriate coefficient of $\left(b_{c}{ }^{\prime}-b_{p}{ }^{\prime}\right)$; if the coefficient is significantly different than zero then the coefficients in each model are significantly different. The whole model specification can be tested by a likelihood ratio test on the coefficients of $\left(b_{c}{ }^{\prime}-b_{p}{ }^{\prime}\right)$ and $\left(s_{p u}-s_{e u}\right)$.

Using the estimated, rather than the actual, values of $F_{i}$ and $f_{i}$ introduces heteroskedasticity into the equation. This causes the estimated t-statistics to be biased away from zero. Therefore we use a likelihood ratio test to test the validity of the model.

The likelihood function is a measure of how likely the it is for us to get the actual observed results, based on the estimated model. The likelihood function measures how closely the pattem of dependent variables based on the estimated coefficients match the actual observed patten of dependent variables. One of the things OLS does is to maximize the value of the likelihood function. The likelihood function is a well known function which gives us a number that we may use to test different model specifications.

The likelihood ratio test requires the estimation of two models; the restricted and the unrestricted models. We then generate a statistic that allows us to test whether the two models are significantly different in a statistical sense. Specifically, $2^{\circ}\left[\ln \left(L_{\text {uwrstrictsa }}\right)\right.$ $\left.\ln \left(\mathrm{L}_{\text {restriesd }}\right)\right] \sim \mathrm{c}^{2}$ (\# restrictions). The symbol " $\sim$ " is read "is distributed as", "ln" is the natural logarithm operator, " $L$ " is the value of the likelihood function from the appropriate model, and "\#restrictions" is the number of restrictions on the restricted model which ate the degrees of freedom for the $c_{2}$ statistic. For this specific instance the two models are:

and

$$
\text { Charge } e_{\text {wrestricted }}=b_{p}{ }^{\prime} X_{i}+\left(b_{c}{ }^{\prime}-b_{p}{ }^{\prime}\right) X_{i} F_{j}+f_{i}\left(\sigma_{p w}-s_{c u}\right)+\text { error }
$$

$$
\text { Charge }_{\text {restriated }}=b_{p}{ }^{\prime} X_{i}+\text { error }
$$


Equation (8) is the restricted model with the restrictions that $\left(s_{p v}-s_{c}\right)$ and $\left(b_{c}^{\prime}-b_{p}\right)$ are zero. Note that (8) is a straightforward linear regression model, while (7) is the more complex switching model defined originally by equations (1) and (2).

First we estimated equations ( $(7)$ and ( 8 ) by OLS to compare the likelihood ratios. There are 13 coefficients restricted to be zero; twelve for $\left(b_{c}{ }^{\prime}-b_{p}{ }^{\prime}\right)$ and one $\left(s_{p s}-s_{c u}\right)$. That is that the twelve coefficients on the explanatory variables are the same for both PTCA and $\mathrm{CABG}\left[\mathrm{b}_{\mathrm{c}}{ }^{\prime}=\mathrm{b}_{\mathrm{p}}{ }^{\prime}\right.$ or $\left.\left(\mathrm{b}_{\mathrm{c}}{ }^{\prime}-\mathrm{b}_{\mathrm{p}}{ }^{\prime}\right)=0\right]$, and the standard error of both models is the same $\left[\left(\mathrm{s}_{\mathrm{vg}}{ }^{-}\right.\right.$ $\left.\mathrm{s}_{\mathrm{cu}}\right)=0$ ]. The $95 \%$ critical value from a $\mathrm{c}^{2}(13)$ is approximately 22.36 , thus any resuit above 22.36 would indicate that the appropriate model is the switching model postulated in (1) and (2) while lower results would indicate that the correct model should be a simple linear model with all coefficients the same for both PTCA and CABG. The results are summarized below in Table 25.

Table 25. Test of Different Coefificients for CABG and PTCA. 95\% Cutoff Threshold: 22.3620 .

\begin{tabular}{|c|c|c|c|}
\hline Category & $\begin{array}{l}\text { Log-Likelihood of } \\
\text { Unrestricted Model } \\
\text { (Equation (7)) }\end{array}$ & $\begin{array}{l}\text { Log-Likelihood of } \\
\text { restricted Model } \\
\text { (Equation (8)) }\end{array}$ & 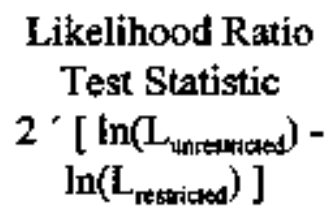 \\
\hline Room & -1060.99 & -1067.90 & 13.82 \\
\hline Intensive Care & -1258.73 & -1264.13 & 10.80 \\
\hline $\begin{array}{l}\text { Laboratory/ } \\
\text { Radiology }\end{array}$ & -1050.51 & 1055.28 & 9.54 \\
\hline Pharmacy & -654.78 & $-667,93$ & 26.30 \\
\hline Rehab & -1080.37 & -1092.37 & 24.00 \\
\hline Operating Room & -1077.26 & -1092.30 & 30.08 \\
\hline $\begin{array}{c}\text { Catheterization } \\
\text { Lab. }\end{array}$ & -1122.25 & -1135.28 & 26.06 \\
\hline $\begin{array}{c}\text { Cardiovascular } \\
\text { Diag. }\end{array}$ & -778.64 & -785.42 & 13.56 \\
\hline Misceilaneous & -643.98 & -655.58 & 23.21 \\
\hline
\end{tabular}

The likelihood ratio statistic is chi square variable with 13 degrees of freedom. At the $95 \%$ level this value is 22.3620 . Therefore, if the likelihood ratio test statistic is greater than 22.3620 we reject the hypothesis that model (1) is the correct model. 
The relevant statistics for Room, Intensive Care, Laboratory/Radiology, and Cardiovascular Diagnostic are all below this critical level. This implies that it is appropriate to run one regression with CABG and PTCA patients together for those four categories., using the treatment variable alone to ascount for the difference between CABG and PTCA patients. The relevant statistics for Pharmacy, Rehabilitation, Operating Room, Catheterization Laboratory, and Miscellaneous, however, are all above the cutoff level of 22.36. This implies that we should run two separate regressions for each category, one for the CABG patients and one for the PTCA patients.

\section{Censoring}

For many of the patients, charges in particular categories were zero. For example Operating Room Charge is zero for many patients because PTCA does not, in general, require an time in the operating room. Because of this, the question of censoring arises. A censored regression is one in which the dependent variable must be greater than some level in order to be observed. If it is not greater than this critical value, then a zero is observed. Take, for example, Intensive Care Charge. This variable is dependent on how "sick" a patient is, the "sicker" the patient, the higher the intensive care charge.

However, the patient must have some minimum level of "sickness" before he is remitted to intensive care. If we try to estimate a linear model when a censored model is appropriate, then wur estimates may be biased. In other words, using a linear model, implies everyone with an Intensive Care charge of zero would be required to be equally "sick", which may not be true.

Expressed mathematically, let the "sickness" of a patient be $a$ ' $X_{i}$. So we have a model of the form:

$$
\begin{gathered}
\text { Charge }=a^{\prime} X_{i}+u_{i} \text { if } a^{\prime} X_{i}+u_{i}>0(9) \\
\text { Charge }=0 \text { if } a^{\prime} X_{i}+u_{i}<0 \quad(10)
\end{gathered}
$$

Note that in this model the minimum "sickness" level is set to 0 . If we were to change it, the only effect would be to change the constant term by whatever we set the minimum level to be. Thus we use zero for simplicity.

A well- known procedure, called Tobit, exists for estimating this type of modei. Estimation of a Tobit model is very similar to the switching model defined by (1) and (2). All that is necessary is to define separate functions for each of the cases (9) and (10). First take the expected value as defined by:

$\mathrm{E}($ Charge $)=[\mathrm{E}($ Charge $\mid$ Charge $>0)] '[$ Proh $($ Charge $>0)]$

$+[\mathrm{E}(\text { Charge } \mid \text { Charge }=0)]^{\circ}[$ Prob $($ Charge $=0)] . \quad(11)$ 
If we define a durnmy variable that is zero when Charge $=0$, and 1 when Charge $>0$, then perform a Probit analysis with that dummy as the dependent veriable and $X$ as the jndependent variables we can estimate Prob(Charge = 1) and Prob(Charge $=0)$.

Specifically, the estimated probability is $F\left(d^{\prime} X_{i}\right)=F_{i}=\operatorname{Prob}\left(C_{\text {Charge }}=1\right)$ and $\left(1-F_{i}\right)=$ Prob(Charge $=0$ ), where $d$ are the estimated probit coefficients. It can be shown that $E($ Charge $\mid$ Charge $>0)$ can be estimated by a' $X_{i}+s\left(f_{i} / F_{i}\right)$, where $f_{i}$ and $F_{i}$ are estimated from the probit analysis, and $s$ can be treated as a coefficient to be estimated. Of course, $\mathbf{E}$ (Charge|Charge $=0$ ) is 0 . Filling in the vajues for equation (11) gives us:

$\mathrm{E}($ Charge $)=\left[a^{r} X_{i}+s\left(\phi_{i} / F_{j}\right)\right] \cdot\left[F_{i}\right]+[0] \cdot\left[1-F_{j}\right](t 2)$

This can be rearranged into:

$$
\mathrm{E}(\text { Charge })=a^{\prime} \mathrm{X}_{\mathrm{i}} \mathrm{F}_{\mathrm{i}}+\mathrm{sf}_{\mathrm{i}},(13)
$$

which can be estimated either by maximum likelinood methods or by a two step process.

We performed the Tobit analysis on all of the Charge categories where it was appropriate (where there were sufficient zeros). Pharmacy Charge and Miscellaneous Charge did not contain zeros and thus were not estimated via Tobit, but all others were. (If all observations are positive, then the two procedures would be identical.)

Equation (13) varies from a straight OLS estimate in $F_{i}$ and $s_{i}$. A sufficient restriction to make the Tobit equation equal to the OLS equation is $F=1$, which means that all observations are positive. This would imply $f=0$. The $95 \%$ value for one restriction is $\mathrm{c}^{2}(1)=3.84146$. This statistic is calculated by taking twice the differences of the relevant log-likelihood functions. Below Table 26 shows the likelihood ratio tests statistics for Tobit vs. OLS.

Table 26 shows that for five of the seven categories tested, Emergency, Laboratory and Radiology, Rehabilitation, Operating Room and Catheterization Laboratory, the relevant test statistic is above the $95 \%$ cutoff level of 3.84146 . That implies that for these five categories Tobit, rather than OLS, is the appropriate estimation technique. For Room and Miscellaneous charges, however, the relevant test statistic was under the $95 \%$ cutoff level. For these charge categories, OLS is the appropriate estimation technique.

Table 26. Test of Tobit vs. OLS. $95 \%$ Cutoff Threshold: 3.84146

\begin{tabular}{|l|c|c|c|}
\hline Category & Tobit Log-Likelihood & OLS Log-likelihood & $\begin{array}{c}\text { Likelihood Ratio Test } \\
\text { Statistic }\end{array}$ \\
\hline Room & -4445.25 & -4446.56 & 2.6 \\
\hline Intensive Care & -4386.25 & -4401.00 & 29.5 \\
\hline
\end{tabular}




\begin{tabular}{|l|c|c|c|}
\hline $\begin{array}{l}\text { Laboratory/ } \\
\text { Radiology }\end{array}$ & -4456.73 & -4458.82 & 4.2 \\
\hline Pharnacy & N/A & N/A & N/A \\
\hline Rehabilitation & -2617.44 & -2668.28 & 101.7 \\
\hline Operating Room & -1939.09 & -2163.93 & 449.7 \\
\hline Cath Lab & -4477.51 & -4491.47 & 27.9 \\
\hline $\begin{array}{l}\text { Cardiovascular } \\
\text { Diag. }\end{array}$ & -4818.01 & -4818.13 & 0.2 \\
\hline Miscellaneous & N/A & N/A & N/A \\
\hline
\end{tabular}

Table 27 summarizes the results of our econometric tests. These tests indicate we should nin the charge regressions for Room and Cardjovascular Diagnostics with CABG and PTCA patients pooled together using OLS; for Intensive Care and Laboratory/Radiology we should run separate CABG and PTCA regressions using Tobit, for Pharmacy and Miscellaneous we should run separate regressions using OLS, and for Rehabilitation, Operating Room and Catheterization Laboratory we should nu separate regressions using Tobit.

Table 27. Summary of Econonetric Tests

\begin{tabular}{|l|c|c|}
\hline Category & Regressions Run Together or Separately? & OLS or Tobit? \\
\hline Room & Together & OLS \\
\hline Intensive Care & Together & Tobit \\
\hline Laboratory/ Radiology & Together & Tobit \\
\hline Pharmacy & Separately & OLS \\
\hline Rehabilitation & Separately & Tobit \\
\hline Operating Room & Separately & Tobit \\
\hline Cath Lab & Separately & Tobit \\
\hline Cardiovascular Diag. & Together & OLS \\
\hline Miscellaneous & Separately & OLS \\
\hline
\end{tabular}




\section{Estimating Cost Differences}

Given our econometric modeling results of Section III, we are now in a position to estimate the available charge and savings from making PTCA technology available to all CABG patients. We make such estimations as follows: First, we nun the appropriate regressions as indicated in Table 27 on each charge category. We then estimate for each CABG patient what their expected (as opposed to their actual) charges would be. We then, using the appropriate equations, estimate what the expected charges for that patient would be were PTCA technology to be available to them. Once that is cornpleted, we calculated a mean savings for each category by summing up all the individual savings and dividing by the number of patients in the sample.

The estimated savings are listed below in Table 28. Table 28 indicates the mean charge of the CABG patients, the mean expected charge were they to undergo PTCA treatment, and the mean expected savings. The last line of the table presents totals charge savings across the nine charge categories. Parenthesis indicate negative numbers.

Table 28. Charge Savings Available From PTCA Technology Category By Category

\begin{tabular}{|l|c|c|c|}
\hline Category & $\begin{array}{c}\text { Mean PTCA } \\
\text { Charge }\end{array}$ & $\begin{array}{c}\text { Mean CABG } \\
\text { Charge }\end{array}$ & $\begin{array}{c}\text { Net Charge } \\
\text { Savings }\end{array}$ \\
\hline Room & $\$ 2239$ & $\$ 5720$ & $\$ 3481$ \\
\hline Intensive Care & 2316 & 5661 & 3345 \\
\hline $\begin{array}{l}\text { Laboratory/ } \\
\text { Radiology }\end{array}$ & 1342 & 3394 & 2052 \\
\hline Pharmacy & 338 & 2773 & 2435 \\
\hline Rehabilitation & 124 & 525 & 401 \\
\hline Operating Room & 308 & 20,626 & 20,319 \\
\hline Cath Lab & 16,101 & 2284 & $(13,817)$ \\
\hline $\begin{array}{l}\text { Cardiovascutar } \\
\text { Diag. }\end{array}$ & 624 & 647 & 23 \\
\hline Miscellaneous & 394 & 8558 & 8144 \\
\hline Total & $\mathbf{2 3 , 7 8 6}$ & $\mathbf{5 0 , 0 8 8}$ & $\mathbf{2 6 , 3 0 2}$ \\
\hline
\end{tabular}


Note that the savings are largest with respect to the operating room, with an average savings of over $\$ 20,000$. Important savings for PTCA patients also arise in Room Charges, Intensive Care, Laboratory, Pharmacy, and under Miscellaneous charges. Since. however, PTCA patients make intensive use of the Cath Lab, additional charges in that area for PTCA amount to almost $\$ 14,000$. The total charge savings available from enhanced PTCA technology amount to over $\$ 26,000$ per patient.

We are also able to use this data to capture the cost savings to society available from such innovations. In a perfectly competitive matket, a firm's charge is equal to its (economic) costs. Hospitals, however, may not cornpete in fully competitive markets and therefore may have charges greater than their economic costs. It is therefore necessary, when converting from charge savings to cost savings, to have in hand appropriate cost/charge ratios. We have such information, category by category, supplied to us by the accounting staff at the surveyed hospital.

We have applied these data to our charge savings and present it below in Table 29. It turns out that our estimated cost savings of $\$ 14,000$ are well below the estimated charge savings of $\$ 26,300$. Since the cost/charge ratios are less than one in every category (the hospital is not selling anything at a loss), we would expect costs to be less than charges. But in this case, the cost savings is only about $\$ 3$ percent of the charge savings.

The major factor in this difference occurs in the operating room rategory. CABG patients incur on average a charge of $\$ 20,600$ in the operating room, which would be reduced to $\$ 300$ were they to undergo PTCA, for a charge savings of over $\$ 20,000$. However, the cost/charge ratio for the operating room at this hospital is only 0.403 , implying that only slightly more than 40 percent of the charge savings are actual cost savings. Thus, a charge savings of over $\$ 20,000$ turns into a cost savings of a little less than $\$ 8200$. 
Table 29. Cost Savings Available From PTCA Technology

\begin{tabular}{|l|c|c|c|}
\hline Category & $\begin{array}{c}\text { PTCA Charge } \\
\text { Savings }\end{array}$ & Cost/Charge Ratio & PTCA Cost Savings \\
\hline Room & $\$ 3481$ & 0.866 & $\$ 3014$ \\
\hline Intensive Care & 3345 & 0.704 & 2284 \\
\hline $\begin{array}{l}\text { Laboratory/ } \\
\text { Radiology }\end{array}$ & 2052 & 0.648 & 1330 \\
\hline Pharmacy & 2435 & 0.375 & 913 \\
\hline Rebabilitation & 401 & 0.684 & 274 \\
\hline Operating Room & 20,319 & 0.403 & 8,188 \\
\hline Cath Lab & $(13,817)$ & 0.408 & $(5637)$ \\
\hline $\begin{array}{l}\text { Cardiovascular } \\
\text { Diag. }\end{array}$ & 23 & 0.420 & 10 \\
\hline Miscellaneous & 8144 & 0.444 & 3592 \\
\hline Total & 26,302 & - & 14,001 \\
\hline
\end{tabular}

\section{Conclusion}

This approach finds that significant per-procedure cost savings would be available if PTCA technology could be adopted for use in all patients currently undergoing CABG, assuming comparable outcomes and repeat procedure rates. Our analysis indicates that the savings would amount to over $\$ 26,000$ in charges or over $\$ 14,000$ in costs per patient, with significant savings in several parts of a hospital. Total expenditures for revascularization would vary, depending on the relevant rate of procedure. Thus, technology that coutd firther extend PTCA technology to more patients could generate substantial savings for the economy. 


\section{Subappendix B1: Calculating Unexpected Adverse Events}

One of the important determinants of patient charges is the number of adverse events experienced by that patient. However, it is likely that the number of adverse events is a function of several of the other explanatory variables used in the charge equation. For example, the less healthy an individual is, the greater the expected charge is likely to be, but the number of adverse events for that patient are likely to be higher also.

We are thus interested in controlling for the adverse events which are the result of the other explanatory variables. To do this we model the number of adverse events based on other variables. We then use this model to predict the number of adverse events a patient should have based on his characteristics. The difference between that actual and predicted values is then used as an explanatory variable in the charge regression.

To illustrate this, consider a model with three variables in the form:

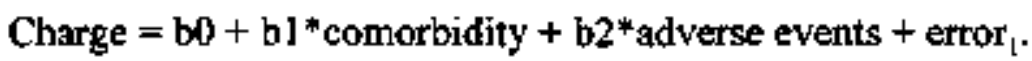

In our model, however, adverse events is a function of comorbidity. A person with a comorbidity score of $\mathrm{X}$ is expected to have $\mathrm{Y}=\mathrm{F}(\mathrm{X})$ adverse events. Because of this comorbidity has two effects on charge. One effect is the direct effect, and the other is an indirect effect based on comorbidity's effect on adverse events. This violates one of the assumptions of stendard statistics and makes the OLS estimates of $b_{1}$ and $b_{2}$ unreliable.

What is done then to avoid this problem is to formulate a model of the form:

$$
\text { Adverse events }=a_{0}+a_{1}{ }^{*} \text { comorbidity }+ \text { error }{ }_{2} \text {. }
$$

Combining (1) and (2) yield a model of the form:

$$
\text { Charge }=c_{0}+c_{1}{ }^{*} \text { comorbidity }+c_{2}{ }^{*} \text { unexpected adverse }+ \text { error } \text {, }
$$

where $c 0=b 0+a 0, c 1=a]+b l_{,} c 2=b 2$, and unexpected adverse $=$ error ${ }_{2}$. In this model the right hand side variables are independent, and thus the model may be estimated by standard techniques (assuming that the other usual econometric assumptions hold).

The chaljenge then is to estimate a model for adverse events. However, adverse events are not a continuous variable, so standard techniques are not applicable. Instead of standard regression we use Poisson regression.

A Poisson randon variable is a count variable. It measures the number of discrete occurrences of an event in some time period, in the case the number of adverse events in the patient's recovery period. The variable in the adverse events model has the probability distribution function defined by: 


$$
\text { Prob }[\text { adverse }=y\}=(\exp \{-q\} * q y) /(y !) \text {. }
$$

To complete the model we must specify $q$ as a function of other variables. The general form is $q=\exp \{\mathrm{Xb}\}$. Where $b$ is a vector of parameters to be estimated and $X$ is a vector of patient characteristics. For this model the patient characteristics in the $\mathrm{X}$ vector are: AMI (acute MI within 24 hours of procedure), PCABG (prior CABG), PPTCA (prior PTCA), PMI (prior MI), COM (comorbidity), SMOKER, PRJORITY (patient priority level), AGE, VESSEL2 (stenosis in two or more vessels), CASETYPE (PTCA $=0$, CABG $=1$ ), GENDER. Setting $y=$ actual number of adverse events, one can then estimate the $\mathrm{b}$ vector via maxinum likelihood methods.

The expected value of a Poisson variable is $\mathrm{q}$, which in this case is $\exp \{\mathrm{Xb}\}$. With the maximum likelihood estinates of b one can predict the number of adverse events for each patient, then define:

$$
\text { Unexpected Adverse }=\text { True Adverse }-\exp \{X \mathbf{D b}\},(5)
$$

Now the values for the unexpected adverse events can be used as an explanatory variable in the charge regression.

The results of the maximum likelihood estimation of the Poisson process are detailed below: 
Table 30. Polsson Regression Estimates (Significant Coefficients in bold)

\begin{tabular}{|l|c|c|}
\hline Variable & Coefficient & T-statistic \\
\hline PCABG & $\mathbf{0 . 4 9 5}$ & 5.47 \\
\hline PPTCA & -0.111 & -1.31 \\
\hline AMI & $\mathbf{0 . 6 5 9}$ & 7.26 \\
\hline PMI & -0.645 & -1.51 \\
\hline COM & -.186 & 9.97 \\
\hline SMOKER & 0.105 & 1.39 \\
\hline PRIORITY & $-\mathbf{0 . 1 3 0}$ & -5.41 \\
\hline AGE & 0.00152 & 0.83 \\
\hline VESSEL2 & -0.0698 & -0.61 \\
\hline CASETYPE & $\mathbf{0 . 4 2 4}$ & 5.66 \\
\hline GENDER & $\mathbf{0 . 2 5 5}$ & 2.92 \\
\hline
\end{tabular}




\section{Subappendix B2: The Choice of PTCA Vs. CABG}

The probit model is used to examine binary choice variables. In this case, we are interested in examining whether a given patient will receive PTCA or CABG as a treatment. Thus, the dependent variable, $Y$, is assigned a value of 0 when we observe PTCA and a value of 1 when we observe CABG. The expected value of $Y$, which is equal to $P_{i}$, the probability of receiving CABG, is then regressed on a set of explanatory variables.

This analysis becomes crucial in our statistical tests in Part 4. The test for sample selection bias requires us to have estimated probabiiities of PTCA and CABG. Given this, probit analysis was performed on our data set, allowing us to generate PTCA and CABG probabilities for each patient. The variables used analysis were:

1. Comorbidity score (COM)

2. Patient gender (GENDER)

3. History of smoking (SMOKER)

4. Patient age (AGE)

5. Whether the patient received a PTCA or CABG within 24 hours of an MI (AMI)

6. Whether the patient had a prior CABG (PRCABG)

7. Whether the patient had a prior PTCA (PRPTCA)

8. Ejection fraction (EF)

9. A dummy variable which is equal to one if two vessels show stenosis (VES2)

10. A dummy variable which is equal to one if three or more vessels show stenosis (VES3)

11. A dummy variable which ii equal to one if the left main coronary artery shows stenosis (LEFT).

The probit regression has the form:

$\mathrm{E}(\mathrm{Y})=\mathrm{P}=\mathrm{F}\left(\beta_{1}+\beta_{1}{ }^{*} \mathrm{COM}+\beta^{*} \mathrm{GEN}+\beta,{ }^{*} \mathrm{SMK}+\beta^{*} \mathrm{AGE}+\beta,{ }^{*} \mathrm{AMI}+\beta,{ }^{*} \mathrm{PRCABG}+\right.$ $\beta,{ }^{*}$ PRPTCA $+\beta,{ }^{*}$ EF $+\beta^{*}$ VES2 $+\beta_{n}{ }^{*}$ VES3 $+\beta_{1}{ }^{*}$ LEFT + e)

Where the subscript $i$ denotes the value for patient $i$. Thus, $P$. is the probability of patient $i$ receiving a $\mathrm{CABG}$. Also the function $F$ is the cumulative distribution function (CDF) for a standard normal variable, which insures the resulting probability is between 0 and 1 . The results of the probit regressions are reported below. 
Table 31. Probit Results (Significant coefficients in bold)

\begin{tabular}{|c|c|c|}
\hline Variable & Coefficient & T-statistic \\
\hline Constant & -0.318 & -0.65 \\
\hline Comorbidity & 0.0692 & 1.86 \\
\hline Gender & -0.372 & -2.49 \\
\hline Smoker & 0.238 & 1.83 \\
\hline Age & -0.020 & -3.32 \\
\hline AMI & -0.217 & -1.13 \\
\hline PRCABG & -1.087 & -6.63 \\
\hline PRPTCA & -0.363 & -2.60 \\
\hline EF60 & 0.0012 & 0.25 \\
\hline VES2 & -0.537 & 2.58 \\
\hline VES3 & 1.019 & 6.35 \\
\hline LEFT & 1.033 & $5.5 !$ \\
\hline $\begin{array}{l}\text { unber of } 0 \text { bsecrist } \\
\text { Correct Prediction }\end{array}$ & $\begin{array}{l}\text { CABG in Sa } \\
\text { Log-titelihg }\end{array}$ & \\
\hline
\end{tabular}

Significant variables are Gender, Age, PRCABG, PRPTCA, VES2, VES3, and LEFT. These regression coefficients are used to generate the probabilities used in the sample selaction test regressions in Part 4. 


\section{Appendix C - Stochastic Frontier Estimation of Cost Models Within the Hospital: The Case of CABG and PTCA}

\section{Introduction}

Assessing of the impact of new technologies on health care costs is a critical pursuit in today's economy. The health care sector is characterized by an extraordinary degree of innovation, perkaps more so than any other sector in the economy. Untike many other areas, however, innovation in this sector is generally perceived as substituting newer technologies which require increased, rather than decreased, resource use. That is, technological innovation appears to be cost increasing. Clearly, we wish to begin the process of detemining whether this common perception is accurate. To do so, we must first understand the basic relationship between the medical care decisions required of exjsting and innovative technologies and how these medical "production functions" affect the cost relationships we observe.

In this part we address these issues by comparing the costs of treatment for two competing technologies for the treatment of coronary artery disease, coronary bypass surgery (CABG) or balloon angioplasty (PTCA). Exploiting a unique data set, we examine costs at the patient level, which allows us to estimate the cost savings that would be available if technological innovations in the less expensive PTCA procedure made that treatment regimen available to all the patients currenty undergoing CABG. This approach is in contrast to previous cost studies, which only employed data at the hospital level.

Section II of our paper addressing several conceptual issues in the estimation of cost functions for hospital services. In Section III we present our estimation technique, data, and specification. Section IV reports the results of our cost estimation. Section V presents the estimated costs savings that would be available as the result in innovation in PTCA technology, and Section VI contains our conclusions.

\section{Estimating Costs in the Hospital: A Return to the Physicians' Workshop Model}

\section{The Appropriate Level of Aggregation}

Many researchers who have empirically examined hospital production (either directly or via a cost function) have assumed one "global" production function for the institution. That is, they posit a relationship between broad classes of inputs (e.g. numbers of nurses, 
numbers of employees, numbers of beds, etc.) and a small set of outputs, typically discharges or bed-days, and employ data aggregated at the per hospital level. Recent examples of such studies include Conrad and Strauss (1983), Menke (1990), Carey and Stefos (1992) and Zuckerman, et al. (1994). Atternativety, there is a second widely used approach based upon Newhouse (1970), which assumes that there is a "global" utility function for the hospital. This utility function leads to behavioral relationships between avaliable inputs and some output measures. Exartples of this (larger) branch of the literature include Granneman, et al. (1986), Thorpe (1988), Wagstaff (1989), Thorpe and Pheips (1990) and Bradford and Craycraft (1996).

The approaches highlighted above have lead to models which are estimated with a high level of aggregation. For example, in the Zuckerman, et al. model, total costs for the hospital (across all departments for three separate treatment settings) are estimated as functions of variables such as percentage of beds classified as intensive care, average Medicare casemix, share of admissions from out of state and the like. This introduces a potentially serious probiem with aggregation bias. Ahern (1993) explores this problem by explicitly accounting for the "softness" in production functions in medicine. She points out that there may be a number of approaches to treating a particular illness, none of which are clearly superior to the others. Consequently, it is not surprising that one observes significant variations in treatment even across small areas. Therefore, estimating production functions can be problematic when using hospitals as the level of aggregation.

In this work, we will appeal to a different theoretical model of the hospital. On a conceptual level, health economists have considered hospitals to be "physicians' workshops" since Pauly's (1980) influential monograph. This model asserts that hospitals exist to provide necessary capital equipment for physicians who each create their own team within the institution to treat patients. Each hospital is therefore not approprately considered a "firm" in the traditional neo-classical sense. Rather, each hospital is a collection of "virtual firms," each defined by a unique provider team and production function. One can extend this analogy further by recognizing that in most eircumstances the actual team utilized will be unique for each patient. That is, when a patient is admitted to the hospital he travels through a treatment process which is tatlored to his particular medical needs and circumstances.

A hospital is therefore a framework which supports a number of different production functions, and that the prodaction function is best defined by using the patient as the unit of analysis. Note that this framework is fairly far removed from the notion of one production function for "hospitals" which can be estimated by examining behavior across a large number of institutions. Instead, this model requires that we examine production at the level of the patient.

Further, it seems most reasonable to pool teams within an institution which are most closely related. For example, a team which is producing treatment for an acute myocardial-infarction (AMI) will face constraints most similar to those faced by another 
team treating an AMI patient than a team treating a patient for gallstones. Consequently, a strategy to minimize the possibility of inappropriately pooling "production functions" is to define the production function for a specific treatment within a single institution. Only then is one likely to be able to estimate a proxuction function which has meaning within the framework of hospital "workshops." This approach requires detailed data on single patients from individual hospitals. We suggest that only after researchers have explored medical production functions at their natural level (the patient) can work begin on expanding the analysis to include cross-institution similarities.

\section{Introducing Non-Cost Minimizing Behavior}

Economists have long recognized that there may be perverse incentives within hospitals (for example, the former Medicare reimbursement cost-plus method which paid hospitals more when they spent more on treating a patient). These incentives lead providers (teams) to follow objectives which are not aimed primarily (or even at all) at minimizing costs. Therefore, when we observe estimated cost differences between two groups it will be impossible to tell whether is it because one is more efficient than the other or whether one simply had "bad luck." For many questions, such as what impact using a new technology will have on costs, we want to explicitly control for inefficiency. That is, we wish to estimate the cost minimization function for the two treatment groups and compare predicted costs using that relationship. Otherwise, we run the risk of making policy prescriptions based not on which technology leads to tt: lowest cost, but rather based on which group happened to be behaving most efficjently when we observed them. It is possible that one group is behaving inefficiently which, using ordinary least square (OLS) would lead to higher predicted costs even though the group's cost minimization function lies below the cost minimization function of the other group. Policy based on OLS in this circumstance would be in error.

One technique which can accommodate differences in efficiency is stochastic frontier estimation. This maximum likelithood technique has been carefully explored in the broader econometrics literature (see, for example, Aigner et al., 1977; Schmidt and Lovell, 1979; Kopp and Diewert, 1982; Kumbhakar, 1987 and Bauer, 1990). However, in health economics it has enjoyed a somewhat mixed reception. 3 The most important complaint related to the umreasonable level of aggregation in existing applications (as discussed above). Such concerns should be assuaged in models which explore production at the level of the patient within a specific disease category within a specific hospital. We believe the analysis pursued below responds to the critics of frontier analysis.

In general, cost frontiers are specified as follows. The general cost frontier is of the form

3 For example, the Journal of Health Economics devoted a recent issue (Volume 13, 1994) to the discussion of stochastic frontiers. The Joumal published a series of responses to papers using the technique where the commentators expressed skepticism regarding the use of frontier analysis (see Dor, 1994; Newhouse, 1994; and Skinner, 1994). 


$$
C=C(\mathrm{P}, q)+\varepsilon
$$

where $\varepsilon$ is assumed to consist of two components, such that $\varepsilon=u+v$, where $u$ is a onesided positive error and $v$ is a nornally distributed (two-sided) error. The $u$ term corresponds to the measures of inefficiency for the specific cost frontier, while $v$ represents the usual error term in econometric regression.

Note that this cost frontier is derived from the production frontier and is theoretically -a function of the output level within the team and of input prices, $C(q, p)$, where $p$ is a vector of input prices and $q$ is the level of output. However, in this particular application, $q=1$ for all observations because each team produces one "treatment," since a team is defined for each patient. In addition, relative prices are the primary theoretical issue for cost minimization (or deviations from that). Therefore, consistent with Schmidt and Lovell $(1979,349)$, we select one input price per department to serve as a normalizing factor, and represent the remaining $\mathrm{N}-1$ input prices as ratios of the numeraire price, $\mathbf{P}_{\mathrm{N}}$.

\section{Modifying the Basic Stochastic Cost Frontier:}

Before specifying the exact form of the estimator for this model, we must consider augmenting the usuat technical relationships presented above. Gaynor and Pauly (1990) point out that for firms which maximize utility, rather than profits, the technical production and cost functions are never observable. This is because behavioral factors which are associated with tastes and preferences enter each decision. Models which omit these behavioral factors will be mis-specified. Extending their rguments in a straight forward fashion also suggests that any factors which contribute to the uncertainty with which the agents approach the decision processes they face will "corrupt" the technical functions in the sense that we may observe different behaviors arising from agents facing the same (q, p) set when these taste or uncertainty factors differ. Therefore, we will include a set of regressors in each of the estimated equations which correspond to these augmenting factors, $\mathbf{D}$. This vector $\mathbf{D}$ will include patient characteristics.

A second point about specification and inference for this particular model is in order before we present the final model. In our model, we will set total costs for observation $j$ as the sum of costs from important sub-cost categories:

$$
C=C_{1}+C_{2}+\ldots+C_{N} \text {, }
$$

where subscripts $1 \ldots N$ represent cost categories 1 through $N$. As will be discussed below, these cost categories will represent "input prices" in this model. However, if one augments this function with the behavioral variable vector, $\mathbf{D}$, and estimates the model, $\mathbf{D}$ would clearly have no explanatory power given the identity in (2). However, when $C_{f}$ is expressed as $N-1$ ratios of the normalizing cost (i.e.. as $C_{i} / C_{N}$ ) then the identity in (2) no longer holds and useful inferences can be drawn from the augmented equation.

In addition to the effect of the behavioral factors on cost, the parameters attached to $C_{i} / C_{N}$ will reveal the degree of substitution or complimentarily that the two input categories have in cost. That is, if the parameter on $C_{i} / C_{N}$ is negative, this suggests that as $C_{i}$ becomes larger relative to $C_{N}$ then total costs fall. This would suggest that one could lower the total cost of providing the single treatment by relying more heavily on the $i^{\text {th }}$ input and less heavily on the $\mathrm{N}^{\text {th }}$. That is, the parameters on the input ratio variables 
will provide important information on the most cost-effective input mix, and so most efficient production techtique. Recall that each observation represents one unit of "output", so altering the input mix as suggested by the parameter signs would allow one to lower cost without changing output at ail.4

Finaliy, we must establish a mechanism to relate the charges for, say, phamacy to the "price" of the pharmaceutical input. One approach would be to use the unique price reported in our data for every compound that is administered as arguments in the cost function. Similar dis-aggregation could be applied for all inputs. There are three major problems with this method. First, there will be many patients who do not use a particular compound (or stent, EKG lead, etc.) so there will be a significant problem with many zero prices. Second, this approach is extraortinarily tedious and pedestrian, to the point of impracticality. Third, since we restrict ourselves to patients at the same institution (for the theoretical reasons discussed above), each patient should stow the same unit price for, say, aspirin. A regression model would not be estimable then, since the Hessian will be singular.

What is required is some level of aggregation. That is, we must aggregate the expenditures on, say, certain classes of pharmaceuticals and let the spending on that group of pharnaceuticals be the "price" for that "input." While there are some drawbacks to this approach, it is consistent with the relevant literature. For example, Hadley, et al. (1994) estimate stochastic cost frontiers for nursing homes and use actual depreciation and interest expenses per bed and wages paid per full time equivalent employee as proxies for the "price" of capital and labor.

\section{Data and Specification}

\section{Data Description}

The data for this study are taken from the internal records of a large hospital located in a major Southern city. There are $\$ 32$ observations representing all patients who were treated for some type of cardiac revascularization during 1994 (where a small number of observations were excluded due to missing data). The patients received either CABG or PTCA. The data are drawn from the detailed charge information and medical chart abstracts. We estimat two classes of frontier: a charge frontiet and a cost frontier. The departmental charges are converted to costs using the cost-charge ratio for each department, as reported by the bospital to the Health Care Financing Administration in

\footnotetext{
4 For example, assumne the coefficient on the category representing the ratio of room cost to costs in the Nth category is negative and significart. That would imply that if the hospital were to change its treatment regimes to allow patients to stay in the hospital longer, the resalting changes in other treatments would, on net, reduce patient costs.
} 
the hospital's cost reports. We therefore had access not only to the usual sorts of information obtained from discharge abstracts but also very detailed information about specific resource usage by each patient.

\section{Dependent Variable}

The dependent variable is the total charge for treatment recorded in the hospital's accounting database and the total cost (converted from the charge using the departinental cost-to-charge ratio for the institution and then aggregated across departments). The charge is not the amount collected, nor does it represent the allowable DRG payment for those patients covered by Medicare. Rather, it represents what the institution would charge for a customer without reference to any exogenously imposed payment constraints. That is, it is a number which is used internally by the institution to track resource use. (The amounts actually billed are a separate entry in the accounting process for this institution.) Charge data should be highly correlated with the actual use of resources in each case. Consequentiy, the cost measure we calculate from charges should atso reflect (hopefully, more directly) real input use.

\section{Explanatory Variables: Input Prices}

There are eight input categories for which charges or costs in each represent price. Pharmaceutical charges (costs) are used as the numeraire (i.e., the Nith input to which every other input price in (3) and (4) below are relative). The remaining input prices are Room Charge/Cost (ROOM), Emergency Room Charge/Cost (ER), Lab Charge/Cost (LAB), Rehab Charge/Cost (REHAB), Operating Room Charge/Cost (OR), Catheterization Lab Charge/Cost (CATH), CV Charge/Cost (CV) and Miscelianeous Charges/Costs (MISC). Each of these is divided by pharmaceutical charges (costs) before being entered into the regression equations in (3) and (4) below.

\section{Explanatory Variables: Behavioral and Health Factors}

A number of additional variables enter (3) below in order to control for behavioral factors which should be important. An index which represents the degree to which comorbidities exist, COM, controls for variations in patient underlying health status prior to the treatment. Several other comorbidity factors are also included. These are whether the patient was admitted with an acute myocardial infarction, ACUMI, whether the patient has previously had bypass surgery, PRCABG, or previously had angioplasty, PRPTCA, the patient's ejection fraction, EF $60,{ }^{5}$ if the blockage is on the left side of the heart,

\footnotetext{
5 Some of the patients in our data set did not have an tjection fraction reconded. Claticians informed us this generally occurs when the ejection fraction equals 60 , the nomal level. Therefore, for the patients with missing data, we set the ejection fraction to 60 .
} 
LEFT, or whether there was blockage in two vessels, VES2, or three or mote vessels, VES3.

A few patient characteristics relevant to treatment or illness are also included. Since men and women may respond differently to illness and medical treatment, a dumby varjable indicating whether the patient is male, GENDER, is also included. Likewise, responses and costs may vary significantly by age, so the patient age, AGE, appears. Finalily, one patient behavioral factor, whether the patient smokes cigarettes, SMOKER, is included. Table 32 presents the means of the dependent and independent variables by patient type (PTCA or CABG).

An additional important determinant of patient charges is the number of adverse events experienced by that patient. However, it is likely that the number of adverse events is a function of several of the other explanatory variables used in the charge equation. For example, the less heal thy an individual is, the greater the expected charge is likely to be, but the number of adverse events for that patient are likely to be higher also.

We are thus interested in controlling for the adverse events which are the result of the other explanatory variables. To do this we model the number of adverse events, based on other variables, using Poisson regression. We then use this model to predict the number of adverse events a patient should have based on his characteristics. The difference between that actual and predicted values is then used as an explanatory variabie in the charge and cost regressions.

\section{Estimation Issues}

There are a number of potential functional form specifications which can be adopted. Theory provides no guidance in this respect. Additionally, given that CABG and PTCA, while ostensibly treating the same condition, are relatively disparate technologies, there is no theoretical reason to suspect that the same cost function necessarily underlie each. We undertook a series of pre-tests to determine how best to proceed.

Our first concern was whether PTCA and CABG patients should be pooled together into one regression. Our ex ante expectations are that this is not likely to be reasonable. The medical procedures are quite different. Additionally, the mean total charge and cost for each are quite disparate: the mean total charge for PTCA in the sample is $\$ 26,458$, while the mean total charge in the sample for CABG is $\$ 47,509$. We ran a likelihood ratio test on the hypothesis that PTCA and CABG patients can be pooled into a single cost function. The test statistic for this test with 23 degrees of freedom (which was performed using the double $\log$ specification) was 46.53 , which rejects the null hypothesis at the 5 percent level of significance. (The relevant test cutoff is 35.2 ) Given this result, and our 
ex ante expectations, we will estimate all of the models hereafter separately for PTCA and CABG patients.

A second concern was which functional form to use. To this end, we estimated the model three times for each group and dependent variabje, using linear, right semi-log and leftsemi log specifications. We recovered the value of the log likelihood finction for each, and the difference between the average total charge or cost and average predicted total charge or cost for each regression. For PTCA patients, the linear model was clearly superior in terms of yielding the highest value to the log likelihood function and generating estimated total charges/costs which most closely approximated actual total charge. On the other hand, the linear and right semi-log functional forms both preformed fairly well in terms of maximizing the log likelihood function and minimizing the difference between predicted and actual charges for the CABG patients. For consistency we chose to use the linear functional form for the CABG patients as well.

This models will follow the basic model discussed in Bauer $(1990,42)$. Assume that the augmented charge or cost function for PTCA and CABG patients are

$$
C_{j}^{k}=a+\gamma_{i}^{k} P_{t, j}+\ldots+\gamma_{-}^{k} P_{-j}+\Gamma^{k} D_{j}+u_{j}^{k}+v_{j}^{z} .
$$

where the quantity is 1 for all observations and the $P_{i j}$ represent relative input prices for the $i^{\mathrm{t}}$ input and the $\mathrm{j}^{\text {th }}$ patient (relative to the pharmacy costs) and $k=$ PTCA, CABG.

Given this, the likelihood function which estimates the parameters of (3) are

$$
\ln L=\frac{J}{2} \ln \left(\frac{2}{\pi}\right)-J \ln \sigma+\sum_{j=1}^{j} \ln \left[J-\Phi\left(\frac{-\varepsilon_{j} \lambda}{\sigma}\right)\right]-\frac{1}{2 \sigma^{2}} \sum_{j=1}^{j} \varepsilon^{2} .
$$

where $J$ is the number of observations, $\varepsilon_{\mathrm{j}}$ is the estimated sum of $u$ and $v, \Phi($.$) is the CDF$ of a standard nomal distribution, $\sigma=\sigma_{v}+\sigma_{v}$ and $\lambda=\sigma_{v} / \sigma_{v}$. The likelihood function is maximized across $\sigma_{u}^{2}, \sigma_{v}^{2}, \Gamma$ and $\gamma$ (where $\Gamma$ and $\gamma$ are the parameters for the equations represented in (3)).

From the estimated models we obtained a number of important pieces of information. The first are consistent estimates of the effect of the patient covariates on the demand for the individual input shares. Second, the technical inefficiency for each observation is found as

$$
\dot{u}_{j}=\frac{\sigma_{z}^{*} \sigma_{k}^{*}}{\sigma^{*}}\left[\frac{\phi\left(\frac{\varepsilon_{j}^{*} \lambda}{\sigma^{*}}\right)}{1-\Phi\left(\frac{\varepsilon_{j}^{*} \lambda}{\sigma^{*}}\right)} \cdot \frac{\varepsilon_{j} \lambda}{\sigma^{*}}\right]
$$

where starred terms mean estimated values and $\phi($.) is the PDF of the standard normal distribution (See Jondrow, et al. 1982).

Finally, it is important to note what the inefficiency estimates do and do not suggest. First, the estimated $\mu_{j}{ }^{*}$ do not reflect how cost-effectively a particular patient is treated relative to the industry (theoretical) cost minimization. That frontier is not estimated. 
What the inefficiencies do reflect is how well a patient is treated relative to all other patients in the specific institution. ${ }^{6}$ That is, a set of patients within the sample are "defined" as charge or cost minimizing and all other patients in the sample score relative to these. Finally, in this case "cost minimizing" means strictly "best at minimizing resource costs." We are sensitive the probabitity that this notion of cost minimization may differ significantly from the physician's or patient's ideas of best practice.

\section{Results}

Table 33 presents the results of the stochastic frontier charge estimates for PTCA and CABG patients in regression equation (3). A number of results are of interest in the PTCA equation. First, note that several of the personal characteristics - the presence of comorbidities, gender, having had a prior CABG or PTCA procedure, having left main arterial disease and the likelihood of unanticipated adverse events - significantly affect the total charges for providing a PTCA. With the exception of prior PTCA, each increases the charge. Having had a prior PTCA appears to significantly reduce the charge associated with the sampled PTCA procedure. The lack of significance for a few variables is also interesting. Having blockage in more than one vessel, VES2 and VES3, does not change charges in a statistically significant manner. Further, having suffered an AMI very recently seems to have no statistical effect on total charges.

Recall that the effect of the charge ratios on the total charge of the PTCA procedure can inform us with respect to the most efficient mix of inputs. That is, a significantly positive effect of one of the charge ratios indicated that using relatively more of that input will raise total charge of supplying the procedure. A significantly negative effect indicates that one could increase the relative use of that input and decrease the total charge of the procedure. For PTCA procedures, three input ratios bave significantly positive effects. The results indicate that using relatively more laboratory resources (LAB), operating room (OR) and $\mathrm{CV}$ inputs significantly increases total charges, without any "payoff" (i.e., more is spent, though the quantity stays the same). In contrast, patients who incur relatively higher room charges (relative to pharmaceutical charges) have significantly lower total charges.

Perhaps a more useful way to think about the parameters on ROOM. LAB, OR and CV are in terms of elasticities. An elasticity is a measure of what percentage change one observes in one thing given a one percent increase in something eise. In this case, the elasticity would be the percentage increase in total charge of the PTCA one would observe from a one percent increase in the rejative use of an input. For the room charges, the elasticity is -0.10 , suggesting that total charges fall by a tenth of a percent if the institution were to increase the relative use of room resources by one percent. The

6 We note that the cost estimation can only estimate the cost minimization frontier in the data set. We therefore cannot estintate the industry cost frontier with the data available to us. 
calculated elasticity of the laboratory resources is 0.10 , the estimated elasticity of the operating room is 0.01 , and the estimated elasticity for the CV unit is 0.03 . In each of these cases, the response of total charge is somewhat muted (i.e. inelastic); however, even a three or four percent decrease in total charge would be very significant from a managerial perspective. These elasticities do suggest that charge reductions in this range are at least potentially feasible.

Table 33 also contains the results of the stochastic frontier charge estimation for the CABG patients. As with the PTCA cases, patjent characteristics are important for those undergoing $C A B G$ treatments. The presence of a higher comortidiy score, having had a prior $\mathrm{CABG}$, and increased unanticipated adverse events significantly increases the total charge of the $\mathrm{CABG}$ procedure. Unlike the PTCA, we find that a recent acute myocardial infarction and the number of vessels revascularized also significantly and positively affects total charge. A recent AMI raises total charges, as does having two vessels revascularized. Oddly, having three or more vessels blocked seems to decrease total charges. Since the "standard" approach for onty one or two blockages would be to use PTCA rather than CABG, it may be that those in the one or two vessel CABG group are relatively more ill than those who have blockage in three or more vessels, and hence require more intensive resource use in some areas.

For CABG patients, four of the charge ratios are significant in the frontier estimation. Using relatively L:ore $\mathrm{CV}$ diagnostics, relatively more catheterization lab time and relatively more miscellaneous charges raișes relative charge in a non-productive manner (charges go up and output is constant). However, unlike the PTCA case, using relatively more operating room time reduces tota charges. That is, when the institution is using a larger proportion of its resources in actually providing the $\mathrm{CABG}$ procedure to a patient (which is done in the operating room), the charge from treating that patient falls.

Again, the most straight forward means of interpreting the magnitude of these significant effects is to use elasticities. The operating room elasticity is largest, at -0.36 ; increasing the relative use of the OR by one percent would lead to over a one-third percent decrease in total charges. This is much larger than the other effects for CABG (and PTCA). The elasticity for miscellaneous charges is next in magnitude, at 0.22 , followed by the elasticity for the cath lab at 0.06 and, finally, the elasticity for the $\mathrm{CV}$ diagnostics at 0.02 . It would take slightly more than a one percent decrease in the relative use of each of these three to equal the charge savings associated with a one percent increase in the relative use of the operating room. Still, the magnitude of these effects are large enough to bring a three or four percent decrease in total charges into the feasible range with no decrease in the provision of service. The possibility that such charge reductions can be achieved by adjusting the production technology is intriguing, and deserving of more attention.

Finally, Tabie 33 presents estimates of the average charge "inefficiency" of the PTCA and $C A B G$ procedures being undertaken within the institution. Recall that in this case "inefficiency" means how much more charge is genetated fot a given patient's treatment than the lowest charge possible in the hospital given the patient's characteristics. That is, 
charge inefficiency reflects the variation within the institution in charges, and can not speak to how well the cost minimization in this institution compares to cost minimization in another. For PTCA patients, the average estimated inefficiency is about $\$ 10,248$, which is about 41 percent of the mean charge for the procedure. This suggests that the hospital is charging over $\$ 10,000$ per patient more than necessary given the lowest cost available in that institution. For CABG patients the average excess charges are approximately the same, at about $\$ 9,990$; though, as a percentage of average charge, the CABG inefficiency is smaller, at 22 percent. Both of these numbers are relatively large, and suggest that there may be room for significant charge (and so potentially cost) savings in the hospital by more careful examination of which patients are treated in the more cost effective manner and working to emulate the procedures used on them with other patients.

Table 34 presents the estimates of the stochastic cost frontier for both PTCA and CABG patients. The qualitative results in the PTCA cost regression with respect to the non-price effects are very similar to those in the charge regression. Increased numbers of comorbidities, patient gender, having had a prior CABG or PTCA, suffering from left main artery disease and having adverse events all significantly affect costs. Unjike the charge estimates, an acute MI just prior to the procedure does significantly affect the costs of providing the PTCA.

In terms of bospital resources, the relative use of lab resourees, the relative use of rehabilitation services and the relative use of $\mathrm{CV}$ diagnostic resources significantly affect the total cost of providing a PTCA. The parameter estimates on both of these input ratios are positive, indicating that increasing the use of these inputs relative to pharmaceutical inputs will increase the total cost of the PTCA. This suggests that the average patjent in the PTCA sample uses relatively too much of these inputs to achieve strict cost minimization. While statistically significant, the magnitude of these effects is not large. The lab input has the largest elasticity, at 0.12 , which suggests that a 1 percent increase in the relative use of lab services will raise total cost by a bit more than one-tenth of 1 percent. The elasticities of rehabilitation and $\mathrm{CV}$ diagnostic services are even smaller, at 0.02 and 0.03 respectively.

For $C A B G$, comorbidities, a recent $M I$, a prior $C A B G$ and unanticipated adverse events raise the cost of providing bypass surgery. In addition, having multiple vessels involved is a significant predictor, as evidenced by the positive and significent effect of having two vesseis stenosed and the negative and significant effect of having 3 or more vessels stenosed on total costs. While the sign patterns may seem somewhat counterintuitive, they are actually what one would expect in the current state of the world. Currently, many patients who need two vessels repaired will have thern done using PTCA technology. Such a person that is actually observed with a $\mathrm{CABG}$ instead suggests that this person is relatively more sick than the average person who needs two vessets reworked. However, a person who needs treatment in three vessels is not at all likely to receive PTCA. 
Again, the parameter estimate on the relative use of the OR resources is negative and significart. This suggests that a shift toward relatively more OR time per CABG (compared to pharmaceutical resources) may actually reduce the total cost of providing the service. The magnitude of this effect is also relatively large when compared to the other elasticities. The estimated elasticity of cost with respect to relative OR use is 0.31 . This means that a one percent increase in relative use of the OR will reduce the total CABG cost by one-third of 1 percent. The other statistically significant medical inguts have positive effects on total costs, indicating over-use on average. These are the emergency room and the cath lab. The elasticities of these input ratios are smaller than for the $O R$, at 0.14 and 0.06 respectively.

Finally, the cost inefficiencies estimated for PTCA and CABG are presented the bontom of Table 34. The absolute level of cost inefficiency for PTCA production is about $\$ 5,200$. The represents 41 percent of the total average cost of supplying the PTCA to patients in the institution. The absolute level of cost inefficiency for CABG patients is $\$ 7,300$, or 29 percent of the total cost of the operation. These inefficiency estimates (at least in percentage terms) are reasonably similar to the estimates of cost inefficiency. While comparable levels of inefficiency have been found in other research of other industries, this does indicate a substantial room for improvement in the average cost of treatunent for the two procedures.

However, a strong word of caution is in sorder. These results are only suggestive, and much more research is necessary to determine how the inefficiency is related to adverse events or quality. While our patient-specific comorbidity and health indicators should have captured most of the variation in relative "complexity", it may be that the measured "inefficiency" captures some measure of quality. A more complete model would be required to determine what this inefficiency actually means. However, the implications are quite intriguing and significant enough to warrant more attention.

\section{Simulating Changing Technology or Practice}

One issue that concerns the medical community and policy-makers alike is what effect shifting treatment standards will have on charges or costs. That is, as PTCA becomes a more mature technology, and new innovations such as stents are perfected, one could image shifting a number of patients from the CABG treatment path to the PTCA treatment path. On the surface this would appear to be a cost-saving move, since the average charge and cost of PTCA is much below the average charge or cost of CABG (as can be seen from Table 32 for this sample). As discussed above, however, one would not want to take such a naive approach, since a number of factors might intervene. The patient populations have different characteristics. The two procedures may be currently provided with different levels of "waste" (or inefficiency). The average PTCA patient has blockage in fewer vessels than the average CABG patient. 
Part of the motivation for the analysis above is to provide an improved methodology for estimating the cost-savings from switching patients from $\mathrm{CABG}$ to PTCA, given that appropriate PTCA technology becomes available. Using the stochastic frontier results, we can control for the observable patient characteristics and the number of vessels treated. Further, since the maximum likelihood regression results produce the "minimum cost" frontier, we can predict cost savings without the presence of confounding inefficiencies (which may or may not persist through time).

To do this we divide the CABG patients into three groups: those requiring treatment in one vessel, those requiring treatment in two vessels, and those requiring treatment in three or more vessels. We then predict the charge and cost for giving each the CABG trealment regime. The predicted charge and cost for each group appears in the first column of Table 35 . Once we have the estimated charges/costs for giving these patients CABG under cost minimization, we then simulate what charges or costs would be to give them PTCA. To do this, each patient is put through the PTCA frontier regression with their own personal characteristics, and with the charge or cost ratio values for the median PTCA patient in theit group (e.g., the charge ratios entered for a two-vessel CABG patient going through the PTCA equation are the charge ratios for the median two-vessel PTCA patient). We do this since the resource use observed for the CABG patients is clearly not the resource use we would observe if they received PTCA. (Recall, that the bypothesis of identical charge functions was rejected above.) The results of the predicted charge or cost of treating curent $\mathrm{CABG}$ patients with PTCA tecknology appeats in the second column of Table 35.

The final column in Table 35 presents the estimated savings from treating various types of CABG patients with PTCA. The savings appear to be significant. Switching onevessel CABG patients to PTCA would save an estimated $\$ 11,966$ in charges and $\$ 3,959$ in costs; switching two-vessel and three or more vessel CABG patients to PTCA appears to result in $\$ 25,394$ and $\$ 17,156$ in charge savings and $\$ 16,387$ and $\$ 8,160$ in costs, respectively.

\section{Conclusions}

Assessing the impact of new technologies on health care costs is an important area for research. Given the high level of innovation in the bealth care sector, care must be taken to understand the likely cost consequences of innovations before increasingly scarce resources are devoted to them. Often, innovation seems to substitute newer technologies which require increased cost for older, less expensive technologies. This paper evaluates this common perception for technologies used to treat coronary artery disease: PTCA and CABG. In undertaking this evaluation, we estimated two separate stochastic frontier models, one for PTCA patients and one for CABG patients, using data taken from detailed clinical and chart files from a large Southern bospita]. The analysis indicates several things. 
First, there is substantial variation in the medical treatment practice even within this one institution. This is revealed as significant levels of inefficiency in the treatment of the average patient for both PTCA and CABG, where nearly $\$ 5,200$ dollars in costs 44 percent of total spending) are ineurred "unnecessarily" on the average PTCA patient and nearly $\$ 7,230$ (29 percent of total spending) are spent "znnecessarity" on the average CABG patient. Second, the particular hospital in question could reduce its costs for care, without reducing the quantity of care, by reallocating its resources to emphasize spending relatively less on some categories of cost and spending relatively more on other categories of cost. Finally, the analysis indicates that if PTCA and CABG were perfect medical substitutes, then significant savings per patient could in fact be had by switching patients from CABG to PTCA. Clearly, this is a counter- factual situation, but it does sugegest that research which is focused on making the two treatment regimes more substitutable may be able to lead to lower costs for treating a patient suffering from coronary artery disease. 
Table 32. Means of Variables for PTCA and CABG Patients

\begin{tabular}{|c|c|c|}
\hline $\begin{array}{l}\text { Explangtory } \\
\text { Variable }\end{array}$ & PTCA Patients & CABG Patients \\
\hline \multicolumn{3}{|l|}{$\begin{array}{l}\text { Comorbidity } \\
\text { Factors }\end{array}$} \\
\hline $\mathrm{COM}$ & 1.4375 & 1.5909 \\
\hline GENDER & 0.3125 & 0.1970 \\
\hline SMOKER & 0.3560 & 0.5455 \\
\hline$\overline{\mathrm{AGE}}$ & 64.4022 & 62.2359 \\
\hline ACUMT & 0.0978 & 0,0682 \\
\hline$\overline{\mathrm{PRCABG}}$ & 0.2826 & 0.0985 \\
\hline PRPTCA & 0.3859 & 0.1742 \\
\hline EF60 & 55.7853 & 52.8485 \\
\hline$\overline{\text { VES2 }}$ & 0.6630 & $0.931 \overline{8}$ \\
\hline$\sqrt{\mathrm{ES} 3}$ & 0.3723 & 0.8333 \\
\hline LEFT & 0.0625 & 0.2879 \\
\hline UNADV & -0.2539 & -0.6491 \\
\hline Charge Ratios & PTCA Patients & CABG Patients \\
\hline ROOM/PHAR & 5.6106 & $2.366 \overline{1}$ \\
\hline ER/PHAR & 4.3453 & 1.9380 \\
\hline LAB/PHAR & 2.5332 & 1.3780 \\
\hline REHAB/PHAR & 0.2013 & 0.2519 \\
\hline OR/PHAR & 0.4434 & 10.5813 \\
\hline CATH/PHAR & 68.7284 & 1.0400 \\
\hline CVIPHAR & 0.7687 & 0.1890 \\
\hline MSC/PHAR & 2.9053 & 3.5588 \\
\hline $\begin{array}{l}\text { TOTAL } \\
\text { CHARGE }\end{array}$ & 25118.59 & 46146.09 \\
\hline Cost Variables & PTCA Patients & CABG Patients \\
\hline ROOMPHAR & 5.6106 & 5.367 \\
\hline ER/PHAR & 8.132 & 3.665 \\
\hline LAB/PHAR & 4.367 & 2.362 \\
\hline REHAB/PHAR & 0.3652 & 0.4522 \\
\hline OR/PHAR & 0.4800 & 11.09 \\
\hline CATH/PHAR & 74.39 & 1.104 \\
\hline CV/PHAR & 0.8567 & 0.2089 \\
\hline MISCPPHAR & 3.436 & 4.178 \\
\hline TOTAL COST & $12607 \overline{41}$ & 25079.33 \\
\hline $\begin{array}{l}\text { Number of } \\
\text { Observations }\end{array}$ & 368 & 132 \\
\hline
\end{tabular}


Table 33. Stochastic Frontier Estimations of TOTAL CHARGE for PTCA and CABG Patients (Linear). T-Statistics in Parentheses

\begin{tabular}{|c|c|c|}
\hline $\begin{array}{c}\text { Explanatory } \\
\text { Variable }\end{array}$ & PTCA Patients & CABG Patients \\
\hline CONSTANT & $10693(2.279)^{* *}$ & $22328(2.216)^{n *}$ \\
\hline $\operatorname{coM}$ & $1529.7(4.301)^{* k * *}$ & $2302.5(3.274)^{* * * *}$ \\
\hline GENDER & $2224.2(1.690)^{*}$ & $3971.8(1.589)$ \\
\hline SMOKER & $914.93(0.750)$ & $739.15(0.311)$ \\
\hline AGE & $31.407(0.542)$ & $29.119(0.227)$ \\
\hline$\overline{\text { ACUMI }}$ & $2185.5(0.884)$ & $12124(3.746)^{* * *}$ \\
\hline PRCABG & $5806.8(4.053)^{* 4 *}$ & $7113.3(1.966)^{* *}$ \\
\hline PRPTCA & $-2497.2(-2.104)^{* 4}$ & $1003.1(0.431)$ \\
\hline$\overline{E F} 60$ & $-4.1937(-0.096)$ & $24.899(0.376)$ \\
\hline VES2 & $-1941.6(-1.167)$ & $14411(2.733)^{n 4 * *}$ \\
\hline VES3 & $1311.7(0.749)$ & $-6126.8(-1.891)^{*}$ \\
\hline LEFT & $5655.4(2.919)^{* * *}$ & $2085.8(0.831)$ \\
\hline$\overline{\mathrm{UNADV}}$ & $3988.4(12.539)^{* * *}$ & $3680.8(4.814)^{* * *}$ \\
\hline (ROOM / PHAR) & $-427.31(-2.147)^{* *}$ & $-1225.5(-0.736)$ \\
\hline (EMERG / PHAR) & $-75.336(-0.432)$ & $1853.8(1.463)$ \\
\hline (LAB / PHAR) & $943.04(2.832)^{N * *}$ & $800.42(0.211)$ \\
\hline (REHAB / PHAR) & $2835.3(1.607)$ & $-4402.5(-6.645)$ \\
\hline (OP/PHAR) & $605.60(2.770)^{* * *}$ & $-1549.5(-4.661)^{* * n *}$ \\
\hline (CATH / PHAR) & $-2.4902(-0.202)$ & $2555.7(2.910)^{* * *}$ \\
\hline (CV/PHAR) & $1128.4(7.102)^{* * * *}$ & $3837.4(1.912)^{*}$ \\
\hline (MISC / PHAR) & $489.97(-1.159)$ & $2793.8(2.421)^{n *}$ \\
\hline Log-Likelihood & -3875.740 & -1375.673 \\
\hline $\begin{array}{l}\text { Inefficiency in } \\
\text { Absolute Dollars }\end{array}$ & $\$ 10247.71$ & $\$ 9990.47$ \\
\hline $\begin{array}{l}\text { Inefficiency as a } \\
\text { Percent of Charges }\end{array}$ & $40.8 \%$ & $21.6 \%$ \\
\hline
\end{tabular}


Table 34. Stochastic Frontier Estimations of TOTAL COST for PTCA and CABG Patients (Linear). T-Statistics in Parentheses

\begin{tabular}{|c|c|c|}
\hline $\begin{array}{l}\text { Explauatory } \\
\text { Variable }\end{array}$ & PTCA Patients & CABG Patients \\
\hline CONSTANT & $3676.3^{* *}(1.58)$ & $11615^{* *}(1.77)$ \\
\hline COM & $699.43 * * *(3.96)$ & $2429.8 * * *(4.00)$ \\
\hline GENDER & $1124.6 *(1.72)$ & $1031(0.52)$ \\
\hline SMOKER & $415.12(0.67)$ & $-795.53(0.61)$ \\
\hline AGE & $30.85(1.06)$ & $-46.56(0.58)$ \\
\hline ACUMI & $1869.5 *(1.78)$ & $11430 * * *(5.0 \mathrm{~L})$ \\
\hline PRCABG & $2761.6^{* * *}(4.00)$ & $9606.4^{* *}(4.25)$ \\
\hline PRPTCA & $-1434.3^{* *}(2.411)$ & $832.09(0.53)$ \\
\hline EF60 & $1.91(0.09)$ & $22.39(0.43)$ \\
\hline VES2 & $.598 .68(0.76)$ & 20149 ** (2.36) \\
\hline VES3 & $425.35(0.54)$ & $.7002 .2 * * *(3.17)$ \\
\hline LEFT & $4619.1 * * *(5.54)$ & $695.37(0.33)$ \\
\hline UNADV & $2053 * * *(18.59)$ & $3874.5 * * *(9.10)$ \\
\hline (ROOM / PHAR) & $-66.96(1.55)$ & $90.82(0.17)$ \\
\hline (EMERG / PHAR) & $-22.79(0.53)$ & $958.58 *(1.86)$ \\
\hline (LAB / PHAR) & $342.21 * * *(3.80)$ & $-367.06(0.21)$ \\
\hline (REHAB / PHAR) & $743.69^{*}(1.66)$ & $1228.4(0.44)$ \\
\hline (OP / PHAR) & $101.99(0.87)$ & $-710.89 * * *(3.33)$ \\
\hline (CATH / PHAR) & $-7.48(1.31)$ & $1281.2 * *(1.94)$ \\
\hline (CV/PHAR) & $457.29^{* * *}(6.22)$ & $-153.67(0.09)$ \\
\hline (MISC / PHAR) & $-175.96(1.05)$ & $734.92(0.99)$ \\
\hline Log-Likelihood & -3666.53 & -1387.34 \\
\hline $\begin{array}{l}\text { Inefficiency in } \\
\text { Absolute Dollars }\end{array}$ & $\$ 5213.48$ & $\$ 7323.07$ \\
\hline $\begin{array}{l}\text { Inefficiency as a } \\
\text { Percent of Costs }\end{array}$ & $41.4 \%$ & $29.2 \%$ \\
\hline
\end{tabular}


Table 35. Predicted Savings from Switching CABG Patients to PTCA

\begin{tabular}{|c|c|c|c|}
\hline $\begin{array}{c}\text { Number of Vessels } \\
\text { with Hiockage }\end{array}$ & $\begin{array}{c}\text { Predicted Dollars for } \\
\text { CABG Treatment for } \\
\text { Current CABG } \\
\text { Patient }\end{array}$ & $\begin{array}{c}\text { Predicted Dollars for } \\
\text { PYCA Treatment for } \\
\text { Current CABG } \\
\text { Patient }\end{array}$ & $\begin{array}{c}\text { Impwted Savings } \\
\text { from Switching } \\
\text { Treatment from } \\
\text { CABG to PTCA }\end{array}$ \\
\hline IVESSEL & $28,715.07$ & $16,749.19$ & $11,965.89$ \\
\hline 2 VESSELS & $45,151.43$ & $19,757.92$ & $25,393.50$ \\
\hline 3 OR MORE VESSELS & $39,753.08$ & $22,596.72$ & $17,156.36$ \\
\hline \multicolumn{4}{|c|}{ CHARGES } \\
\hline I YESSEL & $10,489.68$ & $6,530.59$ & $3,959.09$ \\
\hline 2 VESSELS & $24,789.97$ & $8,402.71$ & $16,387.25$ \\
\hline 3 ORM MORE VESSELS & $17,830.86$ & $9,670.52$ & $8,160.33$ \\
\hline
\end{tabular}




\section{Appendix D - PTCA vs. CABG Across Several Hospitals}

\section{Introduction}

In order to develop the Care Pathway Interaction Model for Coronary Artery Disease (CAD) it was necessary to model the demand for CAD treatment, and the types of treatment, across the American economy. To accomplish this, it was necessary to model in econometric terms the choice of PTCA vs CABG. Ideally, it would have been desirable to obtain data with detailed patient by patient characteristics from all hospitals in the country $y_{3}$, but such data was not available. However, data from selected hospitals across the country was available, and this data was used to econonetrically model the factors that affect the decision by patients and doctors to use either PTCA or CABG to treat $\mathrm{CAD}$. The following section describes the data, and the section after that present the econometric ressults.

\section{Data and Estimation Technique}

We received hospital-based, patient-level data from 12 institutions in the academic medical center consortium. However, the data from several hospitals was incomplete, and data from only six hospitals could be used for analysis. The variables used in the analysis and the predicted effects of these variables on the outcome of CABG treatment as predicted by consultations with clinicians were:

1. Comorbidity score (COM). Predicted effect: Uncertain.

2. Patient gender (GENDER). Predicted effect: Uncertain.

3. History of smoking (SMOKER). Predisted effect: Uncertain.

4. Patient age (AGE). Predicted effect: Uncertain.

5. Whether the patient received a PTCA or CABG within 24 hours of an MI (ACUMI) Predicted effect: Negative. CABG is a difficult regimen for someone who has just had an MI.

6. Whether the patient had a prior CABG (PRCABG). Predicted Effect: Negative.

7. Whether the patient had a prior PTCA (PRPTCA). Predicted effect: Uncernain.

8. Ejection fraction (EF). Predicted Effect: Negative. Low EF implies patient may not do well in surgery.

9. A dummy variable which is equal to one if two vessels show stenosis (VES2). Predicted effect: Positive. CABG does better with nultiple vessels operations.

10. A dumny variable which is equal to one if three or more vessels show stenosis (VES3). Predicted effect: Positive. CABG does better with inultiple vessels operations. 
11. A dummy variable which is equal to one if the left main coronary artery shows stenosis (LEFT). Predicted effect: Positive. Due to the geometry of the heart, CABG does better with left main đisease.

The probit model is used to examine binary choice variables. In this case, we are interested in examining whether a given patient will receive PTCA or CABG as a treatment. Thus, the dependent variable, $\boldsymbol{Y}$, is assigned a value of 0 when we observe PTCA and a value of 1 when we observe CABG. The expected value of $Y$, which is equal to $P$, the probability of receiving CABG, is then regressed on a set of explanatory variables. Given these explanatory variables, the probit regression has the form:

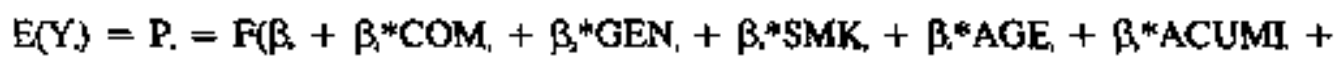

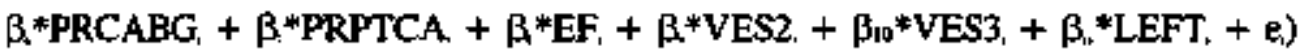

Where the subscript $i$ denotes the value for patient $i$. Thus, P. is the probability of patient $i$ receiving a $\mathrm{CABG}$. Also the function $F$ is the cumtilative distribution function (CDF) for a standard normal variable, which insures the resulting probability is between 0 and 1 . Probit analysis was performed on each hospital individually, and on all hospitals as an aggregate group. The aggregate analysis includes a dummy variable for each hospital.

\section{Results}

\section{Regressions Across the Six Hospitals}

Table 36, Table 37 and Tabie 38 give the regression results across the six hospitals in our sample, as well as the regression results for the data aggregated. 
Table 36. Hospitals 002, 003, 004, and 005 (T-statistics in Parentheses, siglificant coefficients in bold)

\begin{tabular}{|c|c|c|c|c|}
\hline Variable & Hospital 002 & Hospital 003 & Hospital 004 & Hospital 005 \\
\hline Constant & $\begin{array}{l}-1.076 \\
(-3.33)\end{array}$ & $\begin{array}{r}1.448 \\
(2.97)\end{array}$ & $\begin{array}{r}-1.098 \\
(-2.36)\end{array}$ & $\begin{array}{r}-0.109 \\
(-0.32)\end{array}$ \\
\hline Comorbidity & $\begin{array}{l}0.030 \\
(1.47)\end{array}$ & $\begin{array}{c}0.044 \\
(0.92)\end{array}$ & $\begin{array}{l}\mathbf{0 . 1 2 7} \\
(2.25)\end{array}$ & $\begin{array}{l}0.123 \\
(3.42)\end{array}$ \\
\hline Gender & $\begin{array}{l}-0.185 \\
(-2.21)\end{array}$ & $\begin{array}{l}-0.116 \\
(-0.91)\end{array}$ & $\begin{array}{l}-0.077 \\
(-0.58)\end{array}$ & $\begin{array}{l}0.106 \\
(1.12)\end{array}$ \\
\hline Smoker & $\begin{array}{l}0.101 \\
(1.02)\end{array}$ & $\begin{array}{l}-0.153 \\
(-1.18)\end{array}$ & $\begin{array}{l}0.142 \\
(1.05)\end{array}$ & $\begin{array}{l}0.116 \\
(1.19)\end{array}$ \\
\hline Age & $\begin{array}{c}-0.00259 \\
(-0.69)\end{array}$ & $\begin{array}{c}0.0149 \\
(2.66)\end{array}$ & $\begin{array}{c}0.0052 \\
(0.93)\end{array}$ & $\begin{array}{l}0.0133 \\
(3.25)\end{array}$ \\
\hline ACUMI & $\begin{array}{l}-1.146 \\
(-6.54)\end{array}$ & $\begin{array}{l}0.318 \\
(0.98)\end{array}$ & $\begin{array}{l}-1.590 \\
(-5.61)\end{array}$ & $\begin{array}{c}-2.08 \\
(-5.97)\end{array}$ \\
\hline PRCABG & $\begin{array}{c}-1,132 \\
(-11.60)\end{array}$ & $\begin{array}{r}-0.878 \\
(-4.13)\end{array}$ & $\begin{array}{l}-1.192 \\
(-6.02)\end{array}$ & $\begin{array}{r}-0.656 \\
(-5.42)\end{array}$ \\
\hline PRPTCA & $\begin{array}{r}-0.237 \\
(-3.00)\end{array}$ & $\begin{array}{c}-0.030 \\
(-0.180)\end{array}$ & $\begin{array}{r}-0.187 \\
(-1.42)\end{array}$ & $\begin{array}{l}-0.151 \\
(-1.54)\end{array}$ \\
\hline$E F$ & $\begin{array}{c}-0.00384 \\
(-1.45)\end{array}$ & $\begin{array}{c}-0.41 \\
(-6.84)\end{array}$ & $\begin{array}{r}-0.0073 \\
(-1.70)\end{array}$ & $\begin{array}{r}-0.028 \\
(-7.83)\end{array}$ \\
\hline VES2 & $\begin{array}{l}0.753 \\
(5.40)\end{array}$ & $\begin{array}{r}-0.352 \\
(-2.39)\end{array}$ & $\begin{array}{l}1.101 \\
(6.64)\end{array}$ & $\begin{array}{l}0.677 \\
(5.71)\end{array}$ \\
\hline VES3 & $\begin{array}{c}1.102 \\
(12.07)\end{array}$ & $\begin{array}{l}0.789 \\
(4.59)\end{array}$ & $\begin{array}{l}0.803 \\
(5.96)\end{array}$ & $\begin{array}{l}0.842 \\
(8.41)\end{array}$ \\
\hline LEFT & $\begin{array}{l}0.958 \\
(8.28)\end{array}$ & $\begin{array}{l}1.535 \\
(4.62)\end{array}$ & $\begin{array}{r}1.232 \\
(5.71)\end{array}$ & $\begin{array}{l}1.027 \\
(5.38)\end{array}$ \\
\hline Number of Observations & 1767 & 578 & 751 & 1280 \\
\hline \% CABG in Sample & 37.0 & 60.1 & 53.0 & 52.3 \\
\hline$\%$ Correct Predictions & 78.38 & 72.8 & 80.0 & 78.83 \\
\hline Log-Likelithood & -809.65 & -312.65 & -324.96 & -602.21 \\
\hline
\end{tabular}


Table 37. Hospitals 007, 012, and Six Hospitals Agrregated (T-statistles in Parentheses, significant coeficients in bold)

\begin{tabular}{|c|c|c|c|}
\hline Variable & Hospital 007 & Hospital 012 & $\begin{array}{l}\text { Six Hospitals } \\
\text { Aggregated }\end{array}$ \\
\hline Constant & $\begin{array}{l}0.298 \\
(0.70)\end{array}$ & $\begin{array}{l}-0.525 \\
(0.90) \\
\end{array}$ & $\begin{array}{r}-0.634 \\
(-3.85) \\
\end{array}$ \\
\hline Comorbidity & $\begin{array}{r}-0.0147 \\
(-0.38)\end{array}$ & $\begin{array}{c}-0.0178 \\
(-0.29)\end{array}$ & $\begin{array}{r}0.0359 \\
(2.59)\end{array}$ \\
\hline Gender & $\begin{array}{r}-0.405 \\
(-3.15) \\
\end{array}$ & $\begin{array}{c}-0.00061 \\
(-0.00) \\
\end{array}$ & $\begin{array}{r}-0.129 \\
(-2.88) \\
\end{array}$ \\
\hline Smoker & $\begin{array}{l}0.0231 \\
(0.26) \\
\end{array}$ & $\begin{array}{r}-0.109 \\
-(0.63)\end{array}$ & $\begin{array}{l}0.0682 \\
(1.43) \\
\end{array}$ \\
\hline Age & $\begin{array}{c}-0,0041 \\
(1.01)\end{array}$ & $\begin{array}{r}-0.003] \\
(-0.49) \\
\end{array}$ & $\begin{array}{r}0.0059 \\
(3.28) \\
\end{array}$ \\
\hline ACUMJ & $\begin{array}{l}-0.782 \\
(-4.22)\end{array}$ & $\begin{array}{l}-1.276 \\
(2.25) \\
\end{array}$ & $\begin{array}{c}-1.056 \\
(-11.37)\end{array}$ \\
\hline PRCABG & $\begin{array}{l}-0.233 \\
(-1.73)\end{array}$ & $\begin{array}{r}-0.677 \\
(-3.06)\end{array}$ & $\begin{array}{c}-0.738 \\
(-13.28)\end{array}$ \\
\hline PRPTCA & $\begin{array}{l}-0.373 \\
(-3.25)\end{array}$ & $\begin{array}{l}-0.517 \\
(-2.53)\end{array}$ & $\begin{array}{r}-0.252 \\
(-5.56)\end{array}$ \\
\hline $\mathrm{EF}$ & $\begin{array}{c}-0.0181 \\
(-3.22)\end{array}$ & $\begin{array}{c}-0,0183 \\
(-2.66)\end{array}$ & $\begin{array}{c}-0.0145 \\
(-9.09)\end{array}$ \\
\hline VES2 & $\begin{array}{l}0.377 \\
(2.12) \\
\end{array}$ & $\begin{array}{l}0.637 \\
(2.84) \\
\end{array}$ & $\begin{array}{l}0.466 \\
(7.98) \\
\end{array}$ \\
\hline VES3 & $\begin{array}{l}0.272 \\
(1.93) \\
\end{array}$ & $\begin{array}{l}0.780 \\
(3.86)\end{array}$ & $\begin{array}{c}0.818 \\
(16.66) \\
\end{array}$ \\
\hline LEFT & $\begin{array}{r}0.547 \\
(3.50) \\
\end{array}$ & $\begin{array}{r}0.229 \\
(0.85) \\
\end{array}$ & $\begin{array}{c}0.870 \\
(12.76) \\
\end{array}$ \\
\hline $\begin{array}{l}\text { Number of } \\
\text { Observations }\end{array}$ & 621 & 304 & 5301 \\
\hline $\begin{array}{l}\% \text { CABG in } \\
\text { Sample }\end{array}$ & 42.8 & 44.4 & 46.6 \\
\hline $\begin{array}{l}\text { \% Cortect } \\
\text { Predictions }\end{array}$ & 67.5 & $\Upsilon 4.3$ & 74.6 \\
\hline Log-Likelihood & -377.50 & -162.58 & -2761.40 \\
\hline
\end{tabular}


Table 38. Dummy Variable Values in Aggregate Equation (Hospital 002 Null Hospital, Significant Values in bold)

\begin{tabular}{|l|c|c|c|c|c|}
\hline & Hospital 003 & Hospital 004 & Hospital 005 & Hospital 007 & Hospital 0012 \\
\hline Coeff. & $\mathbf{0 . 8 0 4}$ & $\mathbf{0 . 4 9 5}$ & $\mathbf{0 . 5 1 9}$ & 0.119 & $\mathbf{0 . 2 8 1}$ \\
\hline T-statistic & 11.29 & 7.72 & $\mathbf{9 . 7 0}$ & 1.80 & 3.17 \\
\hline
\end{tabular}

We interpret Table 38 first. We use hospital 002 as the "null hospital" in our aggregate equation, which implies that we ran dummy variables for the five other hospitals. All of these coefficients were positive and statistically significant. (The coefficient for hospital 007 was only marginally significant.) This implies that at each of these five hospitals there is a higher proctivity to use CABG instead of PTCA, when compared to hospital 002 .

Not only do hospitals differ with respect to their "initial CABG proclivity," but they also respond differently to differences in patients' conditions. Table 39 summarizes the estitnated effects of different factors across the six hospitals. On many of the variables, there is a striking lack of unifornity. The patient's comorbidity score was only statistically significant in two hospitals. Gender was significant in three bospitals, smoking in one hospital and age was significant in two hospitals. The effects were more

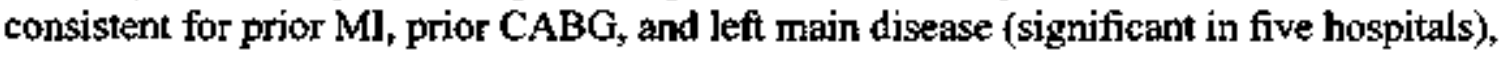
and prior PTCA and ejection fraction (significant in four hospitals). Only the dummy variable for two blockef vessels was significant with the same sign across all six hospitals. (All six coefficient on the variable for three blockages are significant, but one has the opposite sign of the other five.) 
Table 39. Coefficient Significance Acrass Six Hespitals

\begin{tabular}{|l|c|c|}
\hline \multicolumn{1}{|c|}{ Variable } & Number Significant & Sign \\
\hline COM & 2 & + \\
\hline Gender & 3 & - \\
\hline Smoker & 1 & + \\
\hline Age & 2 & + \\
\hline ACUMI & 5 & - \\
\hline PRCABG & 5 & - \\
\hline PRPTCA & 4 & - \\
\hline EF & 4 & - \\
\hline VESS2 & 6 & $+(5),-(1)$ \\
\hline VES3 & 6 & + \\
\hline LEFT & 5 & + \\
\hline
\end{tabular}

A procedure was performed where the treatment for every patient in the data set was predicted besed on each hospital's estimated equation. What was done was to lake every patient's characteristics, and then to predict what kind of procedure they would undergo if they went to each of the six hospitals. The results of this procedure are presented in Table 40. Again, we found important differences across the six hospitals. For example, according to our estimates, only 32 percent of the patients would have undergo CABG treatment had they been at hospital 007 , while almost 54 would have been treated with CABG had they gone to hospital 005. 
Table 40. Predicted CABG at Each Hospital (5301 Total Observations)

\begin{tabular}{|l|c|c|}
\hline Hospital Number & Number CABG Predicted & \% CABG Prediction \\
\hline 002 & 2215 & 41.8 \\
\hline 003 & 2821 & 53.0 \\
\hline 004 & 2704 & 51.0 \\
\hline 005 & 2852 & 53.8 \\
\hline 007 & 1691 & 31.9 \\
\hline 012 & 2377 & 44.8 \\
\hline All Six Hospitals & 2408 & 45.4 \\
\hline
\end{tabular}

\section{Testing For Different Coefficients Across Hospitals}

We have observed that these six hospitals weigh different factors when deciding whether a patient should undergo PTCA or CABG treatment. This section explored whether the differences between hospitals are statistically significant. If the differences are significant, it is statisticatly inappropriate to pool data from these hospitals togeiner in an aggregate equation.

To undertake this task, we first constructed an "unrestricted model"from the six individual regression results reported in Table 36 and Table 37. We then construeted a "likelihood ratio" for these six regressions. This is simply the sum of the likelihood functions for the six regressions. We then took our "restricted model," which is the model where the data is pooled across the six hospitals using durnmy variables for the other five hospitals. The likelihood ratio for this model is the likelihood ratio reported at the bottom of the fourth column of Table 37 .

The likelihood ratio from the unrestricted model is subtracted from the likelihood ratio from the restricted model and then multiplied by -2 . Under the null hypothesis that the coefficients across the six hospitals are similar, this statistic is distributed according to a $\chi 2$ distribution with degrees of freedom equal to the number of restrictions. In this case the number of restrictions are 55 ( 11 coefficients from five models restricted to be the same as the coefficients from the eight model). The $5 \%$ critical value from a $\chi 2(55)$ is approximately 74 .

The sum of the log-likelthoods from the six hospital models is 2589.36. The loglikelihood of the restricted (aggregated) model is 2761.40 . Twice the difference is $2 * 172.04=344.08$, greater than the value of $\chi 2(55)$. Thus, we cannot statistically aggregate the hospitals. 


\section{Meta-Analysis}

Even though we cannot statisticalty aggregate the data from the six hospitals, we can perform a "meta-analysis" (see Wolt, 1986), comparing the restlts across the six hospitals. To calculate the meta-coefficients, we simply take the average coefficient for each independent variable across the six regressions.

The significance levels of the coefficients is more complicated to calculate. Let $p_{i j}$ equal the p-values for the coefficient on independent variable $i$ in the regression relating to hospital $j$, calculated from the relevant t-statistic. Define $S_{i}$ as

$$
S_{\mathrm{j}}=-2 \Sigma \ln \text { Pij over all hospitals } \mathrm{j} \text {. }
$$

If the meta-coefficient on variable $i$ is insignificant, $S_{i}$ is distributed $\chi 2(12)$, with a 5 percent cut-off level of 21.0. From this, we can calculate the p-values on our metacoefficients. Table 41 gives the results of our meta-analysis.

Table 41. Meta-Analysis

\begin{tabular}{|l|c|c|c|}
\hline Variable & Meta-Coeff. Estimate & X2 Statistic & p-Value \\
\hline Constant & -0.002 & 37.48 & 0.000 \\
\hline Comorbidity & 0.0487 & 28.44 & 0.005 \\
\hline Gender & -0.113 & 25.50 & 0.013 \\
\hline Smoker & -0.020 & 12.06 & 0.441 \\
\hline Age & 0.0053 & 30.26 & 0.003 \\
\hline ACUMI & -1.093 & 138.57 & 0.000 \\
\hline PRCABG & -0.793 & 146.35 & 0.000 \\
\hline PRPTCA & -0.249 & 42.63 & 0.000 \\
\hline EF & -0.0196 & 96.60 & 0.000 \\
\hline VES2 & 0.532 & 0.532 & 0.000 \\
\hline VES3 & 0.754 & 0.754 & 0.000 \\
\hline LEFT & 0.921 & 0.921 & 0.000 \\
\hline
\end{tabular}


We observe that all coefficients but the one on smoking are statistically significant. We also note that the signs on these coefficients are consistent with what was predicted to us by clinicians.

Table 42 presents the marginal effects in our meta-model. We first estimated the probability of CABG treatment for our "standard" patient. Since all of our variables are either categorical (dummy) variables, or reported only in integers, we either used median values or the integer values closest to the meant values. The CABG percentage for our standard patient was 71.2 percent. ${ }^{7}$ We then calculated the changes in the probability of CABG treatment given a change in one of the explanatory variables, holding all the other variables at their mean (median) levels.

7 The total $C A B G$ percentage in our data set was 45.4 The median value, however, for VES3 (three vessel blockages) is 0.52 , which increases greatly the CABG probability of our mean (median) patient. 
Table 42. Marginal Effects in Meta-Model (CABG Probability of "Standard" Patient: $71.2 \%$ )

\begin{tabular}{|c|c|c|c|c|}
\hline $\begin{array}{l}\text { Explanatory } \\
\text { Variable }\end{array}$ & $\begin{array}{c}\text { Mean (Median) } \\
\text { Vatue of Standard } \\
\text { Patient }\end{array}$ & $\begin{array}{c}\text { Marginal Change } \\
\text { Made in } \\
\text { Explanatory } \\
\text { Variabłe }\end{array}$ & $\begin{array}{c}\text { CABG } \\
\text { Probability }\end{array}$ & $\begin{array}{c}\text { Change in CABG } \\
\text { Probability }\end{array}$ \\
\hline \multirow[t]{3}{*}{ Comatbidity } & $1.03(1)$ & Increase to 2 & $72.8 \%$ & $1.6 \%$ \\
\hline & & Increase to 4 & 75.9 & 4.8 \\
\hline & & Incretase to 7 & 80.2 & 9.1 \\
\hline Gender & $0.28(0)$ & Increase to 1 & 67.2 & -4.0 \\
\hline Smoker & $0.25(0)$ & Increase to l & 71.8 & 0.7 \\
\hline \multirow[t]{3}{*}{ Age } & $64.16(64)$ & Increase to 65 & 71.3 & 0.2 \\
\hline & & Increase to 70 & 72.2 & 1.1 \\
\hline & & Reduce to 58 & 70.1 & -1.1 \\
\hline ACUMI & $0.07(0)$ & Increase to 1 & 29.6 & -41.5 \\
\hline PRCABG & $0.15(0)$ & lncrease to 1 & 40.7 & -30.4 \\
\hline PRPTCA & $0.25(0)$ & increase to 1 & 62.1 & -9.0 \\
\hline \multirow[t]{2}{*}{$E F$} & $56.98(57)$ & Increase to 58 & 70.5 & -0.7 \\
\hline & & Reduce to 27 & 87.4 & 16.2 \\
\hline VES2 & $0.75(1)$ & $\begin{array}{l}\text { Reduce to 0 } \\
\text { (implying VES3 } \\
\text { reduced to 0) }\end{array}$ & 23.3 & -47.8 \\
\hline VES3 & $0.53(1)$ & Reduce to 0 & 42.2 & -28.9 \\
\hline LEFT & $0.12(0)$ & Increase to 1 & 93.0 & 21.9 \\
\hline
\end{tabular}

The comorbidity score appears to have only a small impact on the CABG percentage, increasing it to 1.6 percent with a comorbidity change of 1 , and 9.1 percent with a comorbidity change of 7 . Moving from a male to a fernale patient reduces the CABG probability 4,0 percent. Age has very small effects, with a reduction in age of 7 reducing the CABG probability 1.1 percent.

Somewhat larger effects show up on the variables representing a patient's medical history. A heart attack in the last 24 hours reduces the CABG probability 41.5 percent. 
Prior CABG treatment reduces the probability 30.4 percent, while a prior PTCA treatment reduces that probability 9.0 percent. Smatl changes in the ejection fraction induce sinall changes in the CABG percentage, but a reduction in the $E F$ by 30 increases the CABG percentage by 16.2 .

Changes in the nature of the blockages has large effects on probability of CABG. Setting VES2 $=0$ (which implies setting VES $3=0$, and is equivajent to reducing the number of blockages from 3 or more to 1 ) reduces the $\mathrm{CABG}$ probability 47.8 percent. Setting only VES $3=0$, which implies recucing the number of blockages to 2 , reduces the CABG probability by 28.9 percent. On the other hand, giving the patient left main disease increases the CABG probability by 21.9 percent, so 93.0 percent. 
Intentionally Left Blank 


\section{Appendix E - A Two-Part Model of the Costs of Treating Benign Prostatic Hyperplasia and the Impact of Innovation}

\section{Introduction}

One of the most common chronic conditions affecting men in the U.S. is benign enlargement of the prostate, known as benign prostatic byperplasia or BPH. This condition affects as many as three quarters of all men aged 80 and oider, and more than balf of men who are at least 60 years old (AHCPR, 1997). There are a wide variety of treatments for BPH, ranging from a surgical procedure involving a large incision in the abdomen (open prostatectomy) to phammaceutical therapy - or ever simple "watchful waiting." Currently, however, the transurethral resection of the prostate (TURP) has achieved a position of dominance for medical interventions. Recent development of more non-invasive treatment modalities - such as transurethral microwave thermotherapy, alpha blocker drug therapies or alpha-reductase inhibitor drug therapies - have stimulated debate regarding what is the most cost-effective method for treating BPH in the genera] population. In this paper we will estimate the average costs of providing a TURP. This measure of average costs can iniorm cost effectiveness studies of TURP, or inform costbenefit studies of aiternative treatment methods.

The treatment decision process for BPH is atypical for many medical conditions which assail the elderly population. In part this is due to the nature of the disease. The primary concern is associated with discomfort of the patient; in nearly all circumstances BPH will not threaten the life of the patient or have consequences for other aspects of the patient's health. Whether a patient will receive treatment or not depends on both the patient's own perception of his discomfort and inconvenience and on the discassions be has with his physician. The process has been referred to as "shared decision making." (See, for example, Roerhborn $(1995,32)$ ). This has implications for estimating costs. Specifically, we must capture two levels of decision making: first we must model the decision to seek treatment or not; second, we must model the cost of treatment, conditional on the patient having decided to seek it.

This section proceeds by first exploring the alterrative econometric models that could be utilized to capture the multi-step cost model associated with TURP. We present the advantages and disadvantages of several models, and the reasons for selecting the model we chose. Second, we discuss the two primary data sources, and how they will be combined in our model. Next, we estimate a model which describes the decision to seek treatment. Following that, we estimate the model of conditional treatment costs. Finatly, we put the two models together to create a single model of the costs associated with TURP, which can be used for policy analysis, in that this model will predict the cost 
associated with supplying TURP to the average man with $\mathrm{BPH}$, rather than supplying TURP to the men who actually selected it. The combined model will be appropriate for asking questions about several issues, including the cost consequences of expanding access to TURP.

\section{Models of Self-Selection}

There is a long literature in economics dealing with consistent estimation in the face of data which are characterized by a large number of zeros. Such models usually take the form:

$$
\begin{gathered}
y_{i}^{*}=\beta x_{i}+u_{i} \\
u_{i}-N\left(0, \sigma^{2}\right),
\end{gathered}
$$

where the dependant variable is not always observed, such that the observed data is generated according to the rule:

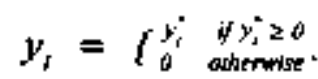

In this model, $y_{j}$ tepresents the costs of providing a TURP to a man suffering from BPH.

One of the earlier methodologies developed for consistent estimation is from Tobin (1958). This model, known as the Tobit, assumes that the unobserved data (i.e. censored data) arise because $y_{i}^{*}$ takes on negative values which, for technological or rationality reasons, camot be observed. The Tobit is less appropriate, however, to situations where the unobservability of the dependant variable is due to some explicit choice.

Heckman (1978) proposed an alternative estimator when the censoring is due to actual choices made by the agents which are being examined. This two-stage model is relatively straight forward. It involves creating an additional variable, $I_{i}$ which equals one when the data are observed and zero otherwise. For this research, $L_{\text {i }}$ takes a value of 1 when a man receives a TURP, and 0 otherwise. The structural equation for this model is generally found by first estimating a probit to the form:

$$
I_{i}=\gamma x_{i}+\eta_{,},(3)
$$

and then recovering the inverse Mill's ratio $\lambda=\phi\left(\gamma x_{1}\right) / \Phi\left(\gamma x_{1}\right)$, where $\phi($.$) and \Phi($. represent the probability density function and the cumulative density function of the standard normal distribution, respectively. Given the inverse Mill's ratio from the first stage, the unconditional estimate of the dependant variable of interest is found by nunning two-stage least squares estimate on 


$$
y_{i}=\beta x_{z i}+\rho \sigma z_{i}+u_{i}
$$

Note that $x_{1}$ and $x_{2}$ must share many variables in common, though $x_{1}$ will, in general, contain identifying variables which are excluded from $x_{2}$. Also $x_{1}$ and $x_{2}$ are generally taken from the same sample. A second variant of this model is available which estimates both stages simuitaneously via maximum fikelihood.

This model is based upon a number of assumptions, and generally is appropriate when the decision process whether to choose a positive level of $y_{i}$ is closely related to the decision process which describes the anount of $y_{i}$ chosen, given the choice to consume some positive amount. There are situations, however, in which this assumption does not necessarily hold. Further, in most circumstances identifying restrictions are needed to eliminate variables from the second stage of the process. That is, researchers must find variables which influence the choice to pick a positive level of $y_{i}$ but do not affect the decision regarding the level of $y_{i}$. Such restrictions may be difficult or inipossible to defend in many circumstances. ${ }^{s}$ Also, this Heckman model require that $x_{1}$ and $x_{2}$ be drawn from the same sample, so that an inverse Mill's ratio can be created for each observation.

A third model has been developed to deal with censored data, and has found wide-spread adoption in health econonics. This model was initially explored by Cragg (1971), and Iater received much more attention due to work by reseacchers on data generated by the RAND Health Insurance Experiment. Labeled the Two-Part model, it involves estimating a first stage probit or logit, as in (3) above, and then estimating on the sub. sample which contions only positive levels of $y_{i}$. The unconditional expected value of $y_{i}$ can then be recovered using

$$
\begin{array}{r}
\ln \left(y_{i}\right)=\beta x_{i}+t_{i}(\mathbf{5}) \\
E\left[y_{s}\right]=\beta_{i} \exp \left(b_{x_{i}}\right) \theta,(0)
\end{array}
$$

where $P$ is the predicted probability of a positive level of $y_{i}$ and is the average of the exponential of etrors from (5). For an example of this model in use, see Manning, et al. (1995).

A substantial debate has been underway for a number of years regarding the relative superiority of the Heckman Self-Selection model versus the Two-Part model. Evidence

${ }^{8}$ Note that it may be possibje to identify the first stage of the process off of the nonlinearities in the probit estimator. The problem with this is that it may introduce serious multicollinearity between the inverse Mill's ratio and the variables in $x_{2}$. In this case, the research is with no recourse. 
presented to date have centered primarily around theoretical claims in favor of the selection model, and Monte Carlo simulation results which have not resolved the matter. On the theoretical front, questions have been raised as to whether there is any joint distribution of $(\eta, u)$ which is consistent with the Two-Part model (i.e., whether the two equations can ever be stochastically independent). On the Monte Carlo front, a series of simulations have been published which indicate that the Two-Part model dominates the sample selection model (Duan, et al., 1984; Hay et al., 1987). Other authors find that the Twor-Part model and sample selection models are either roughly equivalent, or each stightly superior in certain circumstances (Leung and Yu, 1996; Duan and Rogers, 1987).

Here we will utilize the Two-Part model for several reasons. First, given that we are ultimately interested in modeling the cost of TURP, it is reasonable to assume that the decision whether to receive a treatment is independent of the decision to spend a marginal dollar. The first decision involves heavy patient participation. However, the decision to spend a marginal dollar is likely made exclusively by the physician performing the procedure. In this case, a model which assumes intrinsically separate decisions is a better conceptual fit.

A second reason to utilize the Two-Part model follows from the nature of our data. The data we use for the costs of TURP are taken from the 1994 discharge abstracts reported to HClA from the five "all payer" states (California, Colorado, Florida, Maryland and New Jersey). This data, based as it is on discharges, contains only information on those men who actually underwent the procedure. To model the likelihood of the procedure, we utilize a different data set, the National Health Interview Survey (NHIS, years 19861994). This is a survey of the general population, which includes men with $B P H$, some of whom opt for a TURP and some of whom do not. Using this data, we can estimate the first stage logit equation to predict the likelihood of a TURP, and use the predicted probability of a TURP for the average man with BPH as the unbiased estimate of the likelihood for each person in the all-payer sample, in order to implement equation (6).

\section{The First Part Treatment Decision}

The first stage of the Two-Part model involves estimating (3) - whether a TURP is obtained or not - via a logit procedure (which simply insures that the prediction for the likelihood of a TURP does not fall outside the $[0,1]$ interval). The logit is estimated across a sample of men from the NHIS who suffer from BPH. Of the 502 men in the sample, 12.2 percent (or 61) opted to undergo a TURP. We regress the $[0,1]$ indicator across a number of explanatory variables. These are:

AGE The age of the patient

BLACK A dummy variable equaling 1 when the man is black

HISP A dummy variable equaling 1 when the man is Hispanic

MARRIE A dummy variable equaling o when the man is married 


$\begin{array}{ll}\text { EDUC } & \text { Years of education completed } \\ \text { INCOME } & \text { Annual income } \\ \text { INCOME } & \text { Annual income, squared } \\ \text { WORK } & \text { Whether the BPH restricts the man's ability to work } \\ \text { HEALTH } & \text { Self-reported health status } \\ \text { ACTLIMIT } & \text { Whether the BPH restricts the man's normal daily activities } \\ \text { ONSET } & \text { How long since the BPH was diagnosed } \\ \text { NE } & \text { A dummy variable equaling } 1 \text { when the man lives in the Northeast } \\ \text { MW } & \text { A dummy variable equaling } 1 \text { when the man lives in the Midwest } \\ \text { SO } & \text { A dummy variable equaling } 1 \text { when the man lives in the South } \\ \text { RURAL } & \text { A dummy variable equaling } 1 \text { when the man lives in a rural setting } \\ \text { NONPROF } & \text { A dummy variable equaling } 1 \text { when the man was admitted to a non-profit } \\ & \text { hospital }\end{array}$

OTHERHOS A durnny variable equaling 1 when the man was adnitted to a hospital that was neither for-profit nor not for profit

YEAR>89 A dummy variable indicating the TURP occurred after 1989

YEAR>91 A dummy variable indicating the TURP occured after 1991

UROL A dummy variable indicating the man visited a urologist

YR91"UR An interaction term between YEAR $>91$ and UROL

Several variables require explanation. Economists have long argued about whether hospital ownership affects decisions within the institution. For this reason, we include the dunny variables for hospital types to see if for-profit hospitals are more likely to perform TURPs than other kinds of hospitals. A significant parameter on either hospital durnmy would indicate that for-profits behave differently.

In addition, several important changes have taken place in medical technology related to the diagnosis or treatment of BPH during the years. In 1989, a new test for prostate cancer - the PSA test - became widely available. While this test does not detect BPH, a common perception among urologists is that it did bring more men into contact with providers, who were then in a position to diagnose BPH independently of the possibility of cancer. This motivates the YEAR $>89$ dummy variable. In 1991, alpha blockers were recognized as a posentially effective treatment alternative to more invasive methods for BPH. Consequently, one would expect substitution away from TURP afler this time, which explains the inclusion of YEAR $>91$. Finally, given that a medical alternative became both available and widely publicized after 1991 , it is possible that urologists might respond to this "threat" to their livelihood by increasing the strength of their recommendations for TURP. To control for this, an interaction term between YEAR $>91$ and UROL is included.

The regression results for the logit model are presented in Table 43. 
Table 43. Regression Results for First-Stage Logit on Probability of TURP (Tstatistics in pareutheses, significant coefficients in bold)

\begin{tabular}{|c|c|c|c|}
\hline Variable & Coeffucient & Variable & Coefftcient \\
\hline Constant & $\begin{array}{r}-4.37 \\
(2.15)\end{array}$ & NE & $\begin{array}{c}-1.5102 \\
(3.11)\end{array}$ \\
\hline AGE & $\begin{array}{l}0.4218 \\
(2.18)\end{array}$ & MW & $\begin{array}{c}-0.4614 \\
(1.09)\end{array}$ \\
\hline BLACK & $\begin{array}{l}0.7097 \\
(1.28)\end{array}$ & so & $\begin{array}{c}-0.2823 \\
(0.72)\end{array}$ \\
\hline HISP & $\begin{array}{l}0.9128 \\
(1.48)\end{array}$ & RURAL & $\begin{array}{l}0.0804 \\
(1.02)\end{array}$ \\
\hline MARRIED & $\begin{array}{c}-0.1775 \\
(0.44)\end{array}$ & NONPROF & $\begin{array}{l}1.3319 \\
(3.30)\end{array}$ \\
\hline EDUC & $\begin{array}{l}0.4250 \\
(0.82)\end{array}$ & OTHERHOS & $\begin{array}{l}0.8245 \\
(1.56)\end{array}$ \\
\hline INCOME & $\begin{array}{l}0.0118 \\
(0.17)\end{array}$ & YEAR $>89$ & $\begin{array}{c}-0.6244 \\
(1.04)\end{array}$ \\
\hline INCOME2 & $\begin{array}{c}-0.1938 \\
(0.67)\end{array}$ & $Y E A R>91$ & $\begin{array}{c}-0.3272 \\
(0.50)\end{array}$ \\
\hline WORK & $\begin{array}{l}0.6157 \\
(1.54)\end{array}$ & UROL & $\begin{array}{c}-0.0183 \\
(0.04)\end{array}$ \\
\hline HEALTH & $\begin{array}{c}-0.0432 \\
(0.32)\end{array}$ & YR91*UR & $\begin{array}{l}1.5735 \\
(2.08)\end{array}$ \\
\hline ACTLIMIT & $\begin{array}{l}0.1440 \\
(0.61)\end{array}$ & & \\
\hline ONSET & $\begin{array}{c}-0.3683 \\
(2.44)\end{array}$ & & \\
\hline
\end{tabular}

While the primary reason for estimating the logit treatment choice equation is to condition the cost estimates, several results from Table 44 are of interest. Men living in the Northeast are significantly less likely to receive a TURP for their BPH than men living in the other regions of the U.S. This suggests interesting practice variation, though the soture of this variation cannot be determined with this analysis. Of somewhat more interest is the parameter estimate on the interaction term between YEAR>91 and UROL. This parameter is positive and significant, which indicates that after 1991, seeing a urologist increased a man's chance of having a TURP - which was not true prior to $199 \mathrm{I}$ (as evidenced by the very insignificant parameter estimate on UROL). This result is 
consistent with the hypothesis that the introduction of pharmaceutical therapies for BPH lead urologists to increase the pressure they brought to bear on their patients to accept a TURP. However, it is also consistent with the presence of selection effects after 1991, such that only the most likely candidates for TURP actually made it to a urologist, with the less severe BPH patients receiving medical therapy from their general practitioner.

Once the logit model of equation (3) is estimated, we can recover the predicted likelihood of a TURP, $\mathrm{P}$, for the average man in the NHIS sample. This predicted probability of a TURP will be taken as an unbiased estimate of the likelihood of a TURP for each man in the cost regtessions below. Hence, $P$ will replace $P_{i}$ when we finally construct the unconditional cost model from equation (6). The conditional cost estimation is performed in the next section.

\section{The Cost of Undergoing a TURP}

As discussed above, a TURP is an elective procedure. Undergoing a term involves significant econonic costs. Thus, any technology that reduces the number of decisions to undergo TURP may well save resounces for society. In this section, we attempt to model the hospital costs of undergoing TURP.

\section{Data and Estimation Issues}

The data for this section comes from the "All-Payer" data set, data from 1994 on al] payers in all hospitals in five different states: California, Colorado, Florida, Maryland, and New Jersey. Within each state are a different number of hospitals, and within each hospital are a different number of patient observations, as summarized in Table 44. 
Table 44. Data Summery by State

\begin{tabular}{|c|c|c|c|}
\hline State & Hospitals & Observations & Usable Observations \\
\hline California & 347 & 13761 & 10866 \\
\hline Colorado & 41 & 1505 & 1311 \\
\hline Florida & 175 & 9081 & 8122 \\
\hline Maryland & 82 & 2513 & 2182 \\
\hline New Jersey & 84 & 5357 & 4159 \\
\hline Total & 729 & 32,127 & 26,640 \\
\hline
\end{tabular}

Our goal is to econometrically model the determinates of total hospital charge for a patient undergoing TURP. The explanatory variables available to us in the All-Payer data set are

InTOTAL

AGE

COMP

EMERG

RlSK

RACE

DRG306

DRG307

DRG336

MEDICARE

MEDICAID
The natural logarithm of Total Charge.

The age of the patient.

A dummy variable equal to $l$ if the patient suffered complications, 0 otherwise.

A dummy variable equal to 1 if the patient was admitted to the emergency room, 0 otherwise.

The patient's risk adjusted mortality index developed at HClA.

A dummy variable equal to 1 if the patient is known to be white, 0 otherwise.

A dummy variable equal to $I$ if the patient was billed for prostatectomy with complications, 0 otherwise.

A dummy variable equal to 1 if the patient was billed for prostatectomy without complications, 0 otherwise.

A dummy variabie equal to 1 if the patient was billed for transurethral prostatectomy with complications, 0 otherwise.

A dumby variable equal to $l$ if the primary payer was Medicare, 0 otherwise.

A dummy variable equal to $l$ if the primary payer as

Medicaid, 0 otherwise. 
A dummy variable equal to 1 if the primary payer was Blue Cross, 0 otherwise.

OTHER INSURANCE A dummy variable equal to 1 if the primary payer was another form of insurance, 0 otherwise.

As stated above, there are 729 different hospitals in the sample. We expect that each hospital will have its own specific impact on costs. In other words, one hospital may be naturally more or less costly than another, all patient characteristics held constant.

Conceptually, we could adjust for such characteristics by running a durnmy variable for each hospital. With 729 hospitals, however, that could be computationally difficult. Instead, we run a "fixed effects estimated. The fixed effects estimator is calculated as follows: Let $\left\{\mathrm{X}_{i j}, \mathbf{Y}_{\mathrm{ij}}\right\}$ be the vector of the dependent variable $\mathrm{X}$ (total cost) and explanatory variables $Y$, where the subseript (i) refers to patient (i) and the subscript (j) refers to patient (j). Let $X_{n}$ equal the mean value for $X$ for all the patients in hospital (j) and $Y_{*}$ equal a vector of mean values for the variables in those same patients in hospital (j). Let $X_{i}^{f}=X_{i j}-X_{m}$, and $Y_{i}^{f}=Y_{i j}-Y_{m}$. Fixed effects regressions involves running a regression of $Y_{i}^{t}$ on $X_{i}^{i}$. (See Judge, et al $(1985,530-533)$.) We therefore will suppress the constant term in the regression, as well as the dummy variables for each of the hospitals (though none of these are of interest to the present investigation.)

\section{Estimation Results}

Table 45 presents the results of the estimation of the fixed effects model by states, and for an aggregate model across all five states. Patient age is positive and significant in all six regressions, indicating that the older a patient is, the higher the relevant medical costs. Patients with complications also generated higher charges, with the charge increase ranging from 30 to 42 percent. Patients admitted to the emergency room increase costs from 44 to 61 percent.

On the other hand, the patients risk adjusted mortality index had weaker effects. It was only significant in three of the five state equations, and at a relatively low level. The variable for race is insignificant in all five of the state equations.

As for the DRG variables, patients with complications relating to prostatectomy were estimated to have significantly higher costs, with charge increases of 31 to 55 percent. Prostatectorny without complications was not significantly more expensive than the prostatectomy with complications in four of the five state equations. If the patient underwent transurethral prostatestomy with cormplications, that acted to raise charges significantly, in the range of 12 to 20 percent.

With respect to the payer classes, none of the four variables for payer class was significant in the regressions for California, Colorado, Florida, and Maryland. Three of the four, however, where significant in New Jersey. We take this as an indication that 
medical insurance plans are different in New Jersey, that is, that managed care has a smaller share of practices there and has not come to change treatment regimen.

Table 45. Estimation Results - All Payer Data (T-statistics in Parenthesis, signiflennt coefficients in bold)

\begin{tabular}{|c|c|c|c|c|c|c|}
\hline Variable & Califomia & Colorado & Florida & Maryland & New Jersey & $\begin{array}{l}\text { Aggregate } \\
\text { Equation }\end{array}$ \\
\hline $\mathbf{A G E}$ & $\begin{array}{l}0.00157 \\
(3.98)\end{array}$ & $\begin{array}{l}0.00257 \\
(2.291)\end{array}$ & $\begin{array}{l}0.00280 \\
(5.410)\end{array}$ & $\begin{array}{l}0.00451 \\
(3.918)\end{array}$ & $\begin{array}{l}0.0 .0533 \\
(5.537)\end{array}$ & $\begin{array}{l}0.00275 \\
(9.603)\end{array}$ \\
\hline COMP & $\begin{array}{l}0.297 \\
(25.554)\end{array}$ & $\begin{array}{l}0.309 \\
(8.746)\end{array}$ & $\begin{array}{l}0.281 \\
(22.630)\end{array}$ & $\begin{array}{l}0.2310 \\
(9.796)\end{array}$ & $\begin{array}{l}0.421 \\
(17.067)\end{array}$ & $\begin{array}{l}0.304 \\
(39.996)\end{array}$ \\
\hline EMERG & $\begin{array}{l}0.461 \\
(26.481)\end{array}$ & $\begin{array}{l}0.445 \\
(6.453)\end{array}$ & $\begin{array}{l}\mathbf{0 . 4 2 5} \\
(27.350)\end{array}$ & $\begin{array}{l}0.621 \\
(20.185)\end{array}$ & $\begin{array}{l}0.584 \\
(29.436)\end{array}$ & $\begin{array}{l}0.514 \\
(55.747)\end{array}$ \\
\hline RISK & $\begin{array}{l}0.000021 \\
(1.657)\end{array}$ & $\begin{array}{l}0.000080 \\
(3.029)\end{array}$ & $\begin{array}{l}0.00004] \\
(1.235)\end{array}$ & $\begin{array}{l}0.000436 \\
(2.105)\end{array}$ & $\begin{array}{l}0.000047 \\
(2.052)\end{array}$ & $\begin{array}{l}0.000043 \\
(4.368)\end{array}$ \\
\hline RACEOI & $\begin{array}{l}-0.0142 \\
(1.717)\end{array}$ & $\begin{array}{l}0.0376 \\
(1.405)\end{array}$ & $\begin{array}{l}-0.0257 \\
(1.938)\end{array}$ & $\begin{array}{l}-0.0350 \\
(1.591)\end{array}$ & $\begin{array}{l}-0.0345 \\
(1.600)\end{array}$ & $\begin{array}{l}-0.0183 \\
(2.870)\end{array}$ \\
\hline DRG306 & $\begin{array}{l}0.313 \\
(18.998)\end{array}$ & $\begin{array}{l}0.425 \\
(9.275)\end{array}$ & $\begin{array}{l}\mathbf{0 . 3 2 4} \\
(19.574)\end{array}$ & $\begin{array}{l}0.342 \\
(9.200)\end{array}$ & $\begin{array}{l}\mathbf{0 . 5 5 5} \\
(17.466)\end{array}$ & $\begin{array}{l}0.364 \\
(35.346)\end{array}$ \\
\hline DRG307 & $\begin{array}{l}0.0454 \\
(1.670)\end{array}$ & $\begin{array}{l}0.0202 \\
(0.240)\end{array}$ & $\begin{array}{l}0.0773 \\
(2.204)\end{array}$ & $\begin{array}{l}0.0612 \\
(t .008)\end{array}$ & $\begin{array}{l}-0.0172 \\
(0.298)\end{array}$ & $\begin{array}{l}0.0499 \\
(2.570)\end{array}$ \\
\hline DRG336 & $\begin{array}{l}0.134 \\
(19.303)\end{array}$ & $\begin{array}{l}0.142 \\
(6.942)\end{array}$ & $\begin{array}{l}0.118 \\
\text { (I3.544) }\end{array}$ & $\begin{array}{l}0.124 \\
(6.469)\end{array}$ & $\begin{array}{l}0.200 \\
(13.691)\end{array}$ & $\begin{array}{l}0.140 \\
(28.997)\end{array}$ \\
\hline MEDICARE & $\begin{array}{l}0.00283 \\
(0.121)\end{array}$ & $\begin{array}{l}-0.00444 \\
(0.087)\end{array}$ & $\begin{array}{l}-0.00943 \\
(0.366)\end{array}$ & $\begin{array}{l}0.00829 \\
(0.130)\end{array}$ & $\begin{array}{l}-0.108 \\
(2.453)\end{array}$ & $\begin{array}{l}-0.0217 \\
(-1.430)\end{array}$ \\
\hline MEDICAID & $\begin{array}{l}0.00422 \\
(0.165)\end{array}$ & $\begin{array}{l}0.0868 \\
(1.105)\end{array}$ & $\begin{array}{l}-0.0559 \\
(1.320)\end{array}$ & $\begin{array}{l}-0.0201 \\
(0.224)\end{array}$ & $\begin{array}{l}-0.109 \\
(1.489)\end{array}$ & $\begin{array}{l}-0.0226 \\
(1.192)\end{array}$ \\
\hline $\begin{array}{l}\text { BLUE } \\
\text { CROSS }\end{array}$ & $\begin{array}{l}0.0245 \\
(0.831)\end{array}$ & $\begin{array}{l}-0.0454 \\
(0.665)\end{array}$ & $\begin{array}{l}0.0225 \\
(0.790)\end{array}$ & $\begin{array}{l}-0.0174 \\
(0.261)\end{array}$ & $\begin{array}{l}-0.1128 \\
(2.375)\end{array}$ & $\begin{array}{l}-0.0212 \\
(1.165)\end{array}$ \\
\hline $\begin{array}{l}\text { Other } \\
\text { lnstirance }\end{array}$ & $\begin{array}{l}-0.0228 \\
(0.964)\end{array}$ & $\begin{array}{l}-0.0353 \\
(-0.683)\end{array}$ & $\begin{array}{l}-0.0244 \\
(0.897)\end{array}$ & $\begin{array}{l}-0.0272 \\
(0.418)\end{array}$ & $\begin{array}{l}-0.1500 \\
(3.339)\end{array}$ & $\begin{array}{l}-0.0515 \\
(3.317)\end{array}$ \\
\hline RSS & 1066.66 & 126.78 & 209.97 & 257.94 & 687.17 & 3028.85 \\
\hline $\mathrm{R}^{2}$ & 0.214 & $0.24]$ & 0.237 & 0.355 & 0.385 & 0.270 \\
\hline
\end{tabular}




\section{Testing for Fixed Effects and For An Aggregate Model}

Econometrically, our first test is to see whether the fixed effects model (in effect, a dummy variable for each hospital) is appropriate. To test this, we set up two models. In the first model all hospitals were assumed to be identical, all of the observations for one state were pooled and a standard regression estimated via ordinary least squares. In the second, fixed effects, model the marginal effects of each characteristic was assumed to be the same for all hospitals, but the hospitals differed in the intercept term. A model was created with a dummy variable for each hospital in addition to the characteristic variables. The two models were then compared based upon the sum of squared errors. As discussed above, it can be shown that the patient characieristic coefficients of the second model, the one with multiple intercept terms, can be estimated without the intercept terms.

Let the numbet of Iestrictions, \# REST = the number of hospitals in the state. Let the degrees of freedom $\mathrm{df}=$ the number of observations minus \#REST minus the number of variable coefficients minus $1, S_{S E}=$ sum of squared enrors from the restricted, one intercept, model; and $\mathrm{SSE}_{\mathrm{u}}=$ sum of squared enors from the unrestricted, multiple intercept, model. It is known that if the hospitals are all identical the test statistic:

$$
\mathrm{F}=\left[\left(\mathrm{SSE}_{\mathrm{r}}-\mathrm{SSE}_{\mathrm{u}}\right) /(\# \mathrm{REST})\right] /\left[\mathrm{SSE}_{\mathbf{u}} / \mathrm{d}\right]
$$

follows an F-distribution with df the numerator and \# REST the denominator degrees of freedom. Table $\mathbf{4 6}$ presents the results of these tests for all of the hospitals in all states. As the table demonstrates the hypothesis of identical intercepts for each hospital is strongly rejected in favor of the alternative that tach hospital has a separate intercept term. 
Table 46. Test For Fired Effects

\begin{tabular}{|c|c|c|c|c|c|c|}
\hline State & $\mathrm{SSE}_{\mathrm{\tau}}$ & $\operatorname{SSE}_{\mathbf{u}}$ & \#REST & df & $\begin{array}{c}\text { Test } \\
\text { Statistic }\end{array}$ & $\begin{array}{l}\mathrm{F}(1 \%) \\
\text { critical }\end{array}$ \\
\hline California & 1878 & 1067 & 346 & 10,507 & 23.09 & 1.19 \\
\hline Colorado & 198 & 127 & 40 & 1258 & 17.57 & 1.61 \\
\hline Florida & 1243 & 846 & 174 & 7935 & 21.39 & 1.27 \\
\hline Maryland & 324 & 258 & 81 & 2088 & 6.56 & 1.41 \\
\hline New Jersey & 899 & 687 & 83 & 4063 & 15.11 & 1.40 \\
\hline
\end{tabular}

The next question we are interested in whether the coefficients are the same across states. To do this we estimate a separate regression for each state, and then an aggregate equation across all five states, using the fixed effects model. We then compare the sum of squared errors of the five state models to an aggregate model with all of the data from all five states.

In this case it is known that:

$$
\left(\mathrm{SSE}_{\mathrm{F}}-\mathrm{SSE}_{\mathrm{u}}\right)^{*}(\mathrm{~T}-\mathrm{K}) / / * \mathrm{SSE}_{\mathrm{al}}-\mathrm{F}(\mathrm{J}, \mathrm{T}-2 \mathrm{~K}),
$$

where $\mathrm{J}=$ number of restrictions, $\mathrm{T}=$ \# obs, and $\mathrm{K}=$ \# parameters in unrestricted model. In this case $]=48$, and $T-K=26628$. The $1 \%$ critical value for $F(40,4)$ is 1.59. As Table 46 indicates, the sum of the squared errors across the five state models is 2984, while the sum of squared errors in the aggregate model is 3028 . This implies the relevant $F$ statistic $\mathrm{F}=\left(\mathrm{SSE}_{1}-\mathrm{SSE}\right)^{*}(\mathrm{~T}-\mathrm{K})^{\prime} \mathrm{J} \mathrm{JSSE}_{1}=8.23>1.59$. Thus, the hypothesis that all states are the same is rejected at the $1 \%$ level.

\section{Testing For Differential Effects Across States}

While the statistical models for each state are significantly different in a statistical test, a brief review of the relevant parameters indicates they may not be greatly different in an economic sense. The consideration that arises here is the difference between statistical significance and practical importance. Each of these models has several thousand 
observations. This means that it may be possible to very accurately measure the coefficients in question. Something that is measured very accurately may be statistically significantly different than another thing that is also measured very accurately.

For example, if we can measure a person's weight in grams we can say that the difference in their weight from one hour to the next is significantly different, while for any practical application the difference of a few grams does not make any difference. Put another way, in this situation it could be the case that using one set of coefficients we could predict a patient's total charge to be $\$ 1,000.00$ while using the coefficients from a different state we would predict the total charge to be $\$ 1,00 t, 00$, but because a standard error is only a few cents we find these coefficients to be significantly different in the statistical sense.

To address this issue we used the coefficients from each state to estimate the total charge of a "typical" patient and to estimate the changes in those charges when one of the typical patient's characteristics change. The typical patient is the median patient from California (the largest data set) and his characteristic are as follows: $A G E=70 ; C O M P=0$;

EMERG=0; RISK=20; RACE01 =1; DRG306=0; DRG307=0; DRG336=0; MEDICARE $=1$; MEDICAID $=0$; BLUE CROSS $=0$; Other Insurance $=0$.

We calculate the changes by changing one of the relevant variables, and setting the others equal to our typical patient. For example, we change COMP from 0 to 1 , and leave all the other variables equal to that of the typical patient. This raises charges by approximately $\$ 3000$ in California, $\$ 2400$ in Colorado, $\$ 2800$ in Florida, $\$ 1200$ in Maryland, and $\$ 4500$ in New Jersey. The results of the predictions are listed in Table 47: 
Table 47. Different Effects Across States

\begin{tabular}{|c|c|c|c|c|c|}
\hline & Califomia & Colorado & Florida & Maryland & New Jersey \\
\hline \multirow[t]{2}{*}{$\begin{array}{l}\text { Charge for } \\
\text { "Typical" } \\
\text { Patient }\end{array}$} & $\$ 8718$ & $\$ 6023$ & $\$ 8837$ & $\$ 4489$ & $\$ 8598$ \\
\hline & \multicolumn{5}{|c|}{ Predicted Changes in Charges } \\
\hline $\begin{array}{l}\text { Explanatory } \\
\text { Variable's New } \\
\text { Setting }\end{array}$ & Califfomia & Colorado & Florida & Maryland & New Jersey \\
\hline $\mathrm{AGE}=60$ & $-\$ 136$ & $-\$ 168$ & $-\$ 244$ & $-\$ 198$ & -447 \\
\hline $\mathrm{COMP}=1$ & 3013 & 2402 & 2872 & 1162 & 4507 \\
\hline EMERG=] & 5107 & 3711 & 4679 & 3867 & 6823 \\
\hline RISK=100 & 15 & 43 & 29 & 159 & 32 \\
\hline $\mathrm{RACE} 01= \pm$ & 124 & -244 & 230 & 160 & 302 \\
\hline DRG306=] & 3215 & 3510 & 3385 & [83] & 6384 \\
\hline DRG307=1 & 405 & 135 & 710 & 283 & -147 \\
\hline DRG336=] & 1249 & 1009 & 1102 & 590 & 1899 \\
\hline MEDICARE $=0$ & -25 & 30 & 84 & -37 & 977 \\
\hline $\begin{array}{l}\text { MEDICAID }=1 \\
9\end{array}$ & 12 & 633 & -402 & -126 & -18 \\
\hline $\begin{array}{l}\text { BLUE } \\
\text { CROSS=I }\end{array}$ & 191 & -266 & 287 & -114 & -45 \\
\hline $\begin{array}{l}\text { Other } \\
\text { lnsurance=1 }\end{array}$ & -221 & -201 & $-13]$ & .156 & -357 \\
\hline
\end{tabular}

It would appear that there are practical differences among states. Reducing the ages of the patient from 70 to 60 decreases costs by $\$ 136$ in Califormia and $\$ 447$ in New Jersey. Complication increase the cost of a TURP by $\$ 1200$ in Florida, and $\$ 4500$ in New Jersey.

Note that having MEDICAID $=I$ necessitates that MEDICARE $=0$. The same is true for all other payer variables. 
On the other hand, most of the predicted changes are of the same direction and magninude.

\section{Unconditional Cost of TURP}

With the treatment choice logit and the conditional cost estimates by state from earlier, we can construct an average unconditional prediction for the costs of TURP using equation 7. Modifying this exptession slightly to reflect the use of the average probability of a TURP as a unbiased proxy for the estimated probability for each person in the cost data, the expected unconditional cost of a TURP is:

$$
E\left[\operatorname{Cost}_{1}\right]=\operatorname{Pexp}_{\operatorname{ex}}\left(x_{i}\right) \frac{\sum\left[\exp \left(\ln (\operatorname{Cosf},)-b x_{1}\right)\right]}{n}
$$

Note that this expression gives the expected cost of a TURP for the average man with BPH, wather than the average man who received a TURP. From a policy perspective the expression in (7) is the relevant expectation. If we are considering policies which expand the availability of TURP, we will want to know how much it will cost to treat the average man, not the average man atready receiving treatment.

Since our F-Tests in the previous section indicate that each state has a different model, the average expected cost of a TURP will be calculated for each state. Also, the multiplicative factors attached to $\exp \left(b x_{i}\right)$ in (7) are constants, so the average cost can be obtained by simply transforming the average predicted cost from the regressions inTable 45. The predicted unconditional cost of TURP are found is Table 48 below,

Table 48. Average Predicted Unconditional Cost of TURP by State

\begin{tabular}{|c|c|c|c|}
\hline State & $\begin{array}{c}\text { Multiplicative } \\
\text { Factor:P* }\end{array}$ & $\begin{array}{c}\text { Predicted Conditional } \\
\text { Cost of a TURP }\end{array}$ & $\begin{array}{c}\text { Predicted Unconditional } \\
\text { Cost of a TURP }\end{array}$ \\
\hline California & 0.1268 & $\$ 8,908$ & $\$ 1,130$ \\
\hline Colorado & 0.1278 & $\$ 6,218$ & $\$ 750$ \\
\hline Florida & 0.1276 & $\$ 8,413$ & $\$ 1,074$ \\
\hline Maryland & 0.1285 & $\$ 3,832$ & $\$ 492$ \\
\hline New Jersey & 0.1358 & $\$ 8,565$ & $\$ 1,163$ \\
\hline
\end{tabular}

The second column in Table 48 is the predicted cost of supplying a TURP to those men who actually received the procedure. The third column is the predicted cost of supplying a TURP to the average man with $\mathrm{BPH}$, independently of whether he actually receives a 
TURP or not. Note that the dollar amounts in column three are quite low relative to the dollar amounts in column two. Recall that the average man with BPH does not opt to receive a TURP. That the average man does not receive treatment suggests that the condition is not sufficiently severe to warrant the costs of the treatment. If the resource costs necessary to supply a TURP is related to the severity of the enlargement, then it is not at all surprising to find these costs are low in the general BPH population. However, the disparity is quite large, which suggests that this approximation should be taken with some caution.

\section{Conclusion}

BPH is one of the most common chronic conditions for men in the U.S., affiecting the majority of men over the age of 60 . The current "gold standard" treatment for BPH symptoms which are serious enough to warrant intervention is the transurethral resection of the prostate, TURP. Given the widespread use of this procedure, and the millions of dollars that are paid each year by insurers and patients to secure this treatment, the dearth of careful empirical estimates of the true cost of the procedure is remarkable. This study has sought to close this gap by estimating a consistent model of the cost of TURP, controlling for both the decision to seek treatment, and the resource costs incurred when treatment is pursued. The Two-Part model common in health economic research is utilized. The results suggest that the cost associated with providing a TURP for the average man with BPH would be $\$ 492$ to $\$ 1,163$ (depending on the state of residence). Hopefully, these calculation will be useful to researchers, payers and providers who wish to undertake cost-benefit or cost-effectiveness analysis of this common procedure. 
Intentionally Left Blank 


\section{Distribution}

\begin{tabular}{|c|c|c|}
\hline Copies & Majl Stop & Recipient \\
\hline 1 & M/S 0431 & S. G. Varnado, 6500 \\
\hline 1 & M/S 0451 & R. E. Trêl\{ue, 6544 \\
\hline 20 & M/S 0785 & A. E. Sill, 6542 \\
\hline 10 & M/S 0785 & S. Warren, 6542 \\
\hline I0 & M/S 0785 & J. D. Dillinger, 6542 \\
\hline ] & M/S 045] & B. K. Cloer, 6545 \\
\hline I & M/S 1380 & M. Berman, 4271 \\
\hline 1 & M/S 1380 & K. W. Boyack, 4271 \\
\hline 1 & M/S 1378 & M. L. Garcia, 4524 \\
\hline 1 & M/S 1165 & L. E. Larsen, 9300 \\
\hline I & M/S 1378 & C. L. Mitchell, 4500 \\
\hline 1 & M/S 0523 & T. J. Allard, 1002 \\
\hline 1 & M/S 0449 & M. R. Sjulin, 6512 \\
\hline 1 & M/S 0313 & A. K. Miller, 2418 \\
\hline 1 & M/S 0985 & D. H. Schroeder, 2605 \\
\hline t & $\mathrm{M} / \mathrm{S} 0509$ & W. D. Williams, 2300 \\
\hline 1 & $\mathrm{M} / \mathrm{S} 0503$ & G. R. Laguna, 2338 \\
\hline 1 & M/S 0505 & J. T. Love, 2336 \\
\hline 1 & M/S 0529 & M. L. Lovejoy, 2346 \\
\hline 1 & M/S 0188 & M. A. Zanuner, 4526 \\
\hline 1 & $M / S 1231$ & J. R. Bode, 5009 \\
\hline 1 & $M / S 1203$ & A. P. Zelicoff, 5335 \\
\hline 1 & $\mathrm{M} / \mathrm{S} 0570$ & A. L. Sobel, 5908 \\
\hline 5 & M/S 0899 & Technical Library, 4916 \\
\hline 1 & M/S 0619 & $\begin{array}{l}\text { Review \& Approval Desk, } 12690 \\
\text { for DOE/OSTI }\end{array}$ \\
\hline 1 & $\mathrm{M} / \mathrm{S} 9018$ & Central Technical Files, 8940-2 \\
\hline
\end{tabular}

Total Copies 66 